\title{
The Impact of Indoor Environment Quality on People on the Autism Spectrum
}

\author{
Beth Noble
}

A thesis submitted to Victoria University of Wellington in fulfilment of the requirements for the degree of Masters of Building Science 

Preface

Author:

Beth Noble

School of Architecture

Victoria University of Wellington

Email: noblebeth@myvuw.ac.nz

Supervisors:

Dr Nigel Isaacs

Senior Lecturer, Architecture

School of Architecture

Victoria University of Wellington

Email: nigel.isaacs@vuw.ac.nz

Dr Steve Lamb

Research Fellow, Architecture

School of Architecture

Victoria University of Wellington

Email: steve.lamb@vuw.ac.nz 


\section{Acknowledgements}

Many thanks to everyone who has assisted and supported this research and made this study possible. I would especially like to thank my supervisors Dr Nigel Isaacs and Dr Steve Lamb for all their help and continual encouragement. Their feedback and guidance have proved invaluable.

I would like to acknowledge BRANZ and the Building Research Levy who provided financial assistance for this research.

I would like to thank my fellow Masters of Building Science cohort in providing a friendly and cohesive working environment to share ideas and issues, and for providing the initial feedback in my pilot survey. I would especially like to thank Cara Askew and Chloe Cook for their continued support above and beyond this.

I would especially like to thank the 276 participants of my survey. Without their willingness to participate and provide thorough responses to the survey, this research would not have been possible. I would also like to thank the four participants of the second pilot study, for providing their honest feedback to ensure that the survey was accessible and logical.

Finally, I would like to thank all my family and friends who have continually supported me during this research. Their willingness to listen and provide insightful ideas has been invaluable. Special thanks to my parents, Jackie and Roy Noble, and my aunt, Julie Whyte, who were sounding boards throughout this research and provided vital encouragement and feedback. Thanks to Carina and Lyra for their emotional support. Thanks also to my medical team for keeping me healthy and happy. Special thanks to Lucy Croft for proofreading, as well as my brother, Ross Noble, and Becs Peel for their support and listening patience. 


\section{Abstract}

People on the autism spectrum are widely reported to have differences in how they process sensory information compared to people not on the autism spectrum (neurotypical). These differences in sensory processing are prevalent regardless of age or IQ level. All people are affected by the built environment, with indoor environment quality linked to comfort, productivity, health and wellbeing. However, there is little research about the direct impact of the built environment on autistic adults.

This study investigates whether differences in sensory processing impact how autistic people experience the built environment, and whether there were patterns in the effects of different IEQ factors. Adults on the autism spectrum ( $n=83$ ), neurotypical control adults $(n=134)$, and adults with other conditions affecting sensory processing or who were closely related to someone on the autism spectrum ( $n=59)$ participated in an anonymous online survey. Participants were asked about their home and workplace, experiences of the general built environment, and general sensory sensitivity.

Autistic participants, who reported significantly higher sensory processing scores than Control participants, consistently reported higher levels of discomfort in both their home and workplace environments, feeling more overwhelming, stressed, and distracted, and less safe than the Control group in both environments. Though shopping malls, supermarkets, other retail and medical buildings are all essential buildings that people need to frequent to meet material needs and stay healthy, they all caused greater discomfort and distress for Autistic participants, who also avoided them more often. The odds of an Autistic participant avoiding buildings was 8.8 times greater than the Control group. Higher discomfort and distress reported by Autistic participants in office buildings may affects the low employment rates in this population.

People and People Noise were the IEQ factors that, across multiple environments, were rated as highest as a cause of discomfort and avoidance and had the largest difference between Autistic and Control participants, followed by Glare and Electric Light. Meanwhile, Temperature was rated equally highly by both groups, having a large effect but no difference between groups, with a similar trend seen in Air Quality and Air Movement.

Autistic people already struggle with social isolation, early mortality, and low employment rates, which are likely compounded by greater sensory stress from the built environment. Further research into understanding the relationship between the effects of the indoor environment and the differences in sensory processing in people on the autism spectrum is essential to creating solutions for a more accessible built environment. 


\section{Table of Contents}

Preface ..i

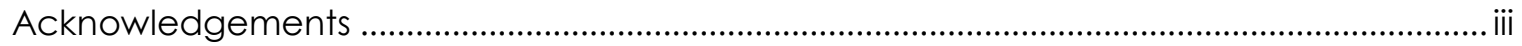

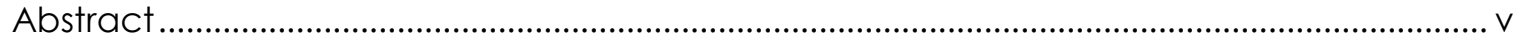

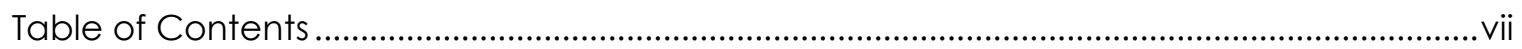

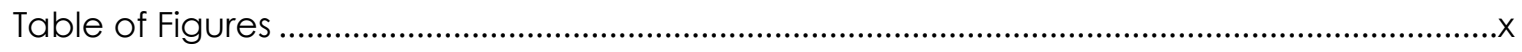

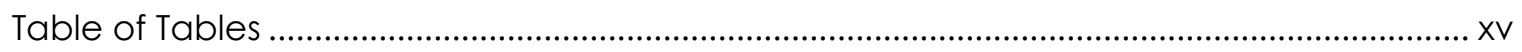

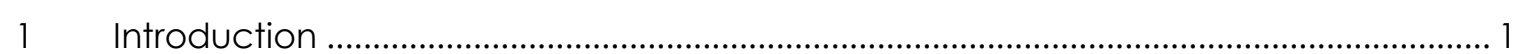

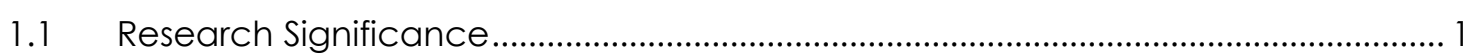

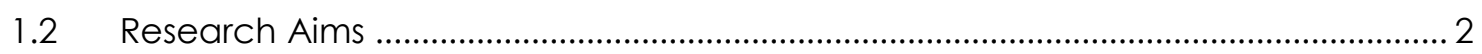

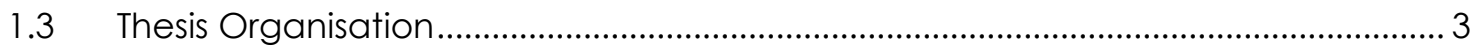

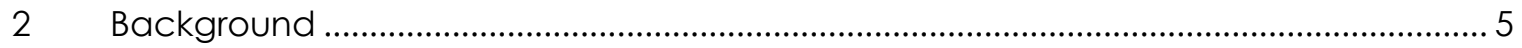

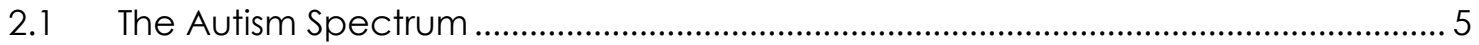

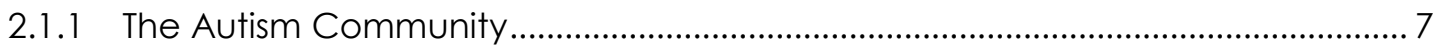

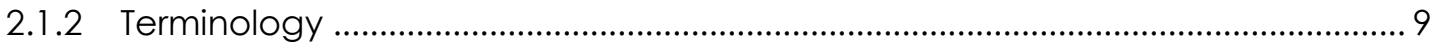

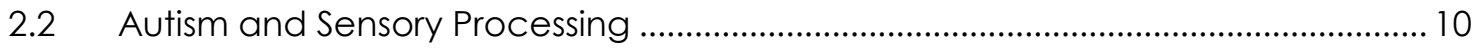

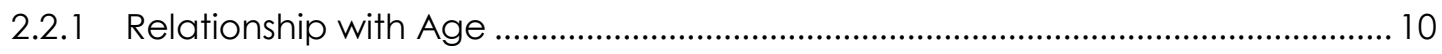

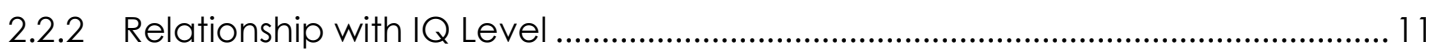

2.2.3 Current Neuroscience Research ....................................................................... 12

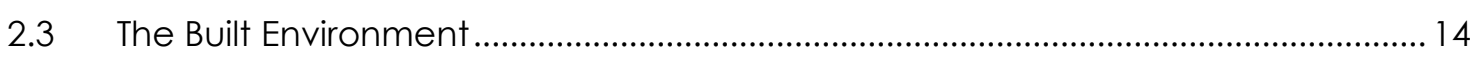

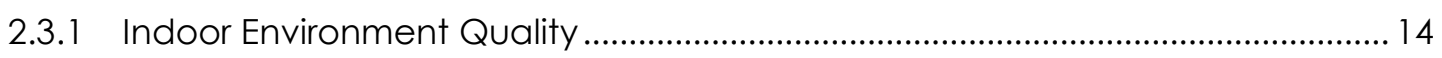

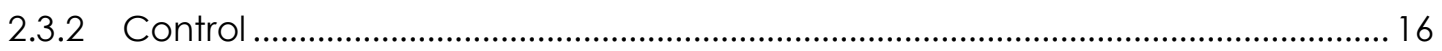

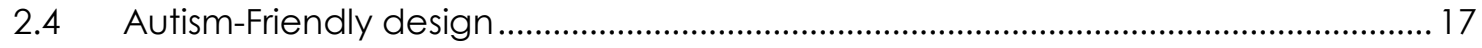

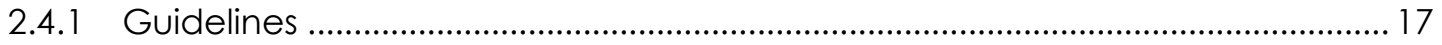

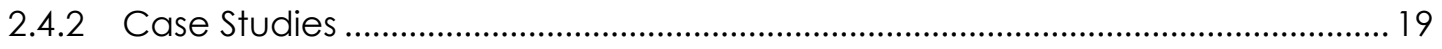

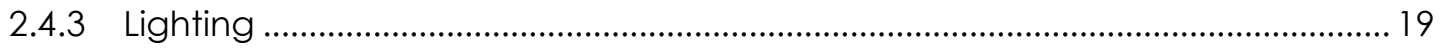

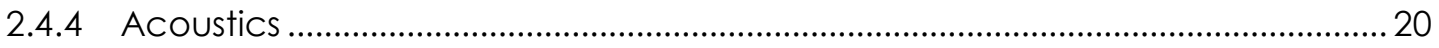

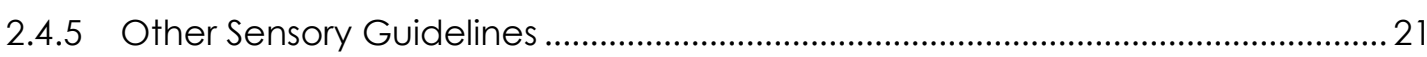

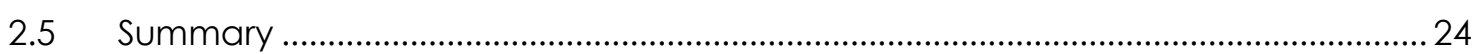

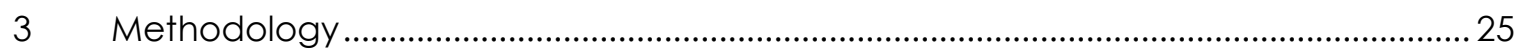

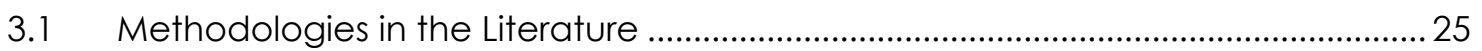

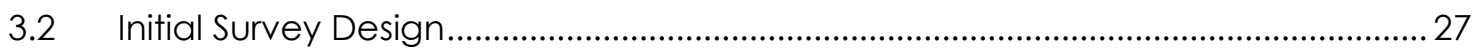

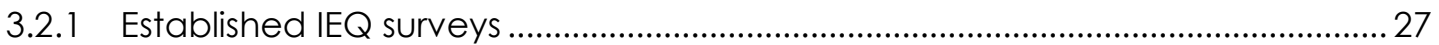

3.2.2 Precedents of surveys for people with disabilities ................................................... 28

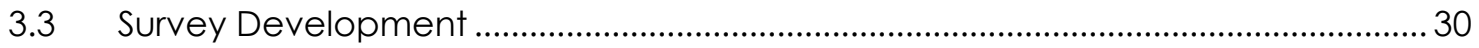

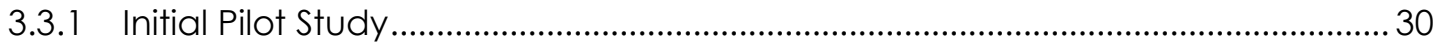


3.3.2 Second Pilot

4 Research Method. 33

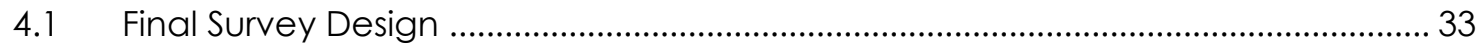

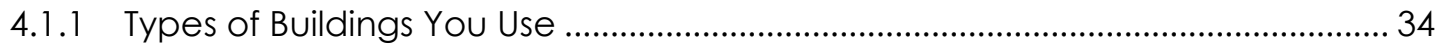

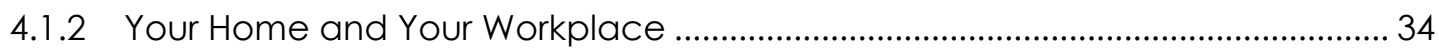

4.1.3 Other Buildings You Use ........................................................................................... 35

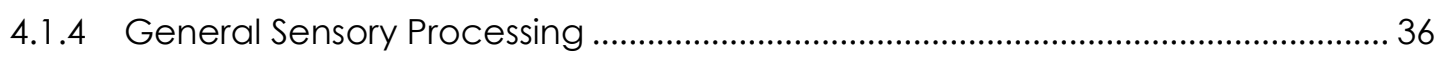

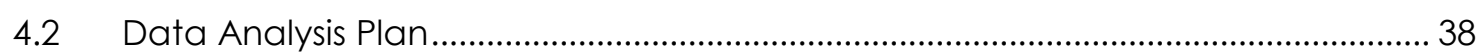

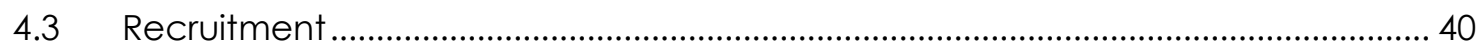

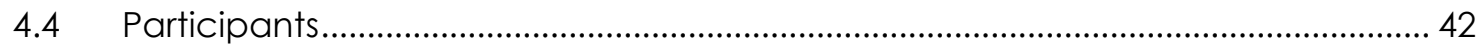

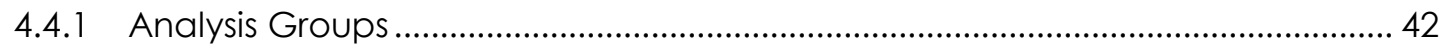

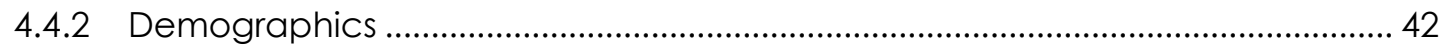

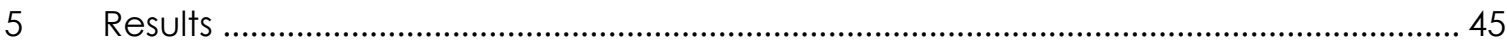

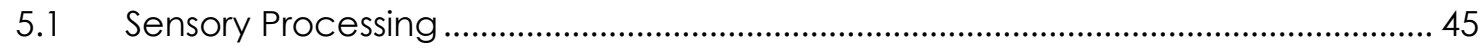

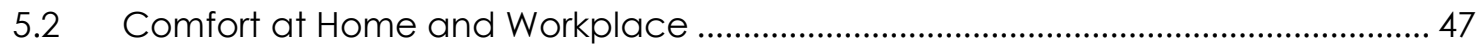

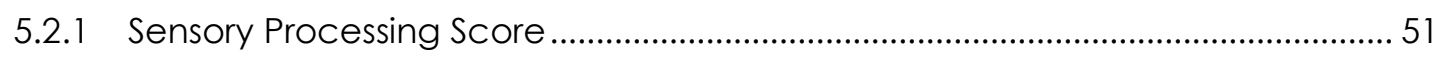

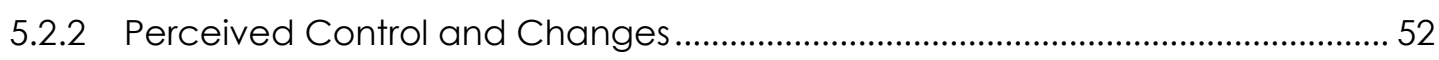

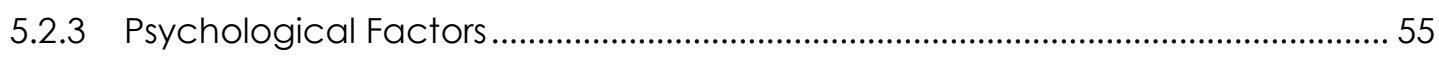

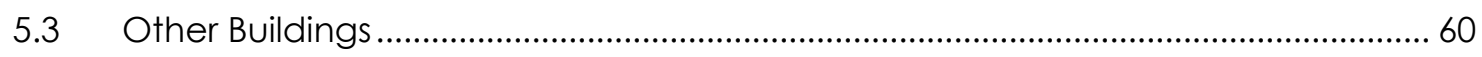

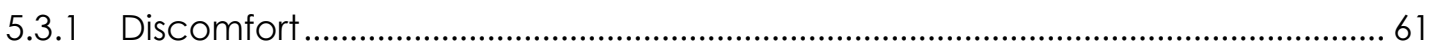

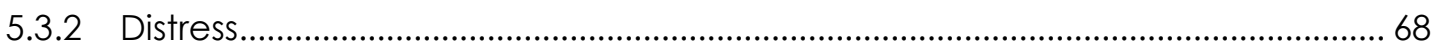

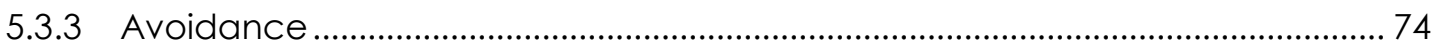

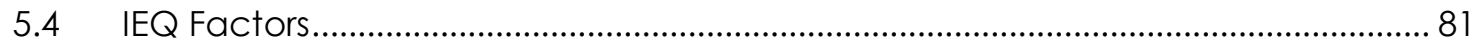

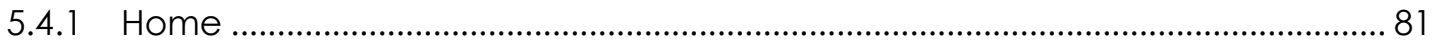

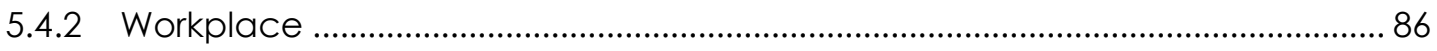

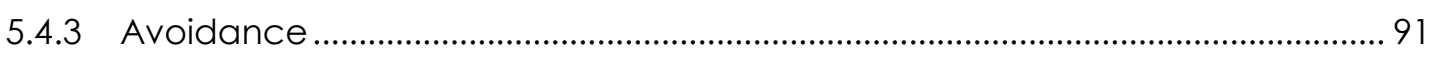

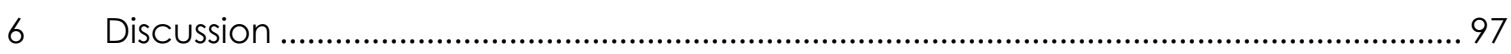

6.1 Question 1: Greater Adverse Effects for Autistic People .......................................... 97

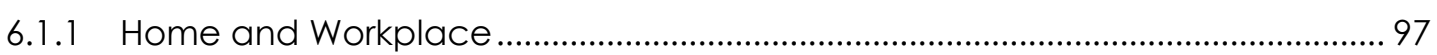

6.1.2 Discomfort and Distress in Other Buildings ............................................................ 101

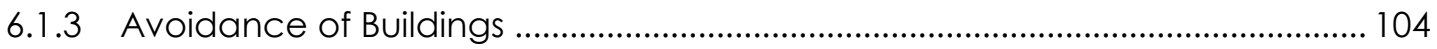

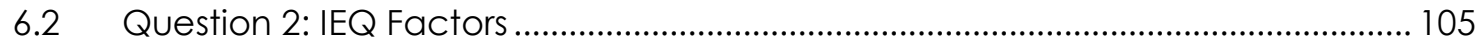

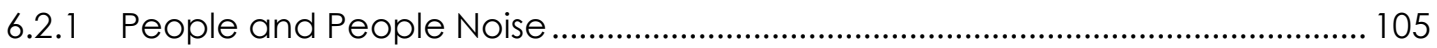

6.2.2 Temperature, Air Quality and Air Movement...................................................... 106

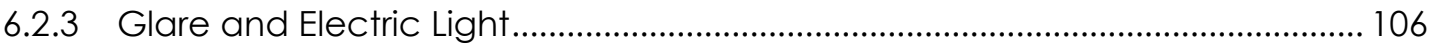

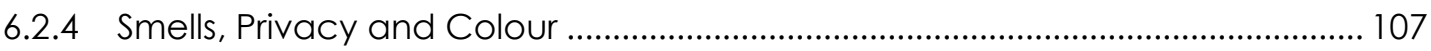




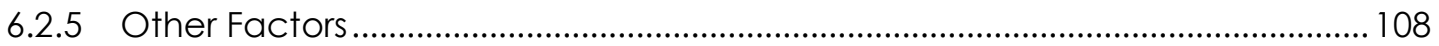

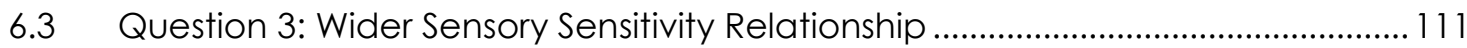

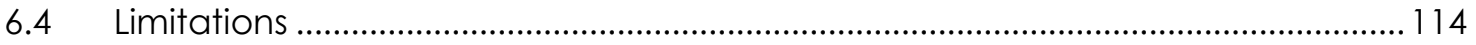

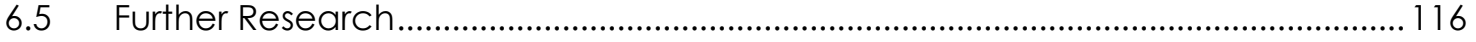

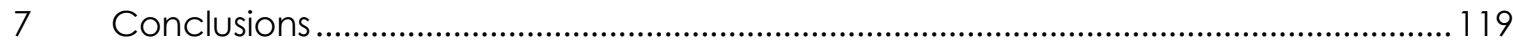

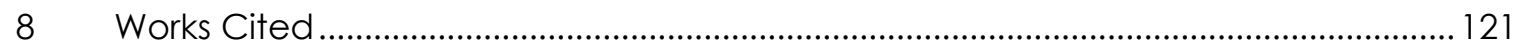

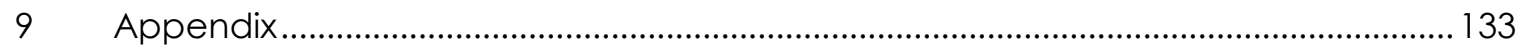

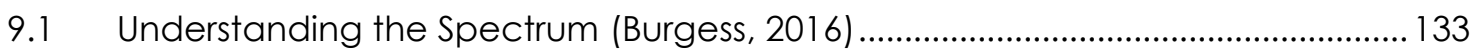

9.2 Supported Living Payment: Definition of a relationship ............................................ 141

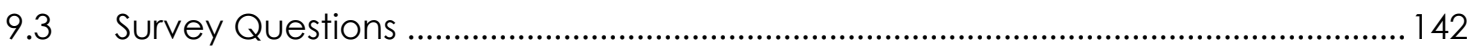

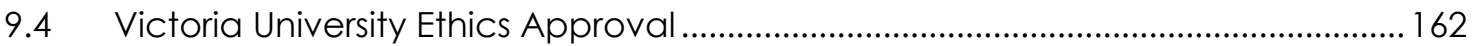




\section{Table of Figures}

Figure 1. Age of Participants by Condition

Figure 2. Comparison of Employment Status between Autistic and Control participants ..43

Figure 3. Sensory Processing Score by Condition

Figure 4. Proportion of Individual Item Answers in Sensory Processing Section .46

Figure 5. Distribution of Home Comfort Scores .47

Figure 6. Distribution of Workplace Comfort Scores .......................................................................

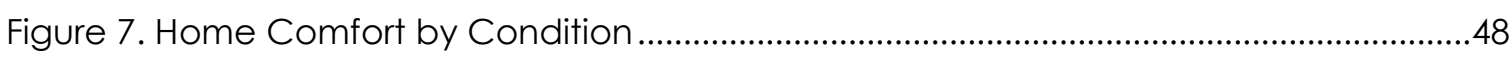

Figure 8. Workplace Comfort by Condition ..................................................................................48

Figure 9. Home Overall IEQ Discomfort by Condition ..................................................................49

Figure 10. Workplace Overall IEQ Discomfort by Condition ......................................................50

Figure 11. Home Comfort vs Sensory Processing Score ...............................................................

Figure 12. Workplace Comfort vs Sensory Processing Score .....................................................51

Figure 13. Home Comfort vs Home Perceived Control .............................................................52

Figure 14. Workplace Comfort vs Workplace Perceived Control ................................................52

Figure 15. Home Perceived Control by Condition ..........................................................................53

Figure 16. Workplace Perceived Control by Condition ..............................................................53

Figure 17. "I find my home overwhelming to my senses" by Condition ....................................57

Figure 18. "I feel stressed/anxious at my home" by Condition .................................................57

Figure 19. "I don't feel safe at my home" by Condition ............................................................57

Figure 20. "I find the indoor environment of my home distracting" by Condition .................57

Figure 21. "I find my workplace overwhelming to my senses" by Condition ...........................57

Figure 22. "I feel stressed/anxious at my workplace" by Condition ............................................57

Figure 23. "I don't feel safe at my workplace" by Condition ...................................................57

Figure 24. "I find the indoor environment of my workplace distracting" by Condition .......57

Figure 25. "I find my home overwhelming to my senses" vs Sensory Processing Score .......59

Figure 26. "I find my workplace overwhelming to my senses" vs Sensory Processing Score

Figure 27. "I feel stressed/anxious at my home" vs Sensory Processing Score .........................59

Figure 28. "I feel stressed/anxious at my workplace" vs Sensory Processing Score ...............59

Figure 29. "I don't feel safe at my home" vs Sensory Processing Score ....................................59

Figure 30. "I don't feel safe at my workplace" vs Sensory Processing Score ..........................59

Figure 31. "I find the indoor environment of my home distracting" vs Sensory Processing Score

Figure 32. "I find the indoor environment of my workplace distracting" vs Sensory Processing Score 
Figure 33. Percentage of Participants who Use Building Types Once a Month or More Frequently

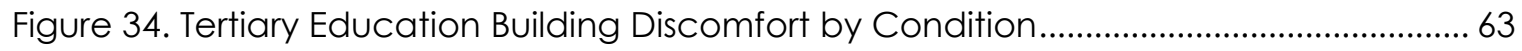

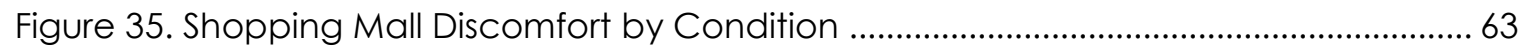

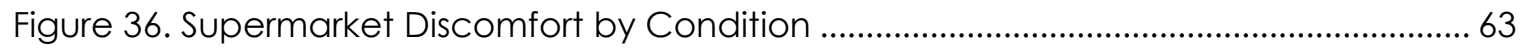

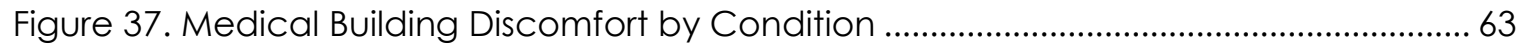

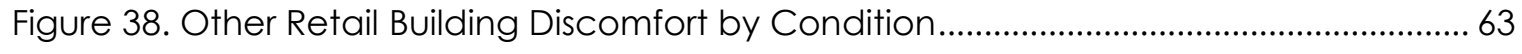

Figure 39. Restaurant/Bar/Café Building Discomfort by Condition .......................................... 63

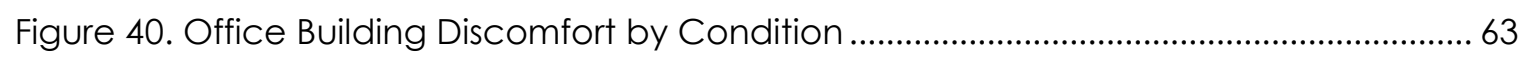

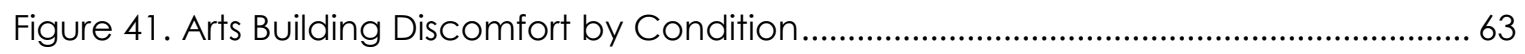

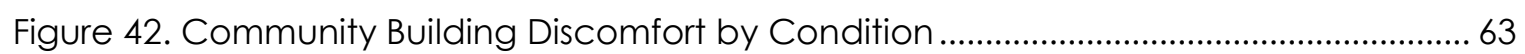

Figure 43. Shopping Mall Discomfort vs Sensory Processing Score (all qualifying participants)

Figure 44. Shopping Mall Discomfort vs Sensory Processing Score (excluding Autistic participants)

Figure 45. Other Retail Building Discomfort vs Sensory Processing Score (all qualifying participants)

Figure 46. Other Retail Building Discomfort vs Sensory Processing Score (excluding Autistic participants)

Figure 47. Supermarket Discomfort vs Sensory Processing Score (all qualifying participants)

Figure 48. Supermarket Discomfort vs Sensory Processing Score (excluding Autistic participants)

Figure 49. Medical Building Discomfort vs Sensory Processing Score (all qualifying participants)

Figure 50. Medical Building Discomfort vs Sensory Processing Score (excluding Autistic participants)

Figure 51. Restaurant/Bar/Café Building Discomfort vs Sensory Processing Score (all qualifying participants)

Figure 52. Restaurant/Bar/Café Building Discomfort vs Sensory Processing Score (excluding Autistic participants).

Figure 53. Arts Building Discomfort vs Sensory Processing Score (all qualifying participants)

Figure 54. Arts Building Discomfort vs Sensory Processing Score (excluding Autistic participants)

Figure 55. Community Building Discomfort vs Sensory Processing Score (all qualifying participants)

Figure 56. Community Building Discomfort vs Sensory Processing Score (excluding Autistic participants)

Figure 57. Office Building Discomfort vs Sensory Processing Score (all qualifying participants) 
Figure 58. Office Building Discomfort vs Sensory Processing Score (excluding Autistic participants)

Figure 59. Tertiary Education Building Discomfort vs Sensory Processing Score (all qualifying participants)

Figure 60. Tertiary Education Building Discomfort vs Sensory Processing Score (excluding Autistic participants)

Figure 61. Distress from Shopping Malls by Condition

Figure 62. Distress from Supermarkets by Condition

Figure 63. Distress from Other Retail Buildings by Condition

Figure 64. Distress from Medical Buildings by Condition

Figure 65. Distress from Restaurant/Bar/Café Buildings by Condition

Figure 66. Distress from Office Buildings by Condition

Figure 67. Distress from Medical Buildings vs Sensory Processing Score (all qualifying participants)

Figure 68. Distress from Medical Buildings vs Sensory Processing Score (excluding Autistic participants)

Figure 69. Distress from Shopping Malls vs Sensory Processing Score (all qualifying participants)

Figure 70. Distress from Shopping Malls vs Sensory Processing Score (excluding Autistic participants)

Figure 71. Distress from Supermarkets vs Sensory Processing Score (all qualifying participants)

Figure 72. Distress from Supermarkets vs Sensory Processing Score (excluding Autistic participants)

Figure 73. Distress from Other Retail Buildings vs Sensory Processing Score (all qualifying participants)

Figure 74. Distress from Other Retail Buildings vs Sensory Processing Score (excluding Autistic participants)

Figure 75. Distress from Restaurant/Bar/Café Buildings vs Sensory Processing Score (all qualifying participants)

Figure 76. Distress from Restaurant/Bar/Café Buildings vs Sensory Processing Score (excluding Autistic participants)

Figure 77. Distress from Office Buildings vs Sensory Processing Score (all qualifying participants)

Figure 78. Distress from Office Buildings vs Sensory Processing Score (excluding Autistic participants)

Figure 79. Incidence of Avoidance by Sensory Processing Score ……...................................74

Figure 80. Count of Building Types Avoided by Condition........................................................75

Figure 81. Proportion of Building Types Avoided by Condition ..................................................75

Figure 82. Frequency of Avoidance of Office Buildings by Condition .....................................77 
Figure 83. Frequency of Avoidance of Shopping Malls by Condition .77

Figure 84. Frequency of Avoidance of Other Retail Buildings by Condition ......................... 77

Figure 85. Frequency of Avoidance of Supermarkets by Condition ........................................ 77

Figure 86. Frequency of Avoidance of Restaurant/Bar/Café Buildings by Condition......... 77

Figure 87. Frequency of Avoidance of Other Retail Buildings vs Sensory Processing Score (all qualifying participants)

Figure 88. Frequency of Avoidance of Other Retail Buildings vs Sensory Processing Score (excluding Autistic participants).

Figure 89. Frequency of Avoidance of Supermarket Buildings vs Sensory Processing Score (all qualifying participants)

Figure 90. Frequency of Avoidance of Supermarket Buildings vs Sensory Processing Score

(excluding Autistic participants).

Figure 91. Frequency of Avoidance of Shopping Malls vs Sensory Processing Score (all qualifying participants)

Figure 92. Frequency of Avoidance of Shopping Malls vs Sensory Processing Score

(excluding Autistic participants).

Figure 93. Frequency of Avoidance of Restaurant/Bar/Café Buildings vs Sensory

Processing Score (all qualifying participants)

Figure 94. Frequency of Avoidance of Restaurant/Bar/Café Buildings vs Sensory Processing Score (excluding Autistic participants)

Figure 95. Frequency of Avoidance of Office Buildings vs Sensory Processing Score (all qualifying participants) 80

Figure 96. Frequency of Avoidance of Office Buildings vs Sensory Processing Score (excluding Autistic participants).

Figure 97. Home Temperature Discomfort by Condition .84

Figure 98. Home People Noise Discomfort by Condition ............................................................. 84

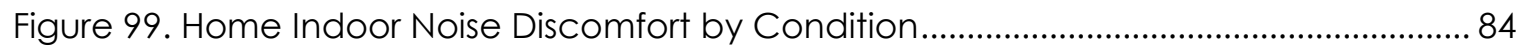

Figure 100. Home Outdoor Noise Discomfort by Condition ........................................................ 84

Figure 101. Home People Discomfort by Condition ................................................................. 84

Figure 102. Home Glare Discomfort by Condition .................................................................... 84

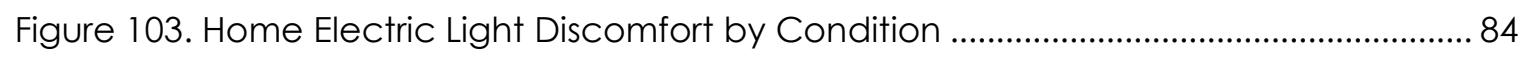

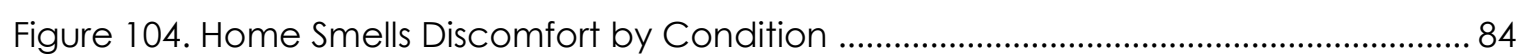

Figure 105. Home Air Quality Discomfort by Condition.................................................................. 84

Figure 106. Home Air Movement Discomfort by Condition ....................................................... 85

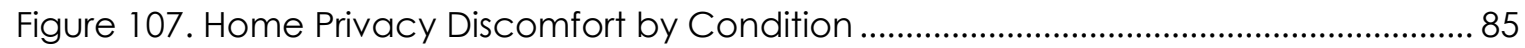

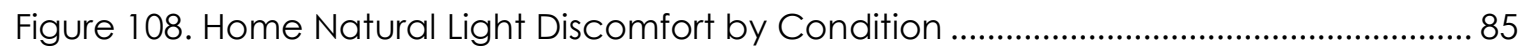

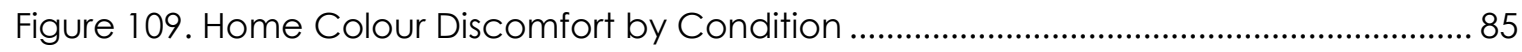

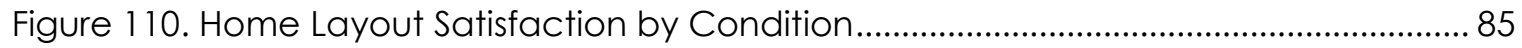

Figure 111. Workplace People Discomfort by Condition ........................................................... 89 
Figure 112. Workplace People Noise Discomfort by Condition

Figure 113. Workplace Indoor Noise Discomfort by Condition

Figure 114. Workplace Glare Discomfort by Condition

Figure 115. Workplace Electric Light Discomfort by Condition .89

Figure 116. Workplace Privacy Discomfort by Condition .89

Figure 117. Workplace Smells Discomfort by Condition .89

Figure 118. Workplace Colour Discomfort by Condition .89

Figure 119. Workplace Temperature Discomfort by Condition. .89

Figure 120. Workplace Air Movement Discomfort by Condition .90

Figure 121. Workplace Air Quality Discomfort by Condition. .90

Figure 122. Workplace Outdoor Noise Discomfort by Condition .90

Figure 123. Workplace Natural Light Discomfort by Condition .90

Figure 124. Workplace Layout Satisfaction by Condition .90

Figure 125. Avoidance as a result of People by Condition .94

Figure 126. Avoidance as a result of People Noise by Condition .94

Figure 127. Avoidance as a result of Other Noise by Condition .94

Figure 128. Avoidance as a result of Glare by Condition .94

Figure 129. Avoidance as a result of Electric Light by Condition .94

Figure 130. Avoidance as a result of Colour by Condition .94

Figure 131. Avoidance as a result of Privacy by Condition .94

Figure 132. Avoidance as a result of Layout by Condition .94

Figure 133. Avoidance as a result of Smells by Condition. .94

Figure 134. Avoidance as a result of Temperature by Condition .95

Figure 135. Avoidance as a result of Air Movement by Condition .95

Figure 136. Avoidance as a result of Air Quality by Condition .95

Figure 137. Avoidance as a result of Natural Light by Condition .95 


\section{Table of Tables}

Table 1. Humphreys' autism-friendly design guidelines (2005) ............................................... 17

Table 2. Vogel's autism-friendly design guidelines (2008) ........................................................ 18

Table 3. Beaver's autism-friendly design guidelines $(2006,2010,2012)$................................ 18

Table 4. Odds Ratios of Autistic participants making, or wanting to make, permanent changes to their home environment, depending on tenure .................................................... 54

Table 5. Psychological Factors of the Home and Workplace Environments by Condition 56 Table 6. Correlation between Psychological Factors of the Home and Workplace

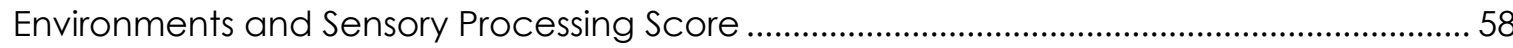

Table 7. Frequency of Discomfort caused by 9 Building Types by Condition ........................ 61

Table 8. Correlation between Frequency of Discomfort and Sensory Processing Score .... 64

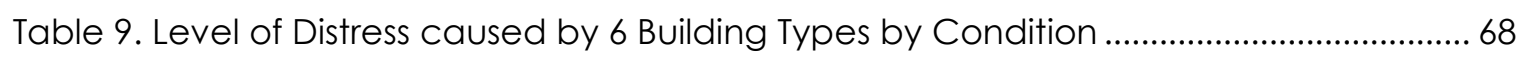

Table 10. Correlation between Level of Distress and Sensory Processing Score ................... 70

Table 11. Correlation between Frequency of Discomfort and Level of Distress for All

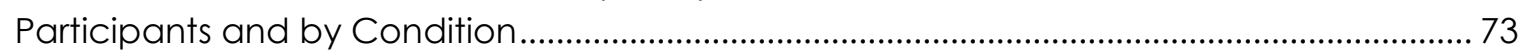

Table 12. Frequency of Avoidance of 5 Building Types by Condition ................................... 76

Table 13. Correlation between Frequency of Avoidance by Building Type and Sensory

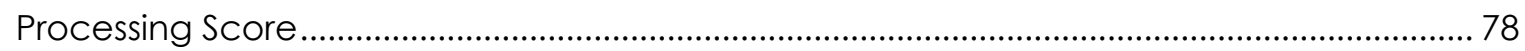

Table 14 Comparison by Condition of Level of Discomfort caused by 14 IEQ Factors at the Home 81

Table 15 Comparison by Condition of Level of Discomfort caused by 13 IEQ Factors at the Workplace 86

Table 16 Avoidance caused by 13 IEQ Factors by Condition .91 


\section{Introduction}

\subsection{Research Significance}

With $24 \%$ of our population identifying as having a disability of some kind (Statistics NZ, 2014), an accessible built environment is essential to one of our largest minorities. While the New Zealand Building Code outlines the importance of a built environment that is accessible to people of all abilities and function, there is often a large gap between the intentions of this and the current built environment (NZ Government, 1992). Accessibility is one of the eight outcomes specified in the New Zealand Disability Strategy as a priority for change in 2016-2026 (Office for Disability Issues, 2016). The United Nations Convention on the Rights to Persons with Disabilities, which New Zealand is a signatory of, also states:

"To enable persons with disabilities to live independently and participate fully in all aspects of life, States Parties shall take appropriate measures to ensure to persons with disabilities access, on an equal basis with others, to the physical environment, to transportation, to information and communications, including information and communications technologies and systems, and to other facilities and services open or provided to the public, both in urban and in rural areas. These measures, which shall include the identification and elimination of obstacles and barriers to accessibility, shall apply to, inter alia:

(a) Buildings, roads, transportation and other indoor and outdoor facilities, including schools, housing, medical facilities and workplaces..." (United Nations, 2007)

People on the autism spectrum constitute approximately $1 \%$ of our population and have differences in how they process sensory information, which is irrespective of age and intellectual ability (Crane, Goddard, \& Pring, 2009; Leekham, Nieto, Libby, Wing, \& Gould, 2007; Minshew \& Hobson, 2008; Tavassoli, Miller, Schoen, Nielsen, \& Baron-Cohen, 2014). For people on the autism spectrum, sensory information that is perceived more intensely (light that is too bright or that flickers, too much background noise, too many people, etc.) can cause sensory overload. These sensory differences mean that the threshold for sensory overload is lower in people on the autism spectrum than in the general population. For example, while a nearby jet engine is likely to get a strong reaction from most people in the general population, for a person on the autism spectrum the same reaction could be caused by ordinary everyday noises, such as the hand dryer in a bathroom.

In children, sensory overload is often seen as a meltdown or behavioural difficulties (NAS, $2016 b)$. In adults, who have often learned to manage their visible reactions, this can still 
cause hidden distress, anxiety and even pain. However, there is limited systematic research into how the differences in sensory processing apply specifically to the indoor environment of buildings, particularly for adults on the autism spectrum.

Research shows that the indoor environment quality (IEQ) of buildings affects all people, impacting on their health and wellbeing, comfort and satisfaction, and productivity (Bluyssen \& Cox, 2002; Fisk, 2002; Wyon \& Wargocki, 2013). These effects are due to many factors that make up IEQ, including thermal comfort, air quality, lighting, and noise (AI Horr et al., 2016). However, even current research is limited in that it usually focuses on office workplaces, and not on the wider built environment, and therefore also only deals with the experiences of the working general population. However, a recent report from Statistics New Zealand (2017) shows that only $22.4 \%$ of the disabled population in NZ are in employment, compared to $69.3 \%$ of the non-disabled population.

While there are some guidelines for 'autism-friendly' design that have been developed internationally, these are highly specific and primarily for residential educational facilities (Beaver, 2006, 2010, 2012; Humphreys, 2005; Mostafa, 2008; Vogel, 2008). The limited existing autism accessibility research largely ignores the wider built environment that is used by all people day-to-day. A first step to being able to improve the built environment to meet the needs of all users is to identify the issues that are faced by adults on the autism spectrum.

\subsection{Research Aims}

It is hypothesised that, due to known differences in sensory processing, people on the autism spectrum will be more sensitive than a control group to indoor environment quality in the built environment. The research aims to identify some of the specific issues that are currently faced in the built environment by adults on the autism spectrum. To achieve this, three primary questions are asked,

1. Are the adverse effects of the indoor environment exacerbated in people on the autism spectrum, compared to those not on the spectrum?

2. Are there patterns in which indoor environment factors produce the largest adverse effects, particularly for those on the autism spectrum?

3. Is there a wider relationship between sensory sensitivity and the effect of the indoor environment of buildings? 


\subsection{Thesis Organisation}

This thesis is organised into 7 chapters. The introductory chapter discusses the significance of the research in order to provide an understanding of the aims for this research.

Chapter 2 reviews and discusses literature on the autism spectrum and sensory processing differences, as well as investigating how the built environment affect people's comfort, health, productivity and wellbeing. These two research areas are then discussed together in regards to current 'autism friendly' design guidelines and other research into sensory considerations in the built environment.

Chapter 3 provides an overview of the methodology used for this research. This includes an analysis of the most appropriate method for this research precedents of IEQ questionnaires and surveys for people with disabilities, the initial survey design, and development of the survey used.

Chapter 4 provides an overview of the format of the final survey design used for this research, as well as a data analysis plan, the recruitment process, and demographics of participants.

Chapter 5 presents the results of the survey, organised by survey question.

Chapter 6 presents a discussion of the key findings of the research, organised by the research aims outlined in Section 1.2. This included limitations of the current research, and recommendations for future research.

Chapter 7 provides the conclusions for this research

References and appendices are found at the back of the document, providing further information on the research, and further reading. Appendix 9.3 presents the final survey design, including the display logic used. 


\section{Background}

Chapter 2 provides an overview of the autism spectrum, including diagnostic criteria, the emerging autistic community, and terminology used throughout this project (Section 2.1). Section 2.2 discusses the links between autism and sensory processing, particularly regarding age and IQ level, as well as current neuroscience research into the importance of sensory processing differences. Section 2.3 provides a brief review of indoor environment quality research regarding the general population, while Section 2.4 addresses previous research in the relationship between the built environment and autism.

In some sections of this chapter, many references are webpages or other non-peerreviewed sources. This is a result of a lack of empirical research in a number of areas, including the use of language and autism-friendly design guidelines. Wherever possible, peer-reviewed sources have been cited, but the lack of these in some areas are an indication of the need for this research.

\subsection{The Autism Spectrum}

Autism spectrum disorder (ASD) is a neurodevelopmental condition that affects social and communication skills, as well as patterns of restricted and repetitive behaviour. The Diagnostic and Statistical Manual of Mental Disorders, $5^{\text {th }}$ edition (DSM-5) now specifies as one of the diagnostic criteria for ASD:

"Hyper- or hypo-reactivity to sensory input or unusual interests in sensory aspects of the environment (such as apparent indifference to pain/heat/cold, adverse response to specific sounds or textures, excessive smelling or touching of objects, fascination with lights or spinning objects)" (American Psychiatric Association, 2013, p. 50)

A person without autism or any other neurodevelopmental condition is often referred to as 'neurotypical'; that is, their brain has developed typically ('normal' as a descriptor is avoided).

Autism is estimated to affect 1 in 100 people in New Zealand, based on American research, with a ratio of 4:1 male to female (Autism New Zealand, 2015). This trend has been increasing over the past half century, though there is debate as to whether this is due to changes in diagnostic criteria picking up more people, a true increase in incidence due to environmental or other factor, or combination of the two. 
Approximately two thirds do not have an intellectual impairment, and approximately three quarters are verbal.

In a survey of 2,080 autistic people, or people responding on their behalf, the National Autistic Society (2016a) found that only $16 \%$ of autistic adults were in full-time employment in the UK, with only $32 \%$ in any kind of paid employment, but over three quarters of people on the autism spectrum who were unemployed wanted to work. No statistics specifically about people on the autism spectrum is gathered in New Zealand, either in terms of the true number of people on the autism spectrum, or employment rates.

In the DSM-5 revision in 2013, ASD was classified by condensing what had been the Pervasive Developmental Disorders (PDD) in earlier editions. These included classical autism (significant verbal impairment, often intellectual impairment), Asperger's Syndrome (average to high IQ, no verbal impairment), PDD-Not Otherwise Specified, and Childhood Disintegrative Disorder (regressive autism). Today, ASD is given as a primary diagnosis, with the specification of being with or without accompanying intellectual or verbal impairments. In previous editions of the DSM, sensory processing was not included as a specific diagnostic criterion. Changes in definitions and diagnosis are common, therefore consideration of terminology in the studies in this review regarding their publication date is necessary.

Premature mortality is an issue for people on the autism spectrum, with a recent Swedish study of 27,000 people on the autism spectrum and 2.6 million controls showing an average life expectancy 16 years less than the general population (Hirvikoski et al., 2016). This effect is greater in autistic people who also have an intellectual disability, where the average life expectancy is 30 years less than the general population, with the most common cause of death being nervous system conditions such as epilepsy, which has a 20-40\% incidence rate in people on the autism spectrum (Cusack, Shaw, Spiers, \& Sterry, 2016; Hirvikoski et al., 2016). For people on the autism spectrum without intellectual impairment, after cardiovascular disease the most common cause of death is suicide, with a risk 9 times greater than the general population. Poor health is common in people on the autism spectrum, with higher incidences across most medical conditions, including stroke, cardiovascular disease, diabetes, respiratory and circulatory conditions. It is not clear why people on the autism spectrum have an increased mortality rate, although links have been suggested to increased stress, social isolation, and depression, sensory overload, often limited diet, and difficulties accessing healthcare (Cusack et al., 2016). 


\subsubsection{The Autism Community}

Throughout the disability sector, the social model of disability is gaining traction. Previously, disability was viewed through the medical model lens, where a person's impairments or differences were disabling and should be fixed or cured, even if they did not cause any pain or illness (Scope, 2017; Shakespeare, 2006). The social model of disability says that disability is caused not by a person's impairments or differences, but rather the way that society is organised and responds to them is disabling. The Office for Disability Issues in New Zealand supports the social model of disability in the Disability Strategy 2016-2026 (Office for Disability Issues, 2016). It is also the foundation of the United Nations Convention on the Rights to Persons with Disabilities, which New Zealand is a signatory of (United Nations, 2007).

The social model of disability has furthered by the concept of 'neurodiversity' for many autistic self-advocates in the autism community. The National Symposium on Neurodiversity defined this as:

"A concept and social movement that advocates for viewing autism as a variation of human wiring, rather than a disease. As such, neurodiversity activists reject the idea that autism should be cured, advocating instead for celebrating autistic forms of communication and self-expression, and for promoting support systems that allow autistic people to live as autistic people" (2011)

The neurodiversity movement is often extended from autism into other conditions such as ADHD and dyslexia. Advocates often suggest that even left-handedness could be seen as an example of neurodiversity acceptance, as left-handedness was once considered something that needed to be cured but is now accepted as part of the natural variation in human brains (Baron-Cohen, 2017; Kawaii, 2016). Neurodiversity also criticises the use of "disorder" for conditions. This is supported by Baron-Cohen (2017) who states that 'disorder' should be used for conditions that show no change in different environments (as is the case with disorders such as anorexia or depression). However, autistic people often can function just as well, if not at times better, than their neurotypical peers when the conditions are right.

There is some criticism of the neurodiversity movement, particularly around the divides of functioning labels. Jaarsma and Welin (2012) are critical of neurodiversity, feeling that it only applies to "high-functioning" autistics and that "low-functioning" autism is always negative and cannot be included in neurodiversity. However, this interpretation seems to misunderstand the principle of neurodiversity as relating only to autism (or other neurodevelopmental conditions) and not co-morbid conditions that can and should be 
treated (such as epilepsy or learning disorders). Support of neurodiversity does not imply that no support systems should be provided, rather the opposite. Support systems should be provided to help autistic people to live as autistic people, though not for the sole purpose of making autistic people 'fit in' with neurotypical society (Baron-Cohen, 2017; National Symposium on Neurodiversity, 2011; Ne'eman, 2010).

\subsubsection{Functioning Labels}

Functioning labels are highly criticised by most autistic self-advocates and the wider neurodiversity movement. People on the autism spectrum are often labelled as "highfunctioning" and "low-functioning", but this label is usually made based on externally observed factors such as intellectual ability, speaking ability, and ability to 'blend in' or 'pass' as neurotypical (Astrid, 2016; Sequenzia, 2013a; Tate, 2014). Autistic self-advocates do not contradict that there are variations in support needs between different people on the autism spectrum, but they propose that instead of using functioning labels, it is better to articulate a person's specific abilities and support needs (Astrid, 2016; Sequenzia, 2014; Tate, 2014).

There are concerns with autistics labelled as "high-functioning" being denied access to services and accommodations and having their challenges dismissed, while those who are considered "low-functioning" are considered incompetent and seen as victims, with those around them only holding low expectations (Ludwig, 2016; Robinson, 2014;

Sequenzia, 2013b). There is criticism that the use of functioning labels does not recognise that functioning ability is not static, and changes largely depending on the environment, stressors, and circumstances. Therefore, a simple "high" or "low" label does not fully encapsulate the variation in functioning ability that can happen over time (Astrid, 2016; Robinson, 2014; Sequenzia, 2013b).

The use of functioning labels also implies a linear spectrum, an idea that is also often criticised in the autism community. Burgess (2016) produced a comic illustrating the idea of the autism spectrum is more like a colour palette than a linear spectrum, with various abilities having different strengths and weaknesses (Appendix 9.1). This illustration shows how all people on the autism spectrum have a varied profile of areas of strengths and areas where support is needed, which is widely accepted amongst both the autism community and some professionals (Baron-Cohen, 2017; Tate, 2014; Winter, 2017).

The terms "high-functioning" and "low-functioning" are not official diagnostic terms and never have been. Instead they are colloquial labels assigned to people on the autism spectrum, usually by professionals and parents. The DSM-5 categorises autism regarding support needs for each of the two aspects of ASD, social/communication and 
restricted/repetitive behaviours. While functioning labels are still commonly used in research, some authors have moved away from the use of them, such as Pellicano \& Stears (2011).

\subsubsection{Terminology}

The National Autistic Society (UK) performed a survey on the preference for the language used to describe autism by autistic people, their families and friends, and professionals (Kenny et al., 2016). From the 3,470 participants, they found that no term was universally preferred, but there were different preferences between groups. There was a high level of agreement between all groups on the preference for "on the autism spectrum", while autistic participants tended to prefer identity-first language such as "autistic", and professionals tended to prefer more clinical terms such as "person with autism" and "autism spectrum disorder".

Throughout this project, the terms "Autistic" or "on the autism spectrum" are used to describe autism, as these are the descriptors known to generally be preferred by the Autistic community. Functioning labels are also not included in this project, in respect of the issues outlined above. People who are not on the autism spectrum are described as "neurotypical", or in the case of the Results and Discussion sections, as the "Control group". 


\subsection{Autism and Sensory Processing}

A link between sensory processing and autism was investigated in many studies during the period the DSM-IV edition was current (1994-2012), which resulted in the sensory processing criterion being added in the DSM-5 revision (American Psychiatric Association, 2013). This section investigates the relationship between sensory processing and autism, and the impact of age and IQ.

The Sensory Profile, or variants of it, was used to assess sensory processing differences in seven of the ten studies below. The Sensory Profile is an assessment considered most appropriate for children 3-10 years old and is performed by an observer, usually a parent (Winne Dunn, 1999). Reports of sensory processing differences using the Sensory Profile are based on observed reactions of the individual by the observer. The Adult/Adolescent Sensory Profile (AASP) is a self-reporting variant available for older persons (Brown \& Dunn, 2002). Only Minshew \& Hobson (2008), Crane, Goddard \& Pring (2009), and Tavassoli et al. (2014) included self-evaluations in their studies. Leekham et al. (2007) used a different evaluation tool, a semi-structured interview with the parent or caregiver of an individual. Tavassoli et al. (2014) used a new evaluation tool, the Sensory Over-Responsivity Inventory (SensOR), a subscale of the Sensory Processing (SP) Scale, which was developed to assess individual sensory domains.

\subsubsection{Relationship with Age}

Children on the autism spectrum have significant sensory processing differences when compared to their neurotypical peers. Kientz \& Dunn (1997) found that there was a statistically significant difference in 84 of 99 sensory processing factors in children aged 313 (85\%). A similar study by Watling et al. (2001) found a statistically significant difference in 8 of 10 sensory factors in children aged 3-6 (80\%). Tomchek \& Dunn (2007) found that $83.6 \%$ of parents of a child on the autism spectrum reported at least one abnormal sensory processing factor, while only $3.2 \%$ in an age-matched control group reported an abnormal factor.

The relationship between autism and sensory processing is found across all ages of people on the autism spectrum (Kern et al., 2006; Leekham et al., 2007; Minshew \& Hobson, 2008). Kern et al. (2006) studied 104 people on the autism spectrum ranging from 3-56 years old and found that sensory processing differences occurred across all age ranges. However, they found that there were less sensory processing differences at high ages. The authors did not report numerical data. This reduction could suggest either that sensory processing improves over time, or that as people on the autism spectrum age 
they learn better coping skills and do not react as visibly, given that the profiling is an observational questionnaire.

Crane, Goddard \& Pring (2009) studied the sensory processing of 36 adults; 18 on the autism spectrum and 18 as a control. They found that the autistic group had significantly higher scores than the control group in the low registration, sensory sensitivity and sensation avoidance quadrants, and significantly lower scores than the control group in the sensation seeking quadrant, where scores in the middle range are considered typical in each quadrant. 17 out of 18 autistic adults reported an extreme result in at least one of the quadrants on the self-reported AASP variant. Within the autistic group, there was much variance in sensory processing abnormalities, but 14 out of 18 reported an extreme result in the sensory avoidance quadrant.

Tavassoli et al. (2014) studied sensory over-responsivity in adults on the autism spectrum in respect of the different domains of sensory processing. Adults on the autism spectrum (n $=221$ ) reported significantly higher sensory over-responsivity across all domains compared to the control group ( $n=181$ ), with the highest differences in hearing, proprioception, touch and vision domains. They found no statistically significant correlation between the SP scale and age of the participants.

\subsubsection{Relationship with IQ Level}

People on the autism spectrum are likely to have sensory processing differences regardless of IQ level (Adamson, O'Hare, \& Graham, 2006; W. Dunn, Myles, \& Orr, 2002; Leekham et al., 2007; Minshew \& Hobson, 2008). Dunn et al. (2002) found that children with Asperger's Syndrome have statistically significant differences from their neurotypical peers in 22 out of 23 sensory processing factors. Adamson et al. (2006) also assessed 44 children across the autism spectrum and found that sensory processing difficulties were common across all IQ levels.

Both Leekham et al. (2007) and Minshew \& Hobson (2008) tested both age and intellectual ability in their studies on sensory processing in individuals with autism. Minshew \& Hobson (2008) only assessed autistic individuals without intellectual impairment, aged 8-52 with a mean age of 17 . They found that these individuals had a $32 \%$ prevalence of sensory difficulties, which is lower than the earlier studies but still significant. As seven out of the nine earlier studies used the Sensory Profile or a variant, it is difficult to directly compare the results as the questions asked may not directly correlate. Minshew \& Hobson's (2008) study collected both self-evaluated and parentally-observed data, and there was no statistically significant difference in the answers between these. Leekham et 
al. (2007) also assessed individuals with a range of ages and IQ levels, and found that sensory processing difficulties were prevalent across all ages and IQ levels. Ninety percent of the individuals had at least one sensory sensitivity, and most had multiple. Age and IQ level were factors that decreased the number of sensory sensitivities in certain areas, primarily visual. Again, the study followed another different assessment tool, and so it is difficult to directly compare results.

Crane, Goddard \& Pring (2009) found some correlations between performance IQ and scores in three of the four AASP quadrants amongst the 18 adults on the autism spectrum (low registration, sensory sensitivity and sensation avoidance), although only the low registration quadrant correlated with full-scale IQ. There was no statistically significant correlation between scores in the sensory sensitivity and sensation avoidance quadrants and full-performance $I Q$, and the low registration correlation was weaker for full-scale IQ compared to performance IQ. There was no correlation between scores in any of the quadrants and verbal IQ. Given that 17 out of the 18 autistic adults in the study showed an extreme difference in at least one of the sensory processing quadrants, it is likely that the correlations found do not predict whether sensory processing differences are present, but rather the strength of the differences in specific quadrants. They also did not find a correlation between levels of sensory processing and levels of autistic traits.

However, Tavassoli et al. (2014) found the opposite effect to Crane, Goddard \& Pring (2009), with no statistically significant correlation between sensory over-responsivity and $I Q$ in 221 adults on the autism spectrum, but a positive relationship between sensory overresponsivity and number of autistic traits. Both studies used the Autism Quotient as a measure of autistic traits, but used different IQ and sensory processing measures.

\subsubsection{Current Neuroscience Research}

It is typically assumed that there are five main senses; tactile, the sense of touch; visual, the sense of seeing; auditory, the sense of hearing; gustatory, the sense of taste; and olfactory, the sense of smell. However, the sensory processing system includes two other main sensory modalities; proprioception, the internal sense of the position and movement of the body; and vestibular, the sense of balance. Information from the individual sensory modalities is transmitted from the peripheral nervous system, to be integrated by the brain to form the complete sensory perception we have of the world. The evidence above showing differences in sensory processing in people on the autism spectrum is now being supported by emerging neuroscience research into sensory perception and integration in the central nervous systems of autistic people (Robertson \& Baron-Cohen, 2017). 
There has been debate over the last decade into the neuroscience behind autistic brains, with some studies showing too many connections in the brain and others showing fewer connections than a typical brain (Robertson \& Baron-Cohen, 2017). Many neuroscientists now agree that there is evidence for both issues, in different systems within the brain. Recent studies have shown that there is overconnectivity in the 'feed-forward' connections in the peripheral nervous system, but underconnectivity in the 'feed-back' connections within the brain that temper sensory experiences (Cerliani et al., 2015; A. J. Khan et al., 2015; S. Khan et al., 2015; J. Wang et al., 2017). In most people, the sensory information coming into the brain is tempered by the feedback, so reduction in the feedback system means that sensory information becomes overwhelming (Zeliadat, 2015). Studies also show problems with the integration of information from multiple senses, which is required for adaptive functioning (Brandwein et al., 2013; A. J. Khan et al., 2015; Russo et al., 2010; J. Wang et al., 2017).

Historically, differences in sensory processing have been considered secondary in people on the autism spectrum, with the primary symptoms being social communication and behaviour based. However, there is speculation whether this assumption could be the opposite way around as more studies show differences in brain structure in the sensory processing regions of the central nervous system in people on the autism spectrum (Robertson \& Baron-Cohen, 2017). Brandwein et al. stated:

"It is not difficult to see how disruptions in fundamental integration of basic sensory information might contribute to social and communicative deficits characteristic of individuals with ASD" (2013, p. 1338)

It is possible that sensory processing could be the primary neurological source of autistic symptoms, with social communication difficulties and restrictive behaviour being a result (Robertson \& Baron-Cohen, 2017). 


\subsection{The Built Environment}

The built environment encompasses all aspects of our surroundings built by humans, including buildings, infrastructure, parks, transportation, and utilities. This section focuses on the indoor environment of buildings, as this is the focus of the research project. A study of over 9,000 people of all ages in America found that people spend $87 \%$ of their time inside a building, of which $69 \%$ is inside their home, and $18 \%$ is in other buildings (Klepeis et al., 2001).

\subsubsection{Indoor Environment Quality}

The Indoor Environment Quality (IEQ) of a building is the relationship between the conditions of a building's environment and their effects on the health and wellbeing of its occupants. Most studies of IEQ assess occupant comfort, well-being, and productivity in office work spaces.

The adverse effects of poor indoor environment quality are well documented. Exposure to poor IEQ can cause both short and long term effects, with links made to Sick Building Syndrome, mental health effects, allergies and asthma, long-term illnesses such as cardiovascular problems, acute respiratory illness and obesity (Bluyssen \& Cox, 2002; Fisk, 2002; Fisk \& Rosenfeld, 1997). These effects stretch across the nervous system, immune system, and endocrine system.

Poor indoor environment quality also affects productivity. Wyon \& Wargocki (2013) reported that the magnitude for negative effects due to the indoor environment could be up to $5 \%$ in the lab and $10 \%$ in the field for adults, and can be over $20 \%$ for children in schools. Lamb \& Kwok (2016) found that environmental stress reduced work performance by between $2.4 \%$ and $5.8 \%$ and impacted on occupant well-being in an 8-month longitudinal study of 114 office workers. Fisk \& Rosenfeld (1997) estimated that by improving IEQ, direct productivity gains of $0.5-5 \%$ could be gained, with the same effect also estimated to improve student learning in schools with improved IEQ.

\subsubsection{IEQ Factors}

Indoor Environment Quality is widely accepted to be the cumulative effect of many different factors that constitute the indoor environment. However, there is a debate about the relative importance of each individual IEQ factor in overall comfort and productivity. All IEQ factors are not point-measures for comfort; rather there is a comfort zone for each factor, which is dependent on and different for each individual person (Al Horr et al., 2016). 
Al Horr et al. (2016) performed a review of 303 studies of IEQ and productivity in office spaces. They identified eight main factors that appeared in many of the studies; Indoor Air Quality and Ventilation, Thermal Comfort, Lighting and Daylighting, Noise and Acoustics, Office Layout, and Views, Look and Feel, Location and Amenities. Based on Centre for the Built Environment (CBE) survey data from 352 buildings with over 43,000 people, Kim \& de Dear (2011) broadly classified the relation between IEQ factors and satisfaction into two categories. Some factors were considered "Basic", where the negative effects outweighed positive effects, so they must be maintained to satisfactory levels. Basic factors included temperature, amount of space, noise level, and visual privacy. Other factors were classified as "Proportional" when overall satisfaction increases or decreases linearly with the satisfaction of the individual factors. Proportional factors included air quality, amount of light, sound privacy, and building maintenance.

Al Horr et al. (2016) identified that thermal comfort, indoor air quality, layout and noise had the most significant effect on productivity. They also found that there were interactions between different IEQ factors, such as between daylighting and thermal and between layout and noise. In an analysis of 10 years of data from the online CBE survey with over 50,000 US respondents, Wargocki et al. (2012) also found that self-estimated job performance was dependent on indoor environmental qualities, where temperature was found to cause the greatest improvement in performance, followed by noise and air quality. In an analysis on the data from 177 UK buildings from the Building Use Studies (BUS) survey, Leaman \& Bordass (2007) found that in order of priority, overall comfort was considered the most important to indoor environment satisfaction, followed by temperature, ventilation, lighting, then noise IEQ factors.

Unlike many other studies, Lamb \& Kwok (2016) found that of the IEQ factors, stress from noise and lighting had the most impact on productivity, with thermal comfort having less impact. Liebl et al. (2012) linked background noise that was of high intelligibility to a decrease in cognitive performance. They also found that while dynamic lighting did not impair cognitive performance, it did cause significant complaints. Well-being was found to be more closely linked to indoor environment qualities than cognitive performance, and the authors note that these effects should be considered separately.

Geng et al. (2017) found that there was a link between thermal satisfaction and increased productivity. They also found that the thermal environment affects all other IEQ factors, where low satisfaction with thermal was linked with higher satisfaction with other IEQ factors. Leaman \& Bordass (2007) also observed a similar effect where overall comfort can stay low when thermal and ventilation problems are solved, as issues with light and noise then become forefront. 


\subsubsection{Control}

People are more satisfied with their indoor environments when they have control over at least one aspect of the indoor environment (Brager, Paliaga, \& De Dear, 2004; Moore, Carter, \& Slater, 2002; Newsham, Veitch, Arsenault, \& Duval, 2004). This effect is true even when the environment is less comfortable, as perceived control appears to offset some of the dissatisfaction. Moore et al. (2002) found that people were satisfied working in lower than recommended light levels when they were given control over dimmable lighting systems. There are claims that many thermostat controls in office buildings are actually unconnected 'dummies', as even the perception of having a control improves complaints, even if in reality that control is fake (Sandberg, 2003).

Clausen \& Wyon (2008) performed a study where participants were given control to make changes to a simulated office environment with a 'limited' budget. There was no consensus on what changes were a priority for all subjects, as all possible combinations of options were chosen by different subjects. Three quarters of subjects chose to make the space cooler, followed by a reduction in noise, better office layout to improve auditory privacy, and more pleasant lighting, with fewer choosing better daylight or views. However, these choices are likely to be affected by the environment being simulated, and optimising for their budget, as not all items were weighted equally. When satisfaction of the group that was allowed to choose their own limited changes was compared to the satisfaction of a group that were given all the changes with no budget, the group with the limited budget was more satisfied, showing having limited control over the environment was more important to subjects than a fully improved environment with no choice. 


\subsection{Autism-Friendly design}

There are many design guidelines for 'autism-friendly' design that have been developed by different architects and researchers. Allowances for sensory processing difficulties are specified in all design guidelines, though to different degrees. However, the design guidelines are highly specific and are primarily used for the design of specialist schools and residential centres for autistic children with very high support needs. Case studies where autism-friendly design has been implemented are generally post-occupancy observational studies, and so the relative impact of different modifications is difficult to ascertain.

\subsubsection{Guidelines}

Humphreys (2005) approaches autism-friendly design guidelines from an architectural perspective, based on the experience of having an autistic brother. His guidelines are not designed for any specific building type and are based primarily on spatial planning and details. However, he also mentions the use of natural light and acoustics with some specifics.

Table 1. Humphreys' autism-friendly design guidelines (2005)

\begin{tabular}{|c|c|}
\hline Criteria & Summary Description \\
\hline $\begin{array}{l}\text { Calm, order and } \\
\text { simplicity }\end{array}$ & planned spaces, consideration of material and colour choice \\
\hline $\begin{array}{c}\text { Minimal details and } \\
\text { materials }\end{array}$ & reducing background visual stimulation \\
\hline Proportion & using the ancient proportional systems in space and structure \\
\hline Natural light & lots of diffuse light, being cautious of glare and shadowing \\
\hline Proxemics & more space per person for social proximity \\
\hline Containment & monitor children but provide 'safe' spaces for wandering \\
\hline Observation & allow for supervision but not intrusion \\
\hline Acoustics & consider acoustic properties of materials \\
\hline
\end{tabular}

Vogel (2008) has a wide and interpretive stance on autism-friendly guidelines. His guidelines are general, and relate primarily to the arrangement of space, how it is used, and the emotional effects of it. While the introduction paragraph in his article mentions a number of sensory issues, he does not specifically address these in this design guidelines. 
Table 2. Vogel's autism-friendly design guidelines (2008)

\begin{tabular}{cc}
\hline Criteria & Summary Description \\
\hline $\begin{array}{c}\text { Flexible \& adaptable } \\
\text { Non-threatening } \\
\text { Predictable } \\
\text { Controllable }\end{array}$ & furnishing, lighting and spatial arrangements \\
spatial planning \\
Sensory-motor attuned \\
Safe & elutter-free, sensory sensitive, low arousal \\
Non-institutional & public and private spaces \\
sensory rooms and spaces
\end{tabular}

Beaver $(2006,2010,2012)$ has produced a number of publications of the design guidelines that he follows at his practice, GA Architects, which specialises in autismfriendly design. These guidelines are generally described as specific physical implementations. Each publication presents his guidelines slightly different, but the overall intention is the same.

Table 3. Beaver's autism-friendly design guidelines $(2006,2010,2012)$

\begin{tabular}{|c|c|}
\hline Criteria & Summary Description \\
\hline Acoustics & reducing background noise, no reflective surfaces \\
\hline Lighting & $\begin{array}{l}\text { flexible and non-institutional, hidden if possible, no flickering } \\
\text { fluorescents }\end{array}$ \\
\hline Windows & $\begin{array}{c}\text { glare control, blinds within double glazing if possible, high windows to } \\
\text { prevent 'escape' }\end{array}$ \\
\hline Heating & no radiators, underfloor/central heating if possible \\
\hline $\begin{array}{l}\text { Space } \\
\text { planning }\end{array}$ & $\begin{array}{l}\text { circulation spaces instead of long corridors, curved walls, simple } \\
\text { geography, quiet rooms and sensory spaces, outdoor space }\end{array}$ \\
\hline Colour & avoid bright and harsh colours \\
\hline Other & $\begin{array}{c}\text { consideration of maintenance and cleaning in material choice, safety } \\
\text { of equipment (hidden pipes, low water temperatures, etc.) in utility } \\
\text { areas }\end{array}$ \\
\hline
\end{tabular}

It should be noted that none of the design guidelines above have empirical data behind their claims, only anecdotal at best. There have, however, been some studies done on the impact of autism-friendly design on autistic people, as outlined below. These are a mix of observational case studies done when design interventions have been implemented, and specific studies. 


\subsubsection{Case Studies}

Whitehurst (2006) performed a case study on a new residential living building housing 12 students at Sunfield School in the UK, designed primarily based on the guidelines produced by Humphreys (2005). The post-occupancy study was a comparison between the old space and the new building. The data are qualitative, which limits the ability to analyse. As the results are reported as "calmer", "more autonomous" and "less intense" (Whitehurst, 2006), it is difficult to assess a frame of reference or a measureable level of improvement that was achieved. No observational measures were recorded, for example, of incidences of children attempting to climb out windows.

McAllister (2010) performed a case study of 9 classrooms in schools in Ireland that were deemed 'ASD-friendly', based on the design criteria laid out by Humphreys (2005) and Vogel (2008). Teachers were asked to rank various factors by what they felt was the most important criteria for autism-friendly design. Overall, the physical factors (comprised of Sensory-Motor Attuned, Good Quality Acoustics, Natural Light and Reduction in Detail) were ranked lowest overall in priority, with the Control \& Safety factors the most important.

In the comments analysis, staff raised the lighting type as being highly important (dimmable, not fluorescent) and that acoustic background noise could be distracting. Physical factors were ranked the lowest, as staff felt that these were factors that students could learn to deal with over time. However, because this is a survey of the importance of design factors by staff, it may not give an accurate representation of the priorities of the students on the autism spectrum in the classroom.

\subsubsection{Lighting}

In many of the sensory profiling studies, and in case studies where indoor environment factors have been ranked, lighting has been assessed as a lower priority than other indoor environment qualities. However, in most of the autism-friendly design guidelines, there are some common specifics that regularly appear. These include reducing glare and avoiding fluorescent lights due to flicker. Sensory profiling asks whether people react to 'bright light' or 'darkness', as opposed to being focused on specific factors such as flickering.

Colman et al. (1976) and Fenton \& Penney (1985) both performed studies on the effect of fluorescent lighting on repetitive behaviours in children on the autism spectrum. Both found that there was an observed increase in repetitive behaviours under fluorescent 
lights in children on the autism spectrum, and recommended the removal of fluorescent lights from therapeutic environments.

Outside of autism-specific design, Wilkins (2015) found that uncomfortable stimuli due to lighting, including spatial configuration, colour and flicker, can affect people's visual comfort. Particularly relating to flicker, he found that the sub-visible flicker can still be perceptible in peripheral vision when the eye moves rapidly. Some people were found to be more susceptible to visual discomfort than others, and the paper includes a study of people with migraines as an example of this. Whether it is possible to link the sensory sensitivity difficulties that people with autism face and the susceptibility to visual discomfort of certain people found by Wilkins warrants further investigation.

Henry (2011) produced a series of 'Designing for Autism' articles for the online ArchDaily, including an article with an analysis of the different design ideas in the design community relating to lighting for autism. He points out that while there is a general consensus on what 'not to do' (i.e. avoiding the use of fluorescents), there is a large debate on what would be considered best practice. Henry also notes that in general for autism design "With so little architectural research in this area, architects tend to rely on anecdotal evidence or methodically flawed studies. Studies with proper controls and sample sizes simply do not exist." (Henry, 2011)

\subsubsection{Acoustics}

Mostafa (2008) performed an experimental research study on the impact of design modifications installed in a classroom. The design modifications were based on the relative importance of different architectural factors to teaching staff and primary caregivers; acoustics, visual (colours \& patterns), visual (lighting), texture, olfactory and spatial sequencing of functions. Teaching staff and primary caregivers believed that acoustics and spatial arrangement were the highest priority. The autistic children did not have input into the prioritising process, although as the children in the study had intellectual and verbal impairments, including them would have been difficult.

Mostafa (2008) installed acoustic materials that reduced background noise from $65.5 \mathrm{~dB}$ to $52.5 \mathrm{~dB}$, and echo ratio from $97 \%$ to $57 \%$. The spatial arrangement of the classroom was also changed to an arrangement that "promoted routine" by dividing the space into "zones" for different activities. There is no discussion of whether the $13 \mathrm{~dB}$ reduction in acoustics achieved is an appropriate level. Further research into different levels of noise reduction to find what is most appropriate would be beneficial. 
Outcomes of the children in the modified classroom were compared to those of another, unmodified classroom at the same school. There were only 6 children in each classroom, for a total of 12 students studied, so the sample size is limited. Mostafa (2008) reported improvements in attention span, response time and behavioural temperament with the classroom modifications. In their analysis of this study, Henry (2012) points out some likely methodological issues with the study due to selection bias and being non-blinded. While Henry uses this study as an example, they point out that many of these issues are common in observational studies, which are the primary way that autism-friendly design is evaluated.

Ellner (2011) performed a similar qualitative study on sensory-sensitive modifications in a classroom with four students on the autism spectrum, for a Master's thesis. The two modifications installed were sound absorbing walls and halogen lighting. There is no information reported on the acoustic or lighting properties of the modifications. The study looked at four students on the autism spectrum at a private specialist school for ASD, PDD, communication disorder, all of whom were males between 12 and 21 and had attended the school for more than a year.

Ellner (2011) found that 3 of the 4 students noticed the change in lighting, and 2 of the 4 noticed the sound absorption. All reported the interventions as positive. The fourth student did not respond to questions appropriately. The students were assessed using a combination of interviews with an Occupational Therapist who worked at the school, and journaling. The limited sample size means that the results are likely not generalisable. Ellner also mention using Facilitated Communication to obtain responses from at least one of the students. This is often not considered a reliable source of information, as results are likely to be influenced by the 'facilitator' (American Speech-Language-Hearing Association, 1994).

\subsubsection{Other Sensory Guidelines}

Stiff (2012) performed a qualitative study of sensory needs in the workplace of seven college students aged 19-22 on the autism spectrum, also for a Master's thesis. While the study investigated the effects of different indoor environment quality factors, it was focussed on the strategies implemented by people, not the environments themselves. Five of the seven students identified auditory sensitivity, four identified lighting sensitivity with three having issues with artificial lighting, and three identified each of smell and tactile sensitivity. All of the sensitivities were highly dependent on the type of job done. The study found that to deal with sensory sensitivities, students relied on a combination of mental strategies and physical interventions like ear plugs, sunglasses and gloves. A 
limitation of the study is that all of the students had limited work experience, working in their jobs primarily in summer breaks.

The Equity Challenge Unit produced a report investigating sensory access barriers to disabled students in the higher education system in the United Kingdom, and provide guidance how to mitigate the barriers identified (Hewitt, Hewiston, O'Toole, \& Haywood, 2009). The report focused on students who had sensory impairments, including visual impairment, Deaf or hard of hearing, and autism. The investigation involved interviews and focus groups with both sensory-impaired students and campus management staff, but no details of participant numbers were reported. The report had a wider focus than the built environment, including recommendations for academics, communication and support services.

The report made a number of specific recommendations for consideration in higher education facilities across the range of sensory impairments, including specific recommendations for students on the autism spectrum (Hewitt et al., 2009). For lighting, it was recommended to avoid the use of fluorescent and spot lighting and to consider using upwards side lighting instead. There was also a specification that if a fluorescent system was installed, to ensure that it was maintained and replaced according to the manufacturer's specifications, and to replace flickering or failed bulbs immediately. For acoustics, the report recommended consideration of ways to reduce background noise, including appropriate reverberation times, and also to make background noise of all HVAC and AV devices a primary consideration when purchasing new equipment. Various other recommendations were also made, including avoiding heavily patterned carpet to avoid visual overload and to have clear signage and doors that are well labelled and swing a consistent direction to assist with navigation.

Based on the experimental study above, Mostafa (2008) produced a "sensory design matrix", to pair individual sensory issues with architectural interventions. The Autism ASPECTSSTM Design Index is based on the needs of an individual, with a focus on seven criteria: Acoustics, Spatial sequencing, Escape spaces, Compartmentalization, Transition spaces, Sensory zoning, and Safety. It was designed for use in individual environments, though Mostafa suggested that it could be used for specialist schools if children were grouped according to sensory needs (2008). The implementation of the index was also tested in home environments (Mostafa, 2014). These studies of the Design Index, in both home and school environments, focus only on children.

Steele and Ahrentzen (2016) published a book about designing housing for people on the autism spectrum, collating quality of life goals and design guidelines from various 
studies of both children and adults on the autism spectrum. The book deals with different residential settings, from individual homes to group residential models, focusing on wider aspects of ensuring quality of life goals are achieved through specific design 


\subsection{Summary}

From the first section of this chapter, sensory processing differences are found across all ages and intellectual abilities of people on the autism spectrum. Age and IQ level appear to affect the severity of sensory processing difficulties in some studies, though the extent of this is not agreed upon. Autistic adults and those without intellectual impairment still exhibit significant sensory processing differences when compared to neurotypical people. Emerging neuroscience research is showing that the differences in sensory processing are due to differences in brain structure, with the possibility of these sensory differences being the primary symptom of autism.

Next, the indoor environment of buildings affects people's health and well-being, comfort and satisfaction, and productivity. There is debate over which IEQ factors have the greatest impact, with different studies showing different results, though in general people are more satisfied in environments they have control over. However, most of the IEQ literature available is based on office workspaces, so these effects may or may not be generalisable to the wider built environment.

These two areas of research are independent, and little research exists that bridges the gap between the sensory experiences of people on the autism spectrum and the effects of the built environment on all people. Design guidelines that have been developed to be 'autism-friendly' are highly specific and are primarily used in specialist schools and residential centres for children on the autism spectrum who have very high support needs. Design guidelines do outline some sensory factors, although empirical assessment of these is limited mostly to post-occupancy observational studies. There is little research about the direct impact of the built environment on adults on the autism spectrum. 


\section{Methodology}

Chapter 3 outlines the process used to develop a research method for this project. Section 3.1 assesses methodologies used in previous research outlined in Chapter 2 and concludes that a survey would be the most appropriate method for this project. Section 3.2 outlines how the survey was initially designed based on precedents of both IEQ surveys and surveys for people with disabilities. Section 3.3 describes the process of developing the survey, including the considerations provided from two pilot studies.

\subsection{Methodologies in the Literature}

When investigating possible methodologies, studies assessed as part of Chapter 2 were analysed to see if they would be applicable to this project. The most common analysis of 'autism-friendly design' is undertaken through post-occupancy observational studies. Whitehurst (2006) performed a post-occupancy observational study of a specialist school residential building that had been built using guidelines by Humphreys (2005). There are two main reasons why this methodology would not be appropriate for this project. Firstly, post-occupancy observation is generally specific to a single building, not the wider built environment. It may not give good exploratory insight into general buildings. Secondly, this is an observational methodology, which does not allow for input from the subjects. Adults on the autism spectrum have often learnt how to 'mask' reactions to their environments, therefore an observer may not be able to pick up on reactions (Attwood, 2007). An observer also may not be able to establish why a person has reacted, or what specifically they have reacted to; for example, a person shading their eyes may be shading from glare, or brightness, or flicker, or any combination.

Experimental studies were performed by Coleman et al. (1976) and Fenton \& Penney (1985) and field studies were performed by Mostafa (2008) and Ellner (2011). While good for establishing associations between variables, these types of studies are specific to the variables that they are testing. As the research question is exploratory, experimental or field studies would not be appropriate until the specific issues are identified.

Both the sensory studies and the IEQ studies in the literature review used surveys/questionnaires. The sensory studies primarily used the Sensory Profile, which is an observer of self-report questionnaire depending on the variant (Adamson et al., 2006; Crane et al., 2009; W. Dunn et al., 2002; Kern et al., 2006; Kientz \& Dunn, 1997; Tomchek \& Dunn, 2007; Watling et al., 2001). The IEQ studies use self-reported surveys about the indoor environment of office buildings (Kim \& de Dear, 2011; Lamb \& KwoK, 2016; Leaman \& Bordass, 2007; Liebl et al., 2012; Wargocki et al., 2012). 
Outside of the reviewed literature, another type of exploratory methodology is interviews and focus groups. These would be able to give detailed information and allow for specific exploration of discussions that arise. However, a major component of autism is difficulties with social communication and resultant anxiety. It could be difficult to recruit participants for interviews or focus groups because of this.

It was decided that a survey method was best suited to the research aims. The survey questions were designed to be exploratory, and a survey did not require the physical presence of participants. There were also precedents of IEQ surveys that were used to develop a survey for this project.

As people on the autism spectrum often struggle with social communication, many find online interaction easier and less intimidating than physical communication (Attwood, 2007). Using an online survey will ensure accessibility for autistic participants, as it does not require face-to-face communication or travel, and can be completed in as much or as little time as each person requires. 


\subsection{Initial Survey Design}

There are a number of existing IEQ surveys that have been developed to study people's experience of the built environment. These are primarily for office buildings. The survey for this project was based on these precedents. However, these surveys needed to be adjusted to suit the audience because people on the autism spectrum process information differently than neurotypical people (Attwood, 2007; Denscombe, 2014). Adjustments were also made to allow for a wider evaluation of buildings than just office buildings.

This section covers established IEQ surveys and precedents of surveys and forms that are designed for people with disabilities. The survey for this project was developed by combining the questions and intent of the IEQ surveys with the format and language of the surveys for people with disabilities. Adjustments due to general knowledge about the processing of people on the autism spectrum are also included.

\subsubsection{Established IEQ surveys}

The two largest IEQ surveys used worldwide are the Building Use Studies Ltd.'s BUS Methodology, and the Centre for the Built Environment's Occupant Indoor Environment Quality (IEQ) Survey (BUS, 2016; CBE, 2014; Dykes, 2012). The CBE survey is only available online, while the BUS Methodology is recommended to be completed using the paper version (Galatioto, Leone, Milone, Pitruzzella, \& Franzitta, 2013). The National Australian Built Environment Rating System (NABERS) is an environmental performance measure of office buildings, schools and homes in Australia (NSW Government, 2016). For a NABERS certification, a building must perform one of these two surveys to validate the occupant satisfaction clauses in the Indoor Environment section (Baird, 2009).

The BUS Methodology was developed in the UK and has been used since 1995, based on an earlier survey created in 1985 (BUS, 2016; Dykes, 2012; Galatioto et al., 2013; Sullivan, Baird, \& Donn, 2013). In 2012 it had been used in over 500 buildings. It consists of four main sections; background, overall building, indoor environment, and travel to work. The indoor environment section is the largest, with 39 questions and seven spaces for comments (Dykes, 2012). The questions in the BUS Methodology are specific, with overall qualities split into sub-categories (Sullivan et al., 2013). For example, lighting questions are split into natural light, glare from sun/sky, artificial light, and glare from lights (Leaman, 2010). The BUS Methodology also has New Zealand benchmarks and was used for the Building Energy End-Use Study (BEES) study (Dykes, 2012). 
The CBE survey was developed in the US and has been used since 1996 (CBE, 2014; Huizenga, Zagreus, Arens, \& Lehrer, 2003; Sullivan et al., 2013). In 2012 it had been used in over 600 buildings. Unlike the BUS methodology, the CBE allows for physical measurements in the data collection (Dykes, 2012; Peretti \& Schiavon, 2011). The CBE survey also first asks for a satisfaction rating of indoor qualities, and if the subject is dissatisfied, the survey re-routes to further specific questions with checklists of issues that the subject could be dissatisfied with (Huizenga et al., 2003). CBE survey data were used in Wargocki et alia's study (2012).

Another approach is the IEQ survey in Lamb \& Kwok's study (2016), a section from a larger survey into wind-induced motion sickness. The IEQ section consisted of four sevenpoint scale questions about light, noise, air quality and temperature. A section on the respondent's workspace also asked their overall comfort and the impact of the environment on work ability using ten-point scales, as well as a checklist question about whether the person had done anything to help cope with the indoor environment.

All three of the surveys primarily use semantic differential seven-point scales for questions. Depending on the question, the "ideal" answer may be low, high, or neutral (Dykes, 2012).

\subsubsection{Precedents of surveys for people with disabilities}

Baron-Cohen et al. (2001) developed a brief, self-administered survey for adults of average or higher intelligence called the Autism Quotient (AQ) test, designed to measure the degree that the subject shows autistic traits. It is not a diagnostic tool, rather is intended as a self-screening tool to inform the incidence of autistic traits in a person. The survey is a 50 item "forced answer", where subjects are asked to rate their agreement/disagreement on a four-point scale. There is no neutral option. As part of the development of the survey, Baron-Cohen et al. checked comprehension of the questions with a trial group of people on the autism spectrum by comparing their answers to the answers of a parent observer. They found that wording comprehension was comparable with neurotypical adults of normal intelligence.

Since 1996, Statistics NZ has performed a Disability Survey after each census (2014). This consists of a screening survey performed on all subjects, and then a further content questionnaire for people who have a disability. As the subject moves through the content questionnaire, sections of questions are introduced and explained:

"The next questions are about your use of health services and help you may get managing everyday activities..." (Statistics NZ, 2001) 
As a whole, the survey questions are progressive and read like a story. Survey questions are also accompanied by specific explanations of terminology:

"Have you ever had what is called a needs assessment, where someone from a needs assessment agency asks you questions about the support you need for everyday living, such as home help, personal care or respite care, which is not funded by ACC?" (Statistics NZ, 2001)

Work and Income New Zealand (WINZ) provide an application form for people applying for the Supported Living Payment, a benefit for people with disabilities who are unable or severely restricted in their ability to work (2016). Like the Disability Survey, the Supported Living Payment form also provides clear explanations of terminology, such as the definition of a relationship for benefit purposes (Appendix 9.2).

Concepts that are abstract or open to interpretation can be difficult for people on the autism spectrum (Attwood, 2007). Explanation of boundaries, intent and context of these concepts must be provided. People on the autism spectrum are also often highly detailoriented and interpret language literally, so questions cannot be ambiguous. This suggests a pilot study should be undertaken with any survey for people on the autism spectrum. 


\subsection{Survey Development}

An initial survey was developed based on the different surveys identified in the literature review with additional author-designed questions. A pilot study was performed on the initial survey design to refine the initial survey, using participants who were knowledgeable about the built environment in general. This pilot study assessed responses to questions for interpretation in the results, as well as including a section to provide feedback. The survey was refined according to the results and feedback; with a transition to a new survey platform also allowing for further options in survey flow. A second, smaller pilot study was performed with two individuals on the autism spectrum and two individuals who were not on the autism spectrum, providing feedback via email after completion. The pilot studies do not form part of the final survey results.

\subsubsection{Initial Pilot Study}

The initial pilot study was performed on twelve students and staff in the 2017 Masters of Building Science cohort. As part of this pilot survey, there was an additional section at the end that asked participants for feedback about the survey. This included ease of answering, and time taken to complete the survey.

As a result of the initial pilot survey, a number of changes were made to the survey questions for greater clarity. This included clarification of a definition for distress, refinement of two of the sensory processing items to be more polarising, adding additional building types, and changing how permanent changes to the home and workplace were asked. All of these changes were made to assist in survey flow and ease of responses.

There was a wide range in the time people took to complete the survey. Half of the pilot participants (6) reported completing the survey in 5-10 minutes, while a quarter (3) reported completing in 15-20 minutes. Of the remaining participants, two reported completing in 10-15 minutes, while one reported taking more than 20 minutes to complete. As the participants in the pilot survey were all students and tutors at the School of Architecture and understood many of the definitions in the survey, this likely contributed to the high number of shorter completion times. Therefore, an estimated average time to complete of approximately 15-20 minutes was appropriate for the final study. There was a wide range of opinions on the length of the survey. Overall, pilot participants felt the survey was slightly too long, which was expected. However, a balance between the survey being slightly too long and collecting the information 
needed to draw conclusions is necessary. Oseland (2007) suggested that a postoccupancy evaluation survey should be $15 \pm 5$ minutes long for optimal responses.

Participants were asked to rate five statements about the survey on a 5-point agree/disagree scale. None of the participants found the survey difficult to follow or the language too complex, and all the participants found that the survey flowed well. Most people found the questions easy to answer and that definitions were clear.

There was also space for participants to comment on the survey. Four had no comment. Two had positive feedback about the survey and questions,

"I think the survey asks appropriate questions and flows well"

"Everything flows well, the questions and tick-boxes are categorised well and cover all the things there is to building types, factors that affect indoor environmental quality and what people do to be more comfortable in the buildings that they use".

Two commented that they found it difficult to answer questions on their discomfort/distress in buildings they don't use regularly in the Other Buildings section,

"Wasn't sure what to put for buildings I don't use"

"Thinking about other buildings that I don't use much/for prolonged periods can be difficult"

Overall, the feedback from the evaluation section in the initial pilot survey was positive. While the initial pilot survey was constructed as a Google Form, as part of the survey refinement the survey was redeveloped using the Qualtrics survey platform. As Qualtrics is a subscription-based service available through the University, it gave more options for survey formatting and control over the flow. One of the biggest advantages of using Qualtrics for this project is that it allowed for comprehensive 'display logic', where survey questions and options could be highly customised based on responses to previous questions. This was applied to many of the questions in the Other Buildings section based on feedback from the initial pilot survey.

\subsubsection{Second Pilot}

A second pilot study was performed with four individuals who were not familiar with building science jargon to check for survey flow and explanations. This is particularly critical when considering a population who can have difficulties with inference and literal 
interpretation of language. Two participants were autistic self-advocates, one of who identified as an unreliable speaker and sometimes uses an electronic tablet for communication. The other two participants were neurotypical. The responses of the participants were not recorded so that should they have chosen to participate in the full study, they would not lose their anonymity. Instead, participants provided feedback via email. All participants were encouraged to give feedback wider than just their own experience, on issues they felt that others completing the survey could face.

All four participants felt that the survey generally worked well, was clear and easy to follow. None of the participants commented on the length of the survey. One of the autistic participants commented that black text on a white background was difficult for people with visual processing issues, so the survey background was changed to a light dull yellow with black text to reduce the colour contrast. Contact information was also highlighted more clearly on the first page of the survey, as one participant commented it was difficult to find.

Both of the autistic participants commented on language. One participant was happy with the language used,

"On a whole you've used language which is simply and easy to understand. That's good because some Autistic's are literal communicators and don't like complicated language"

The other autistic participant made some suggestions about language that was not as clear for them, which resulted in changing "Place of Occupation" to "Workplace". They also commented that they did not know what "Draughts" in the IEQ section was, so this factor was changed to "Air Movement".

There were some recommendations made by the autistic participants that were unable to be implemented due to limitations of the survey platform. Both participants made suggestions about the scales, with one suggesting that adding a central description at 4 on all 7-point scales, and the other suggesting looking into visual scales. Both of these options were investigated, but could not be incorporated into the survey design.

The neurotypical participants both primarily focused on small linguistic issues, picking up small errors in spelling and grammar, which were corrected. There were no complaints about language by either of the neurotypical participants. One participant noted that the scales for some questions were in an opposite order compared to other questions. In response to this feedback, all scales were arranged so that the response options were consistently in the same order across all questions. 


\section{Research Method}

Chapter 4 outlines the method used in this research project. Section 4.1 describes the content of the final survey, including summaries of the different sections of the survey. Section 4.2 outlines the plan for data analysis used in the Chapter 5 results. Section 4.3 describes recruitment of participants for the study, while Section 4.4 summarises the demographics of the participants.

\subsection{Final Survey Design}

As outlined in Chapter 3, the survey questions were developed using the established IEQ survey questions, diagnostic sensory processing questions and general demographics questions. The full survey can be found in Appendix 9.3.

The survey is comprised primarily of multi-choice and check-box questions, and semantic differential ratings. Multiple-choice questions are quantitative and are faster to answer (Denscombe, 2014). However, to a person who is on the autism spectrum and interprets language literally, the answer options may not provide what they feel is an accurate option. While a person not on the autism spectrum is likely to be able to infer the closest answer, this type of generalisation can be difficult for people on the autism spectrum (Attwood, 2007). Likewise, they may not feel that an appropriate answer has been provided as an option. The multiple-choice questions are all mixed-question format; they have an "Other" option where a different answer can be entered (Christensen, Johnson, \& Turner, 2014). There is also a space for any detailed comments at the end of each section.

As comfort is an abstract concept, "comfortable" is clarified as being specifically with respect to IEQ factors. Clarification ensures that the questions are interpreted and answered related to IEQ and not another aspect of comfort not being tested by this survey. A specific definition of workplace is also included. As some people on the autism spectrum may not be employed, this gives an alternative option of either voluntary workplace or other building that time is most spent in outside of the home.

As much as practicable, the survey conforms to the Easy Read recommendations for formatting and language, which were developed by People First and are recommended by the Office for Disability Issues (Office for Disability Issues, 2014; People First NZ, 2017). These are designed to ensure that documents are accessible and easy to read and understand for people with learning disorders, by specifying qualities such as sentence length, font size and choice, and layout. The Cooperative Research Centre for Living with Autism (Autism CRC) in Australia has also published a list of recommendations for 
research with autistic participants that has been considered when developing the survey content and information/consent forms, which includes clear and concise language, consistency, and opportunities for elaboration (Autism CRC, 2016).

There are six sections in the survey; Types of Buildings You Use, Your Home, Your Work, Other Buildings You Use, General Sensory Processing, and Demographics. Each new section starts on a new page and includes an explanation of what the section is about. The explanation is on its own page, to ensure that it is read and understood before questions are started. Questions within sections are grouped, and groups are provided on separate pages to prevent the number of questions on a single page being overwhelming. The start of the Home, Workplace, and Other Building sections also include an explanation of types of indoor environment quality factors.

\subsubsection{Types of Buildings You Use}

The first section of the survey is short, and gathers some basic information about the participant's home, and how often they use various building types. The question regarding the frequency that participants used various building types was used to inform display logic for the Other Buildings section, based on pilot study feedback to reduce asking questions of buildings used infrequently. It also serves to prompt participants to start thinking about the buildings they use regularly in preparation for the rest of the survey.

\subsubsection{Your Home and Your Workplace}

The format of both Home and Work sections are the same to allow for comparison, with one extra question in the Workplace section asking about the type of building. This also allows ease of answering, as new formats are difficult for people on the autism spectrum, so reduction of differences is important (Attwood, 2007). Much of the home and workplace sections are based on existing IEQ surveys, asking first about overall comfort on a 7-point scale from "Not at all comfortable" to "Extremely comfortable", then about discomfort from individual IEQ factors on a 7-point scale from "No discomfort" to "A lot of discomfort".

'Home' was defined in the survey as "the building where you live and sleep most (or all) of the time". For the 'Workplace' section, this was defined as "your main paid or voluntary organisation building or education centre. If your work is based at home or outdoors, or you do not work, please think of the building you would spend the most time in away from the home". As people on the autism spectrum have low employment rates, this was intended to ensure that complete data were obtained for comparison. 
The British Council for Offices released a Guide to post-occupancy evaluation (POE), that outlines construction of POE surveys (Oseland, 2007). By analysing 20 surveys in use at the time of publication and asking an expert panel on their experiences, the Guide offers a list of the most common IEQ factors addressed in POE surveys and suggests a list of topics that should be addressed at a minimum. However, the Guide applies primarily to office spaces, and the post-occupancy surveys are for evaluating a single building, so some of the factors suggested were not included due to not being relevant to this project. Therefore, the list of IEQ factors has been selected from the full list of commonly asked questions published in the Guide (Oseland, 2007).

For all IEQ factors, no guidance was given as to why a factor would be causing discomfort. For example, participants were asked how much Temperature as a factor caused them discomfort, but not whether it caused discomfort due to being too hot or too cold. An IEQ survey is typically used to evaluate a single building, where adjustments are made based on responses, so it is important to gauge why a factor is causing a problem in a post-occupancy evaluation. However, for this project, it does not matter why specifically a factor is a problem, only whether it is or is not, as this research project is about people's perception of the general built environment and not a specific building being assessed.

As well as IEQ factors, participants were also asked to rate a series of statements about the psychological effects of their home and workplace on a 7-point agreement scale, whether they found the environment safe, overwhelming to their stressful, or caused them to feel stressed/anxious. These statements were included to gain additional perspective on how people perceived their environments outside of strictly comfort.

Participants were asked how much control they felt they had over their environment at both home and workplace on a 7-point scale from "No control at all" to "A lot of control", one of the recommended topics in the POE Guide (Oseland, 2007). They were also asked whether they had made any permanent changes to improve the indoor environment at both their home and workplace, and to describe them if they had, as well as whether they would like to make any permanent changes in an ideal world for both environments, and to describe them if they did.

\subsubsection{Other Buildings You Use}

The Other Buildings You Use section is divided into two main parts, discomfort and distress in typical buildings, and avoidance of buildings. This section of the survey was the most 
redeveloped during the survey development process, as there are no precedents of survey questions on these topics.

Based on their answers to how often they used various building types, participants were asked to rate how often the building types they used once a month or more often caused them discomfort on a 7-point scale from "Never" to "Always". Participants were asked to rate their discomfort (as opposed to their comfort) as the project is focused on adverse effects of the built environment

Participants who rated that certain building types caused them regular discomfort (answering ' 3 ' or above) were then asked to rate how much distress a building caused them on a typical visit on a 7-point scale from "No distress at all" to "A lot of distress". This is modelled off the gating method that the CBE survey uses, where participants are asked further questions if they answer that they are dissatisfied with a general IEQ factor to ascertain the cause of their dissatisfaction (ASHRAE, USGBC, \& CISBE, 2010)

When asking about avoidance, if the survey only asked whether participants avoided buildings or not, people could answer "No" when the answer is "No, I can't avoid that building even though I don't like it as I have to use it". Therefore, a single Yes/No question was not sufficient to assess avoidance. Participants are first asked whether they have ever avoided buildings. If they answer "Yes", they are then directed to select the types of buildings that they have ever avoided from a list, the same list of building types used throughout the survey. The survey platform then 'passed forward' the building types that the participant has identified that they have ever avoided and asked how often each of the identified building types is avoided on a 7-point frequency scale from "Never" to "Always". Participants are then asked whether in an ideal world they would avoid going to buildings if they could, and if answering "Yes" given the same checklist of building types to identify as those that they would avoid if they could. If a participant answered "Yes" to either having ever or ideally liking to avoid buildings, they were then directed to a question asking them to rate how much various IEQ factors made them want to avoid buildings, a similar list to the Home and Workplace IEQ sections.

\subsubsection{General Sensory Processing}

The 15 items in the General Sensory Processing section of the survey are based on the Sensory Sensitivity and the Sensation Avoiding sections of the Adult/Adolescent Sensory Profile (Brown \& Dunn, 2002). This project did not have copyright permission to use the original Sensory Profile, so the items were adapted to create an original Sensory Processing Score. The 15 items were each asked on a 5-point frequency scale from 
"Almost Never" to "Almost Always" (coded 0-4), which when summed gave a maximum Sensory Processing Score of 60.

Each individual item is specific to a certain situation, covering various sensory inputs including touch, taste/smell, movement, noise, and visual. A higher score in a particular item represents more sensitivity to that particular input. The items are summed to give an overall score, as it is the pattern of answers that is indicative of a difference in sensory processing, not individual answers. All items relate to sensory hypersensitivity and overresponsivity, as these are the focus of this project, but differences in sensory processing can also be due to under-responsivity and sensory 'seeking'. Differences in sensory processing outside hypersensitivity and over-responsivity are outside the scope of this project. 


\subsection{Data Analysis Plan}

Response data were analysed using the statistical software program R Studio, which uses the R programming language for statistical computing and graphics (R Core Team, 2017). Where needed, supporting analyses were performed using SPSS. As the data are ordinal and non-normal, non-parametric tests were used for data analysis.

Semantic differential ratings are considered discrete ordinal data, as the scale has ordered categories, but the 'distance' between the scale points is not uniform, therefore the data are not continuous. For example, while a 7-point Agree-Disagree scale might be coded -3 to 3 for each answer, the assumption cannot be made that the difference between -3 and -2 is the same as the difference between -2 and -1 , as the scale anchors are descriptive. Many of the data distributions were identified as skewed or non-normally distributed early in the analysis, therefore were treated as non-parametric.

Where possible, Confidence Intervals $(\mathrm{Cl})$ are provided with parameters to provide an estimate of the confidence that is held with the result. A confidence interval is a range that is an estimate of how likely the true value of a parameter for the population falls within the range. The range is calculated from the sample data, and a confidence interval is specified to a given proportion, usually $95 \%$. For a $95 \% \mathrm{Cl}$, if a sample is drawn an infinite number of times, the true parameter will fall within the confidence interval range for $95 \%$ of the samples. Throughout this project, all confidence intervals are $95 \%$.

As the data are ordinal, for a measure of central tendency the median was used instead of the mean. A mean assumes a continuous scale with equal intervals, but neither of these premises are true for an ordinal scale, therefore a mean is considered inappropriate. A median only uses integer numbers, and cannot provide the resolution that a mean does, though it is more robust when dealing with outliers or non-normal data. However, as it is an integer, there are times where a median difference may be zero, or a Confidence Interval has a 0 in the bounds, but still has a statistically significant difference between groups. The other disadvantage of using medians is that many statistical tests are not able to use the median. Confidence intervals for the median in $\mathrm{R}$ are calculated using a ranking formula, where the upper and lower confidence intervals are the value at a calculated rank when all values are ordered.

There are two different ways to calculate median difference, the simple 'difference of the medians': median(A)-median(B), or the 'median of the differences' where the median is taken of the differences between all pairs of items in set $A$ and set $B$ : median(A-B). When working with means, these two formulas are equivalent. However, 
because medians work on ranks, the formulas produce different results when working with medians. The median difference in $\mathrm{R}$ is calculated as the 'median of the differences', so this is what has been used throughout this project.

For testing between groups, Mann-Whitney $U$ tests were used. These are null-hypothesis significant tests, which asks whether two independent samples are selected from populations that have the same distribution. The $U$ statistic is the sum of pairs where one group was greater than the other. In $R$, the wilcox_test function from the \{coin\} package was used, as this calculates an exact $\mathrm{p}$-value that considers ties in the data (Hollander, Wolfe, \& Chicken, 2013). The U statistic is the sum of all pairs that the first group has 'won'; where there are ties, 0.5 is assigned to $U$ for that pair.

Two measures of effect sizes were calculated. Cliff's delta $\delta$ is an effect size used with ordinal data and is a measure of how many times a value from one group is greater than a value from the other group (Cliff, 1993). Cliff's delta is equivalent to a rank biserial correlation, as while the two are calculated differently, their equations are equivalent and produce the same result (Wuensch, 2015). Cliff's delta is linearly related to $U$ from a Mann-Whitney $U$ test, has associated confidence intervals, and produces an effect size between -1 and 1 , where 0 indicates no difference between the two groups, and the further from 0 the greater the effect size (Grissom \& Kim, 2012). The magnitude of Cliff's delta is related to the effect size magnitudes for Cohen's d specified by Cohen (1988), and are interpreted as a small effect is greater than .174, medium is greater than .330, and large is greater than .474, irrespective of sign (Romano, Kromrey, Coraggio, Skowronek, \& Devine, 2006).

The Common Language Effect Size (CLES) was also used, which was proposed by McGraw \& Wong (1992) to be used as an effect size that can be easily understood by the public. The CLES is calculated as a percentage, the probability that a randomly selected sample from one group is greater than a randomly selected sample from the other group, where $50 \%$ indicates there is no effect (Wuensch, 2015). As with Cliff's delta, this effect size calculation can be used with ordinal data as it only requires being able to calculate whether one value is greater than another, without consideration of the magnitude of the difference (Vargha \& Delaney, 2000). Also as with the Mann-Whitney U test, ties are added equally to the probability of both groups (Wuensch, 2015).

When looking at the correlation between two numeric variables, the Spearman rank correlation coefficient was used. This is a non-parametric measure of correlation that compares the relative ranks of each value within a variable, not the values themselves, and is considered appropriate for discrete ordinal values (Grissom \& Kim, 2012). 


\subsection{Recruitment}

The Victoria University Human Ethics Committee approved the research project on the 29 April 2017 (approval number: 24471) (Appendix 9.4). The survey was active for two months, collecting responses between late June and early September 2017.

The survey was disseminated as an online anonymous survey, with no personally identifiable information provided by participants. As the author has established relationships with many in the autism community, an anonymous survey reduced the risk of participants being identifiable by the author. It is not practicable to avoid recruiting participants with whom the author has an existing relationship; this would severely restrict the number of people who would be eligible to participate as the autism community is quite small.

Autism New Zealand and Altogether Autism, the two main Disability Information Advisory Services (DIAS) specialising in autism in New Zealand, were approached to help disseminate the survey to recruit people on the autism spectrum. Both organisations were helpful in sharing the survey invitation on their individual social media pages. The national coordinator for Autism New Zealand was able to pass on the survey invitation to their various regional offices throughout the country to help disseminate it, many of which run specific support groups for adults on the autism spectrum.

There are also many autistic-led organisations and groups, including ASK Trust, Autistic Self-Advocacy Network (ASAN) NZ, and the Autistic Collective, who are proactive in supporting autistic-led research into improvement of outcomes for people on the spectrum. These organisations also were approached to help disseminate the survey, and all shared it on their social media pages.

Personal networks were also used to recruit participants, as the author knows a number of other adults on the autism spectrum. This involved approaching individuals, and asking them to both complete the survey and pass it on to their own networks. An invitation for the survey was also posted on various private and closed groups for people on the autism spectrum and their families on social media. Many autistic people use social media as a preferred method of communication because it removes the difficulties that arise in face-to-face communication. Over the two months that the survey was active, reminders were also posted in the social media groups.

The survey was advertised on local community group pages on social media to recruit control group participants, to ensure a wide range of participants from different demographics. Particularly given the high proportion of people on the autism spectrum 
not in employment, this approach was aimed at selecting a higher number of nonworking participants in the control group also. The survey was also shared by some local businesses among their employees and customers.

Use of social networks to recruit participants allowed for 'snowballing' (Denscombe, 2014). This is where participants are asked to disseminate the survey among their acquaintances, and the sample group grows with each participant. 


\subsection{Participants}

A total of 278 responses were collected while the survey was active. Two of the responses were incomplete in critical sections, so the final number of complete responses is 276.

\subsubsection{Analysis Groups}

Two groups were defined for the purposes of comparative analysis - Autistic and Control.

The Autistic group included any people who identified as being on the autism spectrum $(n=83)$. This included people who identified as also having other conditions and/or family on the spectrum, as identifying as autistic was considered primary. A further 59 participants identified having another condition that affected their sensory processing (e.g. blindness, epilepsy, ADHD) and/or identified as having a family member on the autism spectrum and were excluded from the neurotypical Control group $(n=134)$. When addressing the relationship between wider sensory sensitivity and the built environment, all 276 participants are included in the analysis.

\subsubsection{Demographics}

Of the 276 responses, 44 identified as male, 227 identified as female, and 5 identified as gender diverse. All of the participants who identified as gender diverse also identified as being on the autism spectrum (6\%). Within the Autistic group, $75 \%$ of participants identified as female, and $19 \%$ identified as male. Within the Control group, $84 \%$ of participants identified as female, and $16 \%$ identified as male.

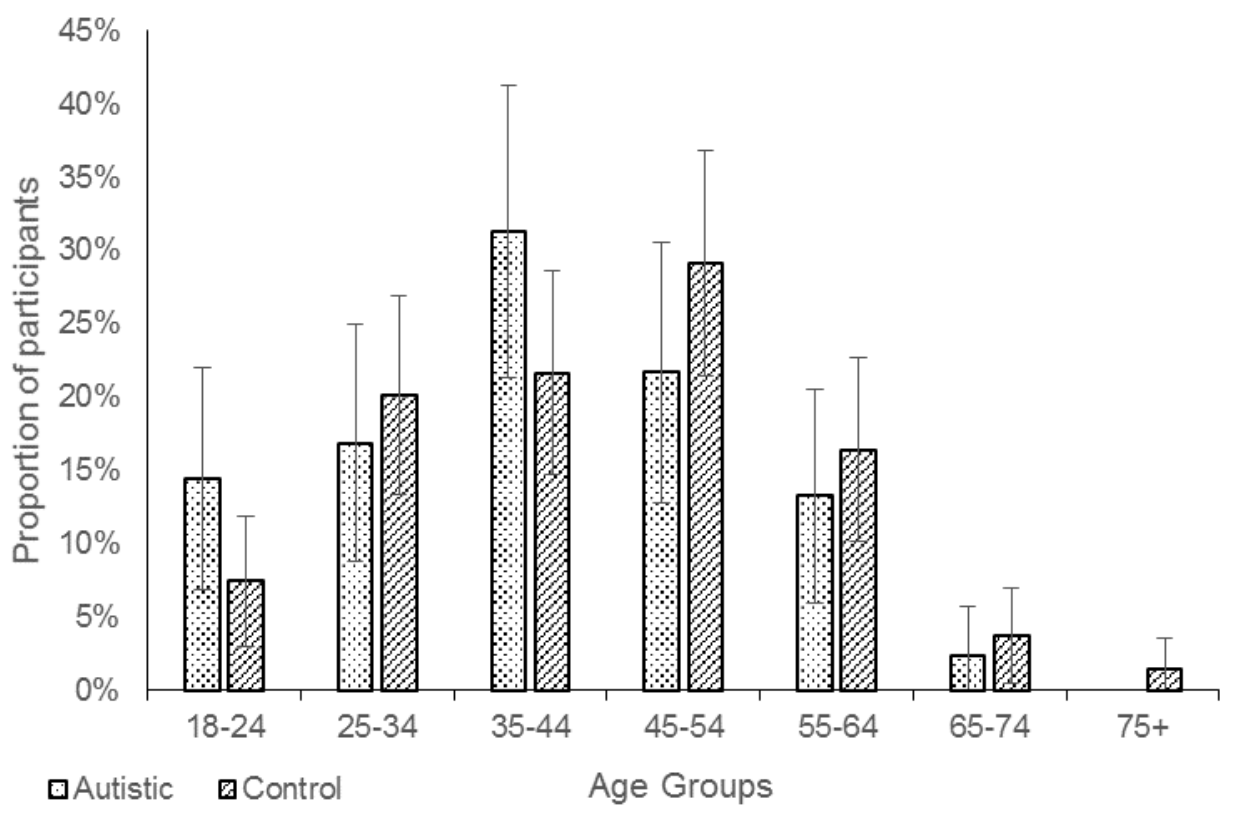

Figure 1. Age of Participants by Condition 
The distribution of ages between the Autistic and Control groups are similar, with both group's distributions being reasonably symmetrical. There were slightly greater number of younger Autistic participants, with $63 \%$ aged below 45, compared to the Control group where $49 \%$ of participants were aged below 45 . Only two participants in the Autistic group were 65 or older, while seven of the Control group participants were 65 or older with two of these aged above 75.

Participants in the Autistic group were more likely to rent their homes $(60 \%)$ compared to the Control group (28\%).

In the Control group, $60 \%$ of participants identified as being in paid full-time employment, compared to only $25 \%$ of the Autistic group. $18 \%$ of the Autistic participants identified as being in paid part-time employment, compared to $11 \%$ of the Control population. Participants in the Autistic and Control groups were equally likely to be self-employed. In total, $85 \%$ of the Control group were in either paid employment or self-employed, compared to only $55 \%$ of the Autistic group.

Participants in the Autistic group were much more likely to be Unoccupied (12\%) compared to the Control group (1\%), two and a half times as likely to be a stay at home parent, and twice as likely to be a student. While no participant in the Control group identified as being a voluntary worked (paid or part time), $6 \%$ of the Autistic group were. There were more participants in the Control group that identified as retired, which is logical given the distribution of ages.

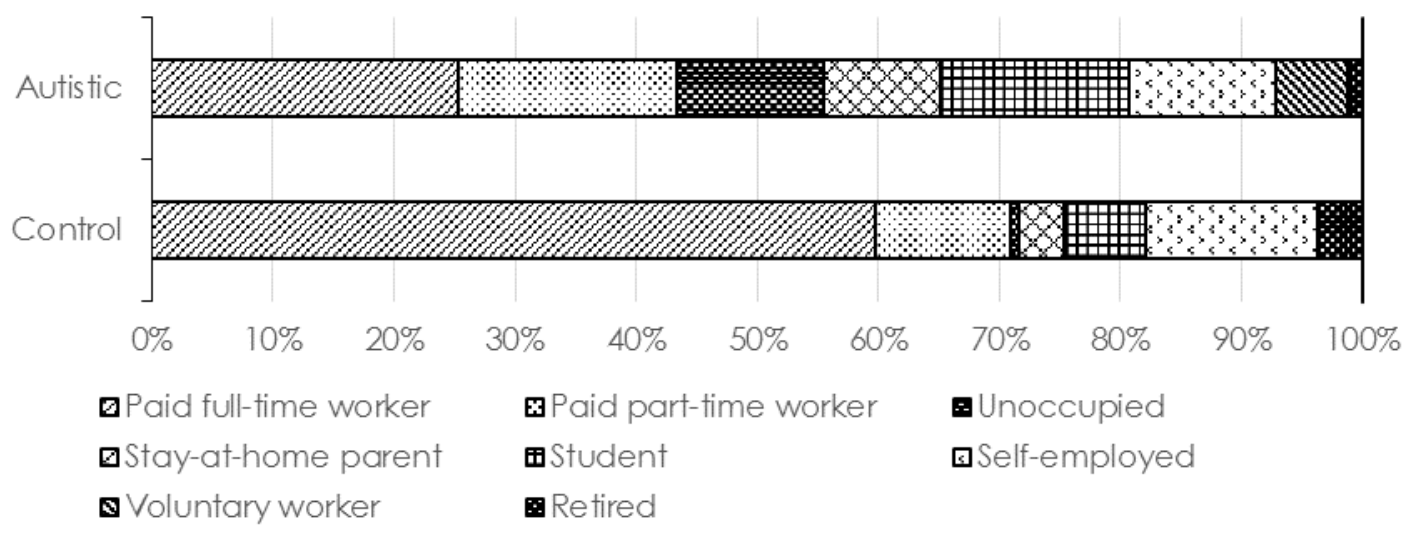

Figure 2. Comparison of Employment Status between Autistic and Control participants

Both the Autistic and the Control group are reasonably well matched on group proportions of gender and age bracket, but the groups have different employment status distributions. 


\section{Results}

Chapter 5 presents the results of the survey. Section 5.1 addresses differences in sensory processing between the Autistic and Control Groups. Section 5.2 considers comfort at both the home and the workplace, as well as perceived control over these environments. Section 5.3 explores participants' experiences of the general built environment, regarding discomfort distress and avoidance by building type. Finally, Section 5.4 analyses the effects of various IEQ factors as a cause of discomfort in the home and workplace and as a cause of avoidance in the general built environment.

\subsection{Sensory Processing}

The median sensory processing score for the Autistic group was $43[39,46]$, with a range of 12 to 60 (Figure 1). The median individual item score for the Autistic group was 3, which matches the "Frequently" anchor. The median sensory processing score for the Control group was $20[18,24]$, with a range of 0 to 45 (Figure 1). The median individual item score for the Control group was 1, which matches the "Almost Never" anchor.

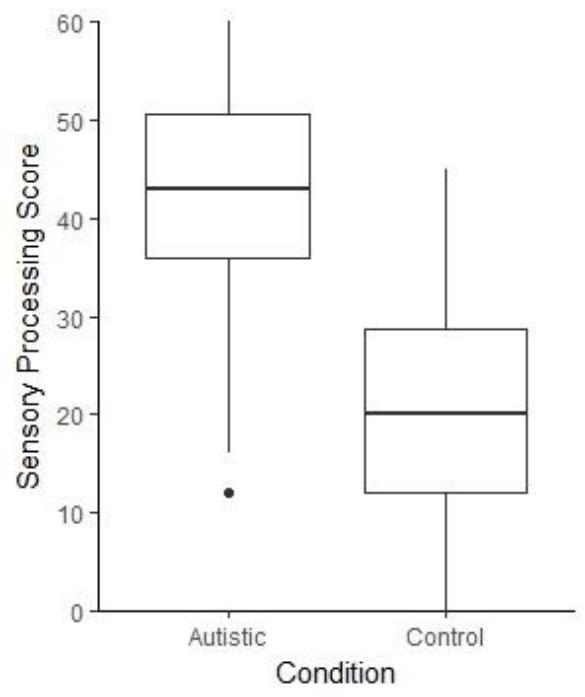

Figure 3. Sensory Processing Score by Condition

The median difference between the Autistic and Control groups was 21 [18, 24], which equates to an effect size of $-.80[-.87,-.71]$ (Cliff's $\delta$ ) indicating a large effect. This was supported by a Mann-Whitney $U$ test that showed a statistically significant difference between the Autistic and Control groups $\left(n_{A}=83, n_{C}=134, U=10032.0, p<.001\right)$. On average, a participant in the Autistic group recorded a higher Sensory Processing Score than a participant in the Control group in $90 \%$ of cases (where $50 \%$ indicates no difference between the groups). A difference of 21 points comprises more than a third of the entire scale, which equates to a difference of between 1 and 2 points on each individual item in the survey section. 
Participants in the autistic group had a much higher proportion of higher answers to individual items than the control group (Figure 2). In the control group, only $19 \%[18,21]$ of answers were "Frequently" or "Almost always", while in the autistic group $63 \%[60,66]$ of answers fell in these two categories across all items and responses. Meanwhile, in the control group, $55 \%[52,57]$ of answers were "Seldom" or "Almost never", while in the autistic group only $15 \%[13,17]$ of answers fell in these two categories.

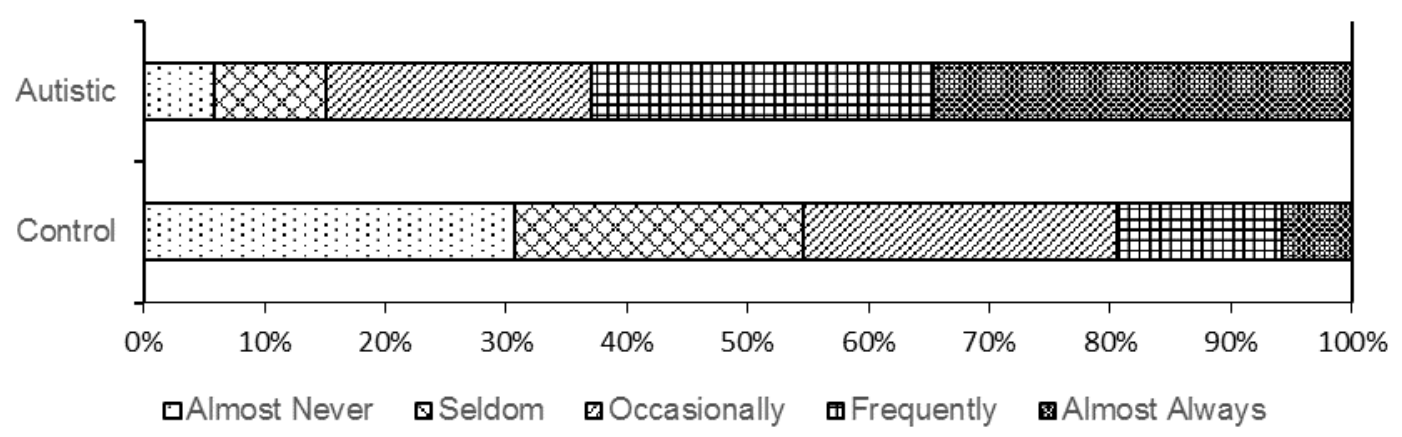

Figure 4. Proportion of Individual Item Answers in Sensory Processing Section 


\subsection{Comfort at Home and Workplace}

The distributions of the overall home comfort scores were negatively skewed towards higher scores for both the Autistic and Control groups (Figure 5). However, the Autistic group had a larger spread than the Control group. This was represented by $22 \%[13,31]$ of the Autistic group having a score of 4 or below, compared with $8 \%[4,13]$ for the Control group. The distribution of the Control group's overall workplace comfort scores was reasonably symmetrical, while the Autistic group had greater variance (Figure 6).

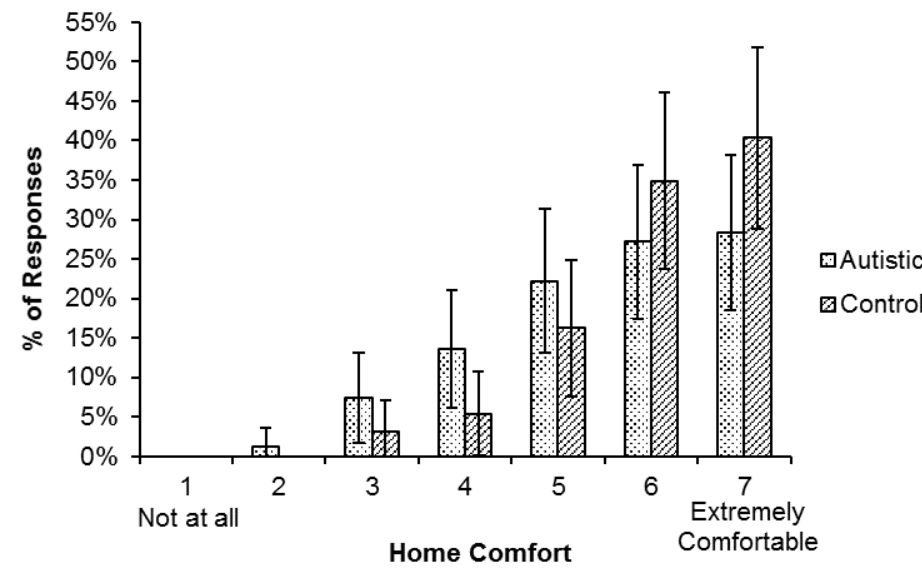

Figure 5. Distribution of Home Comfort Scores

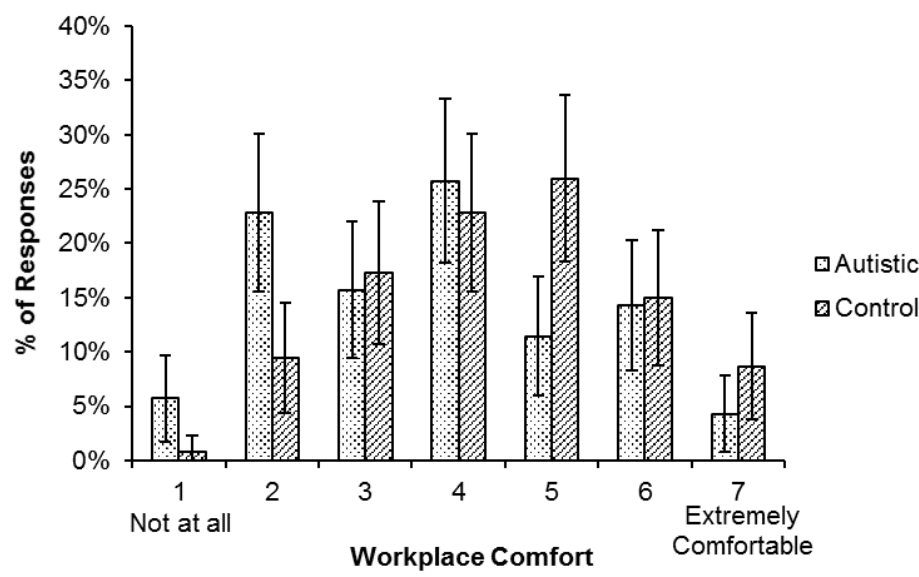

Figure 6. Distribution of Workplace Comfort Scores

The Autistic group had a median overall home comfort rating of $6[5,6]$, the Control group had a median home comfort of $6[6,6]$. While the median difference was $0[-1,0]$, the Autistic group reported a higher proportion of lower home comfort scores than the Control group, with larger first and second quartiles (Figure 7). This was supported by a Mann-Whitney $U$ test that showed a statistically significant difference between the Autistic and Control groups $\left(n_{A}=81, n_{C}=129, U=4049.5, p=.004\right)$, where the Autistic group had a lower mean rank (91) than the Control group (115). This equated to an effect size of $\delta=.22[.07, .37]$ indicating a small-to-medium effect. On average, the 
Control group reported a higher level of overall home comfort than the Autistic group in $61 \%$ of cases (where $50 \%$ indicates no difference).

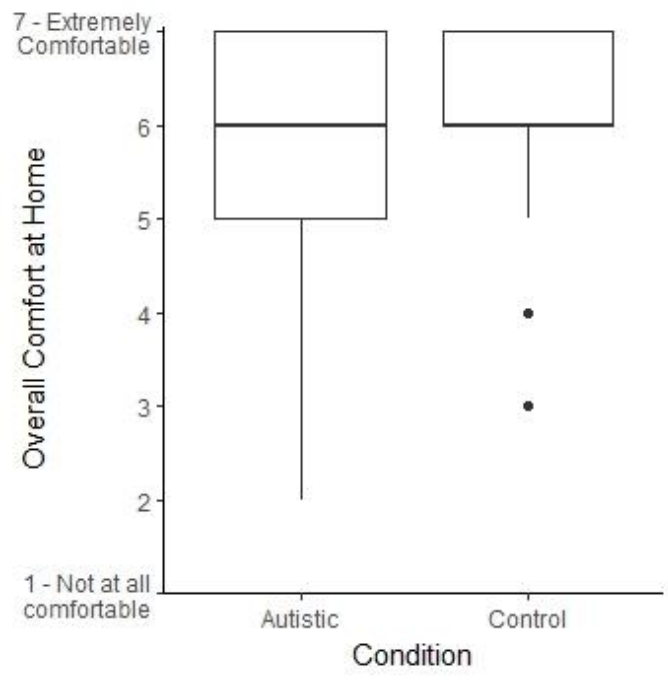

Figure 7. Home Comfort by Condition

The Autistic group had a median overall workplace comfort rating of $4[3,4]$, the Control group had a median home comfort of $4[4,5]$ (Figure 8 ). This equated to a median difference of -1 $[-1,0]$, with the much larger second quartile of the Autistic group indicating a higher number of lower workplace scores. This was supported by a MannWhitney $U$ test that showed a statistically significant difference between the Autistic and Control groups ( $n_{A}=81, n_{c}=129, U=3342.5, p=.003$ ), where the Autistic group had a lower mean rank (83) than the Control group (108). This equated to an effect size of $\delta=$ $.25[.08, .40]$, indicating a small-to-medium effect. On average, the Control group reported a higher level of general workplace comfort than the Autistic group in $62 \%$ of cases.

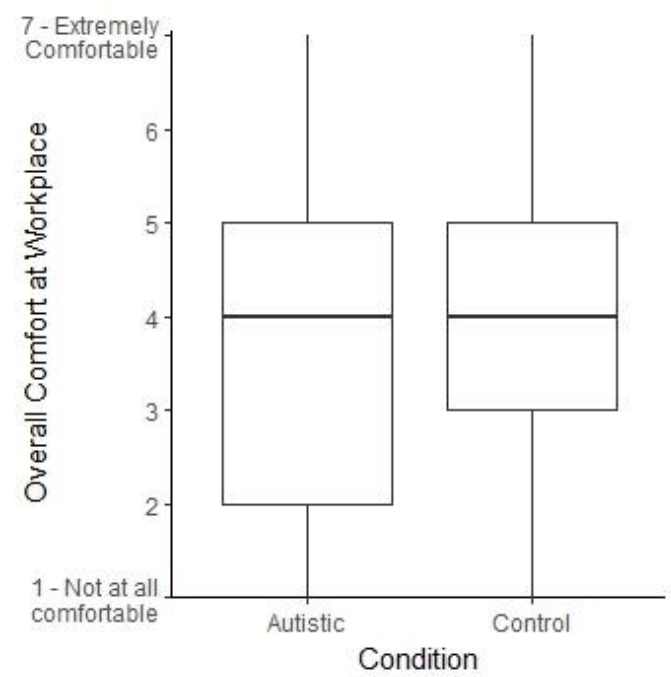

Figure 8. Workplace Comfort by Condition 
Both groups reported a higher level of overall comfort at home than at workplace, with a median decrease of $2[1,2]$ for both groups. With the scale anchors being ' 1 ' to ' 7 ', a drop of 2 between home and workplace was nearly a third of the scale, showing that regardless of condition people were markedly more comfortable at home.

Overall IEQ discomfort at home and the workplace was also calculated by summing the individual discomfort from the 13 IEQ factors, for a maximum total of 78. Overall IEQ discomfort was strongly correlated with overall comfort at the workplace ( $n=268, r_{s}=-.74$ $[-.80,-.68], p=<.001)$, but only moderately correlated at home $\left(n=254, r_{s}=-.21[-.33,-\right.$ $.10], p=<.001)$.

At home, the Autistic group had a median overall IEQ discomfort rating of 25 [23, 32], the Control group had a median home comfort of 13 [11, 15]. This equated to a median difference of $12[9,15]$, to an average score that is higher by 1 across each IEQ factor. This was supported by a Mann-Whitney $U$ test that showed a statistically significant difference between the Autistic and Control groups $\left(n_{A}=83, n_{C}=134, U=8650.0, p\right.$ $<.001)$, which equated to an effect size of $\delta=-.56[-.67,-.31]$ indicating a large effect. On average, the Autistic group reported a higher level of overall home IEQ discomfort than the Control group in $78 \%$ of cases.

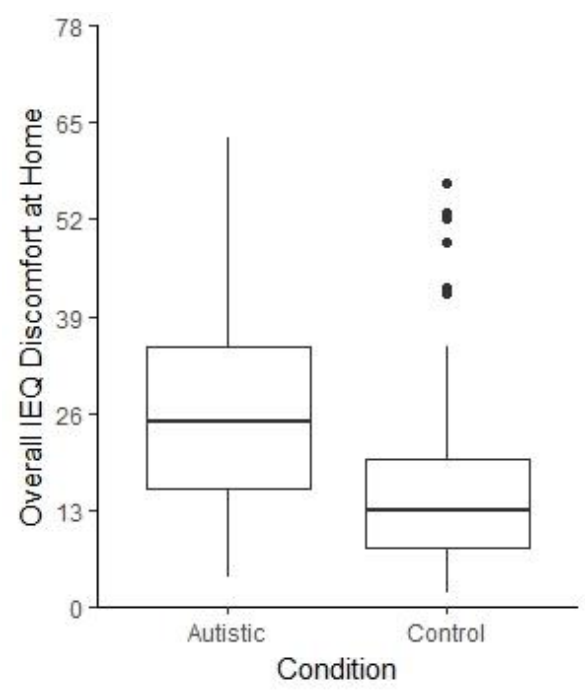

Figure 9. Home Overall IEQ Discomfort by Condition

At the workplace, the Autistic group had a median overall IEQ discomfort rating of 37 [28, $42]$, the Control group had a median home comfort of $23[18,28]$. This equated to a median difference of $12[9,15]$, to an average score that is higher by 1 across each IEQ factor. This was supported by a Mann-Whitney $U$ test that showed a statistically significant difference between the Autistic and Control groups $\left(n_{A}=68, n_{C}=127, U=5727.5, p\right.$ $<.001$ ), which equated to an effect size of $\delta=-.33[-.47,-.16]$ indicating a medium effect. 
On average, the Autistic group reported a higher level of overall workplace IEQ discomfort than the Control group in $66 \%$ of cases.

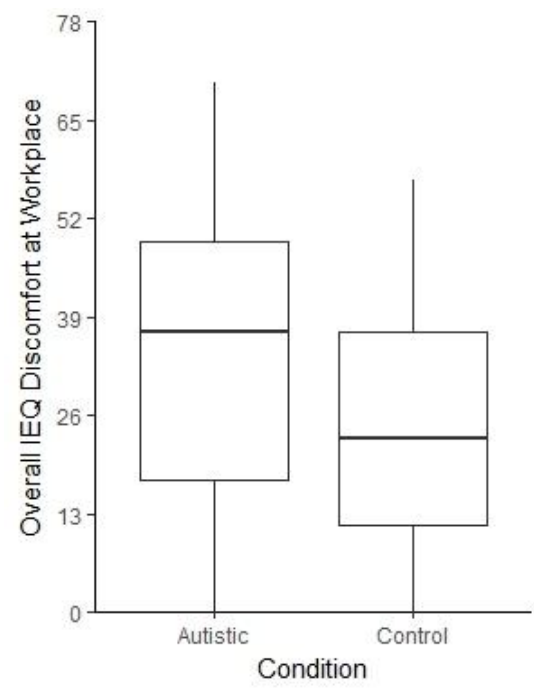

Figure 10. Workplace Overall IEQ Discomfort by Condition 


\subsubsection{Sensory Processing Score}

Sensory processing scores were weakly correlated with overall home comfort scores ( $\mathrm{n}=$ $268, r_{s}=-.21[-.33,-.10], p=<.001$ ) (Figure 11) and moderately correlated with overall workplace comfort scores $\left(n=254, r_{s}=-.39[-.50,-.28], p=<.001\right.$ ) (Figure 12). Both correlations were negative, which indicated that as sensory processing score decreased, comfort score increased. The correlation with workplace comfort was nearly twice as strong as with home comfort, but it was likely that the home comfort coefficient was affected by the reduced range of answers and the large proportion of answers at "A lot of control".

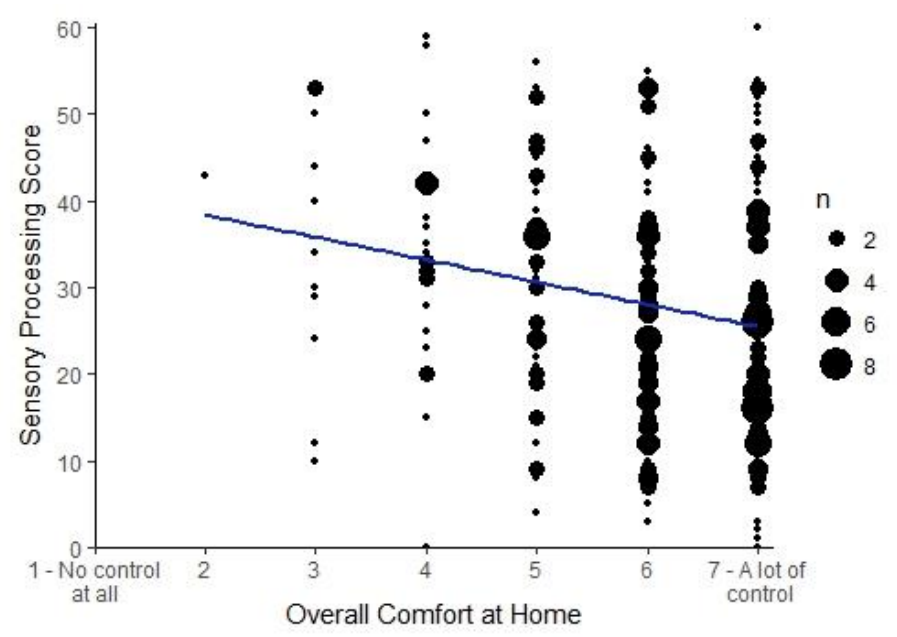

Figure 11. Home Comfort vs Sensory Processing Score

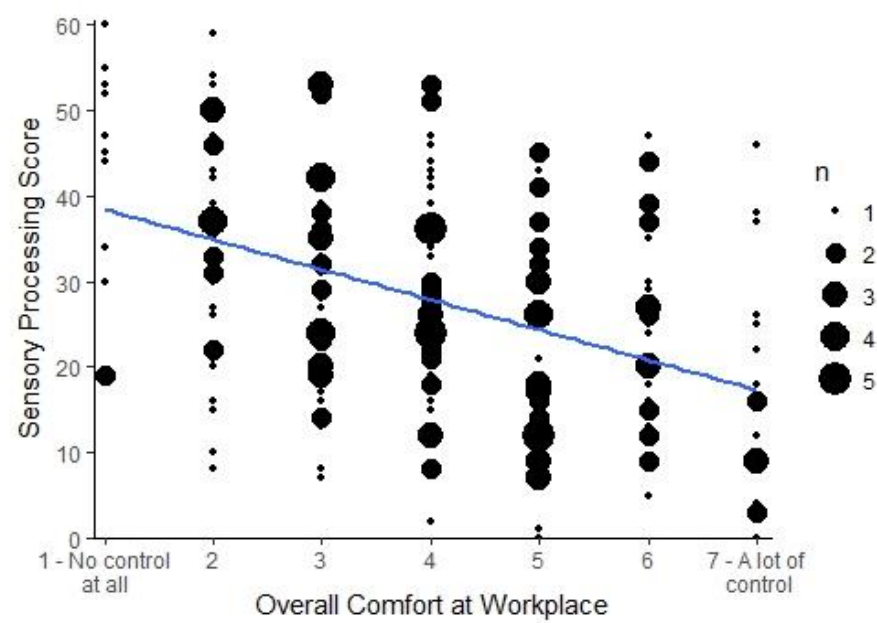

Figure 12. Workplace Comfort vs Sensory Processing Score 


\subsubsection{Perceived Control and Changes}

Overall comfort and perceived level of control over the indoor environment were strongly correlated at home $\left(n=276, r_{s}=.50, p=<.001\right.$ ) (Figure 13), and were moderately correlated at workplace $\left(n=254, r_{s}=.35, p=<.001\right)$ (Figure 14). Both correlations were positive, which indicated that as the perceived level of control over the environment increased, so did overall comfort.

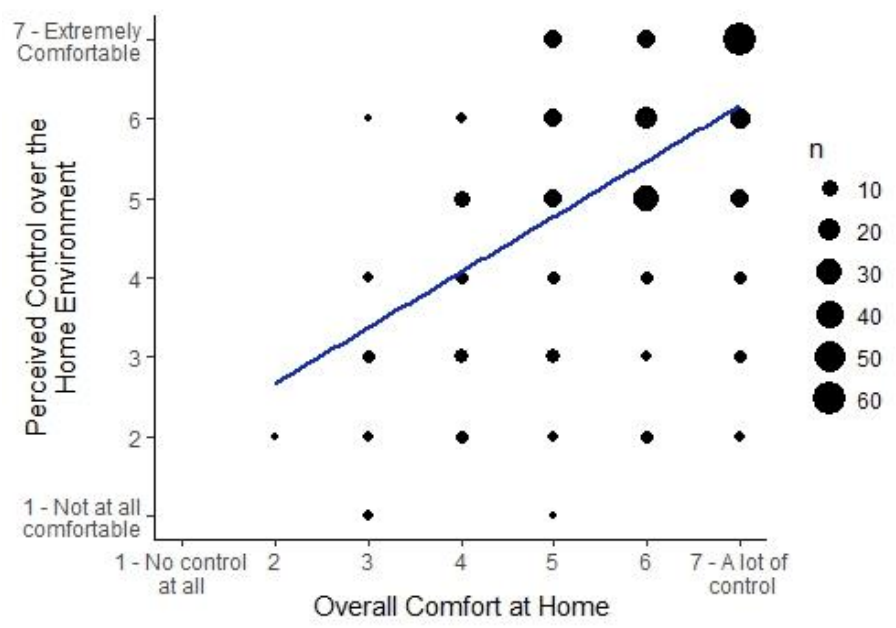

Figure 13. Home Comfort vs Home Perceived Control

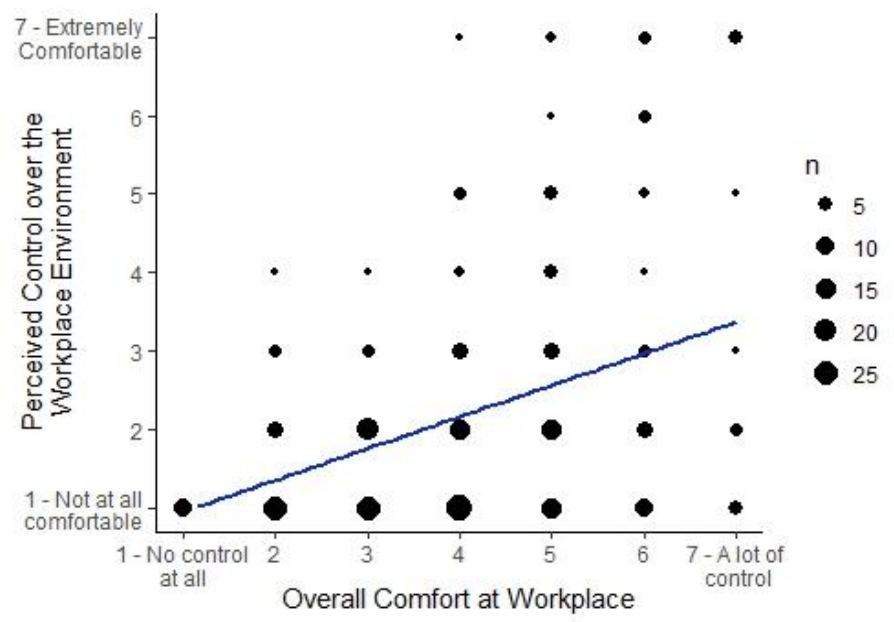

Figure 14. Workplace Comfort vs Workplace Perceived Control

The odds of participants who owned their homes of making permanent changes to their home environment were $2.9[1.7,4.8]$ times greater than participants who rented their homes ( $\left.n_{0}=44, p<.001\right)$, but there was no significant difference in the odds of participants who rented and owned their homes in wanting to make changes to their home environment in an ideal world ( $p=.443)$.

At home, the Autistic group had a median perceived control rating of $5[4,6]$, while the Control group had a median home comfort of $6[6,6]$, which equated to a median 
difference of $-1[-1,-1]$. This was supported by a Mann-Whitney $U$ test that showed a statistically significant difference between the Autistic and Control groups ( $n_{A}=83, n_{C}=$ $134, U=3582.0, p<.001$ ), which equated to an effect size of $\delta=.36[.20, .49]$ indicating a medium effect (Figure 15). On average, the Autistic group reported a higher level of overall workplace IEQ discomfort than the Control group in $78 \%$ of cases.

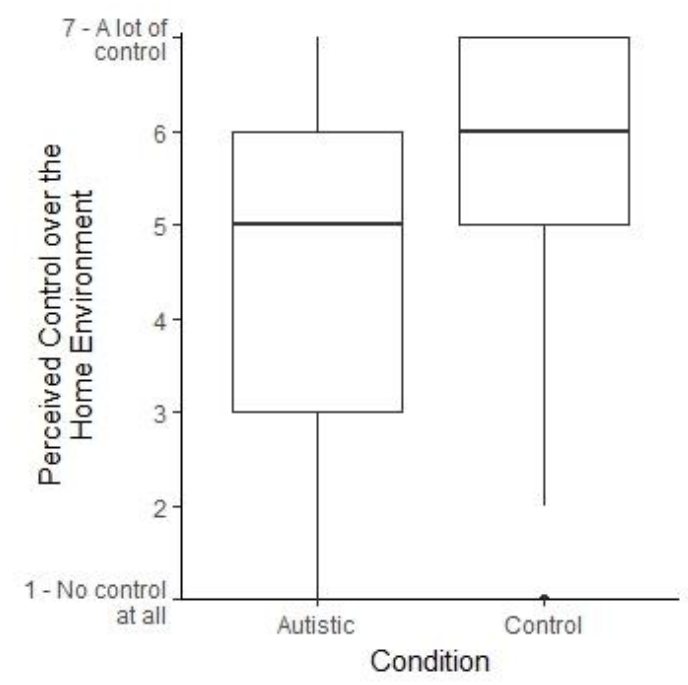

Figure 15. Home Perceived Control by Condition

There was no significant difference between the Autistic and Control groups in perceived control over the workplace environment $\left(n_{A}=69, n_{C}=128, U=3963.0, p=.210\right)$. Both groups identified having very little control over their workplace environments (Figure 16). There was no significant difference in the odds of Autistic and Control participants having requesting permanent changes to their workplace $(p=.967)$, or wanting changes made to their workplace in an ideal world $(p=.797)$.

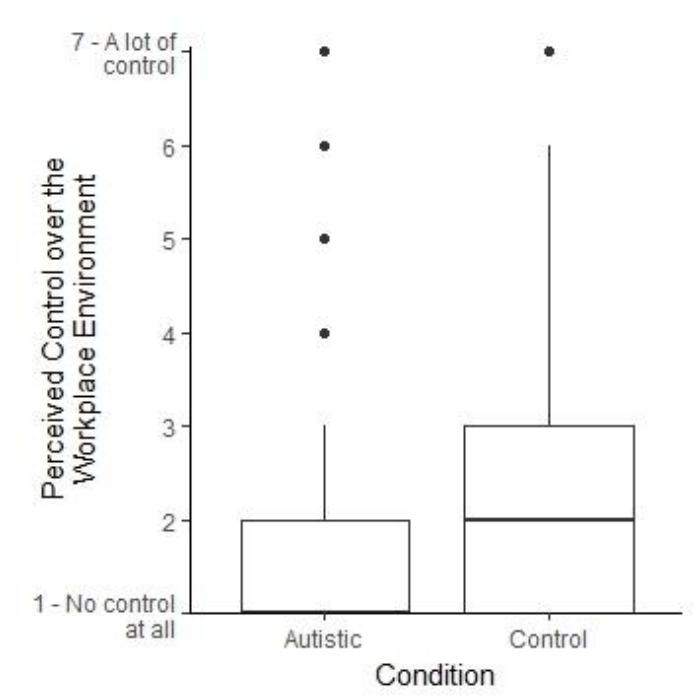

Figure 16. Workplace Perceived Control by Condition 
While Autistic participants did not have greater odds of having made permanent changes to their home environment compared to Control participants when considering both owned and rented homes, the odds that an Autistic participant who rented had made permanent changes to their home environment were 2.1 times greater than a Control group participant who rented (Table 4). However, Autistic participants had greater odds of wanting to make permanent changes to their home environment compared to Control participants when considering both owned and rented homes, but the odds were the same among only Autistic and Control participants who rented.

Table 4. Odds Ratios of Autistic participants making, or wanting to make, permanent changes to their home environment, depending on tenure

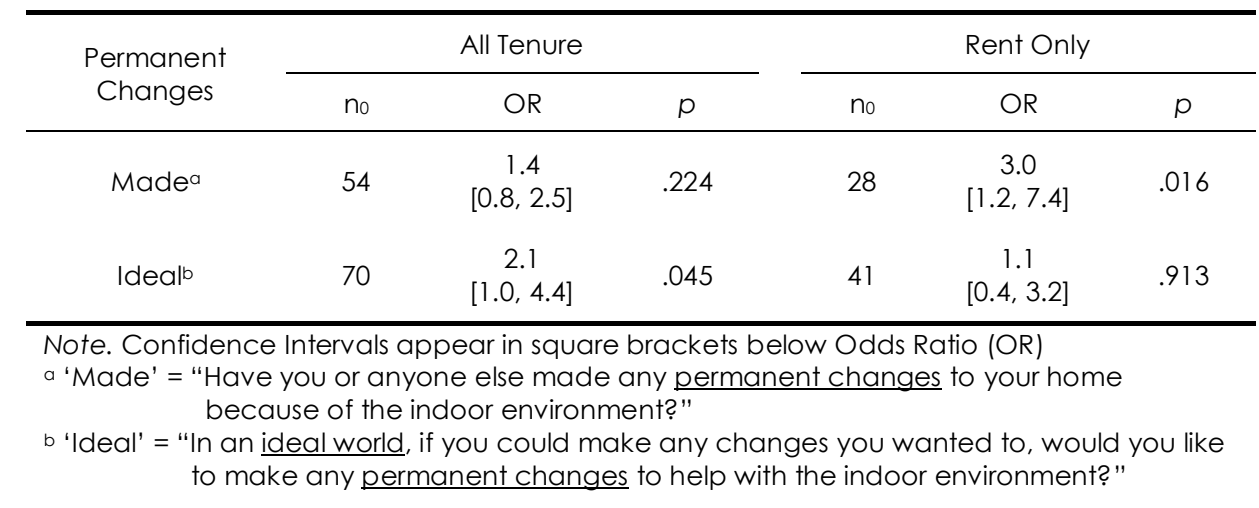




\subsubsection{Psychological Factors}

On average, most participants rated that the home environment was not overwhelming to their senses, was not distracting, did not cause them to feel stressed/anxious, and felt safe (Table 5). However, the Autistic group rate the home environment as significantly more overwhelming, more stressful, more distracting, and less safe relative to the Control group, with effects ranging between medium and large. In Figures Figure 17, Figure 18 , and Figure 19, the lack of first and second quartiles indicates that at least half of all participants in the Control group strongly disagreed that they felt their home environment was overwhelming, stressful, or not safe. Only outliers agreed with these statements in the Control group. On average, the Autistic group reported their home environment caused them to feel more stressed/anxious than the Control group in in $79 \%$ of cases, more distracted in $67 \%$ of cases, was more overwhelming to their senses $73 \%$ of cases, and less safe in $66 \%$ of cases.

On average, the Control group also felt that their workplace environment was not overwhelming to their senses and felt safe, though less so than their home environment (Table 5). The Autistic group also primarily agreed that their workplace environment felt safe, though they rated the environment significantly less safe than the Control group, with a small-to-medium effect size. Participants in the Autistic group equally agreed and disagreed that their workplace environment was overwhelming to their senses, meaning they found the environment significantly more so than the Control group, with a mediumto-large effect size. On average, the Autistic group reported their workplace environment caused them to feel more overwhelmed than the Control group in $70 \%$ of cases and less safe in $65 \%$ of cases.

Both the Autistic and Control groups felt their workplace environment caused them to feel more stressed/anxious and more distracted than the home environment. The Autistic group still felt significantly more stressed/anxious in the workplace environment, with the median tending towards agreement, while the Control group median tended towards disagreement, with a small-to-medium effect (Table 5). An equal proportion of both the Autistic and Control group agreed and disagreed that they found their workplace environment distracting, with a neutral median for both groups (Figure 24). However, there was still a significant difference between the two groups, though the effect is only small. The smaller effect and difference is due to a higher proportion of the Control group agreeing with this statement compared to any other statement. On average, the Autistic group reported their workplace environment caused them to feel more stressed/anxious than the Control group in $66 \%$ of cases and more distracted in $61 \%$ of cases. 
Table 5.

Psychological Factors of the Home and Workplace Environments by Condition

\begin{tabular}{|c|c|c|c|c|c|c|c|c|c|}
\hline \multirow[b]{2}{*}{ Statement } & \multicolumn{3}{|c|}{ Autistic } & \multicolumn{3}{|c|}{ Control } & \multirow{2}{*}{$\begin{array}{c}\text { Median } \\
\text { Difference }\end{array}$} & \multirow[b]{2}{*}{ U } & \multirow[b]{2}{*}{$\delta$} \\
\hline & $\mathrm{n}_{\mathrm{A}}$ & median & $\begin{array}{l}\text { mean } \\
\text { rank }\end{array}$ & $\mathrm{nc}$ & median & $\begin{array}{l}\text { mean } \\
\text { rank }\end{array}$ & & & \\
\hline $\begin{array}{c}\text { Home } \\
\text { Overwhelma }\end{array}$ & 83 & {$[-2,-1]$} & 140 & 134 & {$[-3,-3]$} & 90 & $\begin{array}{c}1 \\
{[1,1]}\end{array}$ & $8116.0^{* * *}$ & $\begin{array}{c}-.47 \\
{[-.59,-.33]}\end{array}$ \\
\hline Home Safeb & 83 & {$[-2,-2]$} & 123 & 134 & {$\left[\begin{array}{c}-3 \\
{[-3,-3]}\end{array}\right.$} & 87 & $\begin{array}{c}0 \\
{[0,1]}\end{array}$ & $7392.5^{* * *}$ & $\begin{array}{c}-.33 \\
{[-.18,-.46]}\end{array}$ \\
\hline Home Stressc & 83 & {$[0,-2]$} & 148 & 134 & {$[-2,-3]$} & 85 & $\begin{array}{c}1 \\
{[1,2]}\end{array}$ & $8767.5^{* * *}$ & $\begin{array}{c}-.58 \\
{[-.68,-.49]}\end{array}$ \\
\hline $\begin{array}{c}\text { Home } \\
\text { Distractiond }\end{array}$ & 83 & $\begin{array}{c}-1 \\
{[-2,0]}\end{array}$ & 132 & 134 & {$[-2,-2]$} & 95 & $\begin{array}{c}1 \\
{[0,1]}\end{array}$ & $7450.5^{* * *}$ & $\begin{array}{c}-.34 \\
{[-.47,-.19]}\end{array}$ \\
\hline $\begin{array}{l}\text { Workplace } \\
\text { Overwhelma }\end{array}$ & 68 & $\begin{array}{c}0 \\
{[-1,1]}\end{array}$ & 124 & 128 & {$[-2,-2]$} & 85 & $\begin{array}{c}1 \\
{[1,2]}\end{array}$ & $6117.5^{* * *}$ & $\begin{array}{c}-.41 \\
{[-.59,-.24]}\end{array}$ \\
\hline $\begin{array}{l}\text { Workplace } \\
\text { Safe }^{b}\end{array}$ & 69 & $\begin{array}{c}-1 \\
{[0,2]}\end{array}$ & 110 & 129 & {$[-2,-2]$} & 81 & $\begin{array}{c}1 \\
{[0,1]}\end{array}$ & $3150.5^{* * *}$ & $\begin{array}{c}-.29 \\
{[-.12,-.44]}\end{array}$ \\
\hline $\begin{array}{l}\text { Workplace } \\
\text { Stressc }\end{array}$ & 69 & $\begin{array}{c}1 \\
{[0,1]}\end{array}$ & 120 & 129 & {$[0,-1]$} & 89 & $\begin{array}{c}1 \\
{[0,2]}\end{array}$ & $5858.0^{* * *}$ & $\begin{array}{c}-.32 \\
{[-.49,-.15]}\end{array}$ \\
\hline $\begin{array}{l}\text { Workplace } \\
\text { Distractiond }\end{array}$ & 69 & $\begin{array}{c}0 \\
{[0,1]}\end{array}$ & 113 & 129 & $\begin{array}{c}0 \\
{[-1,0]}\end{array}$ & 92 & $\begin{array}{c}1 \\
{[0,1]}\end{array}$ & $5858.0^{*}$ & $\begin{array}{c}-.22 \\
{[-.37,-.05]}\end{array}$ \\
\hline $\begin{array}{l}\text { Note. }{ }^{*}=p< \\
\text { difference, an } \\
\text { a 'Ovenwhelm' } \\
\text { b 'Safe' = "I do } \\
\text { c 'Stress' = "I fe } \\
\text { d 'Distraction' }\end{array}$ & $\begin{array}{l}\text { *** } \\
\text { Cliff's } \\
\text { "I finc } \\
\text { feel } \\
\text { stress }\end{array}$ & $\begin{array}{l}=p<.001 . \\
\text { delta }(\delta) . \\
\text { my [home } \\
\text { safe at my } \\
\text { ed/anxious } \\
\text { the indoor }\end{array}$ & $\begin{array}{l}\text { Confide } \\
\text { /workpl } \\
\text { [home/v } \\
\text { at my [r }\end{array}$ & Inter & $\begin{array}{l}\text { als appeo } \\
\text { helming to }\end{array}$ & $\begin{array}{l}r \text { in squa } \\
\text { my sens }\end{array}$ & brackets belc & w the medi & רs, median \\
\hline
\end{tabular}

The Autistic group's responses spread the scale from "Strongly Agree" to "Strongly Disagree" for most statements (Figure 17, Figure 18 \& Figure 20 - Figure 24), but this only occurs in the Control in Figure 21, Figure 22 \& Figure 24. Overall, there are significant differences between the Autistic and Control groups in all the psychological factors, both at home and the workplace. The effect for all four factors was greater at home than at the workplace. This could be affected by the lower proportion of the Autistic group (83\%) that completed the workplace section of the survey. 


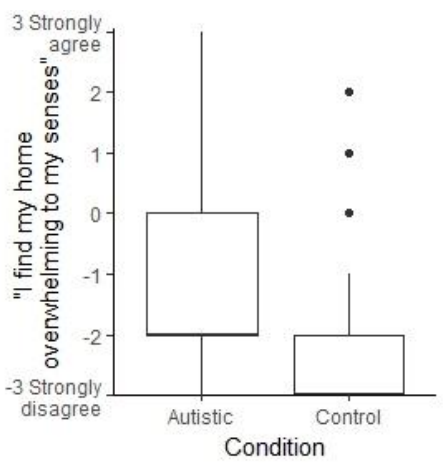

Figure 17. "I find my home overwhelming to my senses" by Condition

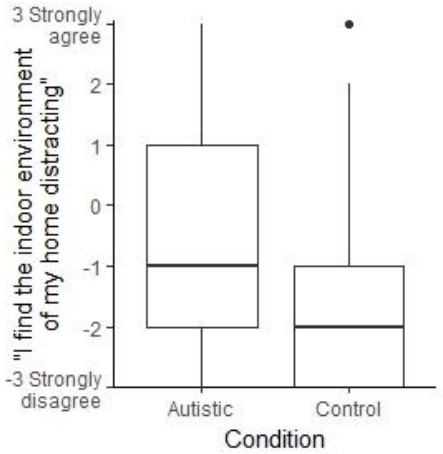

Figure 20. "I find the indoor environment of my home distracting" by Condition

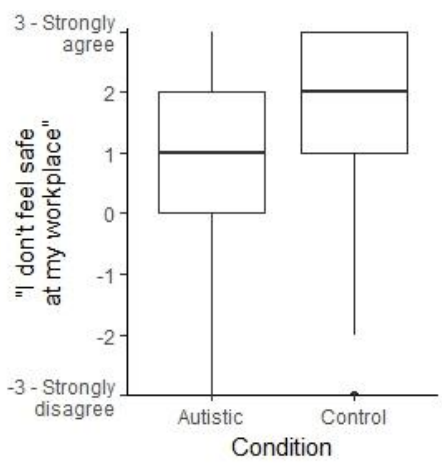

Figure 23. "I don't feel safe at my workplace" by Condition

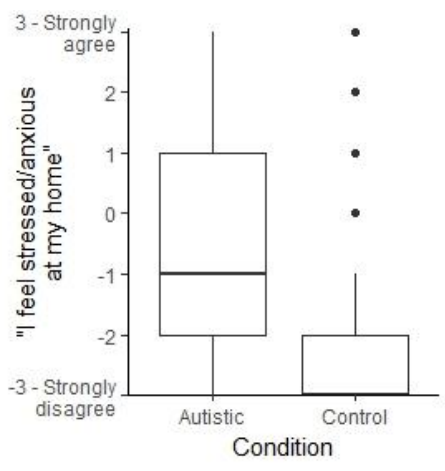

Figure 18. "I feel stressed/anxious at my home" by Condition

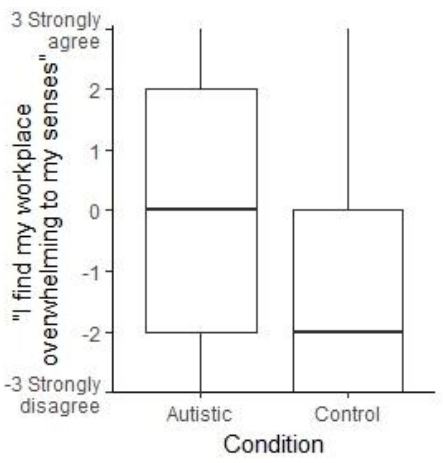

Figure 21. "I find my workplace overwhelming to my senses" by Condition

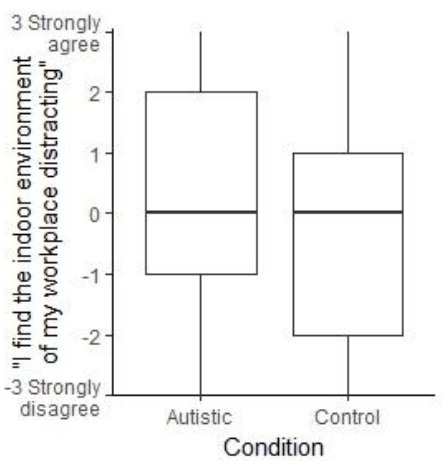

Figure 24. "I find the indoor environment of my workplace distracting" by Condition

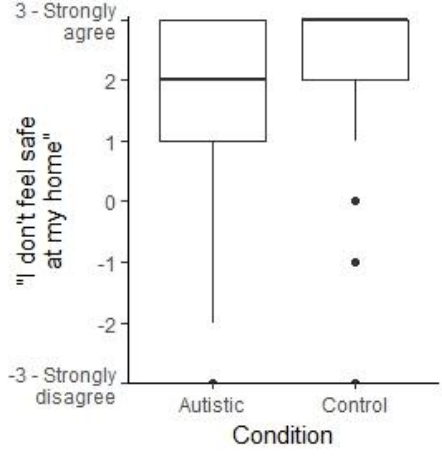

Figure 19. "I don't feel safe at my home" by Condition

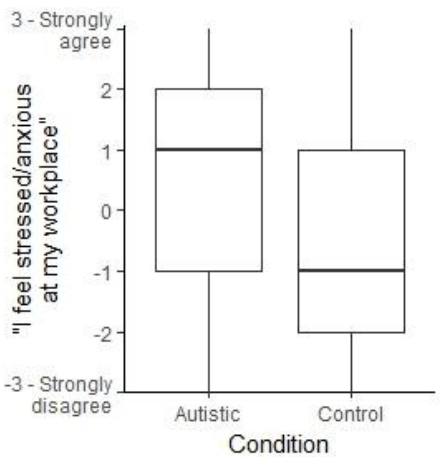

Figure 22. "I feel stressed/anxious at my workplace" by Condition 


\subsubsection{Sensory Processing}

Sensory Processing Score was significantly correlated with all the psychological factors in both environments (Table 6). All correlations are positive, indicating that as sensory processing score increased, so did the negative effects of the indoor environment, with people with higher sensory processing scores feeling more overwhelmed, more stressed/anxious, more distracted, and less safe at both the home and workplace.

Table 6.

Correlation between Psychological Factors of the Home and Workplace Environments and Sensory Processing Score

\begin{tabular}{|c|c|c|c|}
\hline Statement & $\mathrm{n}$ & $r_{s}$ & $p$ \\
\hline $\begin{array}{c}\text { "I find my home overwhelming } \\
\text { to my senses" }\end{array}$ & 276 & $\begin{array}{c}.37 \\
{[.27, .47]}\end{array}$ & $<.001$ \\
\hline "I don't feel safe at my home" & 276 & $\begin{array}{c}.30 \\
{[.19, .41]}\end{array}$ & $<.001$ \\
\hline $\begin{array}{c}\text { "I feel stressed/anxious at my } \\
\text { home" }\end{array}$ & 276 & $\begin{array}{c}.45 \\
{[.33, .55]}\end{array}$ & $<.001$ \\
\hline $\begin{array}{l}\text { "I find the indoor environment } \\
\text { of my home distracting" }\end{array}$ & 276 & $\begin{array}{c}.24 \\
{[.12, .34]}\end{array}$ & $<.001$ \\
\hline $\begin{array}{l}\text { "I find my workplace } \\
\text { overwhelming to my senses" }\end{array}$ & 253 & {$[.39, .61]$} & $<.001$ \\
\hline $\begin{array}{c}\text { "I don't feel safe at my } \\
\text { workplace" }\end{array}$ & 255 & $\begin{array}{c}.44 \\
{[.33, .53]}\end{array}$ & $<.001$ \\
\hline $\begin{array}{l}\text { "I feel stressed/anxious at my } \\
\text { workplace" }\end{array}$ & 255 & $\begin{array}{c}.43 \\
{[.32, .53]}\end{array}$ & $<.001$ \\
\hline $\begin{array}{l}\text { "I find the indoor environment } \\
\text { of my workplace distracting" }\end{array}$ & 255 & $\begin{array}{c}.30 \\
{[.18, .41]}\end{array}$ & $<.001$ \\
\hline
\end{tabular}

Note. Confidence Intervals appear in square brackets below Spearman's rho $\left(r_{s}\right)$.

The correlation between sensory processing score and the effects of the indoor environment were stronger at the workplace than at home for three of the four factors, with only feeling stressed/anxious being equally correlated at both home and workplace (Table 6). This is likely affected by the fewer agreement responses at home, as seen in (Figure 25 - Figure 32). 


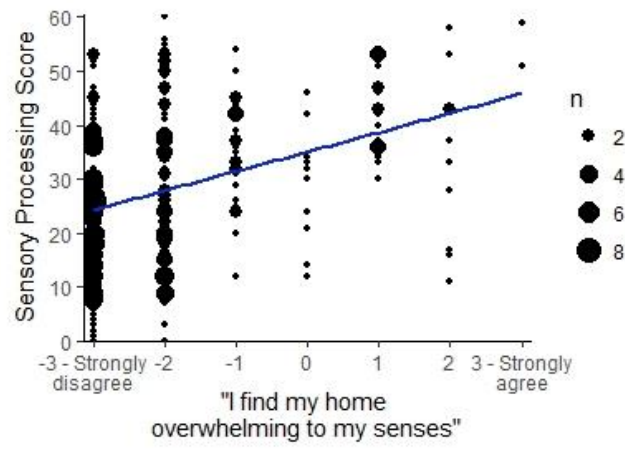

Figure 25. "I find my home overwhelming to my senses" vs Sensory Processing Score

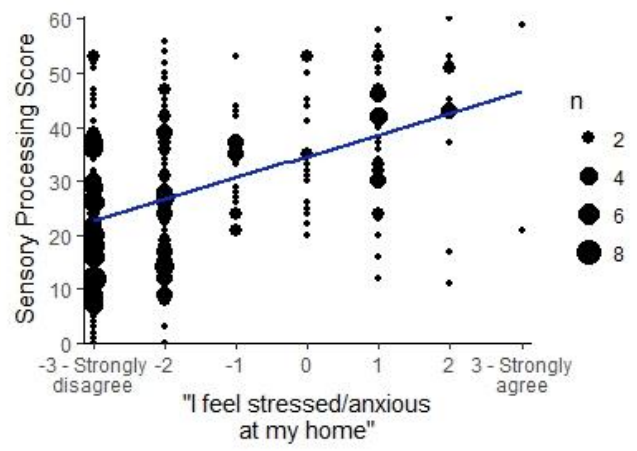

Figure 27. "I feel stressed/anxious at my home" vs Sensory Processing Score

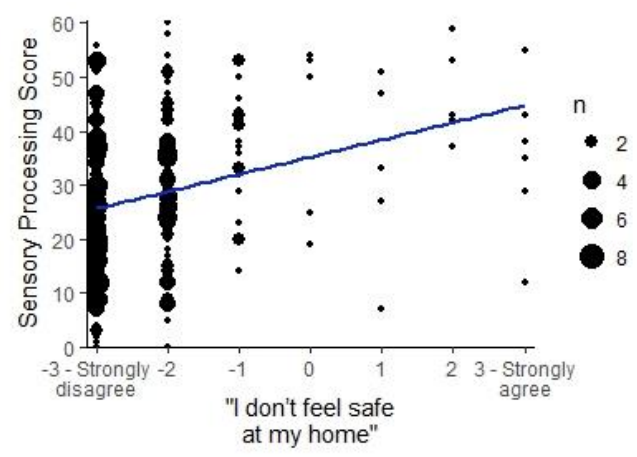

Figure 29. "I don't feel safe at my home" vs Sensory Processing Score

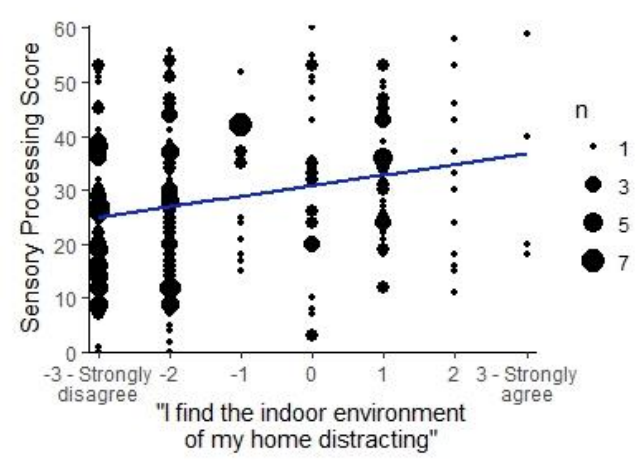

Figure 31. "I find the indoor environment of my home distracting" vs Sensory Processing Score

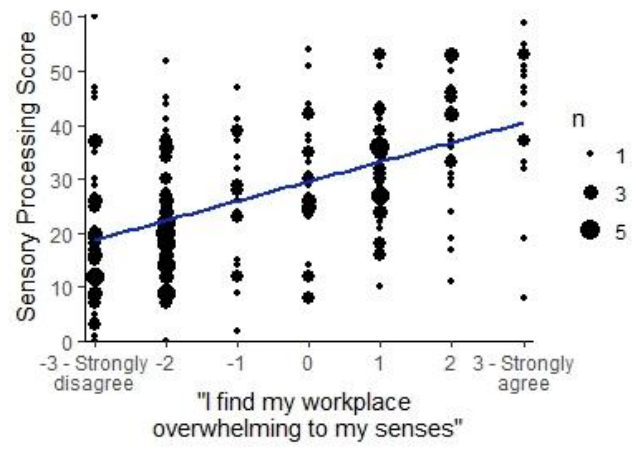

Figure 26. "I find my workplace overwhelming to my senses" vs Sensory Processing Score

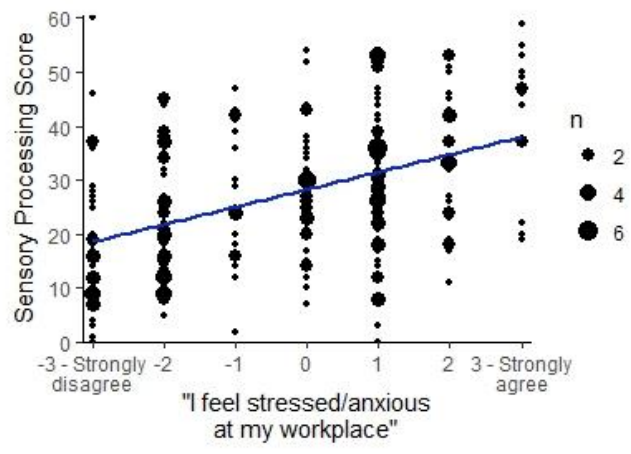

Figure 28. "I feel stressed/anxious at my workplace" vs Sensory Processing Score

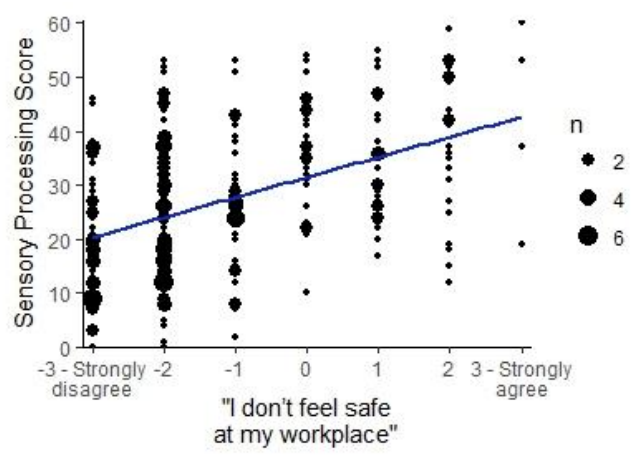

Figure 30. "I don't feel safe at my workplace" vs Sensory Processing Score

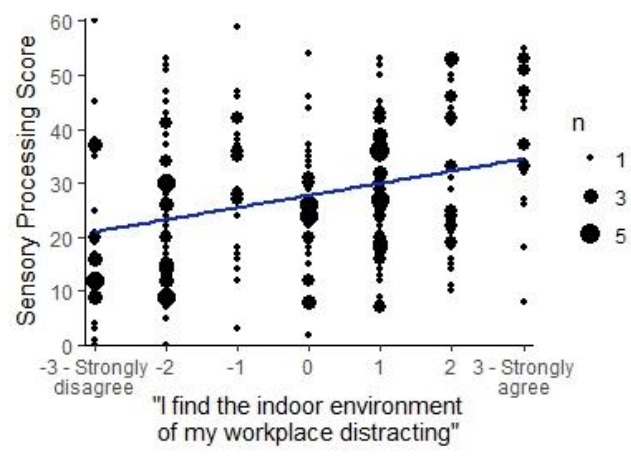

Figure 32. "I find the indoor environment of my workplace distracting" vs Sensory Processing Score 


\subsection{Other Buildings}

Participants in the Control group used Office $(p=.002)$, Mall $(p=.017)$, Supermarket ( $p$ $=.002)$, Other Retail $(p=.005)$ and Restaurant/Bar/Café $(p<.001)$ buildings significantly more frequently than the Autistic group. Participants in the Autistic group used Tertiary ( $p$ $=.042$ ) and Medical $(p=.030)$ buildings significantly more frequently than the Control group. There was no statistically significant difference between the Autistic and Control groups in how frequently participants used School, Arts, Religious, Community, Industrial or Agricultural buildings.

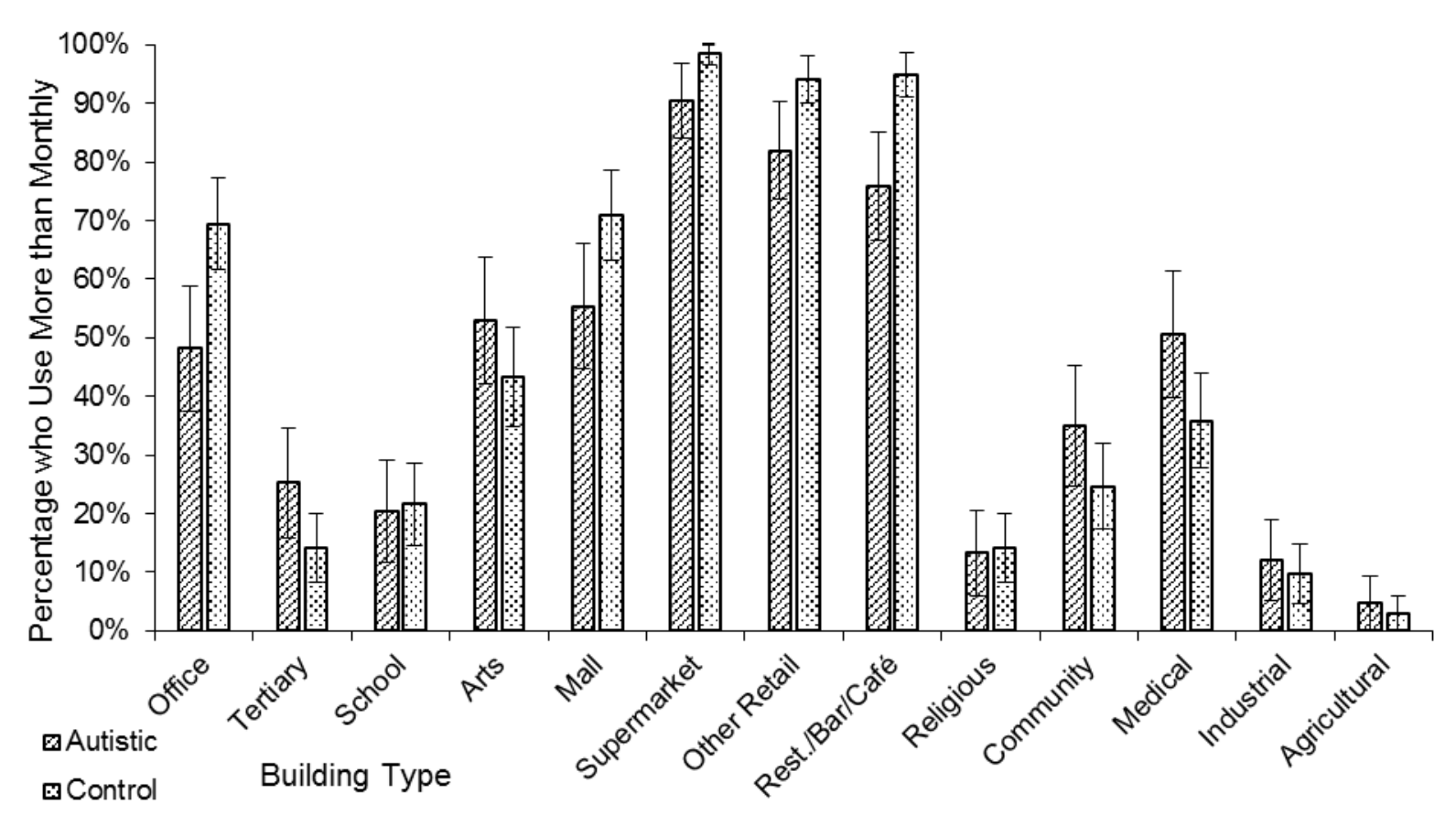

Figure 33. Percentage of Participants who Use Building Types Once a Month or More Frequently 


\subsubsection{Discomfort}

Eight of the nine building types caused qualifying participants (respondents) in the Autistic group significantly more discomfort than the Control group (Table 7). There was no statistically significant difference in how often Tertiary Education Centre buildings caused discomfort between the Autistic and Control group respondents ( $p=.057$ ). However, there was a medium effect size between the two groups and a median difference of 1 , so the lack of statistically significant relationship may be due to the small sample size (Figure 34).

Table 7.

Frequency of Discomfort caused by 9 Building Types by Condition

\begin{tabular}{|c|c|c|c|c|c|c|c|c|c|}
\hline \multirow{2}{*}{ Building Type } & \multicolumn{3}{|c|}{ Autistic } & \multicolumn{3}{|c|}{ Control } & \multirow{2}{*}{$\begin{array}{l}\text { median } \\
\text { difference }\end{array}$} & \multirow{2}{*}{ U } & \multirow{2}{*}{$\delta$} \\
\hline & $\mathrm{n}_{\mathrm{A}}$ & median & $\begin{array}{l}\text { mean } \\
\text { rank }\end{array}$ & $\mathrm{n}_{\mathrm{c}}$ & median & $\begin{array}{c}\text { mean } \\
\text { rank }\end{array}$ & & & \\
\hline Shopping mall & 45 & $\begin{array}{c}6 \\
{[5,7]}\end{array}$ & 97 & 94 & $\begin{array}{c}3 \\
{[3,4]}\end{array}$ & 57 & $\begin{array}{c}2 \\
{[2,3]}\end{array}$ & $904.5^{* * *}$ & $\begin{array}{c}-.57 \\
{[-.72,-.38]}\end{array}$ \\
\hline Supermarket & 75 & $\begin{array}{c}6 \\
{[5,6]}\end{array}$ & 138 & 131 & $\begin{array}{c}3 \\
{[3,4]}\end{array}$ & 84 & $\begin{array}{c}2 \\
{[1,3]}\end{array}$ & $2317.0^{* * *}$ & $\begin{array}{c}-.53 \\
{[-.65,-.37]}\end{array}$ \\
\hline Medical & 41 & $\begin{array}{c}5 \\
{[3,6]}\end{array}$ & 58 & 49 & $\begin{array}{c}2 \\
{[2,3]}\end{array}$ & 35 & $\begin{array}{c}2 \\
{[1,3]}\end{array}$ & $495.0 * * *$ & $\begin{array}{c}-.51 \\
{[-.68,-.28]}\end{array}$ \\
\hline Other Retail & 68 & $\begin{array}{c}4 \\
{[4,5]}\end{array}$ & 126 & 125 & $\begin{array}{c}3 \\
{[2,3]}\end{array}$ & 81 & $\begin{array}{c}1 \\
{[1,2]}\end{array}$ & $2293.0^{* * *}$ & $\begin{array}{c}-.46 \\
{[-.60,-.30]}\end{array}$ \\
\hline $\begin{array}{c}\text { Restaurant/Bar } \\
\text { /Cafe }\end{array}$ & 61 & $\begin{array}{c}4 \\
{[4,5]}\end{array}$ & 118 & 124 & $\begin{array}{c}3 \\
{[3,3]}\end{array}$ & 80 & $\begin{array}{c}1 \\
{[1,2]}\end{array}$ & $2228.0^{* * *}$ & $\begin{array}{c}-.41 \\
{[-.56,-.24]}\end{array}$ \\
\hline Office & 40 & $\begin{array}{c}5 \\
{[4,6]}\end{array}$ & 84 & 90 & $\begin{array}{c}3 \\
{[2,4]}\end{array}$ & 57 & $\begin{array}{c}1 \\
{[1,2]}\end{array}$ & $1068.5^{* * *}$ & $\begin{array}{c}-.40 \\
{[-.59,-.19]}\end{array}$ \\
\hline Arts & 44 & $\begin{array}{c}3 \\
{[2,4]}\end{array}$ & 63 & 58 & $\begin{array}{c}2 \\
{[2,2]}\end{array}$ & 43 & $\begin{array}{c}1 \\
{[0,2]}\end{array}$ & $773.0 * * *$ & $\begin{array}{c}-.39 \\
{[-.58,-.17]}\end{array}$ \\
\hline Community & 30 & $\begin{array}{c}4 \\
{[3,5]}\end{array}$ & 37 & 32 & $\begin{array}{c}2.5 \\
{[2,3]}\end{array}$ & 26 & $\begin{array}{c}1 \\
{[0,2]}\end{array}$ & $311.5^{*}$ & $\begin{array}{c}-.35 \\
{[-.58,-.06]}\end{array}$ \\
\hline $\begin{array}{c}\text { Tertiary } \\
\text { Education }\end{array}$ & 22 & $\begin{array}{c}4 \\
{[2,6]}\end{array}$ & 26 & 22 & $\begin{array}{c}2 \\
{[2,4]}\end{array}$ & 19 & $\begin{array}{c}1 \\
{[0,2]}\end{array}$ & 161.5 & $\begin{array}{c}-.33 \\
{[-.61, .01]}\end{array}$ \\
\hline
\end{tabular}

Shopping Malls, Supermarkets, and Medical buildings all had the largest differences between the Autistic and Control groups (Table 7). The distributions of responses for Shopping Malls and Supermarkets are similar, with the lack of fourth quartile for the Autistic group indicating at least a quarter of the respondents reported Shopping Malls and Supermarkets "Always" causing discomfort (Figure 35 \& Figure 36). Both building types had the highest medians for both groups, so as well as having a large difference they also affect both groups more than other building types. For medical buildings, responses from the Control group were primarily low, with half of responses at ' 2 ' or below, while responses from the Autistic group were higher (Figure 37). On average, the Autistic group reported experiencing discomfort more frequently in Shopping Malls than 
the Control group in $79 \%$ of cases, in Supermarkets in $76 \%$ of cases, and in Medical buildings in $75 \%$ of cases (where $50 \%$ indicates no difference).

Other Retail, Restaurant/Bar/Café, and Office buildings also all had medium-ło-large effects between the Autistic and Control groups (Table 7). The distribution of responses for these building types are similar, with responses from the Control group primarily falling in the lower half of the scale and no responses at "Always", while at least half of responses from the Autistic group falling in the upper half of the scale in all building types (Figure 38, Figure 39 \& Figure 40). On average, the Autistic group reported experiencing discomfort more frequently in Other Retail buildings than the Control group in $73 \%$ of cases, in Restaurant/Bar/Café buildings in $71 \%$ of cases, and in Office buildings in $70 \%$ of cases.

Arts and Community buildings had a medium effect between the Autistic and Control groups (Table 7). There were fewer high responses for these building types from the Autistic group respondents than the other building types, with the lowest medians for both groups in Arts buildings (Figure 41 \& Figure 42). On average, the Autistic group reported experiencing discomfort more frequently in Arts buildings than the Control group in $70 \%$ of cases and in Community buildings in $68 \%$ of cases. 


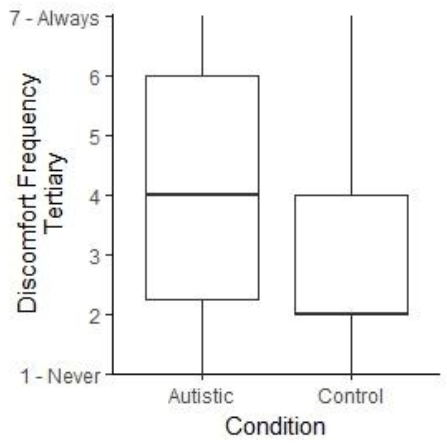

Figure 34. Tertiary Education Building Discomfort by Condition

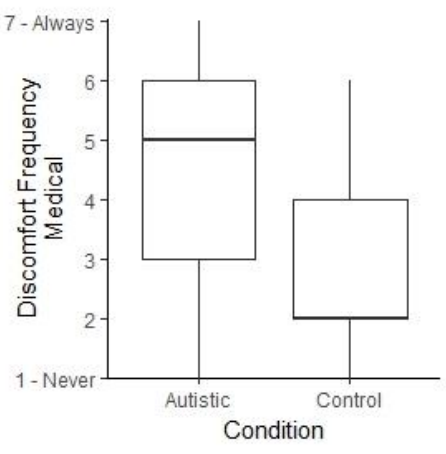

Figure 37. Medical Building Discomfort by Condition

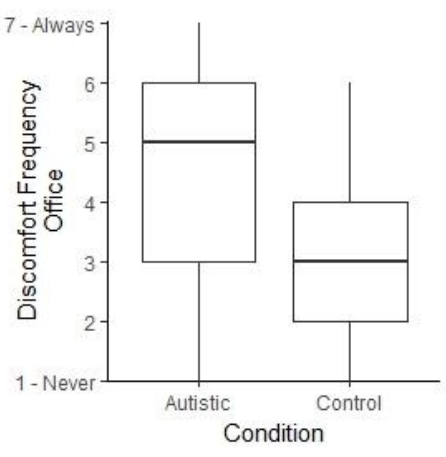

Figure 40. Office Building Discomfort by Condition

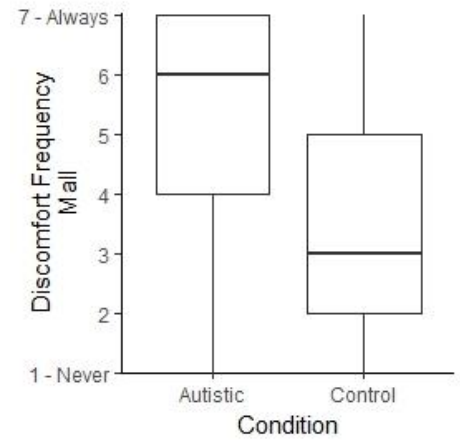

Figure 35. Shopping Mall Discomfort by Condition

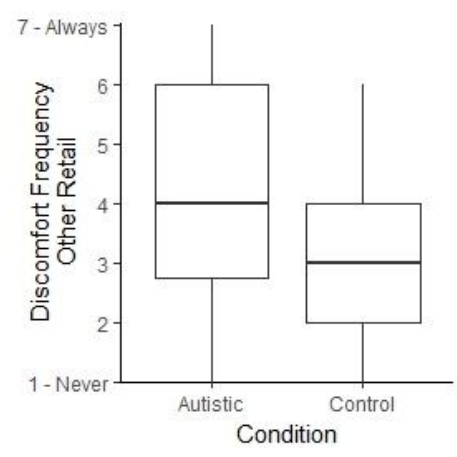

Figure 38. Other Retail Building Discomfort by Condition

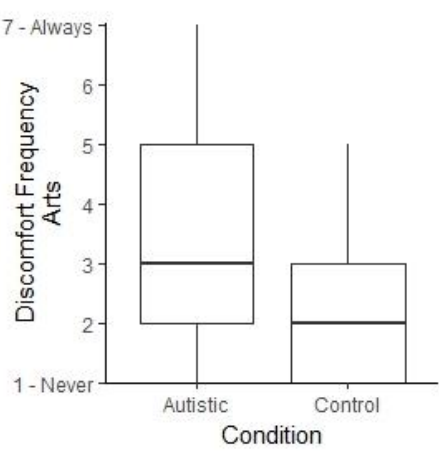

Figure 41. Arts Building Discomfort by Condition

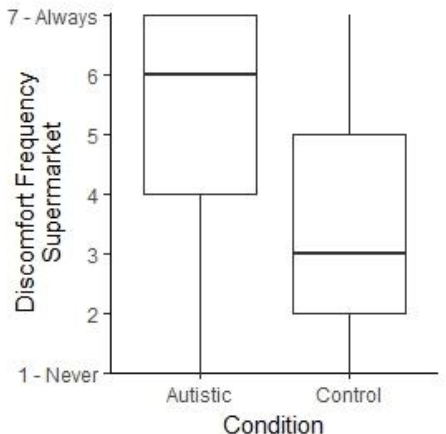

Figure 36. Supermarket Discomfort by Condition

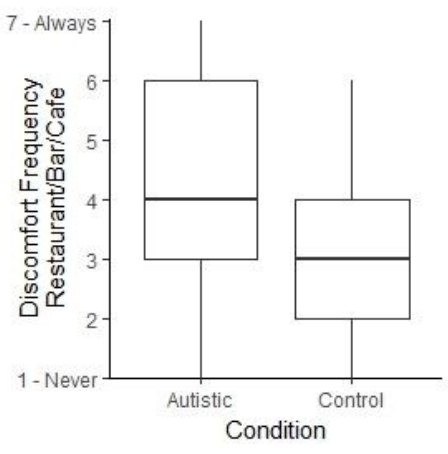

Figure 39. Restaurant/Bar/Café Building Discomfort by Condition

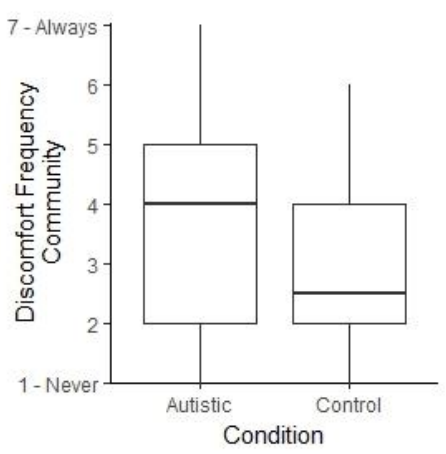

Figure 42. Community Building Discomfort by Condition 


\subsubsection{Sensory Processing}

Across all participants who regularly used the building types, Sensory Processing Score was significantly correlated with frequency of discomfort (Table 8). All correlations are positive, indicating that as sensory processing score increased, so did the frequency of discomfort. The correlations were strong in Shopping Malls, Other Retail buildings, Supermarkets and Medical buildings, moderate in Restaurant/Bar/Café, Arts, Community, and Office buildings, but was weak in Tertiary Education buildings.

Table 8.

Correlation between Frequency of Discomfort and Sensory Processing Score

\begin{tabular}{|c|c|c|c|c|c|c|}
\hline \multirow{2}{*}{ Building Type } & \multicolumn{3}{|c|}{ All qualifying participants } & \multicolumn{3}{|c|}{ Excluding Autistic respondents } \\
\hline & $\mathrm{n}$ & $r_{s}$ & $p$ & $\mathrm{n}$ & $r_{s}$ & $p$ \\
\hline Shopping mall & 181 & $\begin{array}{c}.62 \\
{[.50, .71]}\end{array}$ & $<.001$ & 136 & $\begin{array}{c}.46 \\
{[.30, .59]}\end{array}$ & $<.001$ \\
\hline Other retail & 245 & {$\left[\begin{array}{c}.60 \\
{[.51, .67]}\end{array}\right.$} & $<.001$ & 177 & {$[. .57, .64]$} & $<.001$ \\
\hline Supermarket & 264 & $\begin{array}{c}.58 \\
{[.49, .66]}\end{array}$ & $<.001$ & 189 & $\begin{array}{c}.42 \\
{[.29, .54]}\end{array}$ & $<.001$ \\
\hline Medical building & 109 & $\begin{array}{c}.51 \\
{[.36, .63]}\end{array}$ & $<.001$ & 68 & $\begin{array}{c}.24 \\
{[.01, .45]}\end{array}$ & .045 \\
\hline Restaurant/Bar/Cafe & 233 & $\begin{array}{c}.46 \\
{[.34, .57]}\end{array}$ & $<.001$ & 172 & $\begin{array}{c}.32 \\
{[.18, .45]}\end{array}$ & $<.001$ \\
\hline Arts building & 136 & $\begin{array}{c}.46 \\
{[.30, .59]}\end{array}$ & $<.001$ & 92 & $\begin{array}{c}.24 \\
{[.04, .44]}\end{array}$ & .018 \\
\hline Community building & 79 & {$[.29, .66]$} & $<.001$ & 49 & $\begin{array}{c}.40 \\
{[.12, .62]}\end{array}$ & .004 \\
\hline Office & 166 & $\begin{array}{c}.45 \\
{[.32, .56]}\end{array}$ & $<.001$ & 126 & $\begin{array}{c}.32 \\
{[.17, .47]}\end{array}$ & $<.001$ \\
\hline $\begin{array}{c}\text { Tertiary education } \\
\text { centre }\end{array}$ & 63 & $\begin{array}{c}.29 \\
{[.03, .51]}\end{array}$ & .021 & 41 & $\begin{array}{c}-.06 \\
{[-.38, .26]}\end{array}$ & .684 \\
\hline
\end{tabular}

Note. Confidence Intervals appear in square brackets below Spearman's rho $\left(r_{s}\right)$.

All the correlations were weaker when respondents from the Autistic group were excluded from the analysis (Table 8). As the Autistic group participants had significantly higher Sensory Processing Scores (Section 5.1), this was to test whether the analysis was being skewed by the higher proportion of people on the autism spectrum in the sample compared to the general population. While the correlations were weaker in all cases, they were still significant in all but one building type: Tertiary Education Centres.

The correlation between Sensory Processing Score and frequency of discomfort remained strong only in Other Retail buildings, decreasing to weak in Medical and Arts buildings, and moderate in all other building types except for Tertiary (Table 8). The exclusion of the Autistic participants both removed the highest sensory processing scores, 
and the highest frequency of discomfort scores, weakening the correlations (Figure 43 Figure 60).

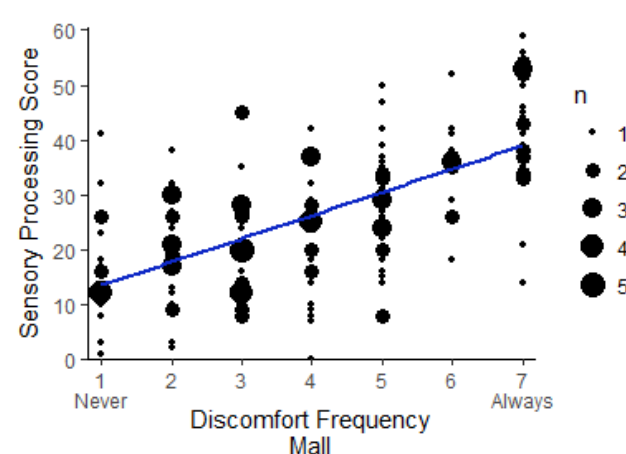

Figure 43. Shopping Mall Discomfort vs Sensory Processing Score (all qualifying participants)

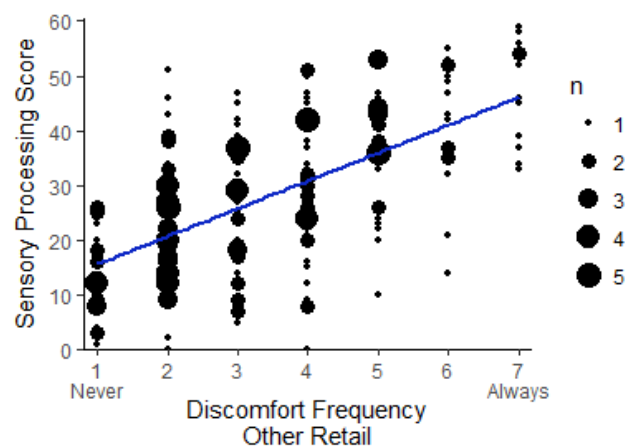

Figure 45. Other Retail Building Discomfort vs Sensory Processing Score (all qualifying participants)

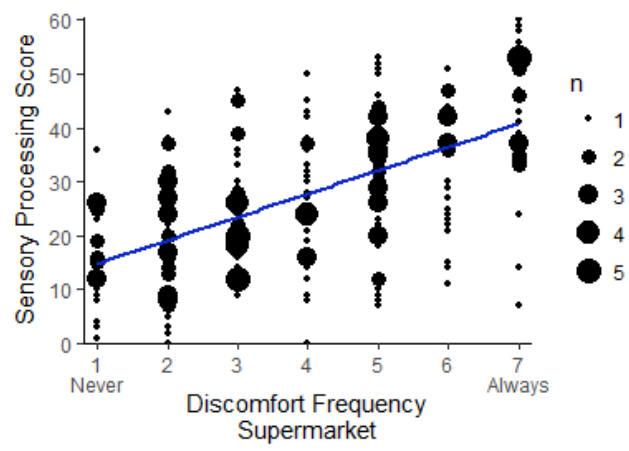

Figure 47. Supermarket Discomfort vs Sensory Processing Score (all qualifying participants)

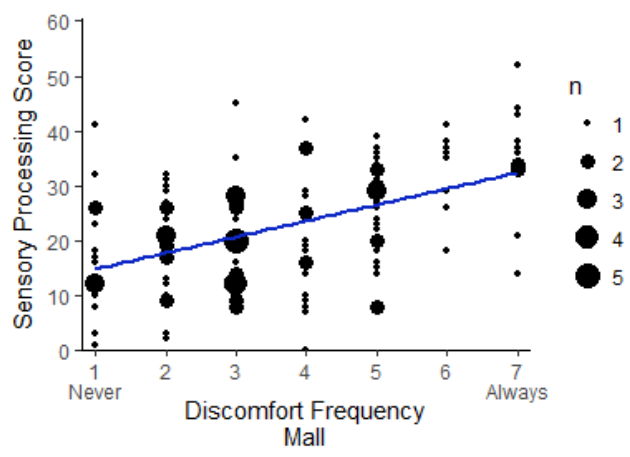

Figure 44. Shopping Mall Discomfort vs Sensory Processing Score (excluding Autistic participants)

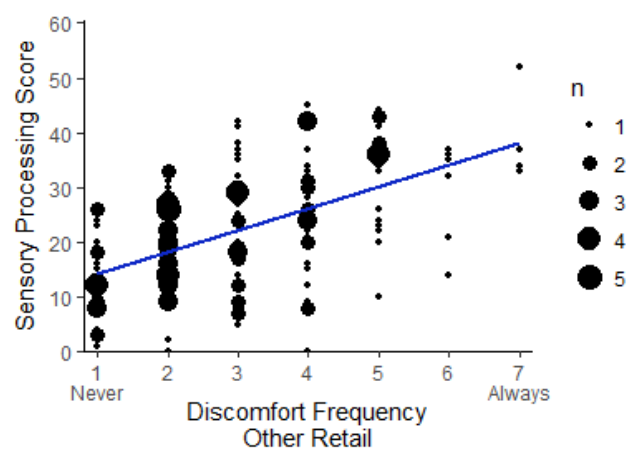

Figure 46. Other Retail Building Discomfort vs Sensory Processing Score (excluding Autistic participants)

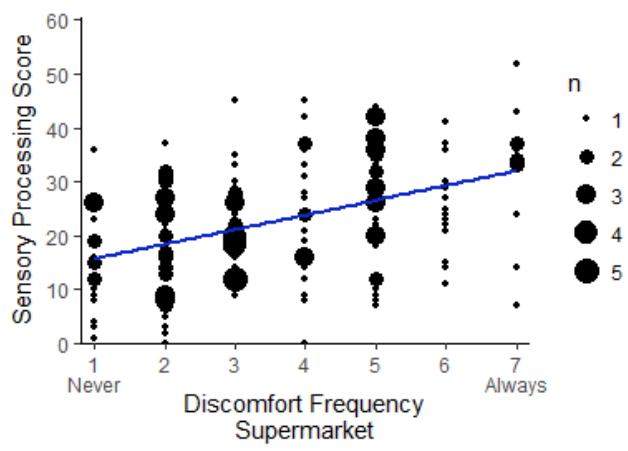

Figure 48. Supermarket Discomfort vs Sensory Processing Score (excluding Autistic participants) 


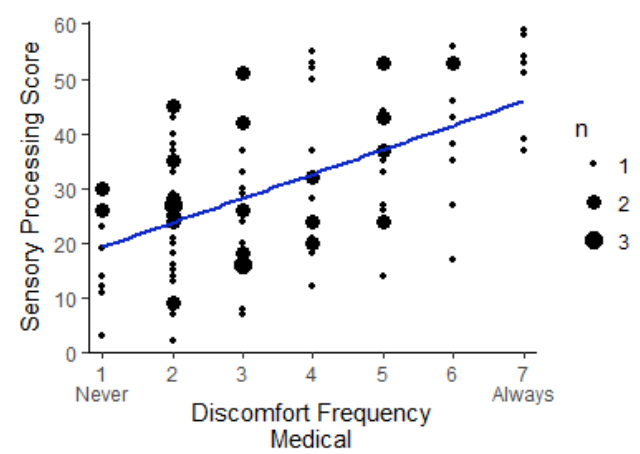

Figure 49. Medical Building Discomfort vs Sensory Processing Score (all qualifying participants)

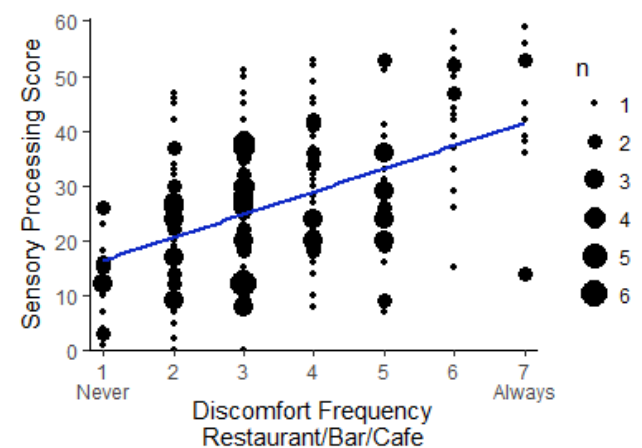

Figure 51. Restaurant/Bar/Café Building Discomfort vs Sensory Processing Score (all qualifying participants)

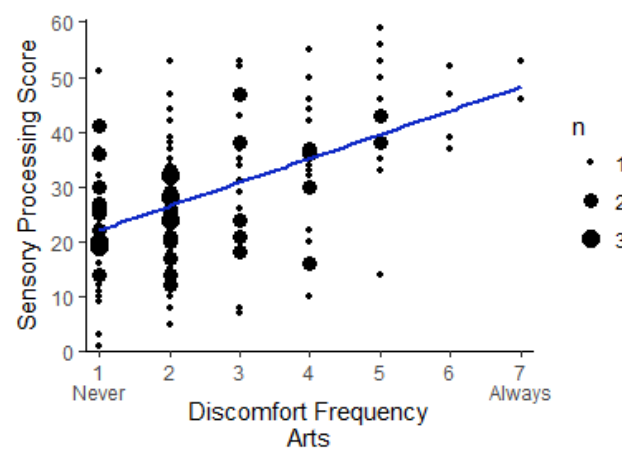

Figure 53. Arts Building Discomfort vs Sensory Processing Score (all qualifying participants)

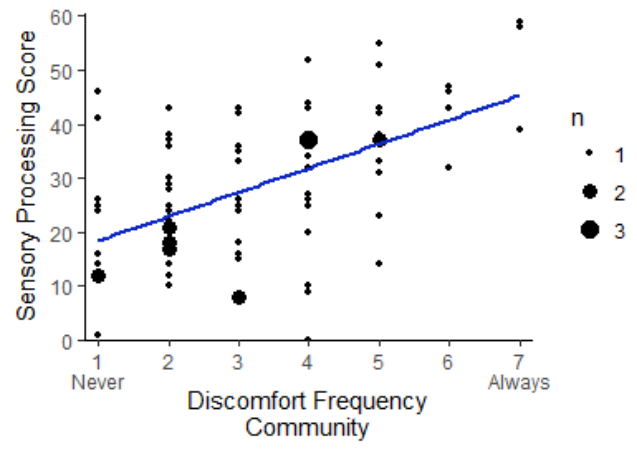

Figure 55. Community Building Discomfort vs Sensory Processing Score (all qualifying participants)

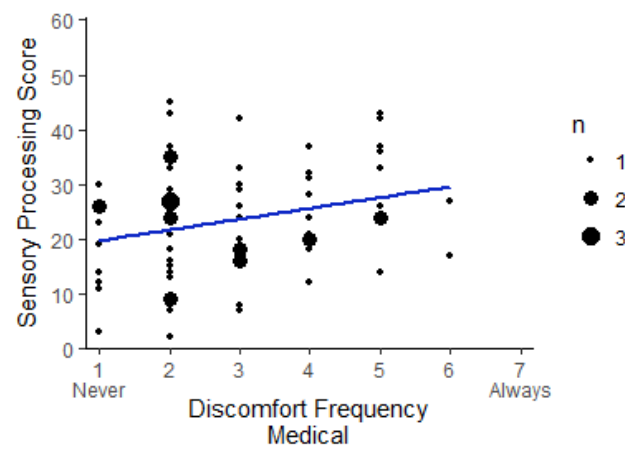

Figure 50. Medical Building Discomfort vs Sensory Processing Score (excluding Autistic participants)

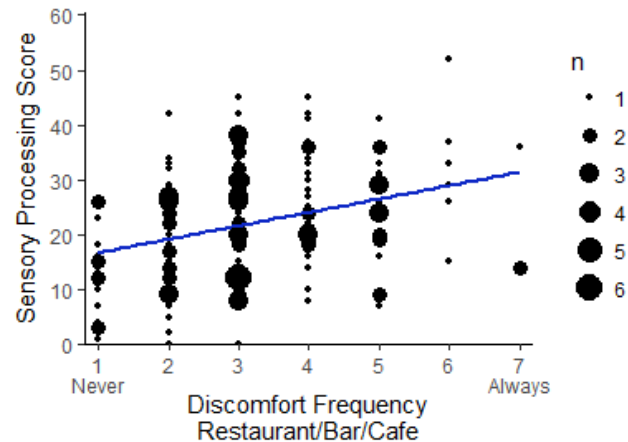

Figure 52. Restaurant/Bar/Café Building Discomfort vs Sensory Processing Score (excluding Autistic participants)

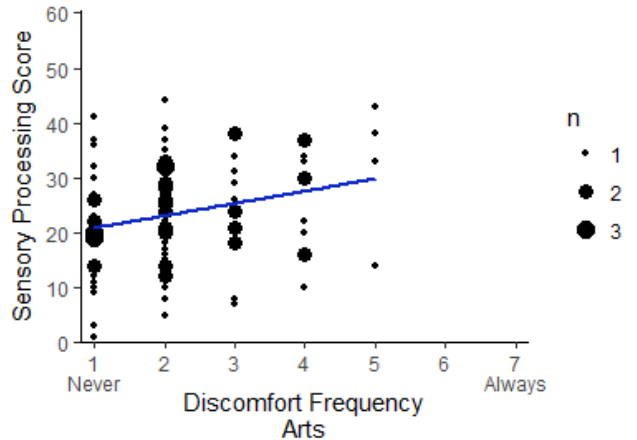

Figure 54. Arts Building Discomfort vs Sensory Processing Score (excluding Autistic participants)

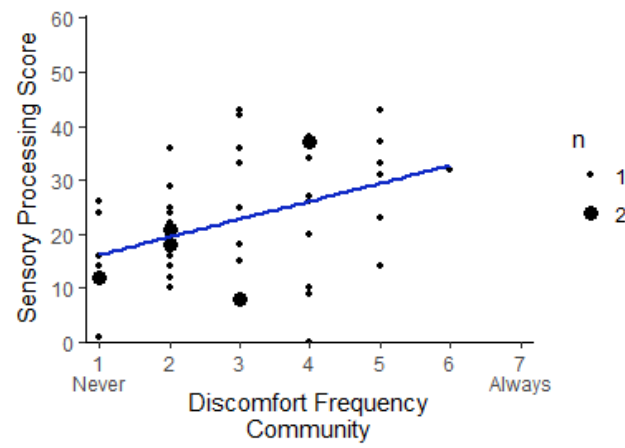

Figure 56. Community Building Discomfort vs Sensory Processing Score (excluding Autistic participants) 


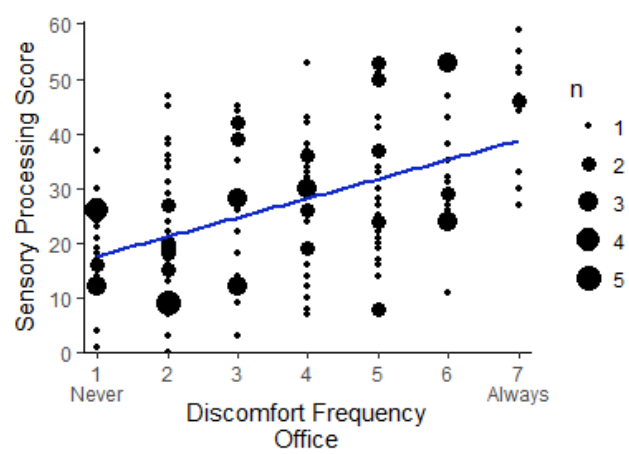

Figure 57. Office Building Discomfort vs Sensory Processing Score (all qualifying participants)

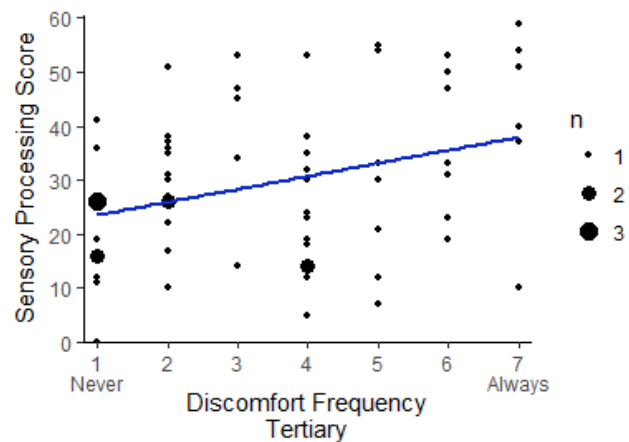

Figure 59. Tertiary Education Building Discomfort vs Sensory Processing Score (all qualifying participants)

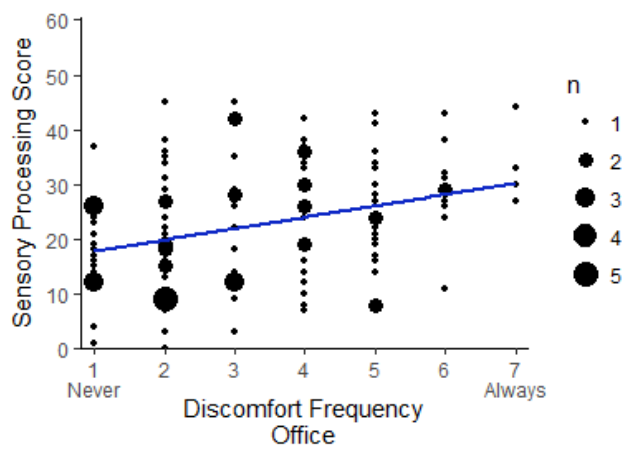

Figure 58. Office Building Discomfort vs Sensory Processing Score (excluding Autistic participants)

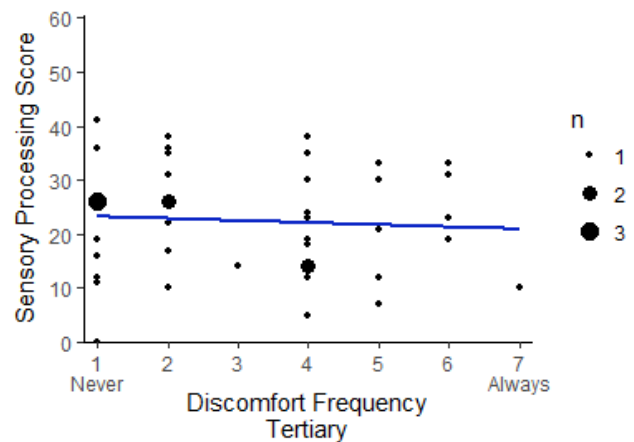

Figure 60. Tertiary Education Building Discomfort vs Sensory Processing Score (excluding Autistic participants) 


\subsubsection{Distress}

There were six buildings from the previous question that had an adequate number of responses with frequent discomfort that qualified to be asked about distress. All six building types caused respondents in the Autistic group significantly more distress than the respondents in the Control group (Table 7). Office buildings were the only building type that had a medium-to-large effect with a median difference of 1 , with all other building types having a large effect with median differences of 2 .

Table 9.

Level of Distress caused by 6 Building Types by Condition

\begin{tabular}{|c|c|c|c|c|c|c|c|c|c|}
\hline \multirow[b]{2}{*}{ Building Type } & \multicolumn{3}{|c|}{ Autistic } & \multicolumn{3}{|c|}{ Control } & \multirow{2}{*}{$\begin{array}{l}\text { median } \\
\text { difference }\end{array}$} & \multirow[b]{2}{*}{ U } & \multirow[b]{2}{*}{$\delta$} \\
\hline & $\mathrm{n}_{\mathrm{A}}$ & median & $\begin{array}{c}\text { mean } \\
\text { rank }\end{array}$ & $\mathrm{n}_{\mathrm{c}}$ & median & $\begin{array}{c}\text { mean } \\
\text { rank }\end{array}$ & & & \\
\hline Shopping mall & 36 & $\begin{array}{c}6 \\
{[4,6]}\end{array}$ & 51 & 40 & $\begin{array}{c}3 \\
{[2,4]}\end{array}$ & 28 & $\begin{array}{c}2 \\
{[1,3]}\end{array}$ & $284.5^{* * *}$ & $\begin{array}{c}-.60 \\
{[-.76,-.38]}\end{array}$ \\
\hline Supermarket & 65 & $\begin{array}{c}5 \\
{[4,6]}\end{array}$ & 91 & 71 & $\begin{array}{c}2 \\
{[2,3]}\end{array}$ & 48 & $\begin{array}{c}2 \\
{[2,3]}\end{array}$ & $842.5^{* * *}$ & $\begin{array}{c}-.63 \\
{[-.75,-.48]}\end{array}$ \\
\hline Other Retail & 50 & $\begin{array}{c}5 \\
{[4,6]}\end{array}$ & 70 & 54 & $\begin{array}{c}2 \\
{[2,3]}\end{array}$ & 36 & $\begin{array}{c}2 \\
{[2,3]}\end{array}$ & $482.5^{* * *}$ & $\begin{array}{c}-.64 \\
{[-.78,-.45]}\end{array}$ \\
\hline Medical & 32 & $\begin{array}{c}5 \\
{[4,6]}\end{array}$ & 34 & 21 & $\begin{array}{c}3 \\
{[1,4]}\end{array}$ & 17 & $\begin{array}{c}2 \\
{[1,3]}\end{array}$ & $116.5^{* * *}$ & $\begin{array}{c}-.65 \\
{[-.83,-.34]}\end{array}$ \\
\hline $\begin{array}{c}\text { Restaurant/Bar } \\
\text { /Cafe }\end{array}$ & 48 & $\begin{array}{c}4.5 \\
{[4,5]}\end{array}$ & 78 & 67 & $\begin{array}{c}2 \\
{[2,2]}\end{array}$ & 43 & $\begin{array}{c}2 \\
{[1,3]}\end{array}$ & $627.0^{* * *}$ & $\begin{array}{c}-.61 \\
{[-.75,-.42]}\end{array}$ \\
\hline Office & 32 & $\begin{array}{c}4 \\
{[3,5]}\end{array}$ & 50 & 45 & $\begin{array}{c}2 \\
{[1,3]}\end{array}$ & 32 & $\begin{array}{c}1 \\
{[1,2]}\end{array}$ & $384.0^{* * *}$ & $\begin{array}{c}-.47 \\
{[-.66,-.22]}\end{array}$ \\
\hline
\end{tabular}

Note. ${ }^{*}=\mathrm{p}<.05,{ }^{* * *}=\mathrm{p}<.001$. Confidence Intervals appear in square brackets below the median, median difference, and Cliff's delta $(\delta)$.

Respondents in the Autistic group reported Shopping Malls causing substantial distress, with no responses below ' 3 ' and at least half or responses falling at ' 6 ' or '7', while the Control group responses primarily fell in the middle and lower end of the scale (Figure 61). On average, the Autistic group reported greater distress in Shopping Malls than the Control group in $80 \%$ of cases (where $50 \%$ indicates no difference).

The distributions of responses for Supermarkets, Other Retail, and Medical buildings are similar to that of Shopping Malls for the Control group, while responses from the Autistic group are lower for all three buildings compared to Shopping Malls (Figure 62, Figure 63 \& Figure 64). For all three building types, three quarters of responses from the Autistic group fell at ' 4 ' or above, while three quarters of the Control group responses fell at ' 4 ' or below. On average, the Autistic group reported greater distress than the Control group in Supermarkets in $82 \%$ of cases, in Other Retail buildings in $82 \%$ of cases, and in Medical buildings in $83 \%$ of cases. 
Again, the distribution of Control group responses for Restaurant/Bar/Café buildings is similar to the previous building types, although the Autistic group responses are lower and are more evenly distributed across the scale compared to the other building types

(Figure 65). On average, the Autistic group reported greater distress in Restaurant/Bar/Café buildings than the Control group in $81 \%$ of cases.

Compared to the other building types, Office buildings caused less distress, with the lowest medians for both groups. Responses from the Control group fell primarily at the lower end of the scale, while responses from the Autistic group fell primarily in the middle of the scale with some higher scores. On average, the Autistic group reported greater distress in Office buildings than the Control group in $73 \%$ of cases.

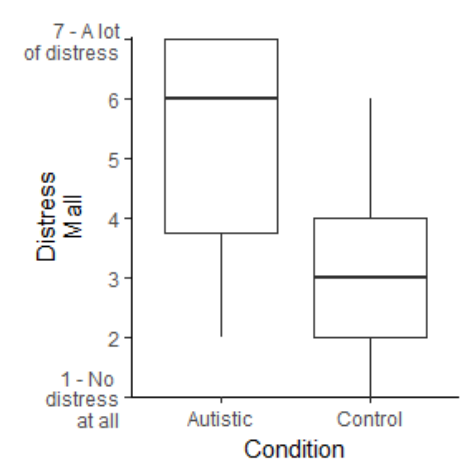

Figure 61. Distress from Shopping Malls by Condition

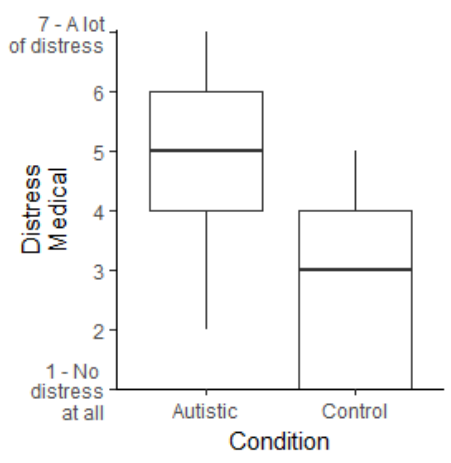

Figure 64. Distress from Medical Buildings by Condition

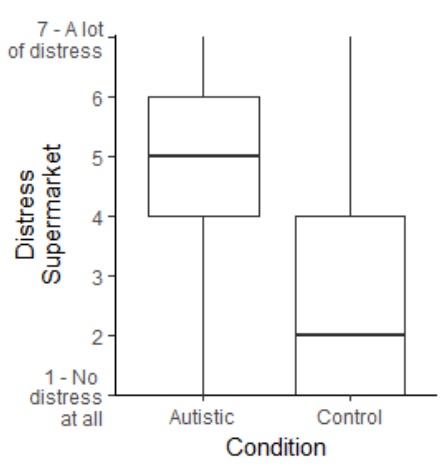

Figure 62. Distress from Supermarkets by Condition

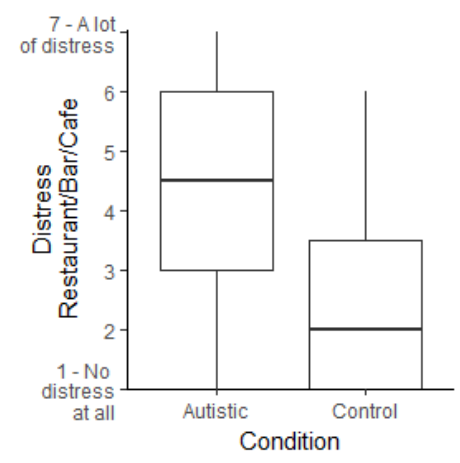

Figure 65. Distress from Restaurant/Bar/Café Buildings by Condition

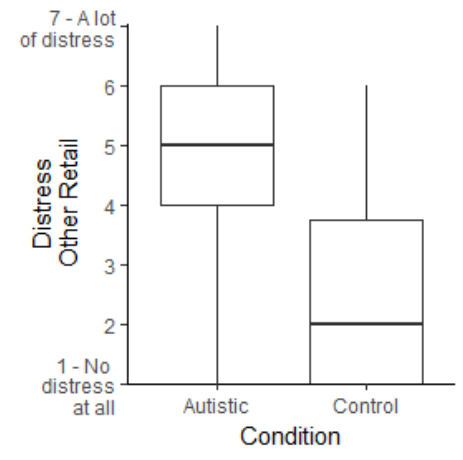

Figure 63. Distress from Other Retail Buildings by Condition

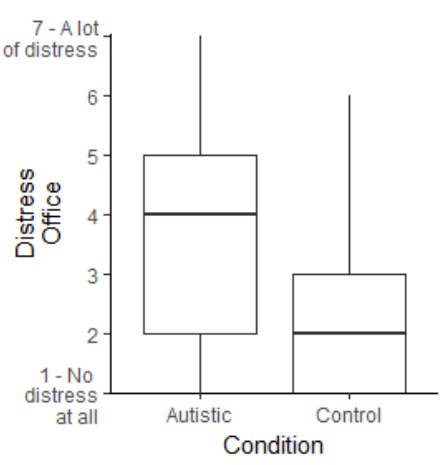

Figure 66. Distress from Office Buildings by Condition 


\subsubsection{Sensory Processing}

Across all six building types, Sensory Processing Score was significantly correlated with level of distress (Table 8). All correlations are positive, indicating that as sensory processing score increased, so did the level of distress. The correlation between Sensory Processing Score and level of distress was strong in all six building types.

While the correlations were weaker in all cases when participants in the Autistic group were excluded from the analysis, they were still significant in all building types (Table 8). The correlation between Sensory Processing Score and level of distress remained strong in Shopping Malls, Other Retail, Restaurant/Bar/Café, and Office buildings, decreasing to moderate in Medical buildings and Supermarkets (Figure 67 - Figure 78).

Table 10.

Correlation between Level of Distress and Sensory Processing Score

\begin{tabular}{|c|c|c|c|c|c|c|}
\hline \multirow{2}{*}{ Building Type } & \multicolumn{3}{|c|}{ All qualifying participants } & \multicolumn{3}{|c|}{ Excluding Autistic respondents } \\
\hline & $\mathrm{n}$ & $r_{s}$ & $p$ & $\mathrm{n}$ & $r_{s}$ & $p$ \\
\hline Medical building & 64 & $\begin{array}{c}.68 \\
{[.50, .80]}\end{array}$ & $<.001$ & 32 & $\begin{array}{c}.43 \\
{[.12, .70]}\end{array}$ & .0 .14 \\
\hline Shopping mall & 107 & $\begin{array}{c}.66 \\
{[.55, .77]}\end{array}$ & $<.001$ & 71 & $\begin{array}{c}.55 \\
{[.38, .69]}\end{array}$ & $<.001$ \\
\hline Supermarket & 177 & $\begin{array}{c}.65 \\
{[.55, .73]}\end{array}$ & $<.001$ & 112 & $\begin{array}{c}.47 \\
{[.32, .60]}\end{array}$ & $<.001$ \\
\hline Other retail & 139 & $\begin{array}{c}.64 \\
{[.53, .74]}\end{array}$ & $<.001$ & 89 & $\begin{array}{c}.54 \\
{[.39, .67]}\end{array}$ & $<.001$ \\
\hline Restaurant/Bar/Cafe & 152 & $\begin{array}{c}.64 \\
{[.54, .72]}\end{array}$ & $<.001$ & 104 & $\begin{array}{c}.50 \\
{[.35, .62]}\end{array}$ & $<.001$ \\
\hline Office & 100 & $\begin{array}{c}.54 \\
{[.38, .66]}\end{array}$ & $<.001$ & 68 & $\begin{array}{c}.54 \\
{[.37, .68]}\end{array}$ & $<.001$ \\
\hline
\end{tabular}

Note. Confidence Intervals appear in square brackets below Spearman's rho $\left(\mathrm{r}_{\mathrm{s}}\right)$. 


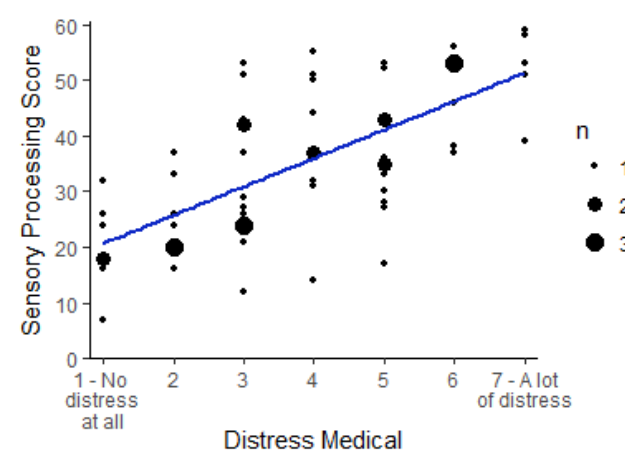

Figure 67. Distress from Medical Buildings vs Sensory Processing Score (all qualifying participants)

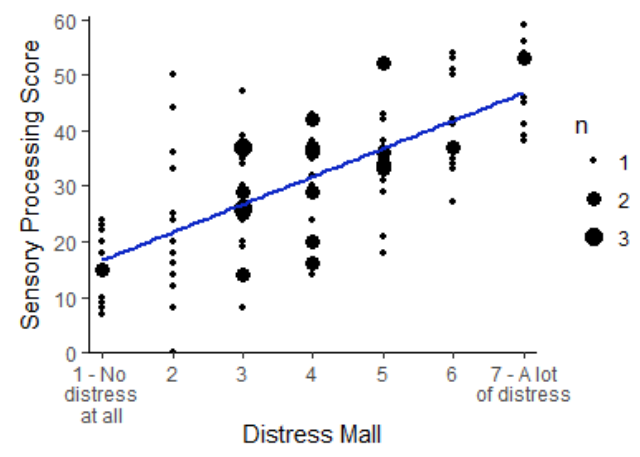

Figure 69. Distress from Shopping Malls vs Sensory Processing Score (all qualifying participants)

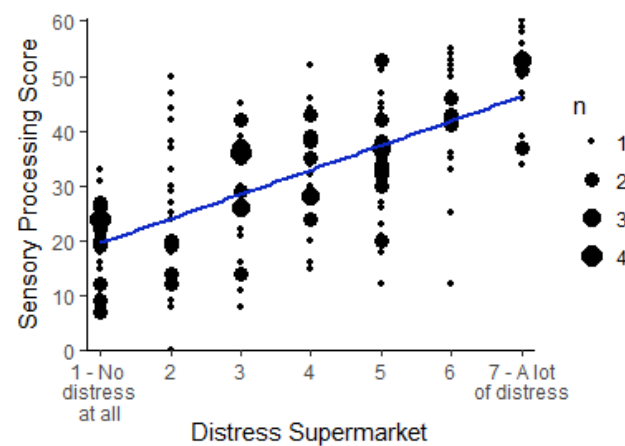

Figure 71. Distress from Supermarkets vs Sensory Processing Score (all qualifying participants)

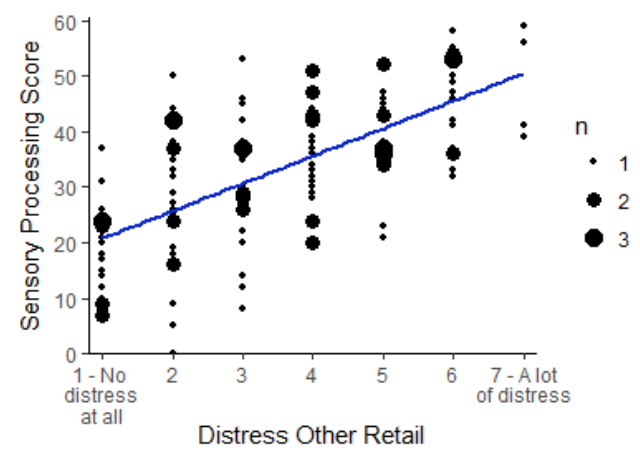

Figure 73. Distress from Other Retail Buildings vs Sensory Processing Score (all qualifying participants)

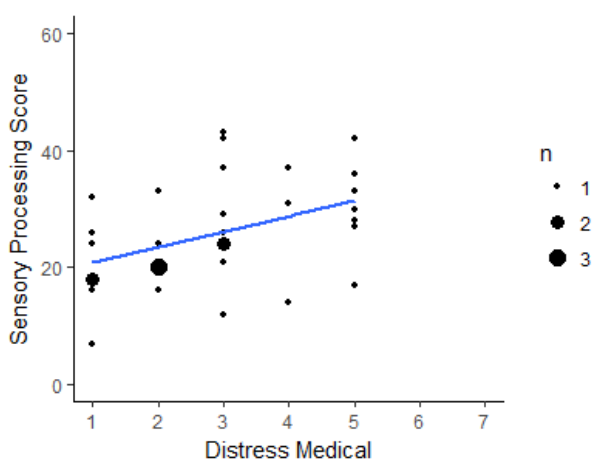

Figure 68. Distress from Medical Buildings vs Sensory Processing Score (excluding Autistic participants)

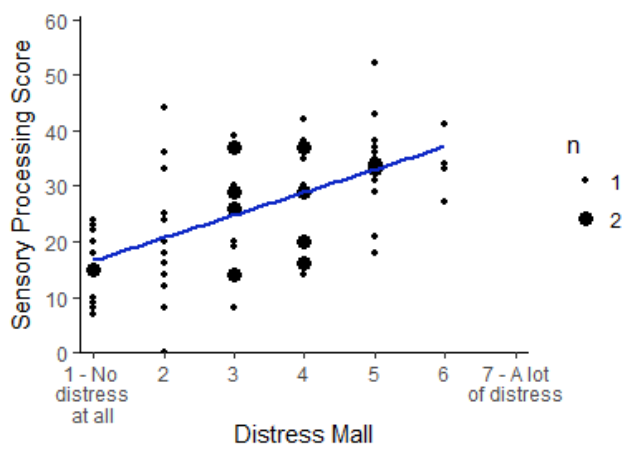

Figure 70. Distress from Shopping Malls vs Sensory Processing Score (excluding Autistic participants)

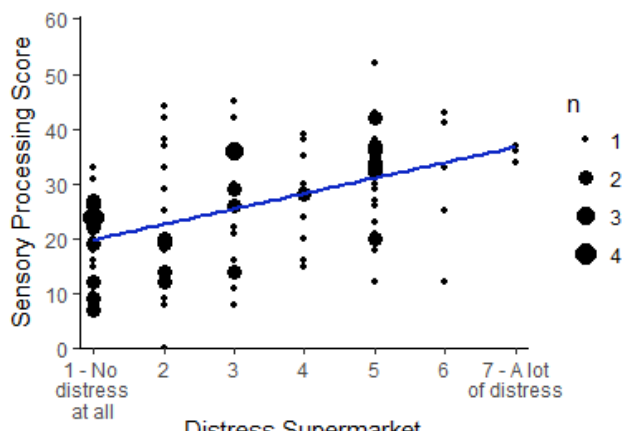

Figure 72. Distress from Supermarkets vs Sensory Processing Score (excluding Autistic participants)

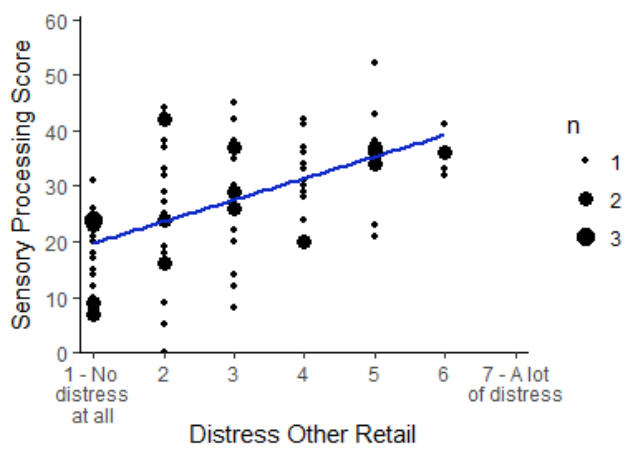

Figure 74. Distress from Other Retail Buildings vs Sensory Processing Score (excluding Autistic participants) 


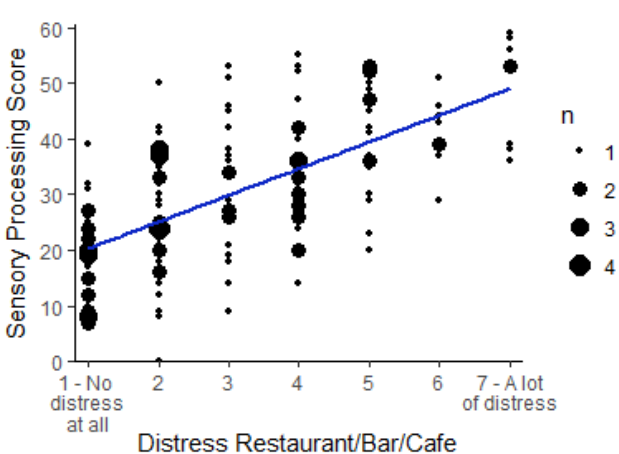

Figure 75. Distress from Restaurant/Bar/Café Buildings vs Sensory Processing Score (all qualifying participants)

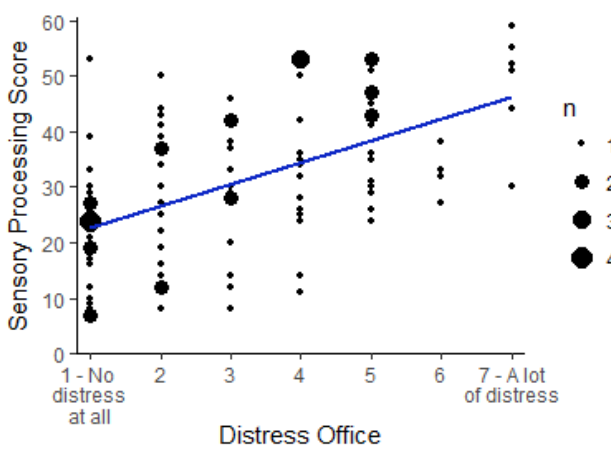

Figure 77. Distress from Office Buildings vs Sensory Processing Score (all qualifying participants)

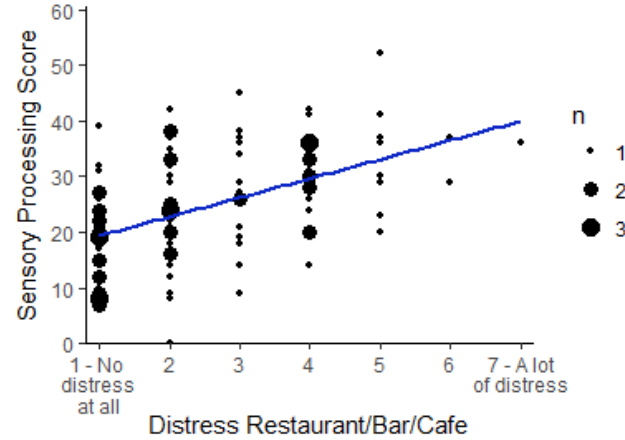

Figure 76. Distress from Restaurant/Bar/Café Buildings vs Sensory Processing Score (excluding Autistic participants)

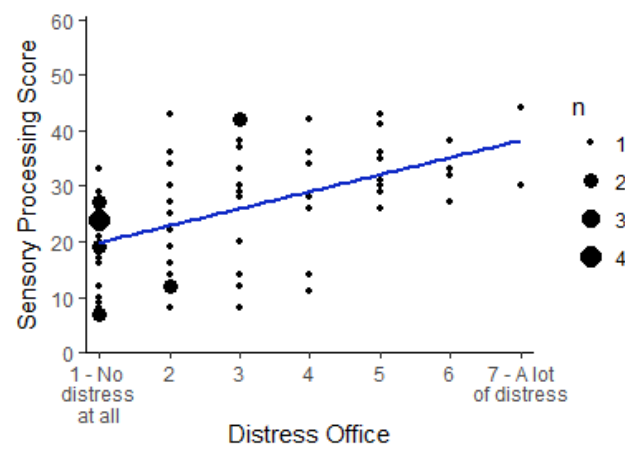

Figure 78. Distress from Office Buildings vs Sensory Processing Score (excluding Autistic participants) 


\subsubsection{Correlation with Discomfort}

For all six building types, level of distress was both strongly and significantly correlated with frequency of discomfort. When analysed separately, the correlation between level of distress and frequency of discomfort was strong in all building types among participants in only the Autistic group, but much weaker in only the Control group. The correlations ranged from weak to strong in the Control group, with level of distress and frequency of discomfort in Other Buildings no longer significantly correlated. However, the Confidence Intervals for the correlation coefficient are wide for all the correlations in only the Control group, indicating there is lower confidence in the estimate of the correlation coefficient for this analysis.

Table 11.

Correlation between Frequency of Discomfort and Level of Distress for All Participants and by Condition

\begin{tabular}{|c|c|c|c|c|c|c|c|c|c|}
\hline \multirow{2}{*}{ Building Type } & \multicolumn{3}{|c|}{ All Participants } & \multicolumn{3}{|c|}{ Autistic Only } & \multicolumn{3}{|c|}{ Control Only } \\
\hline & $\mathrm{n}$ & $r_{s}$ & $p$ & $n$ & $r_{s}$ & $p$ & $n$ & $r_{s}$ & $p$ \\
\hline Medical building & 64 & $\begin{array}{c}.79 \\
{[.63, .88]}\end{array}$ & $<.001$ & 32 & $\begin{array}{c}.88 \\
{[.78, .94]}\end{array}$ & $<.001$ & 45 & $\begin{array}{c}.48 \\
{[.04, .81]}\end{array}$ & .026 \\
\hline Shopping mall & 107 & $\begin{array}{c}.77 \\
{[.66, .84]}\end{array}$ & $<.001$ & 36 & $\begin{array}{c}.81 \\
{[.68, .89]}\end{array}$ & $<.001$ & 40 & $\begin{array}{c}.54 \\
{[.24, .75]}\end{array}$ & .035 \\
\hline Supermarket & 177 & $\begin{array}{c}.71 \\
{[.60, .80]}\end{array}$ & $<.001$ & 65 & $\begin{array}{c}.82 \\
{[.72, .88]}\end{array}$ & $<.001$ & 71 & $\begin{array}{c}.42 \\
{[.17, .61]}\end{array}$ & $<.001$ \\
\hline Other retail & 139 & $\begin{array}{c}.63 \\
{[.49, .75]}\end{array}$ & $<.001$ & 50 & $\begin{array}{c}.73 \\
{[.55, .86]}\end{array}$ & $<.001$ & 54 & {$[-.06, .49]$} & .074 \\
\hline $\begin{array}{c}\text { Restaurant/Bar/ } \\
\text { Cafe }\end{array}$ & 152 & $\begin{array}{c}.59 \\
{[.45, .72]}\end{array}$ & $<.001$ & 48 & $\begin{array}{c}.78 \\
{[.61, .89]}\end{array}$ & $<.001$ & 67 & $\begin{array}{c}.25 \\
{[.01, .48]}\end{array}$ & .043 \\
\hline Office & 100 & $\begin{array}{c}.59 \\
{[.42, .72]}\end{array}$ & $<.001$ & 32 & $\begin{array}{c}.73 \\
{[.45, .88]}\end{array}$ & $<.001$ & 21 & $\begin{array}{c}.31 \\
{[.01, .56}\end{array}$ & $<.001$ \\
\hline
\end{tabular}

Note. Confidence Intervals appear in square brackets below Spearman's rho $\left(r_{s}\right)$. 


\subsubsection{Avoidance}

While $90 \%$ of participants in the Autistic group responded that they had avoided buildings, only $52 \%$ of the control group had. Therefore, the odds of a participant in the Autistic group having ever avoided buildings were $8.8[4.0,19.7]$ times greater than a participant control group ( $\left.n_{0}=65, p<.001\right)$.

Participants who reported they had previously avoided buildings showed a large difference in sensory processing scores, $\delta=.60[.48, .69]$, with a median score of 31 [31, 36], compared with those who had not avoided buildings (17.5 [14, 21]) (Figure 79). The difference was statistically significant $(n 1=181, n 2=94, U=13610, p<.001)$. Participants who had ever avoided buildings had a higher Sensory Processing Score than those who had never in $79 \%$ of cases (where $50 \%$ indicates no difference).

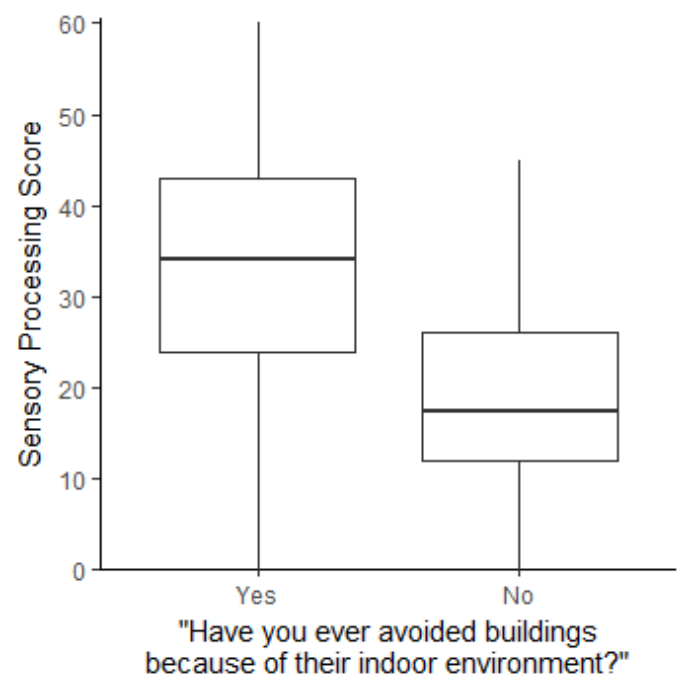

Figure 79. Incidence of Avoidance by Sensory Processing Score

When the number of buildings selected was counted, with participants who had never avoided a building assigned a count of 0 , the respondents from the Autistic group had a median count of $5[4,5]$, while the Control group had a median count of $1[0,1]$. This equated to a median difference of $3[3,4]$, indicating that the Autistic group avoided more different types of buildings than the Control group (Figure 80). This was supported by a Mann-Whitney $U$ test that showed a statistically significant difference between the groups $\left(n_{1}=83, n_{2}=134, U=9273, p<.001\right)$ and equated to an effect size of $\delta=-.67[-.77$, -.35] indicating a large effect. The Autistic group selected a higher number of building types that they had ever avoided than the Control group in $83 \%$ of cases. 


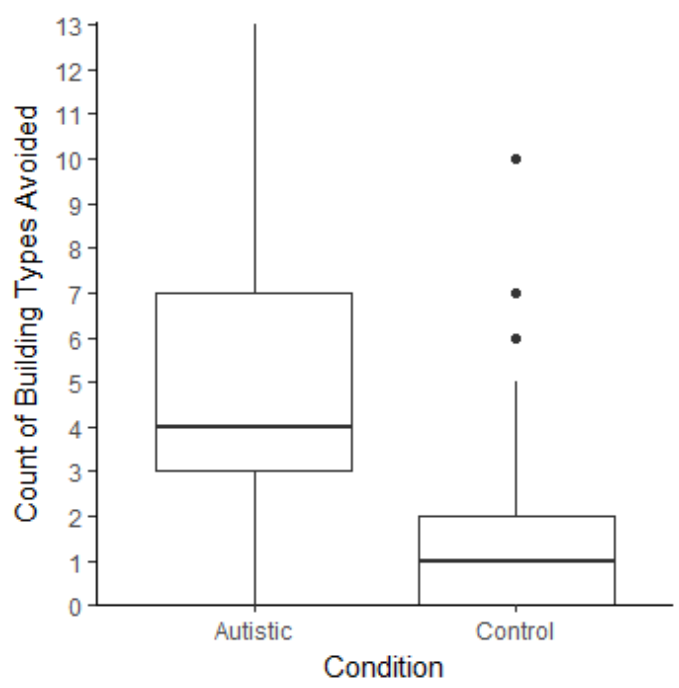

Figure 80. Count of Building Types Avoided by Condition

A higher proportion of participants in the Autistic group responded that they had avoided all types of buildings compared to the Control group (Figure 81). Shopping Malls, Restaurant/Bar/Café and Supermarket buildings were the most avoided by both groups, followed by Other Retail and Office buildings. There were many building types that few of the Control group indicated they had ever avoided.

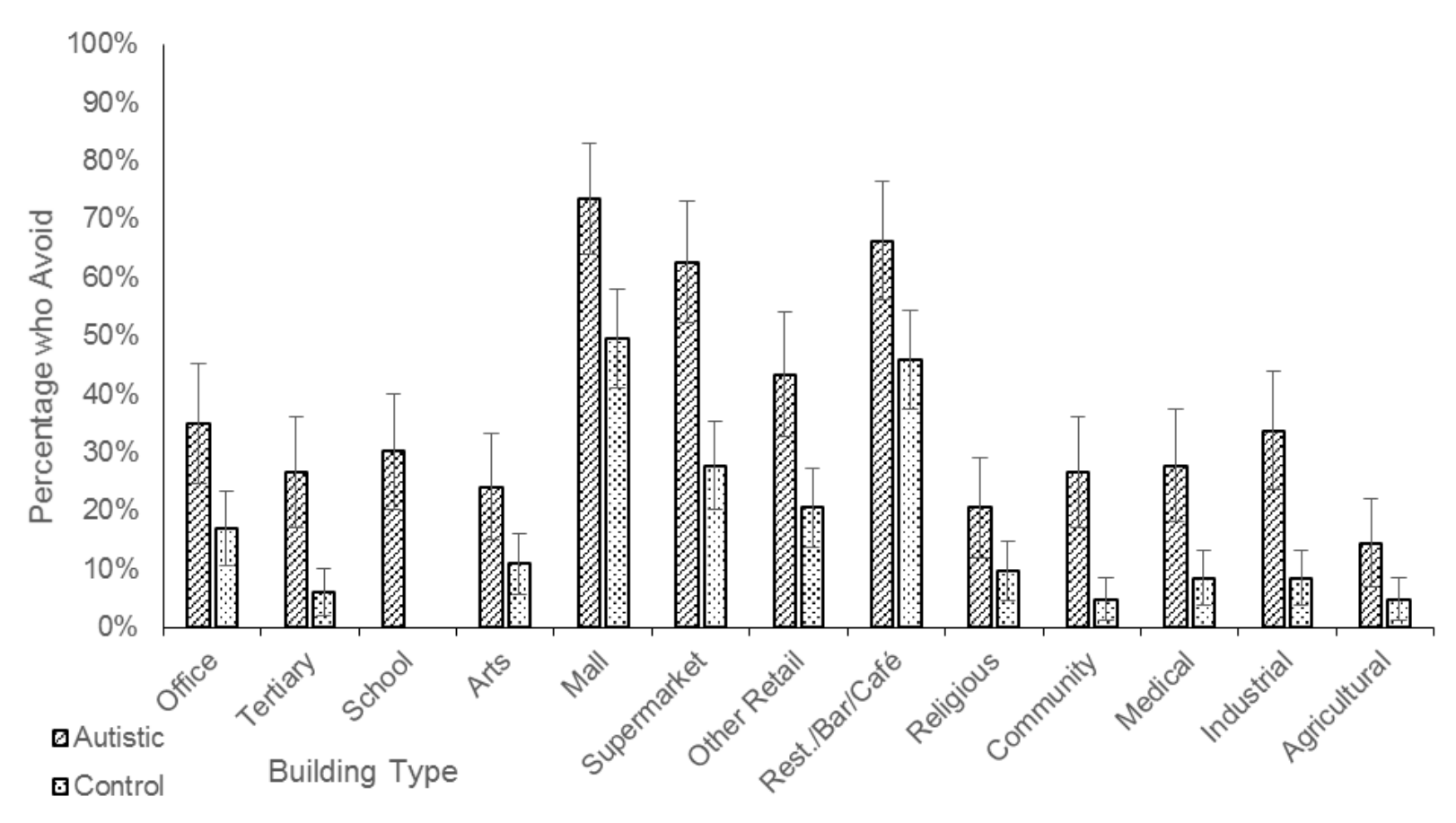

Figure 81. Proportion of Building Types Avoided by Condition 


\subsubsection{Frequency}

Of the participants who had ever avoided each of the different building types, four of the five building types caused respondents in the Autistic group to avoid them significantly more often than the respondents in the Control group (Table 12). There was no statistically significant difference in how often respondents avoided Office buildings between the Autistic and Control group respondents $(p=.196)$. However, there was a small-to-medium effect size between the two groups and a median difference of 1 , so the lack of statistically significant relationship may be due to the small sample size.

Table 12.

Frequency of Avoidance of 5 Building Types by Condition

\begin{tabular}{|c|c|c|c|c|c|c|c|c|c|}
\hline \multirow[b]{2}{*}{ Building Type } & \multicolumn{3}{|c|}{ Autistic } & \multicolumn{3}{|c|}{ Control } & \multirow{2}{*}{$\begin{array}{l}\text { median } \\
\text { difference }\end{array}$} & \multirow[b]{2}{*}{ U } & \multirow[b]{2}{*}{$\delta$} \\
\hline & $\mathrm{n}_{\mathrm{A}}$ & median & $\begin{array}{c}\text { mean } \\
\text { rank }\end{array}$ & $\mathrm{nc}_{\mathrm{c}}$ & median & $\begin{array}{c}\text { mean } \\
\text { rank }\end{array}$ & & & \\
\hline Office & 29 & $\begin{array}{c}5 \\
{[4,6]}\end{array}$ & 24 & 14 & $\begin{array}{c}3.5 \\
{[2,7]}\end{array}$ & 18 & $\begin{array}{c}1 \\
{[0,2]}\end{array}$ & 153.5 & $\begin{array}{c}-.24 \\
{[-.57, .15]}\end{array}$ \\
\hline Shopping mall & 61 & $\begin{array}{c}7 \\
{[6,7]}\end{array}$ & 56 & 41 & $\begin{array}{c}6 \\
{[4,7]}\end{array}$ & 44 & $\begin{array}{c}0 \\
{[0,1]}\end{array}$ & $951.5^{*}$ & $\begin{array}{c}-.24 \\
{[-.44,-.01]}\end{array}$ \\
\hline $\begin{array}{l}\text { Other retail } \\
\text { (shop, dairy) }\end{array}$ & 36 & $\begin{array}{c}5.5 \\
{[5,6]}\end{array}$ & 31 & 17 & $\begin{array}{c}4 \\
{[2,5]}\end{array}$ & 20 & $\begin{array}{c}2 \\
{[0,3]}\end{array}$ & $178.5^{*}$ & $\begin{array}{c}-.42 \\
{[-.68,-.05]}\end{array}$ \\
\hline Supermarket & 52 & $\begin{array}{c}5 \\
{[5,6]}\end{array}$ & 44 & 23 & $\begin{array}{c}3 \\
{[2,5]}\end{array}$ & 24 & $\begin{array}{c}2 \\
{[1,3]}\end{array}$ & $281.0^{* * *}$ & $\begin{array}{c}-.53 \\
{[-.72,-.28]}\end{array}$ \\
\hline $\begin{array}{l}\text { Restaurant/Bar } \\
\text { /Cafe }\end{array}$ & 55 & $\begin{array}{c}5 \\
{[4,6]}\end{array}$ & 58 & 38 & $\begin{array}{c}3 \\
{[2,4]}\end{array}$ & 32 & $\begin{array}{c}2 \\
{[1,3]}\end{array}$ & $463.0^{* * *}$ & $\begin{array}{c}-.56 \\
{[-.71,-.34]}\end{array}$ \\
\hline
\end{tabular}

Note. ${ }^{*}=p<.05,{ }^{* * *}=p<.001$. Confidence Intervals appear in square brackets below the median, median difference, and Cliff's delta $(\delta)$.

Shopping Malls had the highest median avoidance for both groups, so the small-tomedium effect is largely due to higher responses from the Control group compared the other building types (Table 12). Half of respondents in the Autistic group rated their frequency of avoidance at "As much as possible", with none reporting "Rarely" avoiding Shopping Malls (Figure 83). On average, the Autistic group reported avoiding Shopping Malls more frequently than the Control group in $62 \%$ of cases.

Other Retail, Supermarket, and Restaurant/Bar/Café buildings had the largest effects between the Autistic and Control groups (Table 12). While the effect size for Other Retail buildings was medium-to-large, both groups avoided them more frequently than any other building type than Shopping Malls. The distribution of responses for Other Retail and Supermarkets was similar, with the lack of fourth quartile for the Autistic group indicating at least a quarter of the Autistic group "As much as possible" avoided these building types (Figure 84 \& Figure 85). While Restaurant/Bar/Café buildings had the largest effect between the Autistic and Control groups, compared to other building types, overall the responses were slightly lower. This is the only building type where the Autistic group has a 
visible fourth quartile and where no participant in the Control group rated "As much as possible" avoiding Restaurant/Bar/Café buildings (Figure 86). On average, the Autistic group reported avoiding Other Retail buildings more frequently than the Control group in $71 \%$ of cases, Supermarkets in $77 \%$ of cases, and Restaurant/Bar/Café buildings in $78 \%$ of cases.

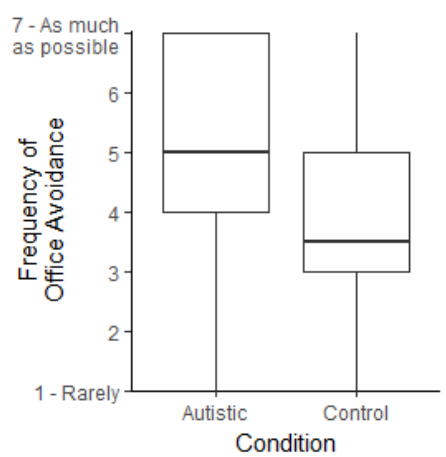

Figure 82. Frequency of Avoidance of Office Buildings by Condition

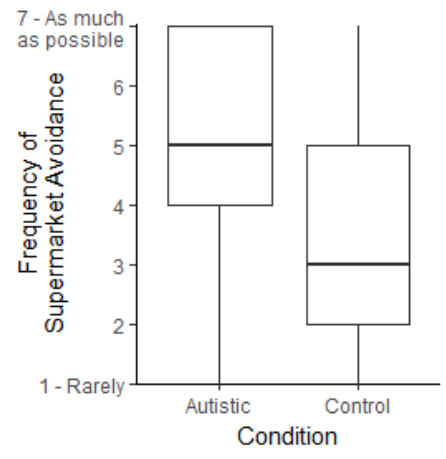

Figure 85. Frequency of Avoidance of Supermarkets by Condition

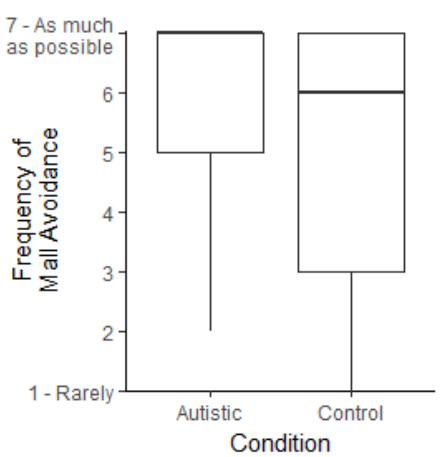

Figure 83. Frequency of Avoidance of Shopping Malls by Condition

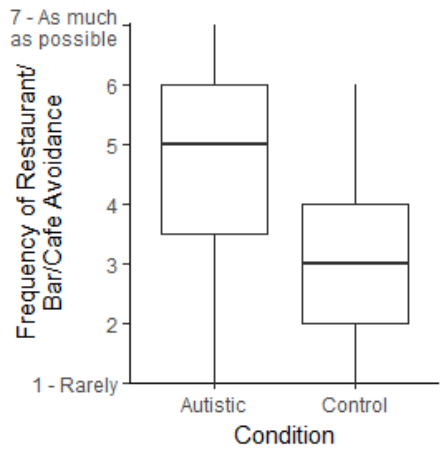

Figure 86. Frequency of Avoidance of

Restaurant/Bar/Café Buildings by Condition

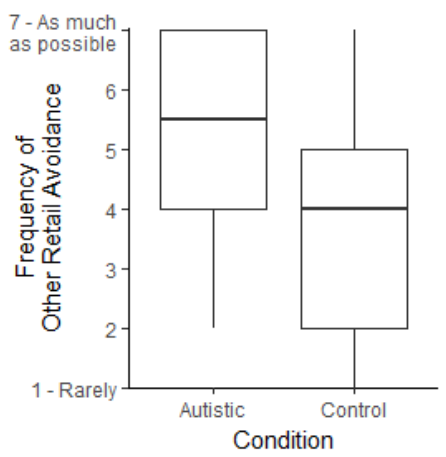

Figure 84. Frequency of Avoidance of Other Retail Buildings by Condition 


\subsubsection{Sensory Processing}

Across all participants who identified as having ever avoided buildings, Sensory

Processing Score was significantly correlated with frequency of avoidance (Table 13). All correlations are positive, indicating that as Sensory Processing Score increased, so did the frequency of avoidance. The correlations were moderate in Shopping Malls, Other Retail buildings, Supermarkets and Medical buildings and weak in Office buildings.

When respondents from the Autistic group were excluded from the analysis, the correlation between Sensory Processing Score and frequency of avoidance remained significant only in Other Retail buildings and Supermarkets (Figure 87 - Figure 96).

However, this is likely due to the reduced sample size, as significantly more participants in the Autistic group identified as avoiding buildings across all building types. This can be seen in the wide Confidence Intervals, indicating that there is lower confidence in the estimate of the correlation coefficient for this analysis.

Table 13.

Correlation between Frequency of Avoidance by Building Type and Sensory Processing Score

\begin{tabular}{|c|c|c|c|c|c|c|}
\hline \multirow{2}{*}{ Building Type } & \multicolumn{3}{|c|}{ All qualifying participants } & \multicolumn{3}{|c|}{ Excluding Autistic respondents } \\
\hline & $n$ & $r_{s}$ & $p$ & $n$ & $r_{s}$ & $p$ \\
\hline $\begin{array}{l}\text { Other retail (shop, } \\
\text { dairy) }\end{array}$ & 69 & $\begin{array}{c}.49 \\
{[.28, .66]}\end{array}$ & $<.001$ & 33 & $\begin{array}{c}.42 \\
{[.02, .71]}\end{array}$ & .016 \\
\hline Supermarket & 97 & $\begin{array}{c}.43 \\
{[.25, .57]}\end{array}$ & $<.001$ & 45 & $\begin{array}{c}.38 \\
{[.09, .60]}\end{array}$ & .001 \\
\hline Shopping mall & 129 & $\begin{array}{c}.42 \\
{[.25, .55]}\end{array}$ & $<.001$ & 68 & $\begin{array}{c}.22 \\
{[-.03, .43]}\end{array}$ & .073 \\
\hline Restaurant/Bar/Cafe & 114 & $\begin{array}{c}.41 \\
{[.27, .55]}\end{array}$ & $<.001$ & 59 & $\begin{array}{c}.17 \\
{[-.08, .42]}\end{array}$ & .189 \\
\hline Office & 49 & $\begin{array}{c}.29 \\
{[.01, .52]}\end{array}$ & .043 & 20 & $\begin{array}{c}-.08 \\
{[-.57, .42]}\end{array}$ & .724 \\
\hline
\end{tabular}

Note. Confidence Intervals appear in square brackets below Spearman's rho $\left(\mathrm{r}_{\mathrm{s}}\right)$. 


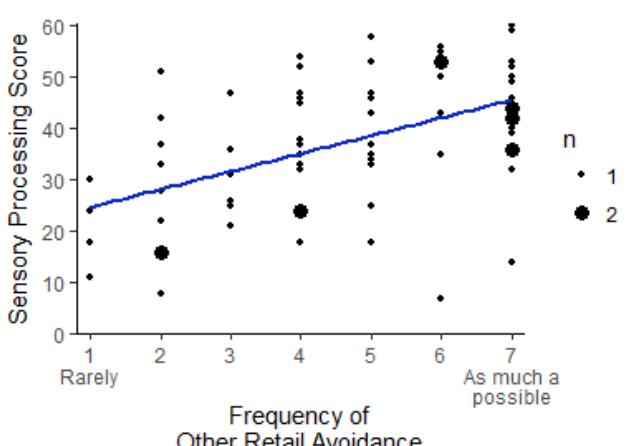

Other Retail Avoidance

Figure 87. Frequency of Avoidance of Other Retail Buildings vs Sensory Processing Score (all qualifying participants)

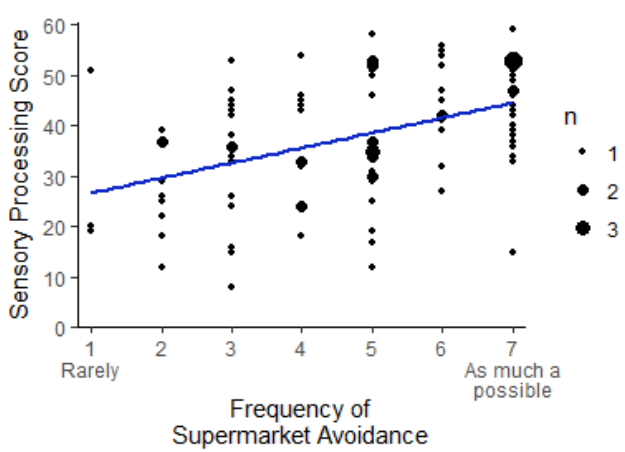

Figure 89. Frequency of Avoidance of Supermarket Buildings vs Sensory Processing Score (all qualifying participants)

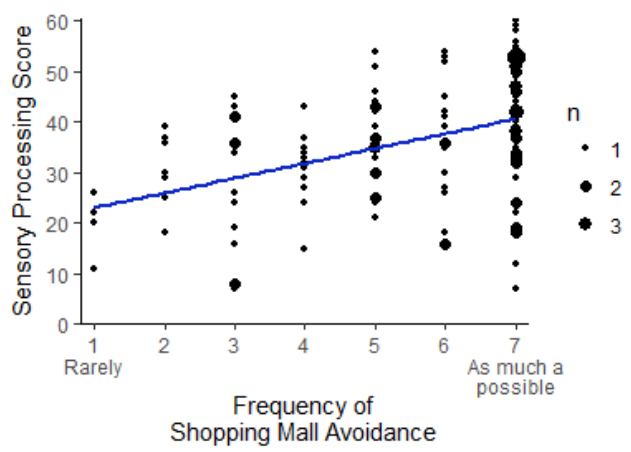

Figure 91. Frequency of Avoidance of Shopping Malls vs Sensory Processing Score (all qualifying participants)

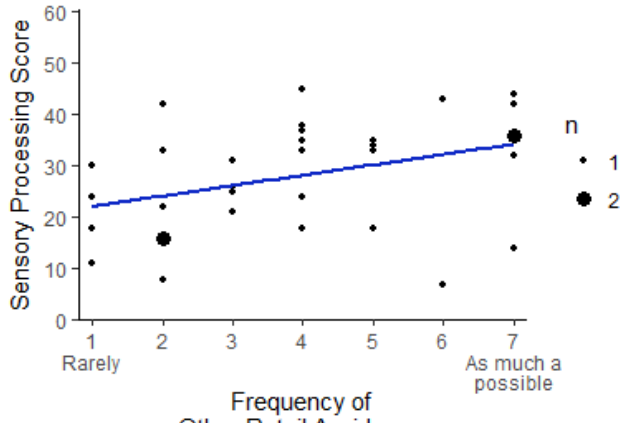

Other Retail Avoidance

Figure 88. Frequency of Avoidance of Other Retail Buildings vs Sensory Processing Score (excluding Autistic participants)

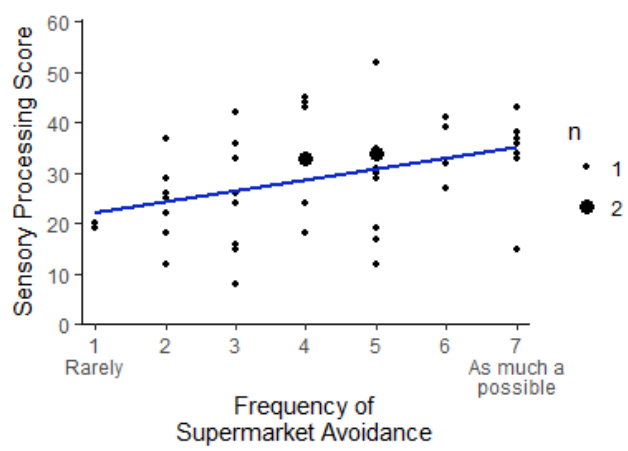

Figure 90. Frequency of Avoidance of Supermarket Buildings vs Sensory Processing Score (excluding Autistic participants)

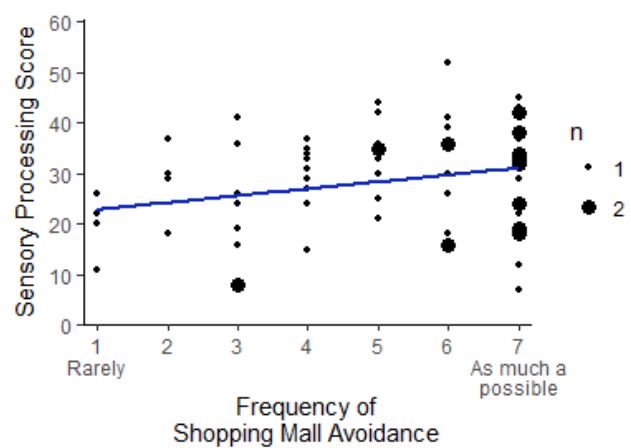

Figure 92. Frequency of Avoidance of Shopping Malls vs Sensory Processing Score (excluding Autistic participants) 


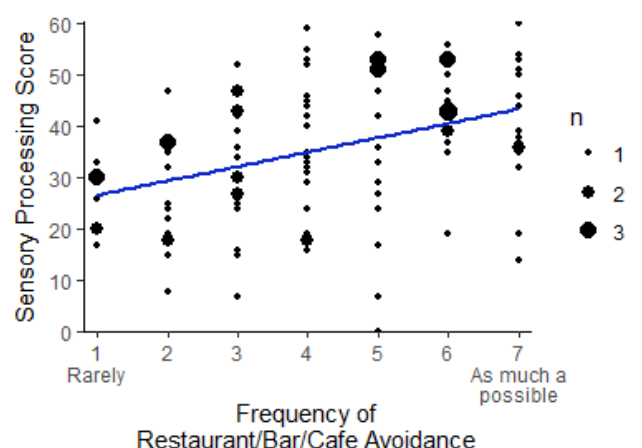

Figure 93. Frequency of Avoidance of Restaurant/Bar/Café Buildings vs Sensory Processing Score (all qualifying participants)

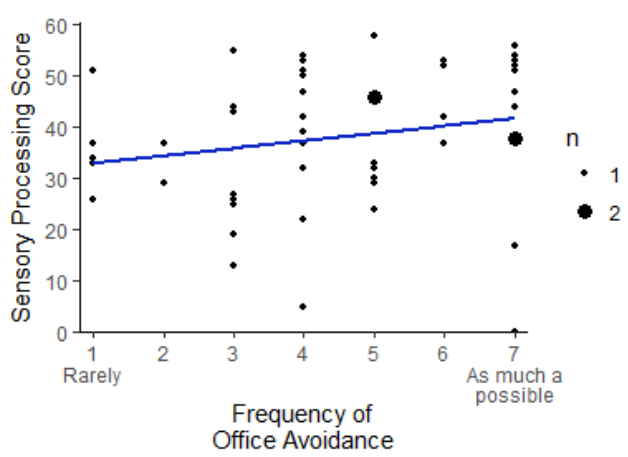

Figure 95. Frequency of Avoidance of Office Buildings vs Sensory Processing Score (all qualifying participants)

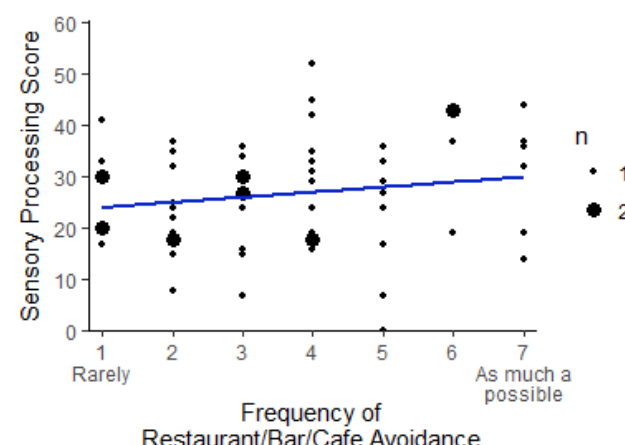

Figure 94. Frequency of Avoidance of Restaurant/Bar/Café Buildings vs Sensory Processing Score (excluding Autistic participants)

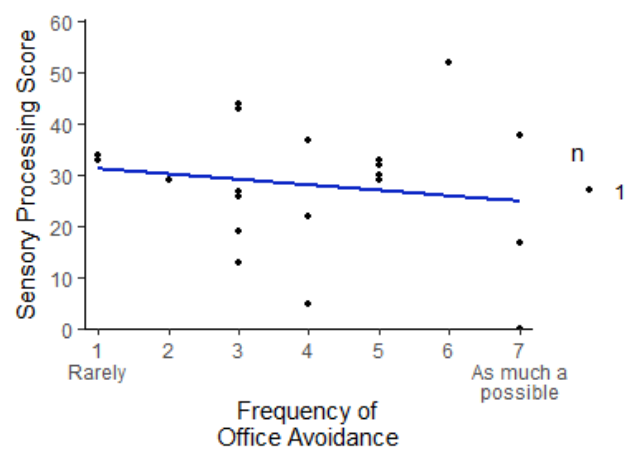

Figure 96. Frequency of Avoidance of Office Buildings vs Sensory Processing Score (excluding Autistic participants) 


\subsection{IEQ Factors}

\subsubsection{Home}

Twelve of the fourteen IEQ factors caused participants in the Autistic group significantly greater discomfort in the Home environment than participants in the Control group (Table 14). Overall, discomfort from all IEQ factors at home was generally low, with no medians in either group falling in the upper half of the scale. There was a much larger spread in responses in the Autistic group across all the IEQ factors, while most factors had only outliers or no responses in the upper end of the scale for the Control group (Figure 97 - Figure 109).

Table 14 Comparison by Condition of Level of Discomfort caused by 14 IEQ Factors at the Home

\begin{tabular}{|c|c|c|c|c|c|c|c|c|c|}
\hline \multirow[b]{2}{*}{ Factor } & \multicolumn{3}{|c|}{ Autistic } & \multicolumn{3}{|c|}{ Control } & \multirow{2}{*}{$\begin{array}{l}\text { median } \\
\text { difference }\end{array}$} & \multirow[b]{2}{*}{ U } & \multirow[b]{2}{*}{$\delta$} \\
\hline & $\mathrm{n}_{\mathrm{A}}$ & median & $\begin{array}{c}\text { mean } \\
\text { rank }\end{array}$ & $\mathrm{nc}_{\mathrm{c}}$ & median & $\begin{array}{c}\text { mean } \\
\text { rank }\end{array}$ & & & \\
\hline Temperature & 83 & $\begin{array}{c}3 \\
{[3,4]}\end{array}$ & 121 & 134 & $\begin{array}{c}3 \\
{[2,3]}\end{array}$ & 101 & $\begin{array}{c}1 \\
{[0,1]}\end{array}$ & $4996.0^{*}$ & $\begin{array}{c}-.19 \\
{[-.34,-.03]}\end{array}$ \\
\hline People Noise & 82 & $\begin{array}{c}4 \\
{[3,5]}\end{array}$ & 146 & 133 & $\begin{array}{c}1 \\
{[1,2]}\end{array}$ & 84 & $\begin{array}{c}2 \\
{[1,2]}\end{array}$ & $2326.5^{* * *}$ & $\begin{array}{c}-.57 \\
{[-.68,-.43]}\end{array}$ \\
\hline Indoor Noise & 81 & $\begin{array}{c}3 \\
{[2,3]}\end{array}$ & 140 & 133 & $\begin{array}{c}1 \\
{[1,1]}\end{array}$ & 88 & $\begin{array}{c}1 \\
{[1,2]}\end{array}$ & $2786.5^{* * *}$ & $\begin{array}{c}-.48 \\
{[-.61,-.34]}\end{array}$ \\
\hline Outdoor Noise & 82 & $\begin{array}{c}3 \\
{[3,4]}\end{array}$ & 136 & 131 & $\begin{array}{c}2 \\
{[2,2]}\end{array}$ & 89 & $\begin{array}{c}1 \\
{[1,2]}\end{array}$ & $2995.5^{* * *}$ & $\begin{array}{c}-.44 \\
{[-.57,-.29]}\end{array}$ \\
\hline People & 82 & $\begin{array}{c}2 \\
{[1,3]}\end{array}$ & 135 & 133 & $\begin{array}{c}1 \\
{[1,1]}\end{array}$ & 91 & $\begin{array}{c}1 \\
{[0,1]}\end{array}$ & $3257.0^{* * *}$ & $\begin{array}{c}-.40 \\
{[-.52,-.26]}\end{array}$ \\
\hline Glare & 83 & $\begin{array}{c}3 \\
{[2,4]}\end{array}$ & 134 & 133 & $\begin{array}{c}2 \\
{[1,2]}\end{array}$ & 92 & $\begin{array}{c}1 \\
{[1,2]}\end{array}$ & $3368.9 * * *$ & $\begin{array}{c}-.39 \\
{[-.52,-.24]}\end{array}$ \\
\hline Electric Light & 83 & $\begin{array}{c}3 \\
{[2,3]}\end{array}$ & 130 & 133 & $\begin{array}{c}2 \\
{[2,2]}\end{array}$ & 95 & {$\left[\begin{array}{c}1 \\
{[0,1]}\end{array}\right.$} & $3755.0^{* * *}$ & $\begin{array}{c}-.32 \\
{[-.46,-.18]}\end{array}$ \\
\hline Smells & 83 & $\begin{array}{c}3 \\
{[2,4]}\end{array}$ & 133 & 133 & $\begin{array}{c}2 \\
{[1,2]}\end{array}$ & 93 & $\begin{array}{c}1 \\
{[1,2]}\end{array}$ & $3446.0^{* * *}$ & $\begin{array}{c}-.38 \\
{[-.51,-.22]}\end{array}$ \\
\hline Air Quality & 83 & $\begin{array}{c}3 \\
{[2,3]}\end{array}$ & 132 & 133 & $\begin{array}{c}1 \\
{[1,2]}\end{array}$ & 94 & $\begin{array}{c}1 \\
{[0,1]}\end{array}$ & $3529.0^{* * *}$ & $\begin{array}{c}-.36 \\
{[-.49,-.21]}\end{array}$ \\
\hline Air Movement & 82 & $\begin{array}{c}2 \\
{[2,3]}\end{array}$ & 123 & 133 & $\begin{array}{c}2 \\
{[2,2]}\end{array}$ & 99 & $\begin{array}{c}0 \\
{[0,1]}\end{array}$ & $4209.5^{*}$ & $\begin{array}{c}-.23 \\
{[-.07,-.37]}\end{array}$ \\
\hline Privacy & 82 & $\begin{array}{c}2 \\
{[1,2]}\end{array}$ & 124 & 132 & $\begin{array}{c}1 \\
{[1,1]}\end{array}$ & 97 & $\begin{array}{c}1 \\
{[0,1]}\end{array}$ & $4022.5^{* * *}$ & $\begin{array}{c}-.26 \\
{[-.39,-.11]}\end{array}$ \\
\hline Natural Light & 83 & $\begin{array}{c}2 \\
{[1,2]}\end{array}$ & 131 & 133 & $\begin{array}{c}1 \\
{[1,1]}\end{array}$ & 94 & $\begin{array}{c}0 \\
{[0,1]}\end{array}$ & $3633.5^{* * *}$ & $\begin{array}{c}-.34 \\
{[-.47,-.20]}\end{array}$ \\
\hline Colour & 82 & $\begin{array}{c}1 \\
{[1,2]}\end{array}$ & 116 & 133 & $\begin{array}{c}1 \\
{[1,1]}\end{array}$ & 103 & $\begin{array}{c}0 \\
{[0,0]}\end{array}$ & 4783.5 & $\begin{array}{c}-.12 \\
{[-.25, .01]}\end{array}$ \\
\hline Layout & 83 & $\begin{array}{c}1 \\
{[0,2]}\end{array}$ & 102 & 134 & $\begin{array}{c}1 \\
{[1,2]}\end{array}$ & 113 & $\begin{array}{c}0 \\
{[-1,0]}\end{array}$ & 4965.0 & $\begin{array}{c}.11 \\
{[-.05, .26]}\end{array}$ \\
\hline
\end{tabular}

Note. ${ }^{*}=p<.05,{ }^{* * *}=p<.001$. Confidence Intervals appear in square brackets below the median, median difference, and Cliff's delta $(\delta)$. 
Temperature was the only factor that, relative to the other factors, caused large discomfort for both groups (Table 14). It was the only discomfort factor where responses from the Control group spread the entire scale (Figure 97). The small effect size is likely due to people in the Control group being more sensitive to discomfort from temperature than the other factors, while the Autistic group is equally as sensitive to temperature as other factors.

The noise-related factors had the highest differences, with People, Indoor, and Outdoor Noise having a large effect in causing greater discomfort in the home environment for the Autistic group compared to the Control group (Table 14). People Noise had the highest median for the Autistic group, while for both People and Indoor Noise over half of the Control group participants rated them as causing "No discomfort" (Figure 98 \& Figure 99). While Outdoor Noise affected the Autistic group participants similarly to the other two noise factors, the distribution of responses from the Control group participants was higher (Figure 100). On average, the Autistic group reported higher discomfort than the Control group due to people noise in $79 \%$ of cases, to indoor noise in $74 \%$ of cases, and to outdoor noise in $72 \%$ of cases (where $50 \%$ indicates no difference).

People had a medium-to-large effect in causing greater discomfort in the home environment for the Autistic group compared to the Control group (Table 14). All quartiles for the Control group fell at 1, which means that apart from the outliers, nearly all of the responses in the Control group reported "No discomfort" (Figure 101). Meanwhile, the Autistic group's responses spread the entire scale, with the fourth quartile falling at the higher end of the scale. On average, the Autistic group reported higher discomfort than the Control group due to people in $70 \%$ of cases.

Glare and Electric Light both had medium effects in causing greater discomfort in the home environment for the Autistic group compared to the Control group (Table 14). The Control group responses fell primarily at the lower end of the scale, with over a quarter reported "No discomfort" for both factors. On average, responses from the Autistic group were slightly higher for Glare than Electric Light, though the distributions of both factors were still higher than the Control group responses (Figure 102 \& Figure 103). On average, the Autistic group reported higher discomfort than the Control group due to electric light in $66 \%$ of cases, and to glare in $69 \%$ of cases

Smells and Air Quality also both had medium effects in causing greater discomfort in the home environment for the Autistic group compared to the Control group, with similar distributions of responses to Glare and Electric Light (Figure 104 \& Figure 105). However, for Air Quality the responses were lower for the Control group, with the first and second 
quartiles of the Control group both falling at 1 showing that at least half of the responses reported "No discomfort". On average, the Autistic group reported higher discomfort than the Control group to smells in $69 \%$ of cases, and to air quality in $68 \%$ of cases.

Air Movement and Privacy both had small effects in causing greater discomfort in the home environment for the Autistic group compared to the Control group (Table 14). While the medians for both groups were the same for Air Movement, the Autistic group reported a higher proportion of higher discomfort scores than the Control group (Figure 106 \& Figure 107). For both factors, nearly all Control group responses fell in the lower half of the scale, with only a few outliers in the upper end of the scale. At least a quarter of responses for the Autistic group fell in the upper end of the scale for both factors. On average, the Autistic group reported higher discomfort than the Control group due to air movement in $61 \%$ of cases, and to privacy in $64 \%$ of cases.

Compared to the other two lighting factors, both the Control and the Autistic group found Natural Light caused less discomfort, though there was still a medium effect (Table 14). All quartiles of the Control group fell at the " 1 ' anchor, with outliers at the other points, showing that nearly all the responses reported "No discomfort". The Autistic group responses fell primarily at the lower end of the scale (Figure 108). While there was a significant difference and medium effect between the groups, the overall level of discomfort caused by Natural Light is low. On average, the Autistic group reported higher discomfort than the Control group due to natural light in $67 \%$ of cases.

There was no statistically significant difference between the Autistic and Control groups in discomfort due to Colour at home ( $p=.075$ ) (Table 14). Both groups had a median of 1 , indicating most of the responses rated "No discomfort" (Figure 109). Colour was the only IEQ factor at home that has a median at the "No discomfort" anchor for the Autistic group

While the rest of the IEQ factors were asked on a discomfort scale, Layout was asked on a satisfaction agreement scale. On average, most participants rated that they were satisfied with the layout of the home environment, though at least a quarter were neutral or dissatisfied (Figure 110). The distribution of responses from both groups was the same and there was no statistically significant difference between the Autistic and Control groups in satisfaction with the home environment $(p=.176)$ (Table 14). 


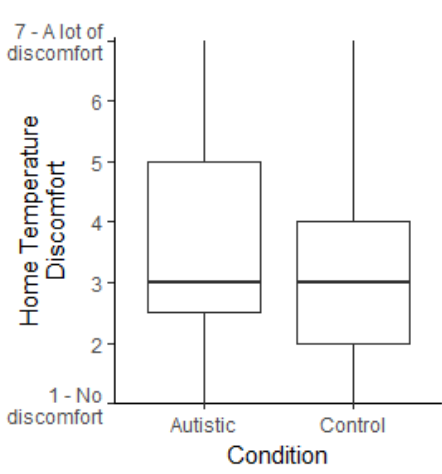

Figure 97. Home Temperature Discomfort by Condition

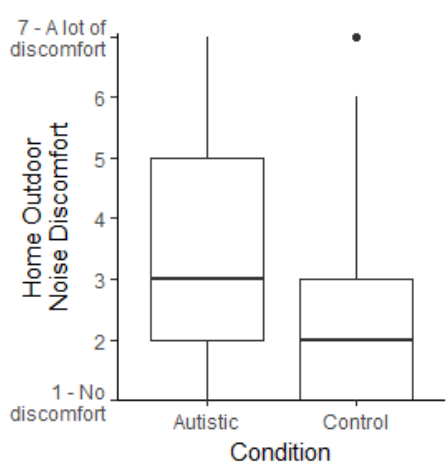

Figure 100. Home Outdoor Noise Discomfort by Condition

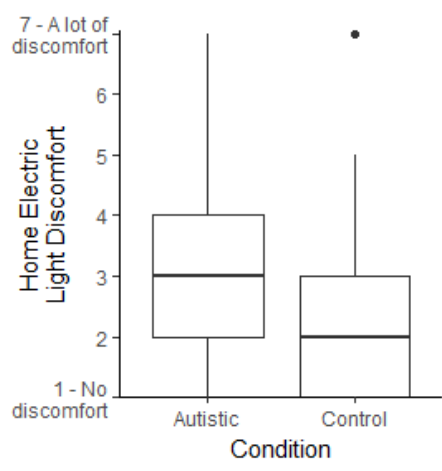

Figure 103. Home Electric Light Discomfort by Condition

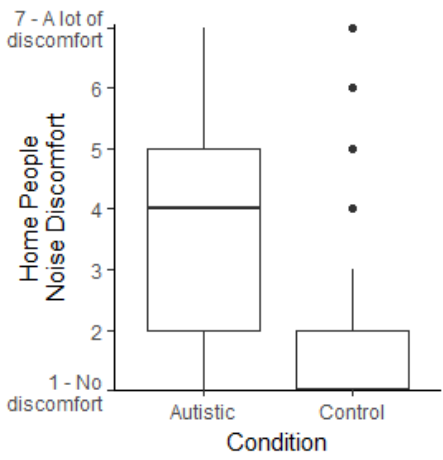

Figure 98. Home People Noise Discomfort by Condition

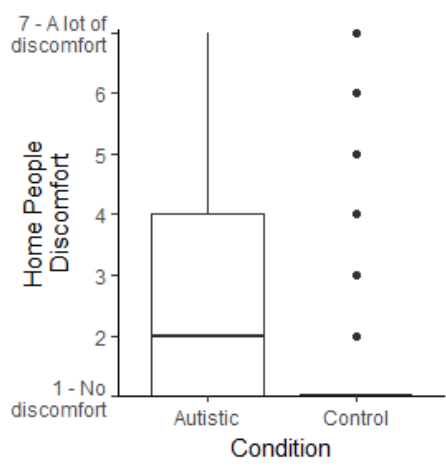

Figure 101. Home People Discomfort by Condition

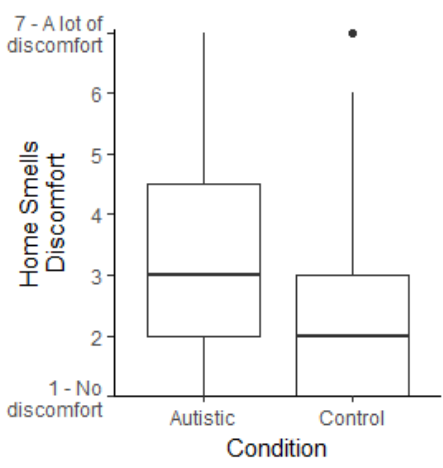

Figure 104. Home Smells Discomfort by Condition

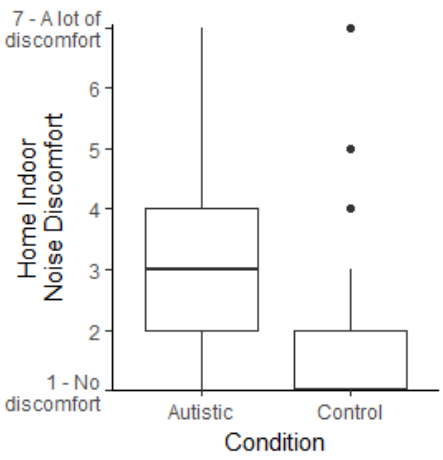

Figure 99. Home Indoor Noise Discomfort by Condition

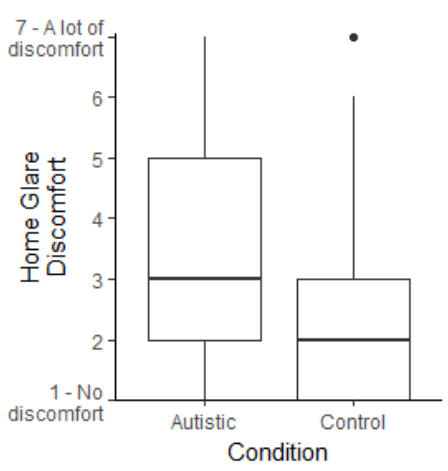

Figure 102. Home Glare Discomfort by Condition

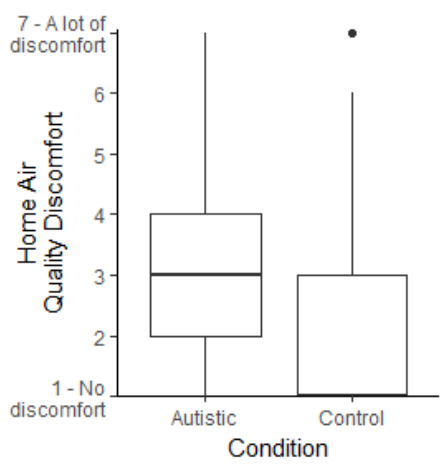

Figure 105. Home Air Quality Discomfort by Condition 


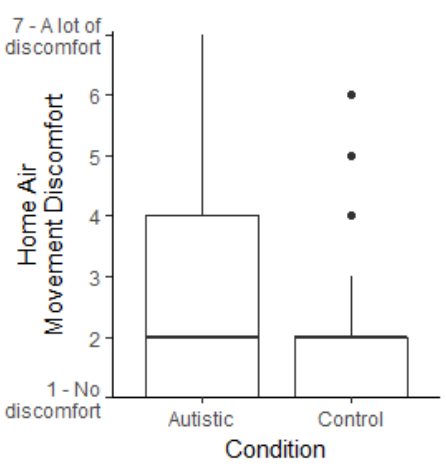

Figure 106. Home Air Movement Discomfort by Condition

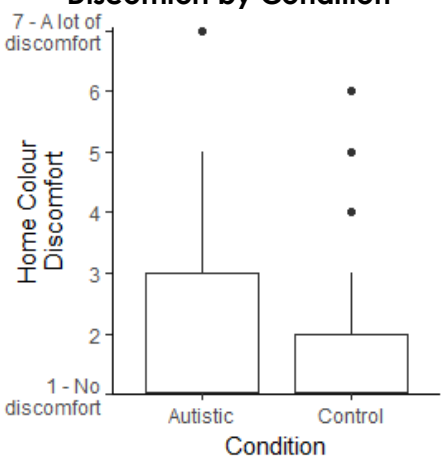

Figure 109. Home Colour Discomfort by Condition

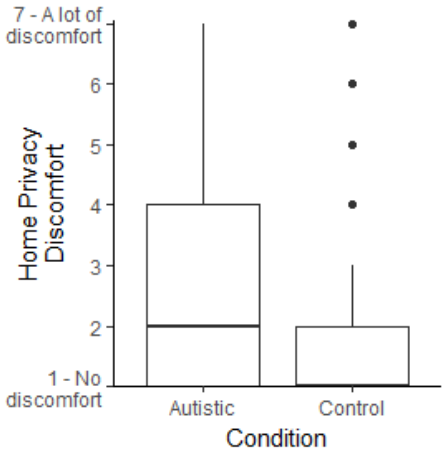

Figure 107. Home Privacy Discomfort by Condition

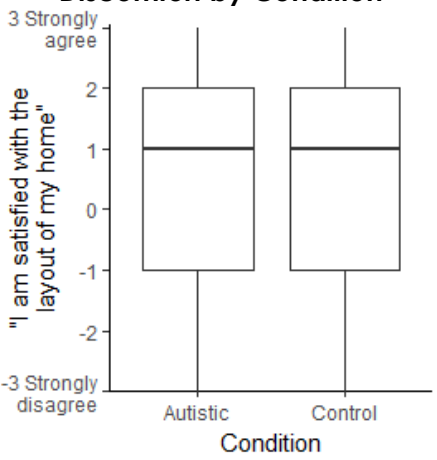

Figure 110. Home Layout Satisfaction by Condition

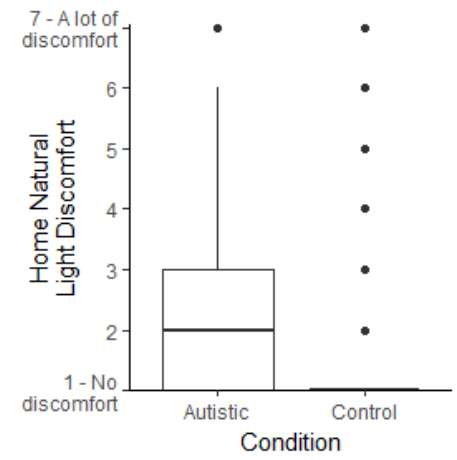

Figure 108. Home Natural Light Discomfort by Condition 


\subsubsection{Workplace}

Eight of the fourteen IEQ factors caused participants in the Autistic group significantly greater discomfort in the Workplace environment than participants in the Control group (Table 15). There was a lot of variance in the amount of discomfort caused by different IEQ factors, with a large spread in responses in both groups across most the IEQ factors.

Table 15

Comparison by Condition of Level of Discomfort caused by 13 IEQ Factors at the Workplace

\begin{tabular}{|c|c|c|c|c|c|c|c|c|c|}
\hline \multirow[b]{2}{*}{ Factor } & \multicolumn{3}{|c|}{ Autistic } & \multicolumn{3}{|c|}{ Control } & \multirow[b]{2}{*}{$\begin{array}{c}\text { Median } \\
\text { Difference }\end{array}$} & \multirow[b]{2}{*}{ U } & \multirow[b]{2}{*}{$\delta$} \\
\hline & $\mathrm{n}_{\mathrm{A}}$ & median & $\begin{array}{c}\text { mean } \\
\text { rank }\end{array}$ & $\mathrm{nc}$ & median & $\begin{array}{c}\text { mean } \\
\text { rank }\end{array}$ & & & \\
\hline People & 69 & $\begin{array}{c}5 \\
{[5,6]}\end{array}$ & 133 & 128 & $\begin{array}{c}2.5 \\
{[2,3]}\end{array}$ & 81 & $\begin{array}{c}2 \\
{[2,3]}\end{array}$ & $2087.0^{* * *}$ & $\begin{array}{c}-.53 \\
{[-.65,-.37]}\end{array}$ \\
\hline People Noise & 69 & $\begin{array}{c}5 \\
{[4,5]}\end{array}$ & 124 & 128 & $\begin{array}{c}3 \\
{[3,4]}\end{array}$ & 85 & $\begin{array}{c}1 \\
{[1,2]}\end{array}$ & $2663.5^{* * *}$ & $\begin{array}{c}-.40 \\
{[-.54,-.23]}\end{array}$ \\
\hline Indoor Noise & 69 & $\begin{array}{c}4 \\
{[4,5]}\end{array}$ & 120 & 128 & $\begin{array}{c}3 \\
{[2,3]}\end{array}$ & 88 & $\begin{array}{c}1 \\
{[1,2]}\end{array}$ & $2798.0^{* * *}$ & $\begin{array}{c}-.33 \\
{[-.48,-.15]}\end{array}$ \\
\hline Glare & 69 & $\begin{array}{c}4 \\
{[3,5]}\end{array}$ & 120 & 127 & $\begin{array}{c}2 \\
{[2,3]}\end{array}$ & 87 & $\begin{array}{c}1 \\
{[0,2]}\end{array}$ & $2928.0^{* * *}$ & $\begin{array}{c}-.33 \\
{[-.48,-.16]}\end{array}$ \\
\hline Electric Light & 70 & $\begin{array}{c}4 \\
{[4,5]}\end{array}$ & 119 & 129 & $\begin{array}{c}3 \\
{[2,4]}\end{array}$ & 90 & $\begin{array}{c}1 \\
{[0,2]}\end{array}$ & $3189.0^{* * *}$ & $\begin{array}{c}-.29 \\
{[-.44,-.13]}\end{array}$ \\
\hline Privacy & 69 & $\begin{array}{c}4 \\
{[4,5]}\end{array}$ & 117 & 128 & $\begin{array}{c}3 \\
{[3,4]}\end{array}$ & 89 & $\begin{array}{c}1 \\
{[0,2]}\end{array}$ & $3180.5^{*}$ & {$\left[\begin{array}{c}-.28 \\
{[-.44,-.11}\end{array}\right]$} \\
\hline Smells & 69 & $\begin{array}{c}3 \\
{[2,5]}\end{array}$ & 120 & 128 & $\begin{array}{c}2 \\
{[2,2]}\end{array}$ & 87 & $\begin{array}{c}1 \\
{[1,2]}\end{array}$ & $2934.5^{* * *}$ & $\begin{array}{c}-.33 \\
{[-.48,-.17]}\end{array}$ \\
\hline Colour & 68 & $\begin{array}{c}2 \\
{[2,3]}\end{array}$ & 113 & 127 & $\begin{array}{c}2 \\
{[1,2]}\end{array}$ & 90 & $\begin{array}{c}1 \\
{[0,1]}\end{array}$ & $3293.0^{*}$ & $\begin{array}{c}-.24 \\
{[-.39,-.07]}\end{array}$ \\
\hline Temperature & 69 & $\begin{array}{c}4 \\
{[3,5]}\end{array}$ & 104 & 129 & $\begin{array}{c}4 \\
{[3,4]}\end{array}$ & 97 & $\begin{array}{c}0 \\
{[0,1]}\end{array}$ & 4114.0 & $\begin{array}{c}-.07 \\
{[-.23, .10]}\end{array}$ \\
\hline Air Movement & 69 & $\begin{array}{c}3 \\
{[2,4]}\end{array}$ & 97 & 127 & $\begin{array}{c}3 \\
{[2,3]}\end{array}$ & 99 & $\begin{array}{c}0 \\
{[0,0]}\end{array}$ & 4301.0 & $\begin{array}{c}.02 \\
{[-.15, .18]}\end{array}$ \\
\hline Air Quality & 69 & $\begin{array}{c}3 \\
{[3,4]}\end{array}$ & 105 & 126 & $\begin{array}{c}3 \\
{[2,3]}\end{array}$ & 94 & $\begin{array}{c}0 \\
{[0,1]}\end{array}$ & 3856.0 & $\begin{array}{c}-.11 \\
{[-.27, .05]}\end{array}$ \\
\hline Outdoor Noise & 67 & $\begin{array}{c}2 \\
{[1,3]}\end{array}$ & 105 & 128 & $\begin{array}{c}2 \\
{[1,2]}\end{array}$ & 94 & $\begin{array}{c}0 \\
{[0,0]}\end{array}$ & 3791.5 & {$\left[\begin{array}{c}-.12 \\
{[-.27, .05]}\end{array}\right.$} \\
\hline Natural Light & 68 & $\begin{array}{c}2 \\
{[1,2]}\end{array}$ & 97 & 127 & $\begin{array}{c}2 \\
{[1,2]}\end{array}$ & 99 & $\begin{array}{c}0 \\
{[0,0]}\end{array}$ & 4247.5 & $\begin{array}{c}.01 \\
{[-.14, .17]}\end{array}$ \\
\hline Layout & 69 & $\begin{array}{c}0 \\
{[-1,0]}\end{array}$ & 101 & 129 & $\begin{array}{c}0 \\
{[-1,0]}\end{array}$ & 98 & $\begin{array}{c}0 \\
{[-1,0]}\end{array}$ & 4321.5 & $\begin{array}{c}.03 \\
{[-.14, .19]}\end{array}$ \\
\hline
\end{tabular}

Note. ${ }^{*}=p<.05,{ }^{* * *}=p<.001$. Confidence Intervals appear in square brackets below the median, median difference, and Cliff's delta $(\delta)$.

People had the largest effect in causing greater discomfort in the workplace environment for the Autistic group compared to the Control group, with the highest median for the Autistic group of all factors (Table 15). Three quarters of the Autistic group responded in the upper end of the scale, while three quarters of the Control group replied in the lower end of the scale (Figure 111). On average, the Autistic group 
reported higher discomfort than the Control group due to People in $76 \%$ of cases (where $50 \%$ indicates no difference).

People Noise and Indoor Noise had medium effects in causing greater discomfort in the workplace environment for the Autistic group compared to the Control group (Table 15). There was a large proportion of high answers from the Autistic group, while most of the Control group responses fell in the middle of the scale for both factors (Figure 112 \& Figure 113). On average, the Autistic group reported higher discomfort than the Control group due to People Noise in $70 \%$ of cases, and to Indoor Noise in $66 \%$ of cases.

Glare had a medium effect and Electric Light had a small-to-medium effect in causing greater discomfort in the workplace environment for the Autistic group compared to the Control group (Table 15). Responses from both groups spread the entire scale, but the second and third quartiles were higher for the Autistic group than the Control group (Figure 114 \& Figure 115). Compared to Glare, which had fewer high responses shown by the larger fourth quartiles for both groups, Electric Light had a smaller effect size due to the higher responses in the Control group. On average, the Autistic group reported higher discomfort than the Control group due to Electric Light in $65 \%$ of cases, and to Glare in $67 \%$ of cases.

Privacy had a small-to-medium effect in causing greater discomfort in the workplace environment for the Autistic group compared to the Control group, but was rated highly compared to most other factors for both (Table 15). The second and third quartiles of the Autistic group were large, indicating a large spread of responses, but the lack of fourth quartile also indicates at least a quarter of the responses indicated "A lot of discomfort" (Figure 116). On average, the Autistic group reported higher discomfort than the Control group due to Privacy in $64 \%$ of cases.

While the medians for both groups were the same, Colour had a small effect in causing greater discomfort in the workplace environment for the Autistic group compared to the Control group (Table 15). The Autistic group reported a higher proportion of higher discomfort scores for colour than the Control group with larger third and fourth quartiles (Figure 118). Smells had a medium effect, with a similar distribution of responses to Colour, though the Autistic group responses were higher (Table 15) (Figure 117). On average, the Autistic group reported higher discomfort than the Control group due to Colour in $62 \%$ of cases, and to Smells in $67 \%$ of cases.

There was no statistically significant difference between the Autistic and Control group respondents in discomfort due to Temperature $(p=.420)$, Air Movement $(p=.829)$ or Air Quality $(p=.185)$ in the workplace environment (Table 15). For all three factors, the 
medians and the distributions of the responses for both groups were the same or similar (Figure 119, Figure 120 \& Figure 121). As with the temperature factor at home, the lack of difference for temperature in the workplace environment was likely due to the higher discomfort experienced by the Control group. While there were no statistically significant differences between the groups, the three factors were rated reasonably highly compared to other IEQ factors in being a cause of discomfort.

Unlike the other two noise factors, there was no statistically significant difference between the Autistic and Control group respondents in discomfort due to Outdoor Noise in the workplace environment, with a negligible effect ( $p=.159$ ) (Table 15). The medians and the distributions of the responses for both groups were the same (Figure 122). There was also no statistically significant difference between the Autistic and Control group in discomfort due to Natural Light in the workplace environment ( $p=.844$ ) (Table 15). Again, the medians for both groups were the same, with similar distributions of responses (Figure 123).

While the rest of the IEQ factors were asked on discomfort scales, Layout was asked on a agreement scale. There was an equal spread of responses that were satisfied and dissatisfied with the layout of the workplace environment for both groups, with the medians both being neutral (Figure 124). There was no statistically significant difference between the Autistic and Control groups in satisfaction with the workplace environment $(p=.735)$ (Table 15) 


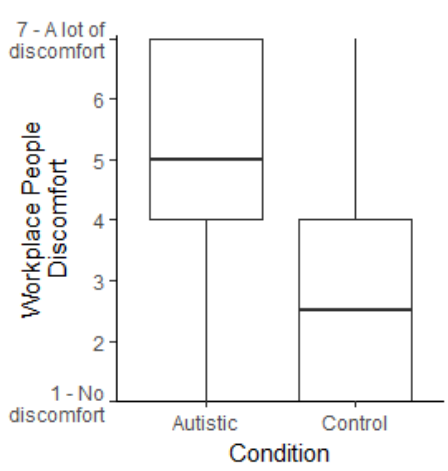

Figure 111. Workplace People Discomfort by Condition

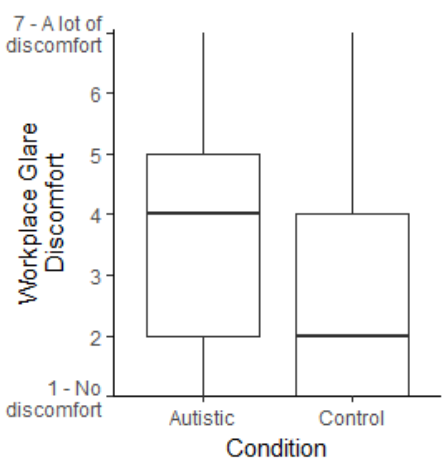

Figure 114. Workplace Glare Discomfort by Condition

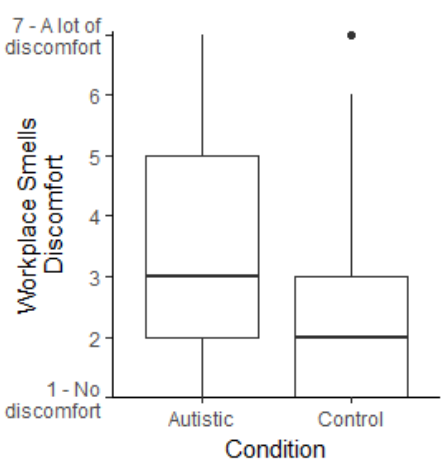

Figure 117. Workplace Smells Discomfort by Condition

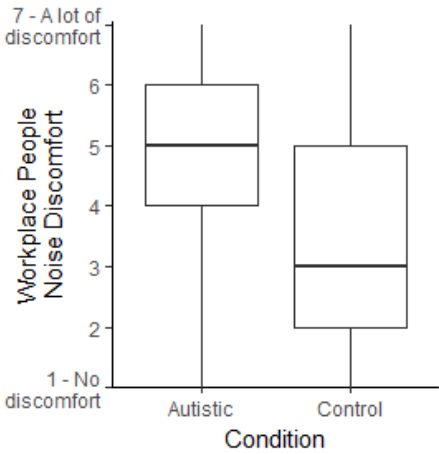

Figure 112. Workplace People Noise Discomfort by Condition

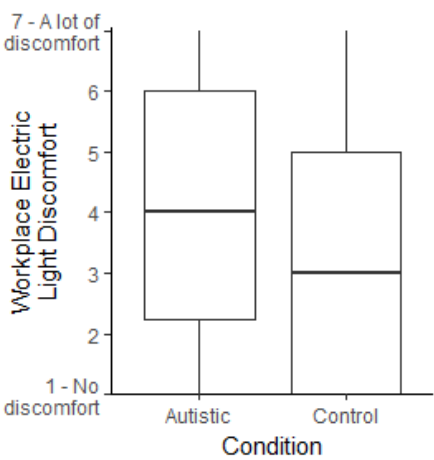

Figure 115. Workplace Electric Light Discomfort by Condition

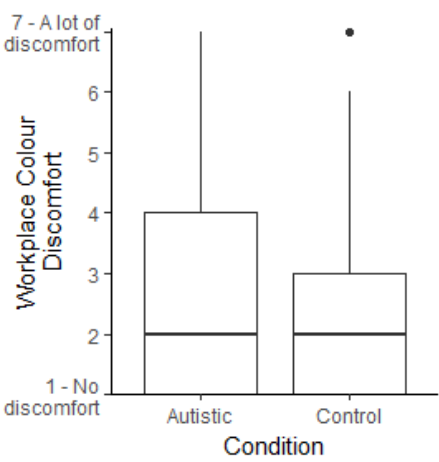

Figure 118. Workplace Colour Discomfort by Condition

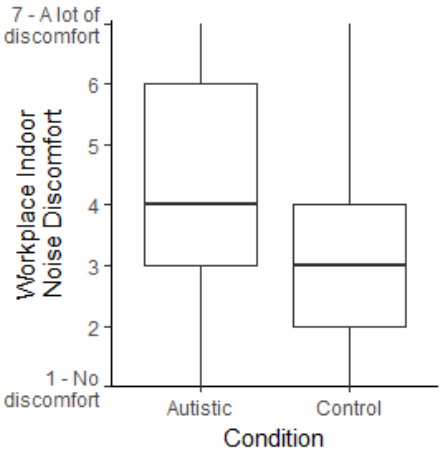

Figure 113. Workplace Indoor Noise Discomfort by Condition

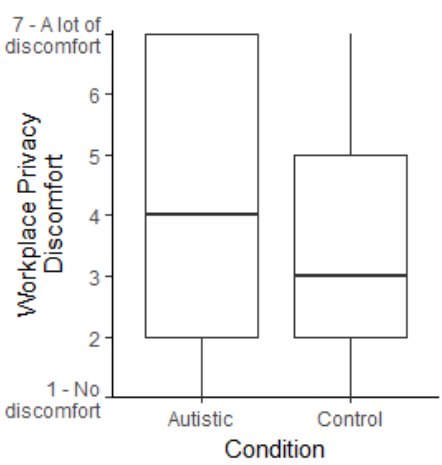

Figure 116. Workplace Privacy Discomfort by Condition

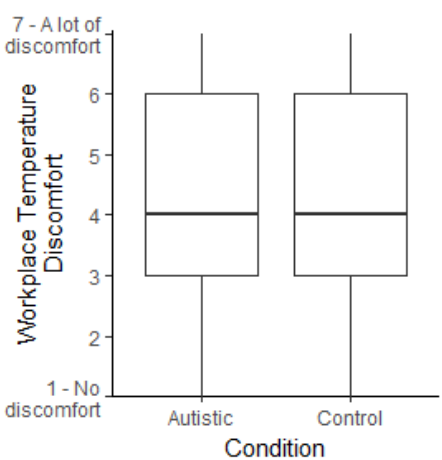

Figure 119. Workplace Temperature Discomfort by Condition 


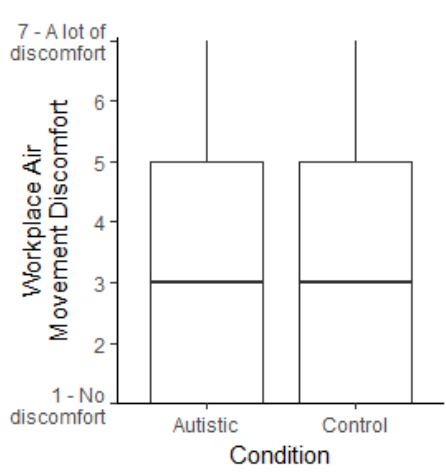

Figure 120. Workplace Air Movement Discomfort by Condition

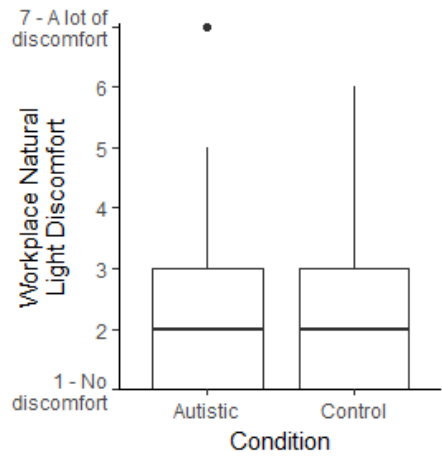

Figure 123. Workplace Natural Light Discomfort by Condition

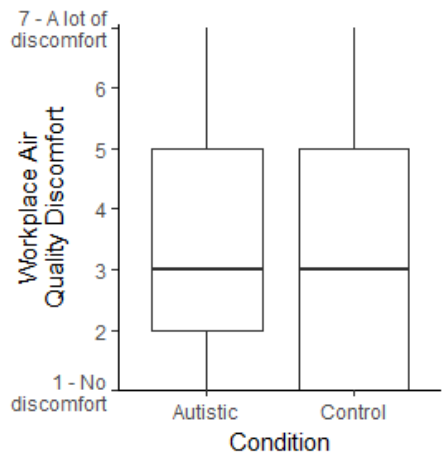

Figure 121. Workplace Air Quality Discomfort by Condition

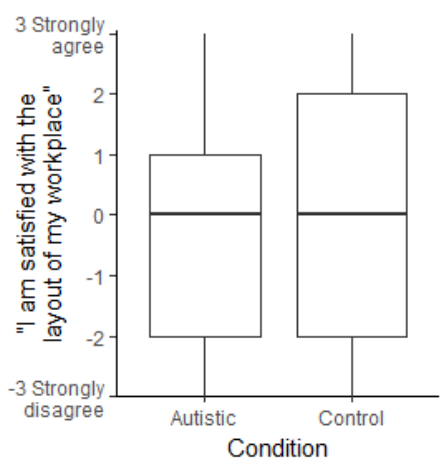

Figure 124. Workplace Layout Satisfaction by Condition

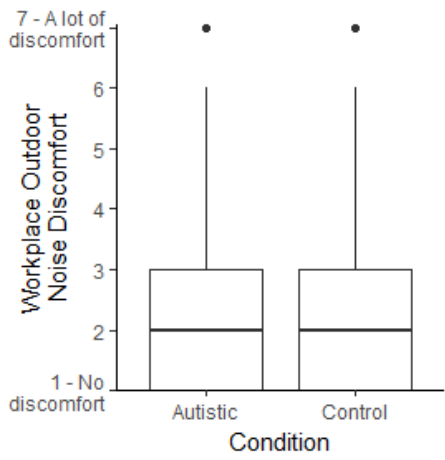

Figure 122. Workplace Outdoor Noise Discomfort by Condition 


\subsubsection{Avoidance}

While $93 \%$ of participants in the Autistic group qualified for this question, only $63 \%$ of participants in the Control group qualified; there was a much larger proportion of participants in the Control group who identified as both never having avoided buildings and as not wanting to avoid buildings in an ideal world. Of the people who identified that they do, or would like to, avoid buildings, nine out of the thirteen IEQ factors caused respondents from the Autistic group to want to avoid buildings significantly more frequently than the Control group respondents (Table 16).

Table 16

Avoidance caused by 13 IEQ Factors by Condition

\begin{tabular}{|c|c|c|c|c|c|c|c|c|c|}
\hline \multirow[b]{2}{*}{ Factor } & \multicolumn{3}{|c|}{ Autistic } & \multicolumn{3}{|c|}{ Control } & \multirow{2}{*}{$\begin{array}{l}\text { Median } \\
\text { Difference }\end{array}$} & \multirow[b]{2}{*}{ U } & \multirow[b]{2}{*}{$\delta$} \\
\hline & $\mathrm{n}_{\mathrm{A}}$ & median & $\begin{array}{c}\text { mean } \\
\text { rank }\end{array}$ & $\mathrm{n}_{\mathrm{c}}$ & median & $\begin{array}{l}\text { mean } \\
\text { rank }\end{array}$ & & & \\
\hline People & 77 & $\begin{array}{c}7 \\
{[7,7]}\end{array}$ & 99 & 84 & $\begin{array}{c}5 \\
{[5,6]}\end{array}$ & 65 & $\begin{array}{c}1 \\
{[0,2]}\end{array}$ & $1854.5^{* * *}$ & $\begin{array}{c}-.43 \\
{[-.56,-.27]}\end{array}$ \\
\hline People Noise & 77 & $\begin{array}{c}7 \\
{[6,7]}\end{array}$ & 97 & 85 & $\begin{array}{c}6 \\
{[5,6]}\end{array}$ & 68 & $\begin{array}{c}1 \\
{[0,1]}\end{array}$ & $2082.5^{* * *}$ & $\begin{array}{c}-.36 \\
{[-.51,-.20]}\end{array}$ \\
\hline Other Noise & 76 & $\begin{array}{c}5 \\
{[4,5]}\end{array}$ & 89 & 82 & $\begin{array}{c}4 \\
{[2,4]}\end{array}$ & 71 & $\begin{array}{c}1 \\
{[0,2]}\end{array}$ & $2392.0^{*}$ & $\begin{array}{c}-.23 \\
{[-.40,-.05]}\end{array}$ \\
\hline Glare & 76 & $\begin{array}{c}5 \\
{[4,5]}\end{array}$ & 96 & 82 & $\begin{array}{c}2 \\
{[2,3]}\end{array}$ & 64 & $\begin{array}{c}2 \\
{[1,2]}\end{array}$ & $1859.0^{* * *}$ & $\begin{array}{c}-.40 \\
{[-.55,-.23]}\end{array}$ \\
\hline Electric Light & 77 & $\begin{array}{c}5 \\
{[4,6]}\end{array}$ & 96 & 83 & $\begin{array}{c}4 \\
{[2,4]}\end{array}$ & 66 & $\begin{array}{c}1 \\
{[1,2]}\end{array}$ & $2014.5^{* * *}$ & $\begin{array}{c}-.37 \\
{[-.52,-.20]}\end{array}$ \\
\hline Colour & 75 & $\begin{array}{c}4 \\
{[2,4]}\end{array}$ & 94 & 83 & $\begin{array}{c}2 \\
{[2,2]}\end{array}$ & 67 & $\begin{array}{c}1 \\
{[0,2]}\end{array}$ & $2053.5^{* * *}$ & $\begin{array}{c}-.34 \\
{[-.50,-.17]}\end{array}$ \\
\hline Privacy & 77 & $\begin{array}{c}5 \\
{[5,6]}\end{array}$ & 92 & 84 & $\begin{array}{c}4 \\
{[3,5]}\end{array}$ & 70 & $\begin{array}{c}1 \\
{[0,2]}\end{array}$ & $2349.5^{*}$ & $\begin{array}{c}-.27 \\
{[-.43,-.10]}\end{array}$ \\
\hline Layout & 77 & $\begin{array}{c}5 \\
{[4,5]}\end{array}$ & 90 & 84 & $\begin{array}{c}4 \\
{[3,5]}\end{array}$ & 73 & $\begin{array}{c}1 \\
{[0,1]}\end{array}$ & $2556.0^{*}$ & $\begin{array}{c}-.21 \\
{[-.38,-.03]}\end{array}$ \\
\hline Smells & 77 & $\begin{array}{c}6 \\
{[5,7]}\end{array}$ & 85 & 85 & $\begin{array}{c}5 \\
{[5,6]}\end{array}$ & 78 & $\begin{array}{c}0 \\
{[0,1]}\end{array}$ & 3007.5 & $\begin{array}{c}-.08 \\
{[-.25, .09]}\end{array}$ \\
\hline Temperature & 76 & $\begin{array}{c}5 \\
{[4,6]}\end{array}$ & 74 & 84 & $\begin{array}{c}5 \\
{[5,6]}\end{array}$ & 86 & $\begin{array}{c}0 \\
{[-1,0]}\end{array}$ & 2696.5 & $\begin{array}{c}.16 \\
{[-.02, .32]}\end{array}$ \\
\hline Air Movement & 77 & $\begin{array}{c}3 \\
{[3,4]}\end{array}$ & 73 & 81 & $\begin{array}{c}4 \\
{[4,5]}\end{array}$ & 86 & $\begin{array}{c}-1 \\
{[-1,0]}\end{array}$ & 2630.0 & $\begin{array}{c}.16 \\
{[-.02, .33]}\end{array}$ \\
\hline Air Quality & 77 & $\begin{array}{c}5 \\
{[4,6]}\end{array}$ & 84 & 84 & $\begin{array}{c}5 \\
{[4,5]}\end{array}$ & 78 & $\begin{array}{c}0 \\
{[0,1]}\end{array}$ & 2983.5 & $\begin{array}{c}-.07 \\
{[-.25, .10]}\end{array}$ \\
\hline Natural Light & 74 & $\begin{array}{c}1 \\
{[1,2]}\end{array}$ & 85 & 81 & $\begin{array}{c}1 \\
{[1,1]}\end{array}$ & 72 & $\begin{array}{c}0 \\
{[0,0]}\end{array}$ & $2474.0^{*}$ & $\begin{array}{c}-.17 \\
{[-.33,-.01]}\end{array}$ \\
\hline
\end{tabular}

Note. $^{*}=p<.05,{ }^{* * *}=p<.001$. Confidence Intervals appear in square brackets below the median, median difference, and Cliff's delta $(\delta)$.

Overall, most of the IEQ factors were high causes of avoidance in the general built environment, with medians for both groups primarily falling in the middle and upper ends of the scale. Responses from both groups spread the scale for most IEQ factors. 
People had the largest effect between the Autistic and Control groups in being a cause of avoidance in the general built environment (Table 16). There was a clear difference in the distribution of responses between the groups. The Control group responses spread the entire scale, with one quarter falling in the lower half of the scale. Meanwhile, nearly all the Autistic group responses fell at ' 5 ' or above, with more than half falling at "A lot" and no responses falling at "Not at all" (Figure 125). On average, the Autistic group reported that People was a greater cause in them wanting to avoid buildings than the Control group in $71 \%$ of cases (where $50 \%$ indicates no difference between the groups).

People Noise had a medium effect between the Autistic and Control groups in being a cause of avoidance in the general built environment (Table 16). As with People, the responses from the Autistic group were high, grouped at the top of the scale with over half at "A lot", while the Control group responses were also high with three quarters of responses falling at the higher end of the scale (Figure 126). The smaller effect size is likely due to higher responses in the Control group. Other Noise had a small effect, with responses from both groups being lower overall when compared to People Noise (Table 16). The distribution of both the Autistic and Control group responses was more even across the scale (Figure 127). On average, the Autistic group reported that People Noise was a greater cause in them wanting to avoid buildings than the Control group in $68 \%$ of cases, and Other Noise in $62 \%$ of cases.

Glare had a medium-to-large large effect and Electric Light had a medium effect in being a greater cause of avoidance in the general built environment for the Autistic group compared to the Control group (Table 16). For Glare, the second and third quartiles of the Autistic group were large, indicating a large spread of responses, but the lack of fourth quartile also indicated at least a quarter of the responses indicated "A lot of discomfort" (Figure 128). The distribution of responses for Electric Light were slightly lower in the Autistic group compared to Glare, though three quarters of the Autistic group responses were in the higher end of the scale (Figure 129). While the median for the Autistic group was the same for both Glare and Electric Light, the Control group median for Glare was much lower, which was the cause of the larger effect size. On average, the Autistic group reported that Glare was a greater cause in them wanting to avoid buildings than the Control group in $70 \%$ of cases, and Electric Light in $68 \%$ of cases.

While Colour had a medium effect in being a greater cause of avoidance in the general built environment for the Autistic group compared to the Control group, both groups had lower medians compared to most other IEQ factors (Table 16). The Control group responses were primarily low, with only the fourth quartile falling in the middle of the scale, while the Autistic group responses fell primarily in the middle of the scale (Figure 
130). On average, the Autistic group reported that Colour was a greater cause in them wanting to avoid buildings than the Control group in $67 \%$ of cases.

Privacy had a small-to-medium effect and Layout had a small effect between the Autistic and Control groups in being a cause of avoidance in the general built environment (Table 16). The distribution of Privacy responses in the Autistic group is similar to the Glare factor, with a large spread across the scale, while responses from the Control group are lower (Figure 131). For Layout, the distribution of Control group responses was similar to the Privacy factor, but the Autistic group responses were slightly lower with fewer high answers (Figure 132). On average, the Autistic group reported that Privacy was a greater cause in them wanting to avoid buildings than the Control group in $64 \%$ of cases.

There was no statistically significant difference in in how much participants wanted to avoid buildings between the Autistic and Control group respondents due to Air Movement $(p=.086)$, Smells $(p=.359)$, Air Quality $(p=.390)$ or Temperature $(p=.086)$ (Table 16). The distributions of the Autistic and Control groups for all four factors were similar, with only minor differences between medians and quartile boundaries (Figure 133 - Figure 136). The lack of difference between the two groups was due to higher responses from the Control group for these four factors, with both Temperature and Smells being particularly high causes of avoidance in the general built environment for both groups. For both Air Movement and Temperature, the Control group responses were higher than the Autistic group, which was unusual compared to all other IEQ factors (Figure 134 \& Figure 135).

While Natural Light had a small effect between the Autistic and Control groups, over half of the responses in both groups were "Not at all" (Table 16). Therefore, while there was a significant difference between the two groups, the difference was not meaningful, being the only IEQ factor that has a median of 1 for both groups (Figure 137). 


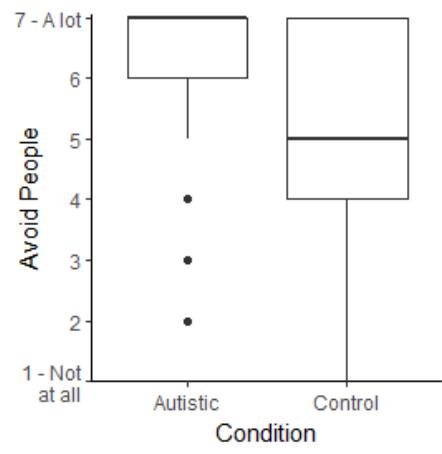

Figure 125. Avoidance as a result of People by Condition

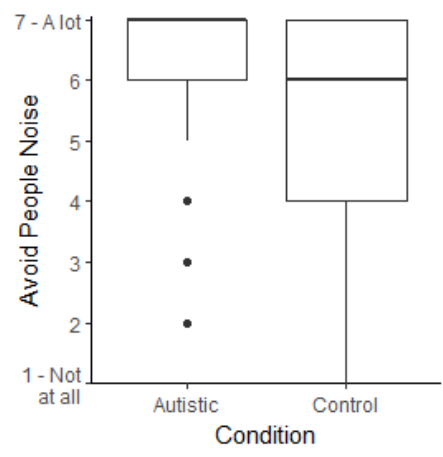

Figure 126. Avoidance as a result of People Noise by Condition

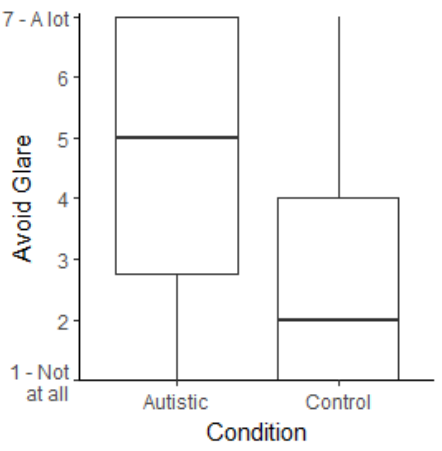

Figure 129. Avoidance as a result of Electric Light by Condition

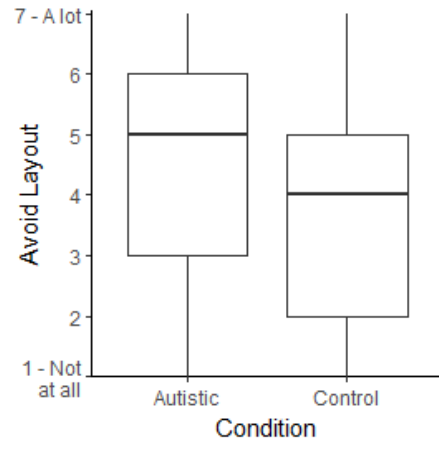

Figure 132. Avoidance as a result of Layout by Condition

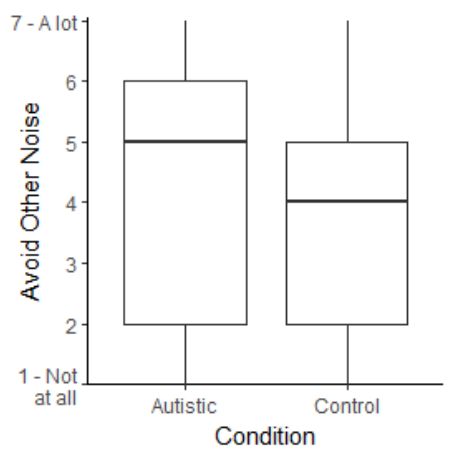

Figure 127. Avoidance as a result of Other Noise by Condition

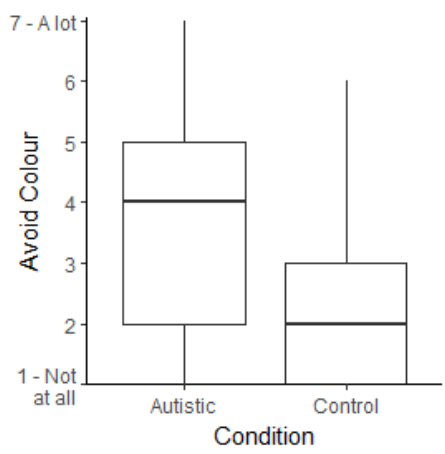

Figure 130. Avoidance as a result of Colour by Condition

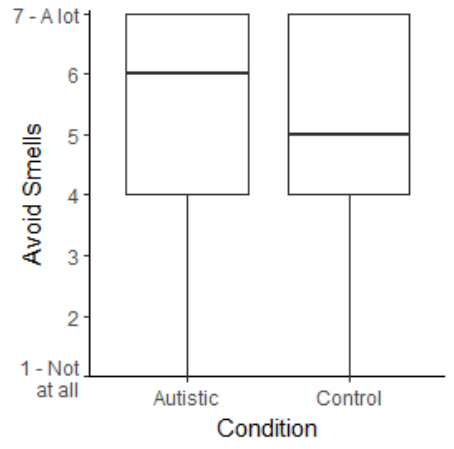

Figure 133. Avoidance as a result of Smells by Condition 


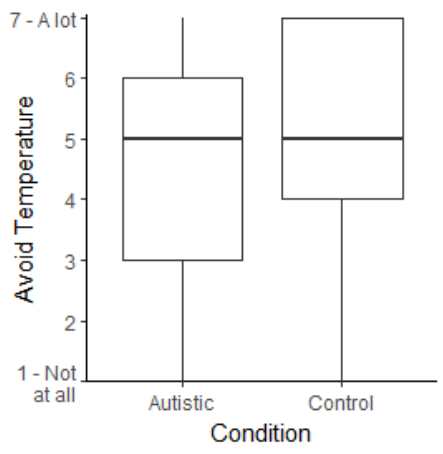

Figure 134. Avoidance as a result of Temperature by Condition

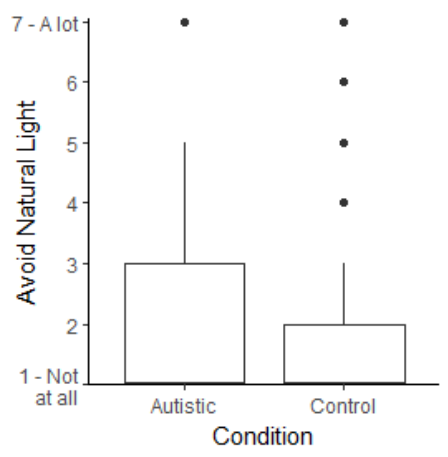

Figure 137. Avoidance as a result of Natural Light by Condition

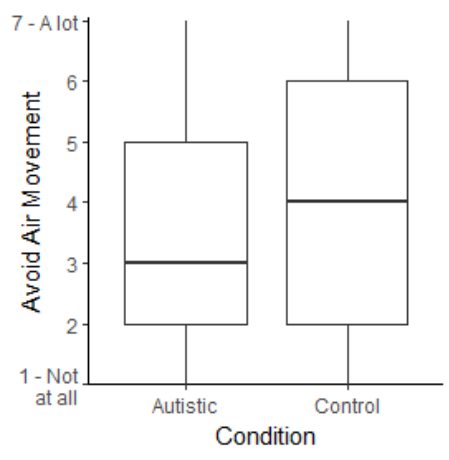

Figure 135. Avoidance as a result of Air Movement by Condition

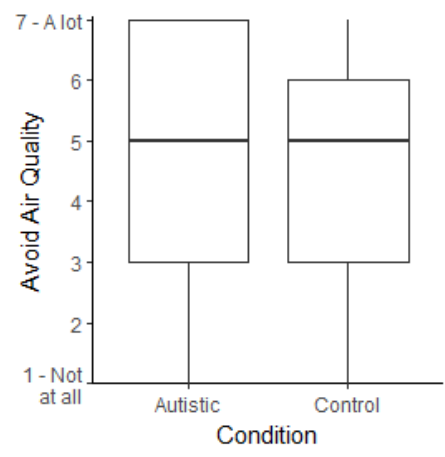

Figure 136. Avoidance as a result of Air Quality by Condition 


\section{Discussion}

This research investigated the role of sensory sensitivity in people's perception of the effects of the built environment, particularly for people on the autism spectrum. Three main aims were identified for investigation (Section 1.2): whether the adverse effects of the indoor environment were exacerbated in people on the autism spectrum; whether there was a pattern in which IEQ factors had the greatest effects; and whether there was a wider relationship between sensory sensitivity and the effects of the indoor environment. Chapter 0 addresses these three aims, as well as the limitations of this study and potential for further research.

\subsection{Question 1: Greater Adverse Effects for Autistic People}

The study first investigated whether there was a difference in sensory processing between people on the autism spectrum and neurotypical people. People on the autism spectrum reported higher Sensory Processing Scores than neurotypical people with a statistically significant median difference spanning a third of the scale. This is consistent with the findings of Crane, Goddard \& Pring (2009), where scores were significantly higher in people on the autism spectrum in the sensory sensitivity and sensation avoidance quadrants of the Adult/Adolescent Sensory Profile, which the current survey section was modelled on. The difference in sensory processing are also consistent with other studies, though was not directly comparable due to different scaling systems (Adamson et al., 2006; W. Dunn et al., 2002; Kern et al., 2006; Kientz \& Dunn, 1997; Leekham et al., 2007; Minshew \& Hobson, 2008; Tomchek \& Dunn, 2007).

Based on this finding, the Autistic group in this study is considered to be representative of the differences in sensory processing found across people on the autism spectrum regardless of age or IQ level. The large difference in sensory processing score between people in the Autistic and Control groups means that the two groups are representative of their populations. While this study is limited to self-selected people on the autism spectrum who are able to use written communication to complete the survey, it is likely that many of the findings will be generalisable to people on the autism spectrum who are much younger or have an intellectual impairment preventing them from participating in this study.

\subsubsection{Home and Workplace}

Overall comfort is considered the most important factor in indoor environment satisfaction (Leaman \& Bordass, 2007). However, this research showed that people on the autism spectrum reported, overall, feeling less comfortable at both their home and their 
workplace than the Control group. This difference was significant, although the effect size for both home and workplace were small-to-medium. Therefore, in general, people on the autism spectrum were likely to be less comfortable in any environment.

One sixth of the Autistic group did not complete the Workplace section. There could potentially have been a larger effect size for the workplace if there was a higher completion rate for the section from the Autistic group. The low rate of completion of the Workplace section among the Autistic group is likely due to the low employment rates within the Autism Community. In this study, $55 \%$ of people on the autism spectrum reported being in some kind of paid employment or self-employment, with $25 \%$ being in full-time paid employment, which is higher than the $16 \%$ found by the National Autistic Society (NAS) (2016a). It is likely that the higher employment rate in this study is due to this survey being limited to those who were able to complete the survey themselves, while the NAS study also allowed others to respond on behalf of people on the autism spectrum. However, the Autistic group employment rate is still much lower than the employment rates for the Control group, where $85 \%$ of people reported being in some kind of paid employment or self-employment, with $60 \%$ being in full-time paid employment.

As well as the direct questions about overall comfort, the overall IEQ discomfort also showed significant differences between the Autistic and Control group, with higher effect sizes for both home and workplace, which is likely the result of differences in sensory processing. People on the autism spectrum reported feeling both less comfortable and more discomfort in both their home and workplace. Overall comfort and IEQ sum discomfort were significantly more highly correlated at workplace than at home. People could be more likely to think of their home as "comfortable", but when presented with a list of IEQ factors realise they feel discomfort from one or more of them.

Also, as the Home section was presented before the Workplace section in the survey, participants may have answered the question with reference to other or previous items. Participants may have rated discomfort for individual IEQ factors higher than they would have if Home was not the first section. Participants could also have different expectations of what they define as discomfort in their home environment compared to their workplaces and rated each scale accordingly. If the survey were repeated, with some participants being given the Home section first and others being given the Workplace section first, this could show whether the effect is due to question order.

An additional question of interest was whether neurotypical people and people on the autism spectrum would report a similar level of comfort at home, but that people on the 
autism spectrum would report a much lower comfort at their workplace than neurotypical people. However, the results suggest people on the autism spectrum found both their homes and workplaces less comfortable than neurotypical people, with the decrease for both groups being about the same.

The result that the Autistic group found their homes less comfortable compared to the Control group was unexpected. While the effect is small, people spend a significant amount of time within their homes, so even a slight reduction in comfort could have large effects on health and well-being. This is supported by the psychological factors analysis, where people on the autism spectrum felt more overwhelmed, more stressed/anxious, and less safe than neurotypical people at both home and their workplace. Across all three psychological factors, the responses from the Autistic group at home were comparable to the responses from the Control group at work. Therefore, thinking about the amount of stress/anxiety, safety and sensory overwhelm an average person feels in the workplace, is how a person on the autism spectrum is likely to feel at home.

Comfort is strongly linked to productivity (Fisk \& Rosenfeld, 1997; Lamb \& Kwok, 2016; Wyon \& Wargocki, 2013). It is likely that people on the autism spectrum, who are already often disadvantaged by social and communication difficulties, are being affected further by indoor environments that they experience much more strongly than the average person. In the workplace, it is possible that indoor environments that are much more uncomfortable, stressful, and overwhelming could be contributing to the lower employment rate in people on the autism spectrum. This could be a combination of direct impacts on sensory overload and also cognitive and productivity effects impacting on existing other areas of difficulty. Therefore, these environments are likely discriminatory towards people on the autism spectrum who have differences in sensory processing, favouring those who are less sensitive to sensory information and conceivably perpetuating the difficulties people on the autism spectrum already face. While productivity has primarily been studied in the workplace, it has been shown that the home environment also has a larger effect on people on the autism spectrum as well, so a future investigation into whether the effects have an impact on areas such as executive planning and organisation in the home as well would be warranted.

\subsubsection{Control}

Across all 276 participants in the study, overall comfort was correlated to control over the indoor environment, which is consistent with earlier studies (Brager et al., 2004; Moore et al., 2002; Newsham et al., 2004). While studies about environmental control have primarily 
been performed in office workspaces, the correlation was found at both home and the workplace in this study.

The correlation between comfort and control was stronger at home than at the workplace. It is possible that people expect to have higher control over their environments at home, but an expectation of lack of control at their workplaces. Therefore, perceived level of control has a greater effect where people expect both to be more comfortable and have more control. People on the autism spectrum felt significantly less control at home, but the same lack of control at their workplace when compared to neurotypical people. This could be because a higher proportion of the Autistic group rented their home as opposed to owning it, with a higher unemployment rate likely meaning lower incomes and therefore possibly lower quality of housing. In New Zealand, the average income of a disabled person is just over half that of a non-disabled person, $\$ 458$ per week compared to $\$ 833$ per week, "from all sources, such as government transfers (e.g. benefits, income support, tax credits), wages and salaries, and self-employment" (Statistics NZ, 2017). There was also a number of participants in the Autistic group who commented that they lived with their parents, and were thus classified as renting in this research. Across all participants, people felt less control over their home if they rented it when compared to those who owned their own homes.

People on the autism spectrum were equally likely to report having made permanent changes to their home environment as neurotypical people, which was unexpected as it was hypothesised that more people on the autism spectrum would make changes to their environments. This is likely influenced again by a much higher proportion of the Autistic group renting, as the odds of people who owned their home reporting making permanent changes were 2.9 times greater than the odds of those who rented. When looking only at the participants who rented their homes, the odds of people on the autism spectrum making permanent changes to their rented homes was 3 times greater.

In combination, people on the autism spectrum who rented still reported feeling less in control over their home environments even though they were more likely to make permanent changes to their rented homes. Further, the odds of people on the autism spectrum reporting wanting to make changes to their home environment was 2 times greater than neurotypical people whether they owned or rented. This lack of control and desire to make changes is likely to be affecting the lower overall comfort of people in the autism spectrum in their homes.

The result that people on the autism spectrum were not more likely to report having either requested or wanted to request changes to their workplace was unexpected, as a large 
proportion of participants in both groups had actively requested that changes be made to their workplace. The lack of difference in perceived control is likely due to a larger proportion of the Control group having answered to having low control, with over three quarters of all participants rating that they had very little or no control at all. Perceived lack of control was a universal problem among all participants.

\subsubsection{Discomfort and Distress in Other Buildings}

Neurotypical people reported feeling discomfort in various building types much less often than people on the autism spectrum, despite people on the autism spectrum using many of the building types significantly less frequently. Tertiary Education Centres were the only building type that did not have a significant difference between the Autistic and Control groups, although as it still had a medium effect this is possibly due to a too small sample size than there truly being no difference.

Shopping malls, supermarkets and medical buildings had the largest effect between people on the autism spectrum and neurotypical people. As people require food to eat, they generally use their local supermarkets to obtain their groceries. However, supermarkets had the highest median frequency of discomfort both in the autistic and control groups, as well as large effects between groups. Therefore, in the simple task of having to buy groceries, the indoor environment is often having a negative effect on all people, but particularly those on the autism spectrum. Likewise, medical buildings also had a particularly large effect, but are also another essential building that people must use to maintain their health.

Shopping Malls are not necessarily an essential environment, as smaller retail options also provide opportunities to meet material needs. However, Other Retail buildings only had a slightly smaller effect size than Shopping Malls. Therefore, as well as more frequent discomfort while getting groceries, people on the autism spectrum are likewise affected while meeting other material needs. Restaurants, Bars and Café's provide opportunities for socialisation and food, but also have a similarly large effect size.

Office buildings had a medium-to-large effect size, which is important when considering employment opportunities. It is estimated that at least $50 \%$ of the working population in America, Japan and northern European countries work in office spaces (Conway, 2017). While data are not available for the New Zealand workforce, it is likely that there is a similar proportion of office workers in our workforce. Given the high unemployment rates within the Autism Community, both published and within this study, it is possible that greater discomfort in office spaces could be having an impact on people on the autism 
spectrum holding employment. Again, this effect is likely to have a direct impact of feeling more uncomfortable, but also be affecting productivity and possibly exacerbating difficulties with social communication with co-workers and employers.

Smaller effects were seen in Arts and Community buildings. Unlike many of the other building types, these buildings could be classified as 'optional'. While Arts and Community buildings are important for cultural pursuits and happiness, they do not provide life essentials in the same way people require groceries or some material needs. Therefore, people have more ability to choose when they visit these buildings. Knowing that greater control is correlated to greater comfort, it is likely that people feel greater control over the choice to use these buildings, and therefore feel less discomfort.

While discomfort was measured on a frequency scale ("how often?"), distress was measured on a quantity scale ("typically how much?"). Across the six building types that were analysed, discomfort and distress were strongly correlated. However, frequency of discomfort and level of distress was much more strongly correlated for people on the autism spectrum than neurotypical people. All correlations were consistently strong for all building types within the Autistic group, while the correlations varied from weak to strong for different building types within the Control group.

Nearly $90 \%$ the Autistic group reported they felt discomfort frequently enough for the survey to ask them about distress in at least one building type, compared to about $70 \%$ of the Control group. Therefore, particularly for those not on the autism spectrum, only those who were most sensitive to feeling regular discomfort were asked. As well as a higher proportion being asked about distress, people on the autism spectrum also each rated more types of buildings for distress than neurotypical people, due to having high discomfort across multiple building types.

The buildings analysed were limited to six building types that were most commonly used by all participants. While Arts buildings were used more frequently than Medical buildings, few participants rated high enough discomfort to be asked about distress to include them. Six building types could be classified as 'essential': Office buildings for employment; Medical to maintain health; Supermarkets for groceries; Shopping Malls or Other Retail to meet material needs; and Restaurant/Bar/Café buildings for socialisation.

Distress had a much larger effect on people on the autism spectrum compared to neurotypical people, with the median distress for all building types falling in the upper end of the scale for the Autistic group. People on the autism spectrum are feeling high levels of stress, to the point of physical reactions, in buildings that all people are required to use regularly. Given the emerging research on early mortality and poor health in 
people on the autism spectrum (Cusack et al., 2016; Hirvikoski et al., 2016), this research suggests that people on the autism spectrum are likely exposed to higher than typical base-line levels of stress, when the built environment alone is causing such adverse effects.

All people feel discomfort on a continuum, where small or infrequent levels of discomfort are usually seen as a typical experience, while higher or regular levels are of concern. However, distress was designed to measure further on the continuum than even high discomfort, measuring the severe responses to the built environment. For this study, distress was defined as "physical and/or psychological reactions such as anxiety, elevated heart rate, sweaty palms, etc." No established scales for measuring adverse effects greater than discomfort or reduced productivity due to the built environment could be found while designing the survey. In the psychology field, the closest scales would be panic disorder scales, which measure the effects of panic attacks on people (Shear et al., 1997). These scales have similar physical reactions as distress was defined as having in this study. Moving forward, development of more robust measures of the adverse effects of the built environment would assist in further clarifying the issues faced by people on the autism spectrum.

While IEQ surveys commonly ask participants about comfort and satisfaction with the indoor environments they assess, study of the adverse effects of indoor environments is generally limited to reduced productivity and well-being. The scales used in this study assessing distress and avoidance of the general built environment are untested and are therefore limited, although have shown some important information about the potential of different ways of measuring other adverse effects of the built environment.

To understand these increased effects, consider a trip to the dentist's office. For a neurotypical person, this is usually a stressful and painful exercise, and causes anxiety for many people. However, for a person on the autism spectrum, these experiences are compounded. From the moment they walk in the door to the practice, the scent of antiseptic is overpowering. Noise can be heard from other offices in the same practice. Bright lights are pointed directly overhead, while the person must keep still as another person leans directly over them, intensely close, while the noise and vibration of a spray or drill is extreme. A trip to the dentist often requires sedation for people on the autism spectrum, as the sensory experience is so overwhelming (Y.-C. Wang, Lin, Huang, \& Fan, 2012). 


\subsubsection{Avoidance of Buildings}

The odds of people on the autism spectrum reporting avoiding buildings were 8.8 times greater than the odds of neurotypical people, with nearly all people on the autism spectrum having ever avoided buildings compared to only half of the neurotypical people. In terms of frequency, neurotypical people did not avoid as many buildings, nor avoid them as often as people on the autism spectrum. Greater avoidance is true across all building types, with a higher proportion of people on the autism spectrum avoiding all types of buildings than neurotypical people. Given the increased discomfort and distress than people on the autism spectrum feel in the built environment, the greater avoidance was expected.

Returning to the concept of 'essential' buildings, a large proportion of people on the autism spectrum are reporting avoiding buildings that people need to use to meet their daily needs. Those who are avoiding these buildings, are avoiding them often. This is likely to be affecting the ability of people on the autism spectrum to live healthy and full lives. There were not enough Control participants who avoided Medical buildings to perform a group analysis, but over a quarter of Autistic participants stated that they had avoided Medical buildings. Of those quarter of people on the autism spectrum who avoid Medical buildings, the frequency they avoided them was high meaning they were avoiding them regularly. Again, considering the poor health and early mortality rate of people on the autism spectrum, not only are there greater stressors due to the built environment likely contributing, but also avoidance of medical buildings could contribute to later medical diagnosis and intervention of treatable conditions. 


\subsection{Question 2: IEQ Factors}

When looking at the results of the IEQ factors across the home, workplace and avoidance sections, individual factors can be considered in two ways, in terms of magnitude and in terms of difference. Magnitude considers the size of the medians of both the Autistic and Control groups, while difference considers the effect size between the groups. Again, particularly in the Avoidance section, only those who responded that they had ever or ideally would like to avoid buildings were asked which factors caused them to, meaning that while nearly all of the Autistic group qualified for this question, only two thirds of the Control group qualified, who are likely the most sensitive of this group.

Median scores for discomfort from IEQ factors at home were much lower than in the Workplace and Avoidance sections. This effect is consistent across all factors. Therefore, when discussing magnitude, it is relative to all other factors within the same section. For example, a median score of 4 for an IEQ factor at home, where the medians range from 1-4, would be considered of large magnitude, but in the avoidance section where the medians primarily fall between 3-7, a median score of 4 for an IEQ factor would be considered of smaller magnitude.

\subsubsection{People and People Noise}

Across all three IEQ sections, People and People Noise were both large in magnitude and large in difference. In particular, both factors have the largest magnitude in the Avoidance section, being the only IEQ factors with a median at the maximum end of the scale for people on the autism spectrum.

For both groups, People was a factor that was larger at both workplace and as a cause of avoidance, although was relatively smaller at home. Given that many people live alone or with family, it is expected that other people are not such a problem at home but are a much larger problem in workplaces and other buildings where larger groups of people congregate. As well, in both the workplace and avoidance sections, People had the largest effect between people on the autism spectrum and neurotypical people. This result is expected, given that people on the autism spectrum often struggle with crowds and large numbers of people. In future, examination of whether it is density or number of people that is the largest problem would help inform design of the built environment. For example, in a large space with a medium number of people, there is lower density but higher numbers, while a smaller number of people in a very small space would have high density despite having fewer people. This relationship could also assist in understanding the effects of people noise, which is likely more dependent on number than density. 
People Noise had the highest median at home for people on the autism spectrum, as well as the largest difference as neurotypical people rated it lowly. However, at the workplace and as a cause of avoidance the result was higher. This is particularly true in the Avoidance section, where People Noise had the highest median for neurotypical people, though the response from people on the autism spectrum was still higher. The large magnitude for this agrees with Al Horr et alia's (2016) and Wargocki et alia's (2012) findings that noise is an IEQ factor that had a large effect on satisfaction and productivity. As People Noise primarily consists of other people talking and is often highly intelligible, Liebl et al. (2012) found that this type of noise has a particularly high impact on cognition and well-being. As well as having the large magnitude because of the large effect on neurotypical people, the even higher effect on people on the autism spectrum is also expected. While noise of high intelligibility is difficult for neurotypical people, they still have a greater ability to manage background noise than people on the autism spectrum, given the established evidence of difficulties in people on the autism spectrum being able to 'tune out' background noise effectively (Sarris, 2016).

\subsubsection{Temperature, Air Quality and Air Movement}

Temperature was consistently rated highly as a cause of discomfort/avoidance across all three IEQ sections, but also showed little difference between people on the autism spectrum and neurotypical people. A similar lack of difference can be seen with Air Quality and Air Movement, though the general magnitude of these is smaller than Temperature.

For all three factors, the lack of difference was due to the Control group rating the factor higher when compared with other IEQ factors, while the Autistic group rated all factors consistently high. Al Horr et al. (2016), Wargocki et al. (2012), Geng et al. (2017), and Leaman \& Bordass (2007) all found that Temperature had high impact on satisfaction and productivity, followed closely by ventilation and indoor air quality, which is consistent with the findings of this study. All three factors have moderate to large magnitudes and affect neurotypical people equally as much as people on the autism spectrum.

\subsubsection{Glare and Electric Light}

Glare and Electric Light were both factors that had large differences between people on the autism spectrum and neurotypical people, though their magnitudes were not as large as People and People Noise. For all three IEQ sections, both factors consistently fell in the middle to upper ranges of the IEQ factor medians for people on the autism 
spectrum, while for neurotypical people the medians for Electric Light were also in the middle range, but the medians for Glare fell in the middle to lower range.

In existing research, there is disagreement on the relative importance of lighting on productivity and satisfaction, with Lamb \& Kwok (2016) finding that lighting had a large effect, Leaman \& Bordass (2007) listing lighting as a factor of moderate importance behind thermal comfort, while Al Horr et al. (2016) and Wargocki et al. (2012) do not specify lighting as a factor with the largest effects on productivity, though they do not claim it has no effect either. Therefore, the finding in this study that the lighting factors have a moderate magnitude behind thermal and air quality environment factors is in accordance with most of the above studies.

Lighting is referenced in many 'autism-friendly' design guidelines, most regularly in reference to the avoidance of fluorescent lighting and glare (Beaver, 2006, 2010, 2012; Henry, 2011; Hewitt et al., 2009; Humphreys, 2005; McAllister, 2010; Vogel, 2008). The consensus on the avoidance of fluorescent lights appears to primarily be as a result of anecdotal evidence, with two studies performed by Colman et al. (1976) and Fenton \& Penney (1985) in a time where fluorescent lights operated at a much lower frequency than today and were more susceptible to visible flicker. In today's high-frequency ballast compact fluorescent lights, the flicker is not perceptible to the eye, but some researchers find that the sub-visible flicker can still cause visual discomfort in peripheral vision (Wilkins, 2015). However, while fluorescents should not visibly flicker in their specified lifetime, they can and do deteriorate at end of life so the issue today could be more to do with poor maintenance than the lights themselves (Hewitt et al., 2009). There are also claims that fluorescents are too bright and unnatural by people on the autism spectrum, which could be a result of the 'white' light being produced by a limited light spectrum. Today, the building industry is moving toward LED lighting due to an emphasis on energy savings, which is even more directional than fluorescent lighting, but can have a more even colour spectrum. Investigation into the cause of fluorescent problems and the implications of a move towards LEDs on people on the autism spectrum is needed.

\subsubsection{Smells, Privacy and Colour}

Smells and Privacy also had moderate magnitudes, though a smaller difference when compared to Glare and Electric Light. Though they both have a similar average magnitude, the profile for each is quite different. Privacy was a factor that had higher medians for both groups at the workplace and mid-range medians as a cause for avoidance but had low medians at home. However, Smells had a higher median for 
both groups at home and as a cause for avoidance, while only a mid-range median at the workplace.

These show that they are factors that are likely particularly sensitive to building type. Few problems with Privacy at home are likely due to the fewer people that reside in residential settings, while it has a much larger effect in the workplace where large numbers of people are often working in limited space.

Colour had a smaller magnitude than most other IEQ factors, and a small difference between people on the autism spectrum and neurotypical people. This was particularly true at home, where there was no statistically significant difference between the groups, with the medians both indicating no discomfort. However, typically home environments do not have bright or harsh colours on surfaces, which are what are specified in the design guidelines to avoid. Therefore, the negligible magnitude and difference is likely due more to the typical design of a home environment.

There were significant differences between the two groups at both workplace and as a cause of avoidance, but the magnitude was still smaller than most other IEQ factors. Given the strong emphasis on colour as an important factor to consider in many design guidelines for 'autism-friendly' buildings, this was initially unexpected (Beaver, 2006, 2010, 2012; Humphreys, 2005; Vogel, 2008). However, when considering the environment, these guidelines are primarily for educational settings for children. Typical classrooms often are bright and visually stimulating, with bright posters and student work adorning the walls, so guidelines encouraging reduction of this are important for this type of environment. However, comparatively workplaces and other buildings are generally more subdued, so colour may be a less substantial problem in these environments.

\subsubsection{Other Factors}

Natural Light had both a small magnitude and no difference. However, this could be due to the way that it was asked about in this study. Too much natural light usually manifests as glare, which was asked about separately and did have large group differences and magnitude. To ask about too little natural light, usually this would be asked about in terms of dissatisfaction as opposed to discomfort.

While People Noise was asked of all three IEQ sections, other noise factors differed between sections. In the Home and Workplace sections, people were asked about Indoor Noise and Outdoor Noise, while in the Avoidance section they were asked about Other Noise. In any future work based on this survey, it would be better if all of the 
environments asked about IEQ factors on the same scales, so they are more easily comparable.

In the Avoidance section, Other Noise had a mid-range magnitude, and a smaller difference between people on the autism spectrum and neurotypical people. As with the other two noise factors, People Noise had a much greater impact on people wanting to avoid buildings. Indoor Noise had a higher median for people on the autism spectrum at home but a low median for neurotypical people, meaning there was a large difference between the groups. The difference at the workplace was smaller, but this is likely due to the higher median for the Control group when compared to home, as the overall magnitude was still larger. Outdoor noise also had a large difference and magnitude at home, while at the workplace these were both small.

At home, there is often a lot more noise from the surrounding environment, as houses are usually close to the street and other houses, as well as being quieter inside so the outdoor noise is more noticeable. However, at the workplace, as People and Indoor Noise are both high, the effects of any noise from outdoors is negligible when compared to the greater internal noise. There are also large differences in scale and materiality, with houses having more external surface with smaller internal area, while workplaces often have larger internal areas, so people are not as close to sources of noise from outdoors.

Noise is consistently rated as a factor that has a high impact on productivity and satisfaction in IEQ research (Al Horr et al., 2016; Kim \& de Dear, 2011; Lamb \& Kwok, 2016; Liebl et al., 2012; Wargocki et al., 2012). Noise also features as an important consideration in 'autism-friendly' design guidelines, particularly in the reduction of background noise and consideration of acoustic properties of materials (Beaver, 2006, 2010, 2012; Ellner, 2011; Hewitt et al., 2009; Humphreys, 2005; Mostafa, 2008). Noise has been evaluated as part of this study as an IEQ factor that often has both large magnitude and large differences, though inconsistency in how this was asked in different sections makes direct comparison difficult.

Layout is the fourth factor that Al Horr at al. (2016) listed as having a high impact on productivity in their review of existing IEQ literature, with noise, thermal comfort and indoor air quality. In the Home and Workplace sections, people were asked to rate whether they felt satisfied with the layout of the environment, as opposed to whether they felt discomfort due to it. For both sections, there was no statistically significant difference in satisfaction between people on the autism spectrum and neurotypical people, with both groups feeling equally neutral in their workplace and slightly satisfied at home. As a cause of avoidance in other buildings, layout had a small difference 
between the two groups, having a slightly greater effect on people on the autism spectrum, with a moderate magnitude when compared to other factors in the section.

The small and negligible differences between the groups was unexpected, as layout is a factor that is considered important in 'autism-friendly' design guidelines for spatial orientation and predictability (Beaver, 2006, 2010, 2012; Humphreys, 2005; Mostafa, 2008; Vogel, 2008). It could be that satisfaction was not the most appropriate way to ask about the effects of layout on people on the autism spectrum. 


\subsection{Question 3: Wider Sensory Sensitivity Relationship}

Despite the large amount of existing research into the effects of IEQ on people, no studies could be found that linked sensory processing with people's experiences of the built environment. It is widely accepted that different people have different expectations for comfort, as such IEQ variables are designed as comfort zones and not point estimates (Al Horr et al., 2016). Though there are clinical measures available to test individuals' sensitivity to the environment, these have not been used to assess whether the differences in individual perception of IEQ are dependent on sensory sensitivity.

When analysing correlations between sensory sensitivity and other variables, all 276 participants were included in the analysis. This includes both family members of people on the spectrum and people with other conditions, as well as people on the autism spectrum and neurotypical people. This means there is a cross-section of the population with various conditions, although the proportion of people on the autism spectrum is much higher than in the general population.

The correlation between overall comfort at home and sensory processing score was weak, but this is likely due to the skewed data. While the non-parametric method of calculating correlations reduces the effect of skewed data, it still relies on ranks, and with so many points at the same rank as well as a reduced scale due to no people rating being uncomfortable at home, the correlation is weak. Many people rated high comfort at home across the spectrum of sensory processing scores, so a weak correlation is not unexpected. The correlation at the workplace is higher, as there was a much higher variance in overall comfort across the scale.

The weak correlation between sensory processing score and perceived control over the environment at both home and the workplace shows that perception of control over the environment is not as dependent on sensory processing as many other variables. However, people who had a higher sensory processing score were more likely to have made permanent changes to their home environment, though not more likely to have requested changes in their workplace environment. Again, it was unexpected that people with a higher sensory processing score were not more likely to request changes to their workplace environment. However, there could be many other considerations that affect the likelihood of requesting changes, such as relationship with superiors or perceived feasibility of changing workplace environment.

Correlations with discomfort in Other Buildings varied greatly depending on the building type. There were strong correlations between sensory processing score and discomfort in 
Shopping Malls, Supermarkets, Other Retail and Medical buildings, while the correlations were moderate for Community, Arts and Restaurant/Bar/Café buildings. As discussed in the first question, the former building types can be classed as 'essential' building types that are required to meet material and health needs, while the latter building types are more 'optional' that people can choose whether to use them or not.

To qualify to answer about discomfort in various building types, participants must have used the building type at least once a month, meaning that there was a similar proportion of people from all of the analysis groups who answered about these buildings. However, only those who rated discomfort highly for a building type would proceed to the question regarding distress. Even within the whole sample, those who had higher sensory processing scores were more likely to be asked about distress, as sensory processing scores were correlated with discomfort. There was a range of sensory processing scores in people who answered about distress, although there was a high proportion of people with low sensory processing scores that did not qualify as they did not feel high discomfort from any building types. A much higher proportion of people on the autism spectrum qualified for the distress question, and they also had much higher sensory processing scores. However, as the correlations were not significantly different when people on the autism spectrum were not included in the analysis, the correlations between sensory processing score and distress were not significantly skewed by the higher proportion of people on the autism spectrum.

People who have ever avoided buildings had a higher sensory processing score compared to those who had never, a difference of a quarter of the sensory processing scale. This difference of 15 points is not as large as the group comparison of 21 points, but includes all participants. This effect is also seen when only considering people who are not on the autism spectrum, neurotypical or otherwise, though the difference is smaller at 8 points.

Moderate correlations between frequency of avoidance and sensory processing score were found for Supermarkets, Shopping Malls, Other Retail, and Restaurant/Bar/Café Buildings. In this case, many of the correlations were significantly weaker when people not on the autism spectrum were not included in the analysis, and only remained significant for Supermarket and Other Retail buildings. However, as the incidence of avoidance is significantly higher in people on the autism spectrum, there were fewer people included in this analysis. As avoidance is an effect that is likely to have many factors, it is likely that a smaller sample size will have issues with variance from these, and a correlation is not found as there are not enough data points to even out this variance. Further investigation into whether avoidance is more strongly linked to being on the 
autism spectrum than sensory processing score is required to understand this relationship, as the results are inconsistent across the analyses and are disadvantaged by small sample sizes. 


\subsection{Limitations}

The survey data in this study were gathered from a self-selected sample, not a population representative sample. The study also did not collect diagnosis reports and presumed validity of self-report. These limitations were mitigated by the sensory processing analysis, with the differences consistent with existing research.

There was a large gender bias, with a much higher proportion of female participants than male participants, although insufficient numbers were available to permit a detailed comparison. This is particularly true in the Autistic group, as autism is documented to affect four times as many males than females, although there were more females than males in the Autistic sample in this study as well. This is likely due, in part, to the use of 'snowball' technique to gather participants, as it favours people with higher interconnections (e.g. autistic females). Autistic females are also over-represented in social media groups, which was a main source of autistic participants. In general, females are more likely to participate in surveys than men (Curtin, Presser, \& Singer, 2000).

There was a lower proportion of renters than the New Zealand average in the Control group, which given the relationships between renting, comfort and control, may have affected the differences found between the two groups. While the proportion of people who rent is higher in the Autistic group, given the low employment rates, it is expected that a higher proportion than average would rent in this group. As the survey was selfselected, with many participants on the autism spectrum recruited through social media groups, there are likely many others who this survey did not reach.

Due to the definition of workplace including other buildings that were not used for employment if the participant was unemployed or worked at home, the workplace section is not completely indicative of places of employment. There were also a number of people who did not read this instruction, and as a result stated in the comments that they had answered the section the same as their home as they worked from home.

The language used for some of the IEQ factors, such as layout, colour, and natural light need to be evaluated to ensure that these are being asked in a precise way. In this study, it is possible that these did not fully evaluate the aspects they were intended to investigate. Also, in future, ensuring that IEQ factors are consistent across survey sections and environments would aid in comparability.

The Sensory Processing Score used in this survey had to be developed as copyright permission was not able to be obtained to use existing clinical sensory processing evaluations due to time constraints. However, this limited the comparability of the sensory 
processing section to existing research. In future, if this study were to be repeated or other studies are done assessing sensory processing, it would be recommended to use an existing sensory processing scale, such as the full Adult/Adolescent Sensory Profile (Brown \& Dunn, 2002) or the SensOR scale used by Tavassoli (2014).

It is common in IEQ sections to use display logic to 'gate' questions asked depending on responses to earlier questions. While this was used effectively in this study in the discomfort section by only requesting evaluation of buildings participants used frequently, this display logic was also implemented in the distress question based on the discomfort question responses. This was based on the assumption that if a person felt little-to-no discomfort in a building, then they would not feel distress. It was implemented to reduce the survey length and keep it manageable for participants. However, given that there were a small number of people that rated a higher level of distress than they did discomfort, it is possible that this 'gating' could have missed people who did not regularly feel discomfort but did feel some distress. If this study were to be repeated, it is recommended to not use display logic on this question to ensure that no irregularities are missed.

There was a much higher proportion of people on the autism spectrum in this study than in the typical population, $30 \%$ compared to the usual $1 \%$. While this is good for the group study section, when looking at the wider relationship between sensory sensitivity and the built environment, as people on the autism spectrum have higher sensory processing scores they could have skewed the sample. While these questions were analysed not including people on the autism spectrum as well as including to allow for this, there was a lot of variation in the results, with some relationships remaining while others became nonsignificant. For the avoidance section, this may be due to a too small sample, as fewer people not on the autism spectrum responded. 


\subsection{Further Research}

A large-scale study assessing the relationship between sensory sensitivity and the effects of indoor environment quality, with a representative sample of the general population, could validate whether there is a relationship. This could involve including a sensory sensitivity section to existing IEQ surveys when performing post-occupancy evaluations such as those using the CBE or BUS surveys, and collecting information across many buildings as has been implemented in many of the IEQ studies (Kim \& de Dear, 201 1; Leaman \& Bordass, 2007; Wargocki et al., 2012).

Development of scales to measure adverse effects outside reduced productivity and general well-being would assist in providing greater information about the negative effects of the built environment. This could be achieved by evaluating and implementing existing psychological scales for measuring negative experiences, or through experimental methods testing physical reactions in conjunction with self-reported evaluation.

As outlined in section 6.2.3, there are many questions raised regarding the mechanisms of why fluorescent lighting causes a problem for people on the autism spectrum, and the implications of the uptake of LED lighting systems as an alternative. A more specific evaluation of fluorescent lighting could assist in answering these questions. This could include experimental studies involving placing people on the autism spectrum under different lighting systems and asking them to evaluate what type of light it is, what specific problems they have with it, performing tasks to test whether there is an effect on cognitive ability, as well as observation of physical responses to support any self-reported problems.

The implications of the results in the Avoidance section should be investigated further to assess the impact they have on people living comfortable and healthy lives. If avoidance were to be assessed in a future study, participants could be asked follow-up questions if they rated that they avoided types of buildings in conjunction with frequency, such as if they identified as avoiding supermarket buildings asking "have you ever gone hungry to avoid having to go to a supermarket?" or "have you become sick or your illness gotten worse because you did not want to go to a medical building?".

Outside the scope of this project, investigation into the move towards flexible desking, open plan offices with minimisation of footprint is needed. This study identified that People and People Noise are a large problem for people on the autism spectrum, issues that are likely to worsen in these new office environments. Additionally, research is 
needed into the effect of instability in flexible desking. It is possible that this move is creating greater inaccessibility for people on the autism spectrum, particularly relating to office-based employment.

Across many of the IEQ factors, similar patterns in magnitude were often seen between people on the autism spectrum and neurotypical people. A question raised from this is, if a building was designed that took into account the needs of people on the autism spectrum, how would this impact on neurotypical people? In particular, would they also be happier in an environment that takes into account the greater sensory sensitivity of people on the autism spectrum? If so, designing environments that are accessible to the most sensitive of the population would likely improve environments for all users.

As well as the quantitative data analysed for this project, there was also a large amount of qualitative data obtained in the form of text comments from the survey, collected primarily to allow people on the autism spectrum to have a say if they felt the given answers did not suit their intentions. Including the qualitative data were outside the scope of this project, but there could be valuable insights if this was analysed in addition. 


\section{Conclusions}

By surveying peoples' perceptions of the built environment, this study identified that people on the autism spectrum experience greater adverse effects of indoor environment quality. People on the autism spectrum, who reported higher levels of sensory sensitivity, consistently reported higher levels of discomfort in both their home and workplace environments, feeling more overwhelming, stressed, and distracted, and less safe than neurotypical people in both environments. They also reported feeling discomfort more frequently, experiencing greater levels of distress, and avoiding buildings more frequently across nearly all building types in the general built environment. The odds of an Autistic participant avoiding buildings was 8.8 times greater than neurotypical participants, with over a quarter of people on the autism spectrum reporting avoiding medical buildings.

Participants on the autism spectrum reported that People and People Noise IEQ factors were the greatest causes of discomfort and avoidance, with much greater effects on them than neurotypical people, followed by Glare and Electric Light. Meanwhile, Temperature was rated equally highly by both groups as a cause of discomfort and avoidance, having a large effect but little to no significant differences between groups, with a similar trend seen in Air Quality and Air Movement. Across all participants, higher Sensory Processing Scores were generally correlated with experiencing more frequent discomfort and greater distress, but was weaker in avoidance of buildings, which may be more influenced by being on the autism spectrum than Sensory Processing Score. Across many of the IEQ factors, similar patterns in magnitude were often seen between people on the autism spectrum and neurotypical people.

The large group differences observed indicate the need for further study into understanding the nature of these effects and explore methods to improve environments to be more accessible to people on the autism spectrum, which may also improve conditions for the broader population. While people on the autism spectrum have clear differences in sensory processing, there is still variance in sensory sensitivity among the general population. A question raised from this research is: if a building was designed that took into account the needs of people on the autism spectrum, how would this impact on neurotypical people? In particular, would they also be more comfortable in an environment that takes into account the greater sensory sensitivity of people on the autism spectrum? If so, designing environments that are accessible to the most sensitive of the population would likely improve the built environment for all users. 
Greater environmental stress for people on the autism spectrum due to differences in sensory processing likely compound existing difficulties with social communication and isolation and may be a contributor to the high rates of early mortality from stress-based conditions and suicide. Additionally, environments that likely discriminate against people on the autism spectrum likely affect the ability to perform daily tasks such as meeting material needs and act as a barrier to employment in a population that has a high rate of unemployment. This study provides exploratory data that can direct further research, with the eventual aim of improving the quality of life and health outcomes for people on the autism spectrum. 


\section{Works Cited}

Adamson, A., O'Hare, A., \& Graham, C. (2006). Impairments in sensory modulation in children with autistic spectrum disorder. The British Journal of Occupational Therapy, 69(8), 357-364.

Al Horr, Y., Arif, M., Kaushik, A., Mazroei, A., Katafygiotou, M., \& Elsarrag, E. (2016). Occupant productivity and office indoor environment quality: A review of the literature. Building and Environment, 105, 369-389.

https://doi.org/10.1016/j.buildenv.2016.06.001

American Psychiatric Association. (2013). Diagnostic and Statistical Manual of Mental Disorders: DSM-5 (5th ed..). Arlington, VA: American Psychiatric Association.

American Speech-Language-Hearing Association. (1994). Facilitated Communication (No. TR1994- 00139). Rockville, MD: American Speech-Language-Hearing Association. Retrieved from http://www.asha.org/docs/html/TR1994-00139.html

ASHRAE, USGBC, \& CISBE. (2010). Performance measurement protocols for commercial buildings. Atlanta: ASHRAE.

Astrid. (2016, May 19). In Between: Walking the Disability Line. Retrieved 22 January 2018, from https://bloggingastrid.com/tag/low-functioning-autism/

Attwood, T. (2007). The Complete Guide to Asperger's Syndrome. Jessica Kingsley Publishers.

Autism CRC. (2016). Inclusive research practice guides and checklists: version 2. Brisbane, Queensland, Australia: Autism CRC Ltd. Retrieved from https://www.autismcrc.com.au/sites/default/files/inlinefiles/Inclusive\%20research\%20practice\%20guides\%20and\%20checklists\%20\%20FInal\%20report.pdf

Autism New Zealand. (2015). About Autism. Retrieved 20 March 2016, from http://www.autismnz.org.nz/about_autism

Baird, G. (2009). Incorporating User Performance Criteria into Building Sustainability Rating Tools (BSRTs) for Buildings in Operation. Sustainability, 1 (4), 1069-1086. https://doi.org/10.3390/su1041069

Baron-Cohen, S. (2017). Editorial Perspective: Neurodiversity - a revolutionary concept for autism and psychiatry. Journal of Child Psychology and Psychiatry, 58(6), 744-747. https://doi.org/10.1111/jcpp.12703 
Baron-Cohen, S., Wheelwright, S., Skinner, R., Martin, J., \& Clubley, E. (2001). The AutismSpectrum Quotient (AQ): Evidence from Asperger Syndrome/High-Functioning Autism, Malesand Females, Scientists and Mathematicians. Journal of Autism and Developmental Disorders, 31 (1), 5-17. https://doi.org/10.1023/A:1005653411471

Beaver, C. (2006). Designing environments for children and adults with autistic spectrum disorder. Presented at the International Conference on Autism, Cape Town. Retrieved from http://www.autism-architects.com/wpcontent/uploads/2012/03/Cape-Town-Conference-Paper-2006-pdf.pdf

Beaver, C. (2010). Autism-Friendly Environments. The Autism File, 34, 82-85.

Beaver, C. (2012, June). How good design can influence ASD behaviours. Healthcare Design and Management, 30-32.

Bluyssen, P. M., \& Cox, C. (2002). Indoor environment quality and upgrading of European office buildings. Energy and Buildings, 34 (2), 155-162. https://doi.org/10.1016/S0378-7788(01)00101-3

Brager, G., Paliaga, G., \& De Dear, R. (2004). Operable windows, personal control and occupant comfort. Center for the Built Environment. Retrieved from https://escholarship.org/uc/item/4x57v1pf.pdf

Brandwein, A. B., Foxe, J. J., Butler, J. S., Russo, N. N., Altschuler, T. S., Gomes, H., \& Molholm, S. (2013). The Development of Multisensory Integration in HighFunctioning Autism: High-Density Electrical Mapping and Psychophysical Measures Reveal Impairments in the Processing of Audiovisual Inputs. Cerebral Cortex, 23(6), 1329-1341. https://doi.org/10.1093/cercor/bhs109

Brown, C., \& Dunn, W. (2002). Adolescent/Adult Sensory Profile®. Retrieved 7 February 2018, from

https://www.pearsonclinical.com/therapy/products/100000434/adolescentadultsensory-profile.html

Burgess, R. (2016). Understanding The Spectrum [Comic]. Retrieved from http://theoraah.tumblr.com/post/142300214156/understanding-the-spectrum

BUS. (2016). BUS Methodology: BUS methodology - Occupant Satisfaction Evaluation. Retrieved 29 April 2016, from http://www.busmethodology.org/

CBE. (2014, June 20). Center for the Built Environment: Occupant IEQ Survey. Retrieved 29 April 2016, from http://www.cbe.berkeley.edu/research/briefs-survey.htm 
Cerliani, L., Mennes, M., Thomas, R. M., Martino, A. D., Thioux, M., \& Keysers, C. (2015). Increased Functional Connectivity Between Subcortical and Cortical RestingState Networks in Autism Spectrum Disorder. JAMA Psychiatry, 72 (8), 767-777. https://doi.org/10.1001/jamapsychiatry.2015.0101

Christensen, L. B., Johnson, R. B., \& Turner, L. A. (2014). Research Methods, Design and Analysis (12th edition). Pearson.

Clausen, G., \& Wyon, D. P. (2008). The Combined Effects of Many Different Indoor Environmental Factors on Acceptability and Office Work Performance. HVAC\&R Research, 14(1), 103-113.

Cliff, N. (1993). Dominance statistics: Ordinal analyses to answer ordinal questions. Psychological Bulletin, 114 (3), 494-509. http://dx.doi.org/10.1037/00332909.114.3.494

Cohen, J. (1988). Statistical Power Analysis for the Behavioural Sciences (Second). Hillsdale, New Jersey: Lawrence Erlbaum Associates.

Colman, R. S., Frankel, D. F., Ritvo, E., \& Freeman, B. J. (1976). The effects of fluorescent and incandescent illumination upon repetitive behaviors in autistic children. Journal of Autism and Childhood Schizophrenia, 6(2), 157-162. https://doi.org/10.1007/BF01538059

Conway, B. (2017, May 12). Office Buildings. Retrieved 8 February 2018, from https://www.wbdg.org/building-types/office-building

Crane, L., Goddard, L., \& Pring, L. (2009). Sensory processing in adults with autism spectrum disorders. Autism, 13(3), 215-228. https://doi.org/10.1177/1362361309103794

Curtin, R., Presser, S., \& Singer, E. (2000). The Effects of Response Rate Changes on the Index of Consumer Sentiment. Public Opinion Quarterly, 64 (4), 413-428. https://doi.org/10.1086/318638

Cusack, J., Shaw, S., Spiers, J., \& Sterry, R. (2016). Personal tragedies, public crisis: The urgent need for a national response to early death in autism. Autistica. Retrieved from https://www.autistica.org.uk/downloads/files/Personal-tragedies-public-crisisONLINE.pdf\#asset:1499

Denscombe, M. (2014). The Good Research Guide: For small-scale social research projects (Fifth edition). Open University Press.

Dunn, W., Myles, B. S., \& Orr, S. (2002). Sensory Processing Issues Associated With Asperger Syndrome: A Preliminary Investigation. American Journal of Occupational Therapy, 56(1), 97-102. https://doi.org/10.5014/ajot.56.1.97 
Dunn, Winne. (1999). Sensory Profile. Retrieved 20 March 2016, from http://www.pearsonclinical.com/therapy/products/100000566/sensoryprofile.html

Dykes, C. (2012). User Perception Benchmarks for Commercial and Institutional Buildings in New Zealand. Retrieved from http://researcharchive.vuw.ac.nz/handle/10063/2091

Ellner, M. L. (2011). A qualitative study: Perspectives from students with autism on classroom environmental adaptations for the enhancement of attention and engagement during learning tasks (M.S.). Temple University, United States -Pennsylvania. Retrieved from http://search.proquest.com.helicon.vuw.ac.nz/pqdtglobal/docview/877985098/a bstract/61E245DAEDF343D7PQ/2

Fenton, D. M., \& Penney, R. (1985). The Effects of Fluorescent and Incandescent Lighting on the Repetitive Behaviours of Autistic and Intellectually Handicapped Children. Australia and New Zealand Journal of Developmental Disabilitie, 11 (3), 137-141.

Fisk, W. J. (2002). How IEQ affects health, productivity. ASHRAE Journal, 44 (5), 56.

Fisk, W. J., \& Rosenfeld, A. H. (1997). Estimates of Improved Productivity and Health from Better Indoor Environments. Indoor Air, 7(3), 158-172. https://doi.org/10.1111/j.1600-0668.1997.t01-1-00002.x

Galatioto, A., Leone, G., Milone, D., Pitruzzella, S., \& Franzitta, V. (2013). Indoor Environmental Quality Survey: A Brief Comparison between Different Post Occupancy Evaluation Methods. Advanced Materials Research, 864-867, 1148 1152. https://doi.org/10.4028/www.scientific.net/AMR.864-867.1148

Geng, Y., Ji, W., Lin, B., \& Zhu, Y. (2017). The impact of thermal environment on occupant IEQ perception and productivity. Building and Environment, 121, 158-167. https://doi.org/10.1016/j.buildenv.2017.05.022

Grissom, R. J., \& Kim, J. J. (2012). Effect Sizes for Research: Univariate and Multivariate Applications (Second). Taylor \& Francis Group.

Henry, C. (2011, October 19). Designing for Autism: Lighting. ArchDaily. Retrieved from http://www.archdaily.com/177293/designing-for-autism-lighting/

Henry, C. (2012, May 10). Pitfalls of Observational Studies. ArchDaily. Retrieved from http://www.archdaily.com/233177/pitfalls-of-observational-studies 
Hewitt, J., Hewiston, C., O'Toole, G., \& Haywood, N. (2009). Sensory access in higher education: guidance report 2009. Equality Challenge Unit. Retrieved from http://www.ecu.ac.uk/wp-content/uploads/external/Sensory-access-in-highereducation-guidance.pdf

Hirvikoski, T., Mittendorfer-Rutz, E., Boman, M., Larsson, H., Lichtenstein, P., \& Bölte, S. (2016). Premature mortality in autism spectrum disorder. The British Journal of Psychiatry, 208(3), 232-238. https://doi.org/10.1192/bjp.bp.114.160192

Hollander, M., Wolfe, D. A., \& Chicken, E. (2013). Nonparametric Statistical Methods. Wiley.

Huizenga, C., Zagreus, L., Arens, E., \& Lehrer, D. (2003). Measuring indoor environmental quality: a web-based occupant satisfaction survey. Greenbuild, Pittsburgh PA. Retrieved from https://escholarship.org/uc/item/8zc5c32z.pdf

Humphreys, S. (2005). Autism and Architecture. Retrieved from https://web.archive.org/web/20150929023148/http://www.autismsocietycanada. ca/images/dox/Autism_and_Architecture_08_Humphreys.pdf

Jaarsma, P., \& Welin, S. (2012). Autism as a Natural Human Variation: Reflections on the Claims of the Neurodiversity Movement. Health Care Analysis, 20 (1), 20-30. https://doi.org/10.1007/s10728-011-0169-9

Kawaii, A. (2016, March 21). Left-Handedness. Retrieved 24 January 2018, from https://aegyokawaiisneurodiversityblog.wordpress.com/2016/03/21/lefthandedness/

Kenny, L., Hattersley, C., Molins, B., Buckley, C., Povey, C., \& Pellicano, E. (2016). Which terms should be used to describe autism? Perspectives from the UK autism community. Autism, 20(4), 442-462.

Kern, J. K., Trivedi, M. H., Garver, C. R., Grannemann, B. D., Andrews, A. A., Savla, J. S., ... Schroeder, J. L. (2006). The pattern of sensory processing abnormalities in autism. Autism, 10(5), 480-494. https://doi.org/10.1177/1362361306066564

Khan, A. J., Nair, A., Keown, C. L., Datko, M. C., Lincoln, A. J., \& Müller, R.-A. (2015). Cerebro-cerebellar Resting-State Functional Connectivity in Children and Adolescents with Autism Spectrum Disorder. Biological Psychiatry, 78(9), 625-634. https://doi.org/10.1016/j.biopsych.2015.03.024

Khan, S., Michmizos, K., Tommerdahl, M., Ganesan, S., Kitzbichler, M. G., Zetino, M., ... Kenet, T. (2015). Somatosensory cortex functional connectivity abnormalities in autism show opposite trends, depending on direction and spatial scale. Brain: A Journal of Neurology, 138 (Pt 5), 1394-1409. https://doi.org/10.1093/brain/awv043 
Kientz, M. A., \& Dunn, W. (1997). A Comparison of the Performance of Children With and Without Autism on the Sensory Profile. American Journal of Occupational Therapy, 51 (7), 530-537 8p.

Kim, J., \& de Dear, R. (2011). Nonlinear relationships between individual IEQ factors and overall workspace satisfaction. Building and Environment, 49, 33-40. https://doi.org/10.1016/j.buildenv.2011.09.022

Klepeis, N. E., Nelson, W. C., Ott, W. R., Robinson, J. P., Tsang, A. M., Switzer, P., ... Engelmann, W. H. (2001). The National Human Activity Pattern Survey (NHAPS): a resource for assessing exposure to environmental pollutants. Journal of Exposure Science and Environmental Epidemiology, 11 (3), 231. https://doi.org/10.1038/sj.jea.7500165

Lamb, S., \& Kwok, K. C. S. (2016). A longitudinal investigation of work environment stressors on the performance and wellbeing of office workers. Applied Ergonomics, 52, 104-111. https://doi.org/10.1016/j.apergo.2015.07.010

Leaman, A. (2010). Are buildings getting better?'. Arup Journal, 1 (2010), 4-8.

Leaman, A., \& Bordass, B. (2007). Are users more tolerant of 'green' buildings? Building Research \& Information, 35(6), 662-673. https://doi.org/10.1080/09613210701529518

Leekham, S. R., Nieto, C., Libby, S. J., Wing, L., \& Gould, J. (2007). Describing the sensory abnormalities of children and adults with autism. Journal of Autism \& Developmental Disorders, 37(5), 894-910 17p.

Liebl, A., Haller, J., Jödicke, B., Baumgartner, H., Schlittmeier, S., \& Hellbrück, J. (2012). Combined effects of acoustic and visual distraction on cognitive performance and well-being. Applied Ergonomics, 43(2), 424-434. https://doi.org/10.1016/j.apergo.2011.06.017

Ludwig, F. L. (2016). What is Low-Functioning Autism? Retrieved 23 January 2018, from http://www.franklludwig.com/autismlowfunctioning.html

McAllister, K. (2010). The ASD-friendly classroom: design complexity, challenge and characteristics. In Design Research Society Conference. Retrieved from http://www. designresearchsociety. org/docs-procs/DRS2010/PDF/084. pdf. Retrieved from http://www.designresearchsociety.org/docsprocs/DRS2010/PDF/084.pdf

McGraw, K. O., \& Wong, S. P. (1992). A common language effect size statistic. Psychological Bulletin, 111 (2), 361-365. http://dx.doi.org/10.1037/00332909.111 .2 .361 
Minshew, N. J., \& Hobson, J. A. (2008). Sensory sensitivities and performance on sensory perceptual tasks in high-functioning individuals with autism. Journal of Autism \& Developmental Disorders, 38(8), 1485-1498.

Moore, T., Carter, D. J., \& Slater, A. I. (2002). User attitudes toward occupant controlled office lighting. Lighting Research and Technology, 34 (3), 207-219. http://dx.doi.org.helicon.vuw.ac.nz/10.1191/13657828021t0480a

Mostafa, M. (2008). An architecture for autism: Concepts of design intervention for the autistic user. Archnet-IJAR: International Journal of Architectural Research, 2(1), $189-211$.

Mostafa, M. (2014). An Architecture for Autism: Application of the Autism ASPECTSSTM Design Index to Home Environments. The International Journal of the Constructed Environment, 4(2), 25-38. https://doi.org/10.18848/2154-8587/CGP/v04i02/37413

NAS. (2016a). The autism employment gap: Too Much Information in the workplace (No. 2992). London, UK: The National Autistic Society. Retrieved from http://www.autism.org.uk/ /media/nas/getinvolved/tmi/tmi\%20employment\%20report\%2024pp\%20web.ashx?la=en-gb

NAS. (2016b, March 9). Meltdowns in autistic people - NAS. Retrieved 18 February 2018, from http://www.autism.org.uk/about/behaviour/meltdowns.aspx

National Symposium on Neurodiversity. (2011, April 8). What is Neurodiversity? Retrieved 22 January 2018, from https://neurodiversitysymposium.wordpress.com/what-isneurodiversity/

Ne'eman, A. (2010). The Future (and the Past) of Autism Advocacy, Or Why the ASA's Magazine, The Advocate, Wouldn't Publish This Piece. Disability Studies Quarterly, 30 (1). Retrieved from http://dsq-sds.org/article/view/1059

Newsham, G., Veitch, J., Arsenault, C., \& Duval, C. (2004). Effect of dimming control on office worker satisfaction and performance. In Proceedings of the IESNA Annual Conference (pp. 19-41). Citeseer. Retrieved from http://citeseerx.ist.psu.edu/viewdoc/download?doi=10.1.1.200.4892\&rep=rep 1 \&ty pe=pdf

NSW Government. (2016). NABERS Indoor Environment. Retrieved 29 April 2016, from http://www.nabers.gov.au/public/WebPages/ContentStandard.aspx?module=21 \&template=3\&include=IndoorEnvironment.htm\&side=new-IE-docs.htm

NZ Government. (1992). Building Regulations. Wellington [N.Z.]: New Zealand Government. 
Office for Disability Issues. (2014). A guide to making Easy Read information. Retrieved 29 January 2018, from https://www.odi.govt.nz/guidance-and-resources/a-guide-tomaking-easy-read-information/

Office for Disability Issues. (2016). New Zealand Disability Strategy 2016-2026 (p. 52). Ministry of Social Development. Retrieved from https://www.odi.govt.nz/assets/New-Zealand-Disability-Strategy-files/pdf-nzdisability-strategy-2016.pdf

Oseland, N. (2007). British Council for Offices guide to post-occupancy evaluation. London: British Council for Offices.

Pellicano, E., \& Stears, M. (201 1). Bridging autism, science and society: moving toward an ethically informed approach to autism research. Autism Research, 4(4), 271-282. https://doi.org/10.1002/aur.201

People First NZ. (2017). Easy Read Information. Retrieved 26 February 2018, from http://www.peoplefirst.org.nz/news-and-resources/easy-read-resources/

Peretti, C., \& Schiavon, S. (2011). Indoor environmental quality surveys. A brief literature review. Center for the Built Environment. Retrieved from http://escholarship.org/uc/item/Owblvoss

R Core Team. (2017). R: A Language and Environment for Statistical Computing (Version 3.3.3). Vienna, Austria: R Foundation for Statistical Computing. Retrieved from https://www.R-project.org

Robertson, C. E., \& Baron-Cohen, S. (2017). Sensory perception in autism. Nature Reviews Neuroscience, 18(11), 671. https://doi.org/10.1038/nrn.2017.112

Robinson, J. E. (2014, December 22). High Functioning Aspies Don't Know What Real Autism Is. Retrieved 22 January 2018, from http://www.psychologytoday.com/blog/my-life-aspergers/201412/highfunctioning-aspies-dont-know-what-real-autism-is

Romano, J., Kromrey, J. D., Coraggio, J., Skowronek, J., \& Devine, L. (2006). Exploring methods for evaluating group differences on the NSSE and other surveys: Are the t-test and Cohen'sd indices the most appropriate choices. In annual meeting of the Southern Association for Institutional Research. Citeseer.

Russo, N., Foxe, J. J., Brandwein, A. B., Altschuler, T., Gomes, H., \& Molholm, S. (2010). Multisensory processing in children with autism: high-density electrical mapping of auditory-somatosensory integration. Autism Research, 3(5), 253-267. https://doi.org/10.1002/aur.152 
Sandberg, J. (2003, January 15). Employees Only Think They Control Thermostat. Wall Street Journal. Retrieved from http://www.wsj.com/articles/SB1042577628591401304

Sarris, M. (2016, May 19). What do we know about noise sensitivity in autism? Retrieved 11 February 2018, from https://iancommunity.org/ssc/noise-sensitivity-autism

Scope. (2017). What is the social model of disability? | Disability charity Scope UK. Retrieved 23 January 2018, from https://www.scope.org.uk/about-us/ourbrand/social-model-of-disability

Sequenzia, A. (2013a, January 19). When Autistics Grade Other Autistics. Retrieved 22 January 2018, from https://ollibean.com/autistics-grade-autistics/

Sequenzia, A. (2013b, September 26). More Problems with Functioning Labels. Retrieved 22 January 2018, from https://ollibean.com/problems-functioning-labels/

Sequenzia, A. (2014, September 14). Attitudes - Grading People by Amy Sequenzia. Retrieved 22 January 2018, from https://ollibean.com/attitudes-grading-people/

Shakespeare, T. (2006). The Social Model of Disability. In The Disability Studies Reader (2nd ed., pp. 197-204). New York: Taylor \& Francis Group. Retrieved from https://disabilitystudies.nl/sites/disabilitystudies.nl/files/beeld/onderwijs/lennard_d avis_the_disability_studies_reader_secbookzz-org_0.pdf\#page=216

Shear, M. K., Brown, T. A., Barlow, D. H., Money, R., Sholomskas, D. E., Woods, S. W., ... Papp, L. A. (1997). Multicenter Collaborative Panic Disorder Severity Scale. American Journal of Psychiatry, 154(11), 1571-1575. https://doi.org/10.1176/ajp.154.11.1571

Statistics NZ. (2001). Disability Survey 2001: Adult Content Questionnaire (Form). Retrieved from

http://www2.stats.govt.nz/domino/external/quest/sddquest.nsf/12df43879eb9b25 e4c256809001ee0fe/77b99aaca0a018e2cc256ad8001d7c10/\$FILE/Adult\%20Cont ent.PDF

Statistics NZ. (2014, June 23). Disability Survey. Retrieved 30 April 2016, from http://www.stats.govt.nz/browse_for_stats/health/disabilities.aspx

Statistics NZ. (2017). Disabled people twice as likely to be unemployed. Retrieved from http://www.stats.govt.nz/browse_for_stats/income-andwork/employment_and_unemployment/LabourMarketStatisticsDisability_MRJun 17 qtr.aspx

Steele, K., \& Ahrentzen, S. (2016). At Home With Autism: Designing Housing for the Spectrum. Policy Pr. 
Stiff, A. F. (2012). Autism Spectrum Disorder: Sensory Needs in the Workplace. Retrieved from

https://digitalcommons.wku.edu/cgi/viewcontent.cgierreferer=https://www.bing. com/\&httpsredir=1 \&article=2183\&context=theses

Sullivan, J., Baird, G., \& Donn, M. (2013). Measuring Productivity in the Office Workplace. Centre for Building Performance Research. Retrieved from https://www.msd.govt.nz/documents/about-msd-and-our-work/about$\mathrm{msd} /$ structure/pmcoe/publications/measuring-productivity-in-the-officeworkplace.docx

Tate, R. (2014, October 19). What's the Difference Between High Functioning and Low Functioning Autism? Retrieved 23 January 2018, from https://autismwomensnetwork.org/whats-the-difference-between-highfunctioning-and-low-functioning-autism/

Tavassoli, T., Miller, L. J., Schoen, S. A., Nielsen, D. M., \& Baron-Cohen, S. (2014). Sensory over-responsivity in adults with autism spectrum conditions. Autism, 18(4), 428-432. https://doi.org/10.1177/1362361313477246

Tomchek, S. D., \& Dunn, W. (2007). Sensory processing in children with and without autism: a comparative study using the short sensory profile. American Journal of Occupational Therapy, 61 (2), 190-200.

United Nations. UN Convention on the Rights of Persons with Disabilities (2007). Retrieved from http://www.un.org/disabilities/documents/convention/convoptprot-e.pdf

Vargha, A., \& Delaney, H. D. (2000). A Critique and Improvement of the CL Common Language Effect Size Statistics of McGraw and Wong. Journal of Educational and Behavioral Statistics, 25(2), 101-132. https://doi.org/10.3102/10769986025002101

Vogel, C. L. (2008). Classroom Design for Living and Learning with Autism. Autism Asperger's Digest. Retrieved from http://www.designshare.com/index.php/archives/901

Wang, J., Fu, K., Chen, L., Duan, X., Guo, X., Chen, H., ... Chen, H. (2017). Increased Gray Matter Volume and Resting-State Functional Connectivity in Somatosensory Cortex and their Relationship with Autistic Symptoms in Young Boys with Autism Spectrum Disorder. Frontiers in Physiology, 8. https://doi.org/10.3389/fphys.2017.00588

Wang, Y.-C., Lin, I.-H., Huang, C.-H., \& Fan, S.-Z. (2012). Dental anesthesia for patients with special needs. Acta Anaesthesiologica Taiwanica, 50(3), 122-125. https://doi.org/10.1016/j.aat.2012.08.009 
Wargocki, P., Frontczak, M., Schiavon, S., Goins, J., Arens, E., \& Zhang, H. (2012). Satisfaction and self-estimated performance in relation to indoor environmental parameters and building features. In Proceedings of 10th International Conference on Healthy Buildings (Vol. 1). Retrieved from http://escholarship.org/uc/item/451326fk.pdf

Watling, R. L., Deitz, J., \& White, O. (2001). Comparison of sensory profile scores of young children with and without autism spectrum disorders. American Journal of Occupational Therapy, 55(4), 416-423.

Whitehurst, T. (2006). The impact of building design on children with autism spectrum disorders. Good Autism Practice, 7(1), 31-38.

Wilkins, A. J. (2015). A physiological basis for visual discomfort: Application in lighting design. Lighting Research and Technology, 29-38. https://doi.org/10.1177/1477153515612526

Winter, P. (2017, November 10). So you think we're 'too high-functioning'? Retrieved 22 January 2018, from http://strangeringodzone.blogspot.com/2017/09/so-you-thinkwere-too-high-functioning.html

Work and Income NZ. (2016). Supported Living Payment Application (Form). Ministry of Social Development. Retrieved from http://www.workandincome.govt.nz/documents/forms/supported-livingpayment-application.pdf

Wuensch, K. L. (2015, June 16). Nonparametric Effect Size Estimators. East Carolina University Department of Psychology. Retrieved from http://core.ecu.edu/psyc/wuenschk/docs30/Nonparametric-EffectSize.pdf

Wyon, D. P., \& Wargocki, P. (2013). How indoor environment affects performance. ASHRAE Journal, 55(3), 46-52.

Zeliadat, N. (2015, May 4). Brain connections give clues to sensory problems in autism. Retrieved 26 January 2018, from https://medicalxpress.com/news/2015-05-brainclues-sensory-problems-autism.html 


\section{Appendix}

9.1 Understanding the Spectrum (Burgess, 2016)

Due to copyright, this comic has been redacted

Please see the original work at:

http://theoraah.tumblr.com/post/142300214156/understanding-the-spectrum

This page has been intentionally left blank 
This page has been intentionally left blank 
This page has been intentionally left blank

Appendix - Understanding the Spectrum (Burgess, 2016) | 135 
This page has been intentionally left blank 
This page has been intentionally left blank 
This page has been intentionally left blank 
This page has been intentionally left blank 
This page has been intentionally left blank 


\subsection{Supported Living Payment: Definition of a relationship}

Whether people are single or a couple affects eligibility for certain income assistance and the rate at which we can pay that assistance.

When we determine your entitlement to income assistance, we will consider you to be in a relationship if you are married, in a civil union, or in a de facto relationship, and have a degree of companionship.

By degree of companionship, we mean two people (or the same or opposite sex):

- are committed to each other emotionally for the foreseeable future and

- are financially interdependent on each other.

To give you a better idea of what we mean by this, think about whether:

- you live together at the same address most of the time

- you live separately but stay overnight at each other's place a few nights a week

- you share responsibilities, for example bringing up children (if any)

- you socialise and holiday together

- you share money, bank accounts or credit cards

- you share household bills

- you have a sexual relationship

- people think of you as a couple

- you give each other emotional support and companionship

- your partner would be willing to financially support you if you couldn't support yourself. 


\subsection{Survey Questions}

\section{Sensory Sensitivity in the Built Environment}

The Information Sheet for this project can be found at http://bit.ly/2rTJLtW. Please read it before beginning the survey.

This is a survey about your experience of the indoor environment of buildings, which includes factors such as lighting, noise and thermal comfort.

- You must be over 18 to participate in this study.

- Please only complete this survey once.

- There are no right or wrong answers.

- Please skip any questions you feel uncomfortable answering.

- Some of the questions will ask you about places you have been. We are mainly interested in your experiences of these buildings. These questions are not designed to make judgments about the types of buildings you use.

- How you feel and building conditions can change on different days, and even throughout any given day. Please do your best to answer how you feel in general in this building.

- Please do not include any personally identifiable information in your responses.

- There will be space for you to comment on specifics if you would like to.

- Please contact me at noblebeth@myvuw.ac.nz if you have any questions.

- We appreciate your participation and value your feedback.

You can ask questions or withdraw from the study at any point before the end of the survey by closing your internet browser window. Once you have completed and submitted the survey at the end, you are no longer able to withdraw from the study.

By clicking the button below, you confirm that you have read and understood the information sheet and give your informed consent to participate in this study.

\section{Types of Buildings You Use}

This section asks you about the types of buildings you use. This includes your home, your workplace, and other buildings you regularly use.

\section{Q1 What kind of building is your home?}

O A stand-alone house

O An attached house

O An apartment

O Other (please specify) 
Q2 Do you rent or own your home?

O Rent

O Own

O Other (please specify)

Q3 Approximately how often do you use the following types of buildings?

This is simply an estimate. If you are unsure, take your best guess

\begin{tabular}{|c|c|c|c|c|c|}
\hline Office building & 0 & 0 & 0 & 0 & 0 \\
\hline $\begin{array}{c}\text { Tertiary education } \\
\text { centre (university, } \\
\text { polytech) }\end{array}$ & 0 & 0 & 0 & 0 & 0 \\
\hline $\begin{array}{c}\text { Primary or } \\
\text { secondary school }\end{array}$ & O & $\mathrm{O}$ & $\mathrm{O}$ & $\mathrm{O}$ & $\mathrm{O}$ \\
\hline $\begin{array}{c}\text { Arts building } \\
\text { (museum, theatre, } \\
\text { library) }\end{array}$ & 0 & 0 & 0 & 0 & 0 \\
\hline Shopping mall & 0 & 0 & 0 & 0 & 0 \\
\hline Supermarket & 0 & 0 & 0 & 0 & 0 \\
\hline $\begin{array}{l}\text { Other retail (shop, } \\
\text { dairy) }\end{array}$ & 0 & 0 & O & $\mathrm{O}$ & $\mathrm{O}$ \\
\hline Restaurant/Bar/Cafe & 0 & 0 & O & $\mathrm{O}$ & 0 \\
\hline Religious building & $\mathrm{O}$ & O & $\mathrm{O}$ & $\mathrm{O}$ & $\mathrm{O}$ \\
\hline $\begin{array}{c}\text { Community building } \\
\text { (hall, community } \\
\text { centre) }\end{array}$ & $\mathrm{O}$ & $\mathrm{O}$ & $\mathrm{O}$ & $\mathrm{O}$ & O \\
\hline $\begin{array}{l}\text { Medical buildings } \\
\text { (doctor, dentist, } \\
\text { therapist, hospital) }\end{array}$ & $\mathrm{O}$ & $\mathrm{O}$ & $\mathrm{O}$ & $\mathrm{O}$ & O \\
\hline $\begin{array}{l}\text { Industrial buildings } \\
\text { (factory, } \\
\text { warehouse) }\end{array}$ & $\mathrm{O}$ & $\mathrm{O}$ & $\mathrm{O}$ & $\mathrm{O}$ & $\mathrm{O}$ \\
\hline Agricultural buildings & 0 & $\mathrm{O}$ & $\mathrm{O}$ & O & $\mathrm{O}$ \\
\hline $\begin{array}{l}\text { Other (please } \\
\text { specify) }\end{array}$ & $\mathrm{O}$ & $\mathrm{O}$ & $\mathrm{O}$ & O & $\mathrm{O}$ \\
\hline $\begin{array}{l}\text { Other (please } \\
\text { specify) }\end{array}$ & $\mathrm{O}$ & $\mathrm{O}$ & $\mathrm{O}$ & $\mathrm{O}$ & O \\
\hline
\end{tabular}




\section{Indoor Environment in Buildings You Use}

The next three sections ask you about the indoor environment of your home, place of occupation, and other buildings. At the end of each section, you will be able to add any extra information if you feel something has not been covered in the questions.

The indoor environment is the combination of factors that affect how comfortable a person is inside a building. These factors include things like lighting, noise, temperature, and air quality.

\section{Your Home}

Thinking about your home.

For this survey, your home is the building where you live and sleep most (or all) of the time.

Answer the following questions about your home's indoor environment in general. If you have any specifics, there is space at the end of this section.

Q4 Overall, how comfortable do you feel at home in regard to the indoor environment?

O 1 - Not at all comfortable

O 2

○ 3

○ 4

○ 5

O 6

O 7 - Extremely comfortable 
Q5 How much do the following factors cause you discomfort at home?

\begin{tabular}{|c|c|c|c|c|c|c|c|}
\hline Electric light & 0 & 0 & 0 & 0 & O & $\mathrm{O}$ & $\mathrm{O}$ \\
\hline Natural light & 0 & O & 0 & 0 & O & 0 & O \\
\hline Glare & $\mathrm{O}$ & $\mathrm{O}$ & $\mathrm{O}$ & $\mathrm{O}$ & $\mathrm{O}$ & $\mathrm{O}$ & $\mathrm{O}$ \\
\hline Colour & $\mathrm{O}$ & $\mathrm{O}$ & $\mathrm{O}$ & $\mathrm{O}$ & $\mathrm{O}$ & $\mathrm{O}$ & $\mathrm{O}$ \\
\hline Air quality & $\mathrm{O}$ & $\mathrm{O}$ & $\mathrm{O}$ & $\mathrm{O}$ & $\mathrm{O}$ & $\mathrm{O}$ & $\mathrm{O}$ \\
\hline Smells & $\mathrm{O}$ & $\mathrm{O}$ & $\mathrm{O}$ & $\mathrm{O}$ & $\mathrm{O}$ & $\mathrm{O}$ & $\mathrm{O}$ \\
\hline $\begin{array}{c}\text { Air } \\
\text { movement }\end{array}$ & $\mathrm{O}$ & $\mathrm{O}$ & $\mathrm{O}$ & $\mathrm{O}$ & O & $\mathrm{O}$ & $\mathrm{O}$ \\
\hline Temperature & O & $\mathrm{O}$ & 0 & 0 & 0 & 0 & 0 \\
\hline $\begin{array}{l}\text { Too many } \\
\text { people }\end{array}$ & $\mathrm{O}$ & $\mathrm{O}$ & $\mathrm{O}$ & 0 & O & $\mathrm{O}$ & O \\
\hline Privacy & $\mathrm{O}$ & $\mathrm{O}$ & $\mathrm{O}$ & O & $\mathrm{O}$ & $\mathrm{O}$ & $\mathrm{O}$ \\
\hline People noise & 0 & $\mathrm{O}$ & 0 & 0 & O & 0 & $\mathrm{O}$ \\
\hline $\begin{array}{c}\text { General } \\
\text { indoor noise }\end{array}$ & $\mathrm{O}$ & O & $\mathrm{O}$ & $\mathrm{O}$ & $\mathrm{O}$ & $\mathrm{O}$ & O \\
\hline $\begin{array}{l}\text { Outdoor } \\
\text { noise }\end{array}$ & 0 & $\mathrm{O}$ & $\mathrm{O}$ & $\mathrm{O}$ & O & $\mathrm{O}$ & O \\
\hline
\end{tabular}

Q6 Please rate the following statements in regard to your home

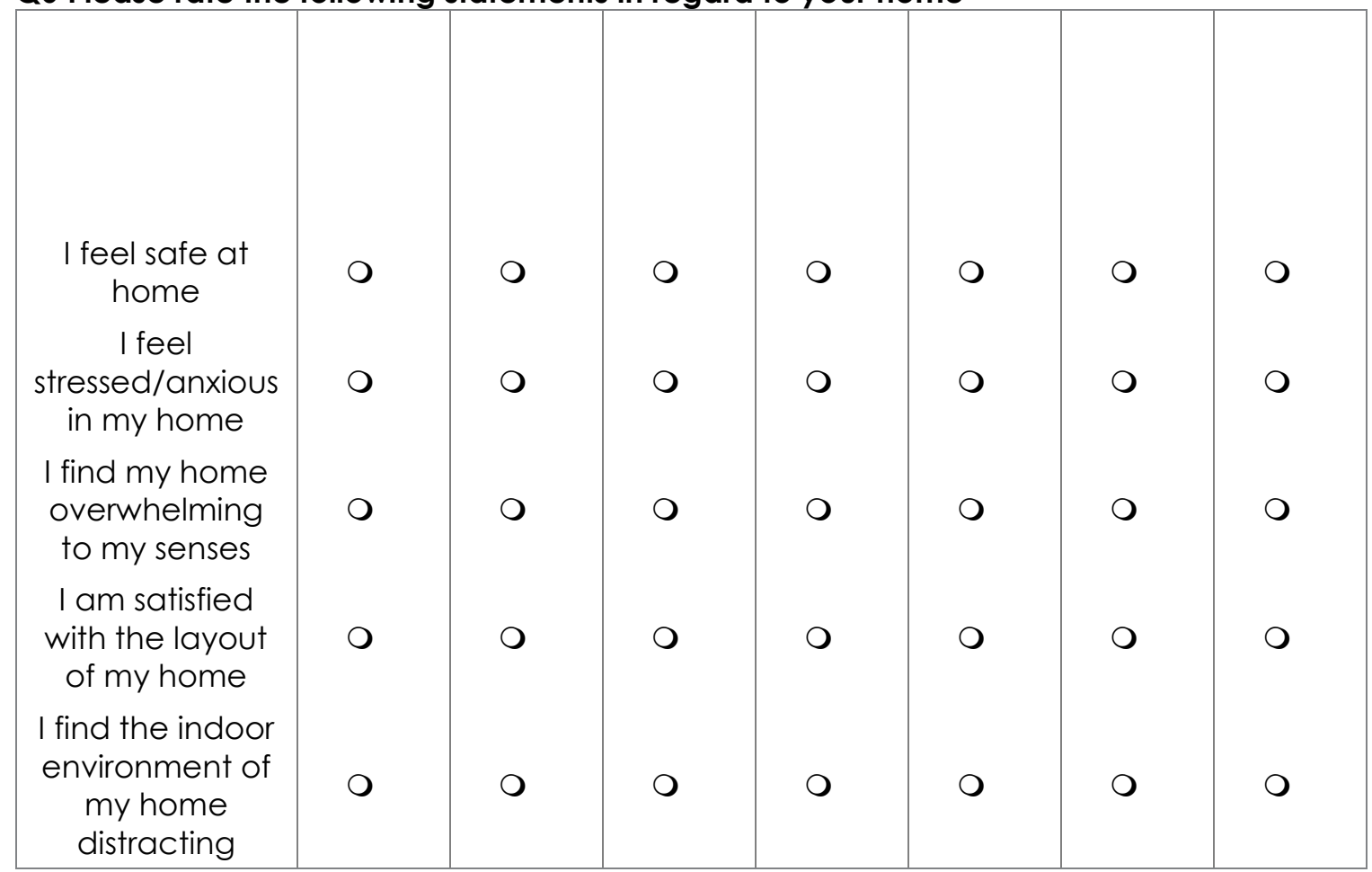


Q7 Overall, how much control over the indoor environment of your home do you feel you have?

O 1 - No control at all

O 2

○ 3

○ 4

O 5

O 6

O 7 - A lot of control

Display This Question:

If Q7: 4 or less is Selected

Q8 Is there a reason why you don't you feel you have much control at your home?

Q9 Have you or anyone else made any permanent changes to your home because of the indoor environment?

For example, changed the light fittings or blinds/curtains to reduce glare, installed acoustic insulation to reduce road noise or installed double glazing/curtains for temperature, etc.

O Yes

O No

Display This Question:

If $Q 9$ Yes Is Selected

Q10 What changes did you make and why?

Q11 In an ideal world, if you could make any changes you wanted to, would you like to make any permanent changes to help with the indoor environment?

O Yes

O No

Display This Question:

If $Q 11$ Yes Is Selected

Q12 What changes would you like to make and why?

Q13 Are there any other comments you have about your home relating to the indoor environment?

O Yes (please enter below)

O No comment 


\section{Your Workplace}

Thinking about your workplace.

For this survey, your workplace is your main paid or voluntary organisation building or education centre.

If your work is based at home or outdoors, or you are unoccupied, please think of the building you would spend the most time in away from the home.

Answer the following questions based on this building in general. If you have any specifics, there is space at the end of this section.

Remember, the indoor environment is the combination of factors that affect how physically comfortable a person is inside a building. These factors include things like lighting, noise, temperature and air quality.

\section{Q14 What type of building are you describing as your workplace?}

O Residential building that is not your own (house, apartment)

O Office building

O Tertiary education centre (university, polytech)

O Primary or secondary school

O Arts building (museum, theatre, library)

O Shopping mall

O Supermarket

O Other retail

O Restaurant/Bar/Cafe

O Religious building

O Community building (hall, community centre)

O Medical building (doctor, dentist, therapist, hospital)

O Industrial building (factory, warehouse)

O Agricultural building

If Q3 Other 1 (please specify) Is Not Empty

O \{bring forward text from Q2 Other 1 \}

If $Q 3$ Other 2 (please specify) Is Not Empty

O \{bring forward text from Q2 Other 2\}

O Other (please specify) 
Q15 Overall, how comfortable do you feel in this building in regard to the indoor environment?

O 1 - Not at all comfortable

○ 2

○ 3

○ 4

○ 5

O 6

O 7 - Extremely comfortable

Q16 How much do the following factors cause you discomfort in this building?

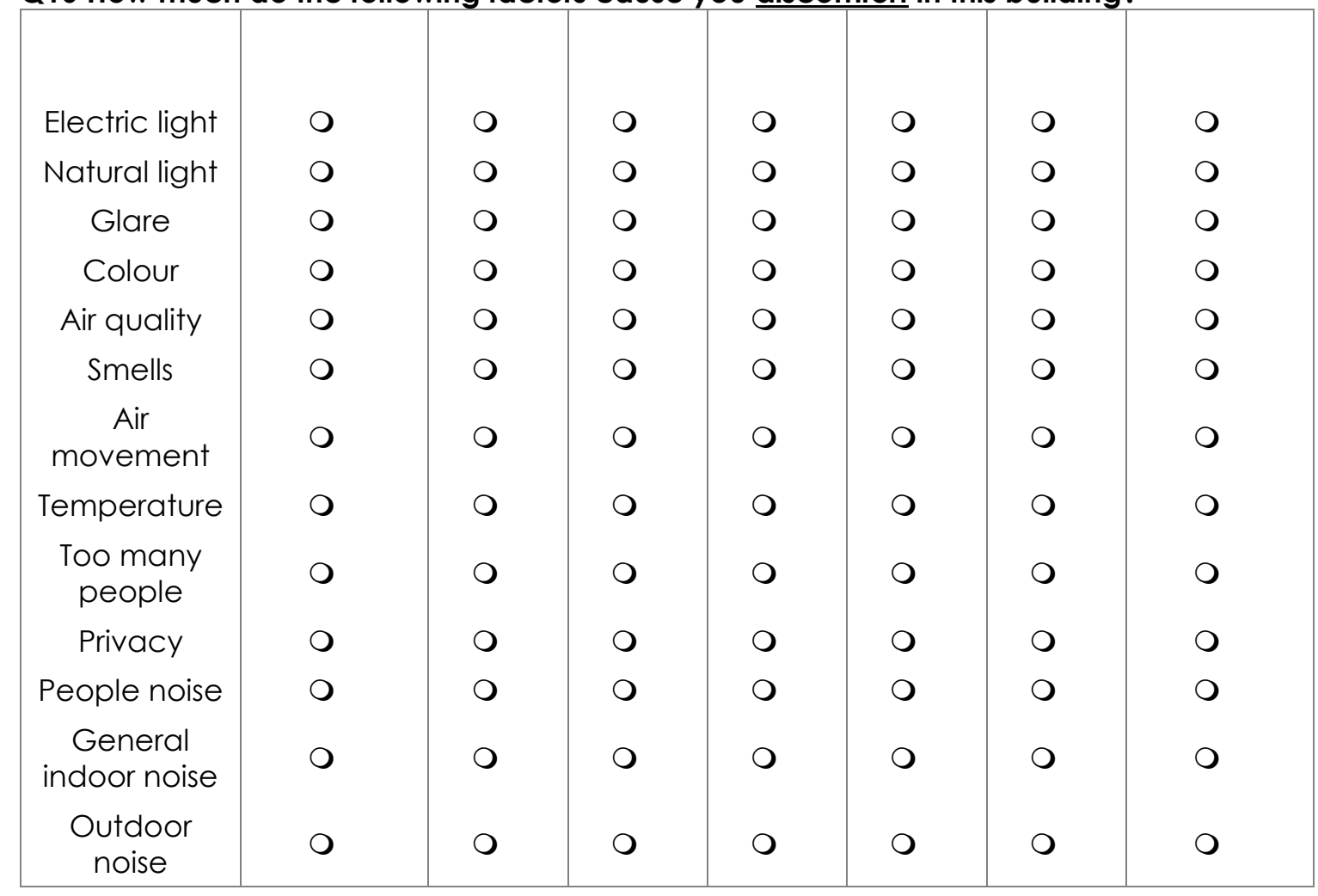


Q17 Please rate the following statements in regard to this building

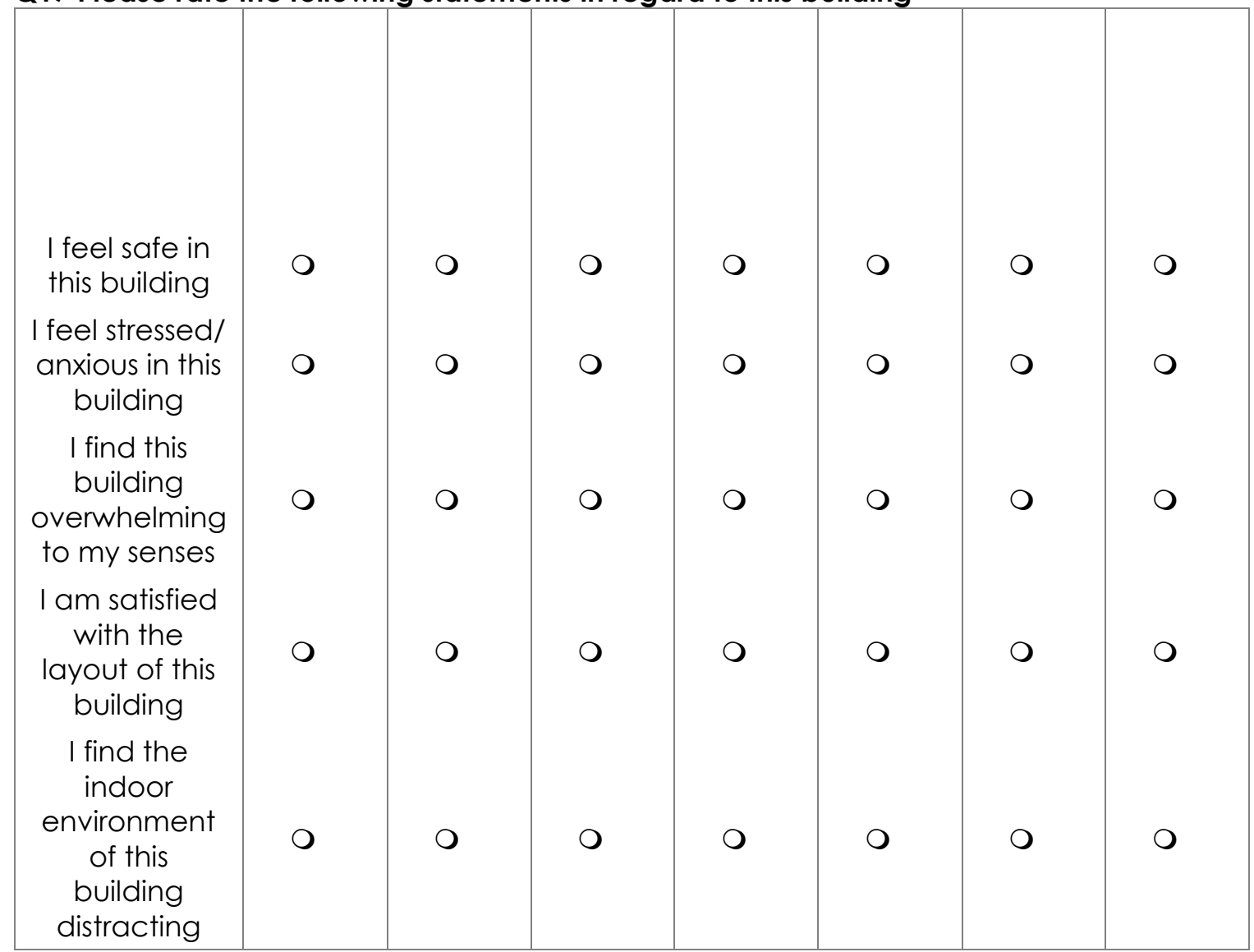

Q18 Overall, how much control over the indoor environment of your workplace do you feel you have?

O 1 - No control at all

○ 2

○ 3

○ 4

○ 5

○ 6

O 7 - A lot of control

Display This Question:

If Q18 4 or less is Selected

Q19 Is there a reason you don't feel you have much control at your workplace? 
Q20 Have you had to request any permanent changes be made to your workplace because of the indoor environment?

For example, light fittings replaced, blinds/curtains installed, moved workspace, etc.

O Yes

O No

Display This Question:

If $Q 20$ Yes is Selected

Q21 What changes did you request?

Q22 In an ideal world, if you could make any changes you wanted to, are there any permanent changes to your workplace that you would like to be made to help with the indoor environment?

O Yes

O No

Display This Question:

If $Q 22$ Yes is Selected

Q23 What changes would you like in an ideal world?

Q24 Are there any other comments you have about this building relating to the indoor environment?

O Yes (please enter below)

O No comment 


\section{Other Buildings You Use}

Thinking about other buildings you have used in the last month.

Remember, the indoor environment is the combination of factors that affect how physically comfortable a person is inside a building. These factors include things like lighting, noise, temperature and air quality.

Q25 Thinking of all the times you use each building type, how often do you find the indoor environment of the following buildings causes you discomfort?

\begin{tabular}{|c|c|c|c|c|c|c|c|}
\hline & $\begin{array}{c}1 \text { - } \\
\text { Never }\end{array}$ & 2 & 3 & 4 & 5 & 6 & $\begin{array}{c}7 \text { - } \\
\text { Always }\end{array}$ \\
\hline $\begin{array}{c}\text { If Q2 Office building Is } \\
\text { Monthly or More Regularly } \\
\text { Office building }\end{array}$ & 0 & 0 & 0 & 0 & 0 & 0 & 0 \\
\hline $\begin{array}{l}\text { If Q2 Tertiary education } \\
\text { centre (university, polytech, } \\
\text { etc.) Is Monthly or More } \\
\text { Regularly } \\
\text { Tertiary education centre } \\
\text { (university, polytech, etc.) }\end{array}$ & 0 & 0 & 0 & 0 & 0 & 0 & 0 \\
\hline $\begin{array}{c}\text { If Q2 Primary or secondary } \\
\text { school Is Monthly or More } \\
\text { Regularly } \\
\text { Primary or secondary } \\
\text { school }\end{array}$ & 0 & 0 & 0 & 0 & 0 & 0 & 0 \\
\hline $\begin{array}{l}\text { If Q2 Arts building (museum, } \\
\text { theatre, library) Is Monthly } \\
\text { or More Regularly } \\
\text { Arts building (museum, } \\
\text { theatre, library) }\end{array}$ & 0 & 0 & 0 & 0 & O & 0 & O \\
\hline $\begin{array}{c}\text { If Q2 Shopping mall Is } \\
\text { Monthly or More Regularly } \\
\text { Shopping mall }\end{array}$ & 0 & 0 & 0 & 0 & 0 & 0 & 0 \\
\hline $\begin{array}{c}\text { If Q2 Supermarket Is } \\
\text { Monthly or More Regularly } \\
\text { Supermarket }\end{array}$ & 0 & 0 & 0 & 0 & 0 & 0 & O \\
\hline $\begin{array}{l}\text { If Q2 Other retail (shops, } \\
\text { dairies, etc.) Is Monthly or } \\
\text { More Regularly } \\
\text { Other retail (shops, dairy, } \\
\text { etc.) }\end{array}$ & 0 & 0 & 0 & 0 & 0 & 0 & 0 \\
\hline $\begin{array}{l}\text { If Q2 Restaurant/Bar/Eatery } \\
\text { etc. (any building where } \\
\text { you have eaten) Is Monthly } \\
\text { or More Regularly } \\
\text { Restaurant/Bar/Cafe etc. }\end{array}$ & 0 & 0 & 0 & 0 & 0 & 0 & 0 \\
\hline
\end{tabular}




\begin{tabular}{|c|c|c|c|c|c|c|c|}
\hline & $\begin{array}{c}1- \\
\text { Never }\end{array}$ & 2 & 3 & 4 & 5 & 6 & $\begin{array}{c}7 \text { - } \\
\text { Always }\end{array}$ \\
\hline $\begin{array}{l}\text { If Q2 Religious building Is } \\
\text { Monthly or More Regularly } \\
\text { Religious building }\end{array}$ & 0 & 0 & 0 & 0 & 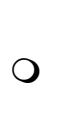 & 0 & 0 \\
\hline $\begin{array}{l}\text { If Q2 Community building } \\
\text { (hall, community centre, } \\
\text { etc.) Is Monthly or More } \\
\text { Regularly } \\
\text { Community building (hall, } \\
\text { community centre, etc.) }\end{array}$ & 0 & 0 & 0 & 0 & 0 & 0 & 0 \\
\hline $\begin{array}{c}\text { If Q2 Medical buildings } \\
\text { (doctors, dentists, therapists, } \\
\text { hospital, etc.) Is Monthly or } \\
\text { More Regularly } \\
\text { Medical buildings (doctor, } \\
\text { dentist, therapist, hospital, } \\
\text { etc.) }\end{array}$ & 0 & 0 & 0 & $O$ & 0 & 0 & 0 \\
\hline $\begin{array}{c}\text { If Q2 Agricultural buildings Is } \\
\text { Monthly or More Regularly } \\
\text { Industrial buildings (factory, } \\
\text { warehouse, etc.) }\end{array}$ & 0 & 0 & 0 & 0 & 0 & 0 & $O$ \\
\hline $\begin{array}{l}\text { If Q2 Agricultural buildings Is } \\
\text { Monthly or More Regularly } \\
\text { Agricultural building }\end{array}$ & 0 & 0 & 0 & 0 & 0 & 0 & 0 \\
\hline $\begin{array}{c}\text { If Q2 Other } 1 \text { (please } \\
\text { specify) Is Monthly or More } \\
\text { Regularly } \\
\text { \{bring forward text from Q2 } \\
\text { Other 1\} }\end{array}$ & 0 & 0 & 0 & 0 & 0 & 0 & 0 \\
\hline $\begin{array}{c}\text { If Q2 Other } 2 \text { (please } \\
\text { specify) Is Monthly or More } \\
\text { Regularly } \\
\text { \{bring forward text from Q2 } \\
\text { Other } 2\}\end{array}$ & 0 & 0 & 0 & 0 & 0 & 0 & 0 \\
\hline
\end{tabular}


Display This Question:

If Q25 4 or More is Selected

Q26 Thinking of a typical time you use each type of building, how much distress does each indoor environment cause you?

Distress is physical and/or psychological reactions such as anxiety, elevated heart rate, sweaty palms, etc.

\begin{tabular}{|c|c|c|c|c|c|c|c|}
\hline $\begin{array}{l}\text { If Q24 Office building } \\
\text { Is Sometimes or more } \\
\text { Office building }\end{array}$ & 0 & 0 & 0 & 0 & 0 & 0 & 0 \\
\hline $\begin{array}{c}\text { If Q24 Tertiary } \\
\text { education centre } \\
\text { (university, polytech, } \\
\text { etc.) Is Sometimes or } \\
\text { more } \\
\text { Tertiary education } \\
\text { centre (university, } \\
\text { polytech, etc.) }\end{array}$ & 0 & 0 & 0 & 0 & 0 & 0 & O \\
\hline $\begin{array}{c}\text { If Q24 Primary or } \\
\text { secondary school Is } \\
\text { Sometimes or more } \\
\text { Primary or secondary } \\
\text { school }\end{array}$ & 0 & 0 & 0 & 0 & 0 & $\mathrm{O}$ & O \\
\hline $\begin{array}{l}\text { If Q24 Arts building } \\
\text { (museum, theatre, } \\
\text { library) Is Sometimes or } \\
\text { more } \\
\text { Arts building (museum, } \\
\text { theatre, library) }\end{array}$ & 0 & 0 & $\mathrm{O}$ & 0 & O & 0 & 0 \\
\hline $\begin{array}{l}\text { If Q24 Shopping mall Is } \\
\text { Sometimes or more } \\
\text { Shopping mall }\end{array}$ & 0 & 0 & 0 & 0 & 0 & 0 & 0 \\
\hline $\begin{array}{l}\text { If Q24 Supermarket Is } \\
\text { Sometimes or more } \\
\text { Supermarket }\end{array}$ & 0 & 0 & 0 & 0 & 0 & 0 & O \\
\hline $\begin{array}{l}\text { If Q24 Other retail } \\
\text { (shops, dairy, etc.) Is } \\
\text { Sometimes or more } \\
\text { Other retail (shops, } \\
\text { dairy, etc.) }\end{array}$ & 0 & 0 & 0 & 0 & O & 0 & O \\
\hline $\begin{array}{c}\text { If Q24 } \\
\text { Restaurant/Bar/Cafe } \\
\text { etc. Is Sometimes or } \\
\text { more } \\
\text { Restaurant/Bar/Cafe } \\
\text { etc. (any building } \\
\text { where you have } \\
\text { eaten) }\end{array}$ & 0 & 0 & 0 & 0 & 0 & 0 & 0 \\
\hline
\end{tabular}




\begin{tabular}{|c|c|c|c|c|c|c|c|}
\hline & $\begin{array}{c}1-\text { No } \\
\text { distress at } \\
\text { all }\end{array}$ & 2 & 3 & 4 & 5 & 6 & $\begin{array}{c}7 \text { - A lot of } \\
\text { distress }\end{array}$ \\
\hline $\begin{array}{c}\text { If Q24 Religious } \\
\text { building Is Sometimes } \\
\text { or more } \\
\text { Religious building }\end{array}$ & 0 & 0 & 0 & 0 & 0 & 0 & 0 \\
\hline $\begin{array}{l}\text { If Q24 Community } \\
\text { building (hall, } \\
\text { community centre, } \\
\text { etc.) Is Sometimes or } \\
\text { more } \\
\text { Community building } \\
\text { (hall, community } \\
\text { centre, etc.) }\end{array}$ & 0 & 0 & 0 & 0 & 0 & 0 & 0 \\
\hline $\begin{array}{l}\text { If Q24 Medical } \\
\text { buildings (doctor, } \\
\text { dentist, therapist, } \\
\text { hospital, etc.) Is } \\
\text { Sometimes or more } \\
\text { Medical buildings } \\
\text { (doctor, dentist, } \\
\text { therapist, hospital, } \\
\text { etc.) }\end{array}$ & 0 & 0 & 0 & 0 & 0 & 0 & 0 \\
\hline $\begin{array}{c}\text { If Q24 Industrial } \\
\text { buildings (factory, } \\
\text { warehouse, etc.) Is } \\
\text { Sometimes or more } \\
\text { Industrial buildings } \\
\text { (factory, warehouse, } \\
\text { etc.) }\end{array}$ & 0 & 0 & 0 & O & O & 0 & 0 \\
\hline $\begin{array}{l}\text { If Q24 Agricultural } \\
\text { building Is Sometimes } \\
\text { or more } \\
\text { Agricultural building }\end{array}$ & 0 & 0 & 0 & $\mathrm{O}$ & O & 0 & 0 \\
\hline $\begin{array}{l}\text { If Q24 \{bring forward } \\
\text { text from Q2 Other 1\} } \\
\text { Is Sometimes or more } \\
\text { \{bring forward text } \\
\text { from Q2 Other 1\} }\end{array}$ & 0 & 0 & 0 & 0 & 0 & 0 & 0 \\
\hline $\begin{array}{l}\text { If Q24 \{bring forward } \\
\text { text from Q2 Other } 2\} \\
\text { Is Sometimes or more } \\
\text { \{bring forward text } \\
\text { from Q2 Other 2\} }\end{array}$ & 0 & 0 & 0 & 0 & 0 & 0 & $\mathrm{O}$ \\
\hline
\end{tabular}


Q27 Have you ever avoided buildings because of their indoor environment?

O Yes

O No

Display This Question:

If Q27 Yes is Selected

Q28 What types of buildings have you avoided because of their indoor environment?

Please select as many as apply

- Office buildings

Tertiary education centres (university, polytech, etc.)

- Primary or secondary schools

arts buildings (museum, theatre, library)

a Shopping malls

a Supermarkets

Other retail (shops, dairy, etc.)

a Restaurant/Bar/Cafe etc. (any building where you have eaten)

Religious buildings

- Community buildings (hall, community centre, etc.)

a Medical buildings (doctor, dentist, therapist, hospital, etc.)

Industrial buildings (factory, warehouse, etc.)

a Agricultural buildings

Other (please specify) 


\begin{tabular}{|c|c|c|c|c|c|c|c|}
\hline \multicolumn{8}{|c|}{$\begin{array}{l}\text { Display This Question: } \\
\text { If Q28/SelectedChoicesCount Is Greater Tha } \\
\text { Carry Forward Selected Choices from Q28 } \\
\text { Q29 How often do you avoid these buildings? }\end{array}$} \\
\hline Office building & 0 & $\mathrm{O}$ & 0 & O & 0 & O & 0 \\
\hline $\begin{array}{c}\text { Tertiary education } \\
\text { centre (university, } \\
\text { polytech, etc.) }\end{array}$ & $\mathrm{O}$ & $\mathrm{O}$ & $\mathrm{O}$ & $\mathrm{O}$ & O & O & $\mathrm{O}$ \\
\hline $\begin{array}{l}\text { Primary or secondary } \\
\text { school }\end{array}$ & $\mathrm{O}$ & $\mathrm{O}$ & O & $\mathrm{O}$ & $\mathrm{O}$ & $\mathrm{O}$ & O \\
\hline $\begin{array}{l}\text { Arts building } \\
\text { (museum, theatre, } \\
\text { library) }\end{array}$ & $\mathrm{O}$ & $\mathrm{O}$ & $\mathrm{O}$ & $\mathrm{O}$ & O & $\mathrm{O}$ & $\mathrm{O}$ \\
\hline Shopping mall & 0 & O & 0 & 0 & 0 & O & 0 \\
\hline Supermarket & $\mathrm{O}$ & $\mathrm{O}$ & O & $\mathrm{O}$ & O & O & O \\
\hline $\begin{array}{l}\text { Other retail (shops, } \\
\text { dairies, etc.) }\end{array}$ & $\mathrm{O}$ & $\mathrm{O}$ & $\mathrm{O}$ & $\mathrm{O}$ & $\mathrm{O}$ & $\mathrm{O}$ & $\mathrm{O}$ \\
\hline $\begin{array}{l}\text { Restaurant/Bar/Eatery } \\
\text { etc. (any building } \\
\text { where you have } \\
\text { eaten) }\end{array}$ & $\mathrm{O}$ & $\mathrm{O}$ & $\mathrm{O}$ & $\mathrm{O}$ & O & $\mathrm{O}$ & $\mathrm{O}$ \\
\hline Religious building & $\mathrm{O}$ & $\mathrm{O}$ & $\mathrm{O}$ & $\mathrm{O}$ & O & $\mathrm{O}$ & $\mathrm{O}$ \\
\hline $\begin{array}{l}\text { Community building } \\
\text { (hall, community } \\
\text { centre, etc.) }\end{array}$ & O & O & $\mathrm{O}$ & $\mathrm{O}$ & O & $\mathrm{O}$ & $\mathrm{O}$ \\
\hline $\begin{array}{l}\text { Medical buildings } \\
\text { (doctors, dentists, } \\
\text { therapists, hospital, } \\
\text { etc.) }\end{array}$ & $\mathrm{O}$ & $\mathrm{O}$ & $\mathrm{O}$ & $\mathrm{O}$ & $\mathrm{O}$ & $\mathrm{O}$ & $\mathrm{O}$ \\
\hline $\begin{array}{l}\text { Industrial buildings } \\
\text { (factory, warehouse) }\end{array}$ & $\mathrm{O}$ & $\mathrm{O}$ & $\mathrm{O}$ & $\mathrm{O}$ & O & $\mathrm{O}$ & $\mathrm{O}$ \\
\hline Agricultural buildings & $\mathrm{O}$ & $\mathrm{O}$ & $\mathrm{O}$ & $\mathrm{O}$ & O & $\mathrm{O}$ & $\mathrm{O}$ \\
\hline $\begin{array}{l}\text { Other (please } \\
\text { specify) }\end{array}$ & 0 & 0 & 0 & 0 & 0 & 0 & 0 \\
\hline
\end{tabular}

Q30 In an ideal world, would you avoid going to certain building types if you could because of the indoor environment?

O Yes

O No 
Display This Question:

If Q30 Yes Is Selected

\section{Q31 Which types of buildings would you avoid if you could?}

Please select as many as apply

- Office building

- Tertiary education centre (university, polytech, etc.)

- Primary or secondary school

arts building (museum, theatre, library)

a Shopping mall

a Supermarket

O Other retail (shops, dairies, etc.)

- Restaurant/Bar/Eatery etc. (any building where you have eaten)

Religious building

- Community building (hall, community centre, etc.)

- Medical buildings (doctors, dentists, therapists, hospital, etc.)

Industrial buildings (factory, warehouse, etc.)

agricultural buildings

Other (please specify)

\section{Display This Question:}

If Q27 Yes is Selected

Or Q30 Yes is Selected

Q32 How much do the following factors make you want to avoid buildings?

\begin{tabular}{|c|c|c|c|c|c|c|c|}
\hline & & & & & & \\
Electric light & 0 & 0 & 0 & 0 & 0 & 0 & 0 \\
Natural light & 0 & 0 & 0 & 0 & 0 & 0 & 0 \\
Glare & 0 & 0 & 0 & 0 & 0 & 0 & 0 \\
Colour & 0 & 0 & 0 & 0 & 0 & 0 & 0 \\
Air quality & 0 & 0 & 0 & 0 & 0 & 0 & 0 \\
Smells & 0 & 0 & 0 & 0 & 0 & 0 & 0 \\
Draughts & 0 & 0 & 0 & 0 & 0 & 0 & 0 \\
Temperature & 0 & 0 & 0 & 0 & 0 & 0 & 0 \\
People noise & 0 & 0 & 0 & 0 & 0 & 0 & 0 \\
Outside & 0 & 0 & 0 & 0 & 0 & 0 & 0 \\
noise & 0 & 0 & 0 & 0 & 0 & 0 \\
Too many & 0 & 0 & 0 & 0 & 0 & 0 & 0 \\
people & 0 & 0 & 0 & 0 & 0 & 0 \\
Privacy & 0 & 0 & 0 & 0 & 0 \\
Layout & 0 & 0 & 0 & & & \\
\hline
\end{tabular}


Display This Question:

If Q27 Yes Is Selected

Or Q30 Yes Is Selected

Q33 Would you like to make any comment on why and/or how often you avoid buildings?

O Yes

O No comment 


\section{General Sensory Processing}

Now a few general questions about your sensory processing. There is no right or wrong answer to these questions, we just want to get a general idea of how you experience the world from a sensory perspective.

\section{Q34 Please rate the following statements}

\begin{tabular}{|c|c|c|c|c|c|}
\hline & $\begin{array}{l}\text { Almost } \\
\text { Never }\end{array}$ & Seldom & Occasionally & Frequently & $\begin{array}{l}\text { Almost } \\
\text { Always }\end{array}$ \\
\hline $\begin{array}{c}\text { I become bothered when I } \\
\text { see lots of movement around } \\
\text { me }\end{array}$ & $\mathrm{O}$ & $\mathrm{O}$ & $\mathrm{O}$ & $\mathrm{O}$ & $\mathrm{O}$ \\
\hline $\begin{array}{c}\text { I do not like to go to places } \\
\text { that have bright lights or are } \\
\text { very colourful }\end{array}$ & O & $\mathrm{O}$ & O & O & $\mathrm{O}$ \\
\hline $\begin{array}{l}\text { I have to move away when I } \\
\text { smell a strong scent }\end{array}$ & O & O & O & O & $\mathrm{O}$ \\
\hline $\begin{array}{l}\text { I choose to shop in smaller } \\
\text { stores because I'm } \\
\text { overwhelmed in large stores }\end{array}$ & O & O & O & $\mathrm{O}$ & $\mathrm{O}$ \\
\hline I am not very coordinated & $\mathrm{O}$ & $\mathrm{O}$ & $\mathrm{O}$ & $\mathrm{O}$ & $\mathrm{O}$ \\
\hline $\begin{array}{l}\text { I am uncomfortable wearing } \\
\text { certain fabrics }\end{array}$ & $\mathrm{O}$ & $\mathrm{O}$ & O & O & $\mathrm{O}$ \\
\hline $\begin{array}{l}\text { I avoid standing in lines or } \\
\text { standing close to other } \\
\text { people because I do not like } \\
\text { to be too close to others }\end{array}$ & $\mathrm{O}$ & O & O & O & $\mathrm{O}$ \\
\hline I stay away from crowds & O & O & O & $\mathrm{O}$ & $\mathrm{O}$ \\
\hline $\begin{array}{l}\text { I startle easily at unexpected } \\
\text { or loud noises }\end{array}$ & $\mathrm{O}$ & $\mathrm{O}$ & O & O & $\mathrm{O}$ \\
\hline $\begin{array}{l}\text { I notice noises that others } \\
\text { don't seem to hear }\end{array}$ & $\mathrm{O}$ & $\mathrm{O}$ & O & $\mathrm{O}$ & $\mathrm{O}$ \\
\hline $\begin{array}{c}\text { I find it difficult to work with } \\
\text { background noise }\end{array}$ & $\mathrm{O}$ & O & O & O & $\mathrm{O}$ \\
\hline $\begin{array}{l}\text { I am over-sensitive to } \\
\text { environmental stimulation }\end{array}$ & $\mathrm{O}$ & $\mathrm{O}$ & O & $\mathrm{O}$ & $\mathrm{O}$ \\
\hline I don't like to be touched & $\mathrm{O}$ & O & O & 0 & 0 \\
\hline $\begin{array}{l}\text { I have difficulty staying } \\
\text { focused on one task }\end{array}$ & 0 & 0 & O & O & 0 \\
\hline $\begin{array}{l}\text { I find that lights that flicker } \\
\text { are very uncomfortable or } \\
\text { painful }\end{array}$ & O & 0 & O & O & 0 \\
\hline
\end{tabular}




\title{
Demographics
}

Finally, this section asks you a few questions about demographics. These will never be used to identify you, they are just for sample statistics.

\author{
Q35 What do you identify your gender as? \\ O Male \\ O Female \\ O Gender Diverse
}

\section{Q36 What is your age range?}
O $18-24$
○ $25-34$
O $35-44$
O $45-54$
O $55-64$
O $\quad 65-74$
O $75+$

\section{Q37 What is your primary occupation?}

O Paid full-time worker

O Paid part-time worker

O Student

O Stay-at-home parent

O Voluntary worker (full or part time)

O Unoccupied

O Self-employed

O Other (please specify)

\section{Q38 Do you live in New Zealand?}
O Yes
O No

\section{Q39 Do any of the following apply to you?}

Please tick as many as apply

a I am on the Autism Spectrum (including ASD, Autism, Asperger's, PDDNOS)

I I have a Sensory Processing Disorder (including APD)

a I have other condition(s) that affects my sensory processing (please specify)

a I don't have any of these conditions 
Q40 Do you have any immediate family (parents, siblings, children, partner) who are on the Autism Spectrum?
O Yes
O No

Q41 Do you have any other comments that you would like to make?

This is the final opportunity you have to share your thoughts

$\mathrm{O}$ Yes

O No comment

Thank you very much for completing the survey today.

It would be much appreciated if you could pass on the survey link and information sheet to others you know, to ensure that this reaches as many people as possible across a wide cross-section of the population.

By clicking the button below, you are submitting your responses to the researchers. If you wish to withdraw from the study, please do not click on the submit button and just exit your browser window.

If you would like to receive a summary of the research project once it is complete, please enter your email address below. Your email address will not be linked to the responses you have given in the survey. 
MEMORANDUM

\begin{tabular}{|c|c|}
\hline TO & Beth Noble \\
\hline COPY TO & Nigel Isaacs, Dr Steve Lamb \\
\hline FROM & AProf Susan Corbett, Convener, Human Ethics Committee \\
\hline DATE & 29 April 2017 \\
\hline PAGES & 1 \\
\hline SUBJECT & $\begin{array}{l}\text { Ethics Approval: } \mathbf{2 4 4 7 1} \\
\text { The Impact of Indoor Environment Quality on People on the Autism } \\
\text { Spectrum }\end{array}$ \\
\hline
\end{tabular}

Thank you for your application for ethical approval, which has now been considered by the Standing Committee of the Human Ethics Committee.

Your application has been approved from the above date and this approval continues until 4 March 2018. If your data collection is not completed by this date you should apply to the Human Ethics Committee for an extension to this approval.

Best wishes with the research.

Kind regards

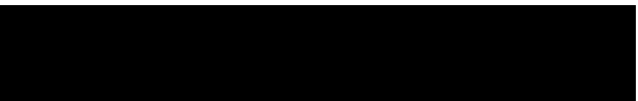

\section{Susan Corbett}

Convener, Victoria University Human Ethics Committee 